\title{
$\mathrm{S} B$
355 UC-NRLF \\ в 4 522 024 \\ R72
}

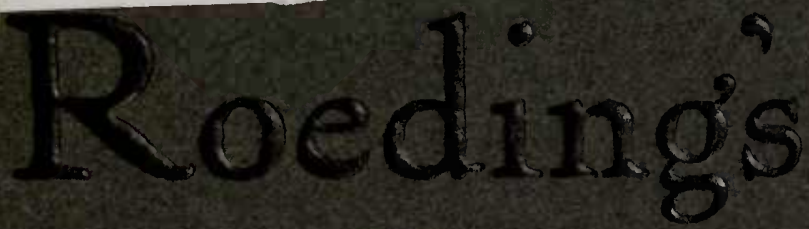

Pruit Growers

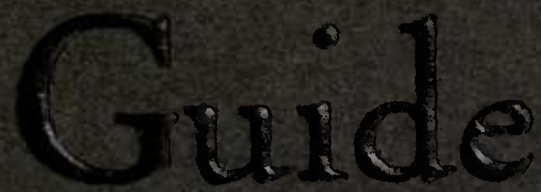




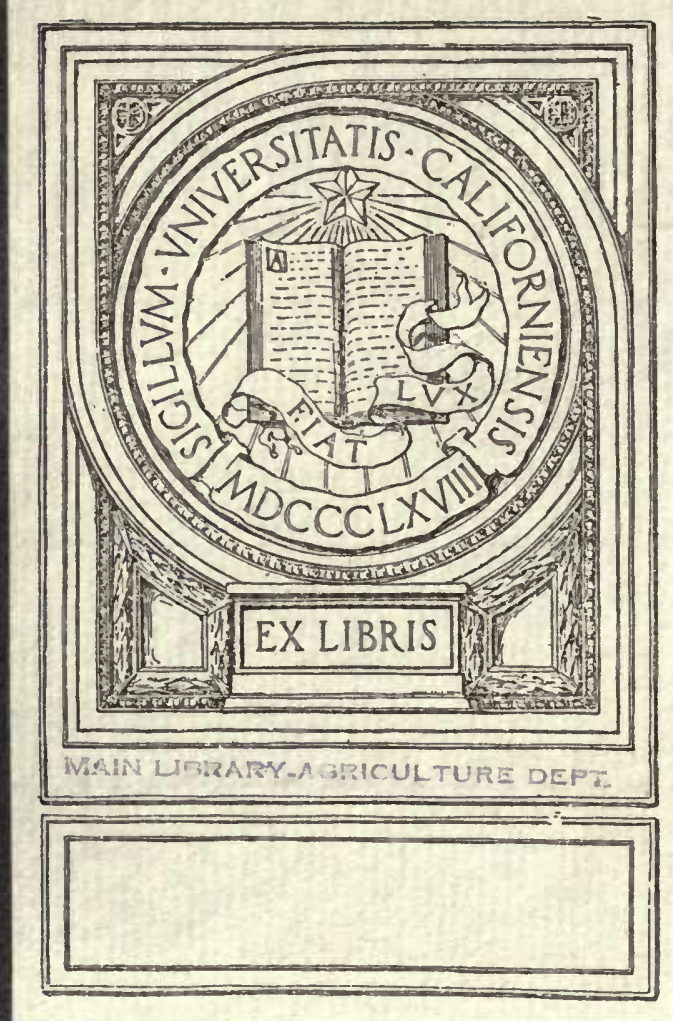




\title{
ROEDING'S FRUIT GROWERS' GUIDE
}
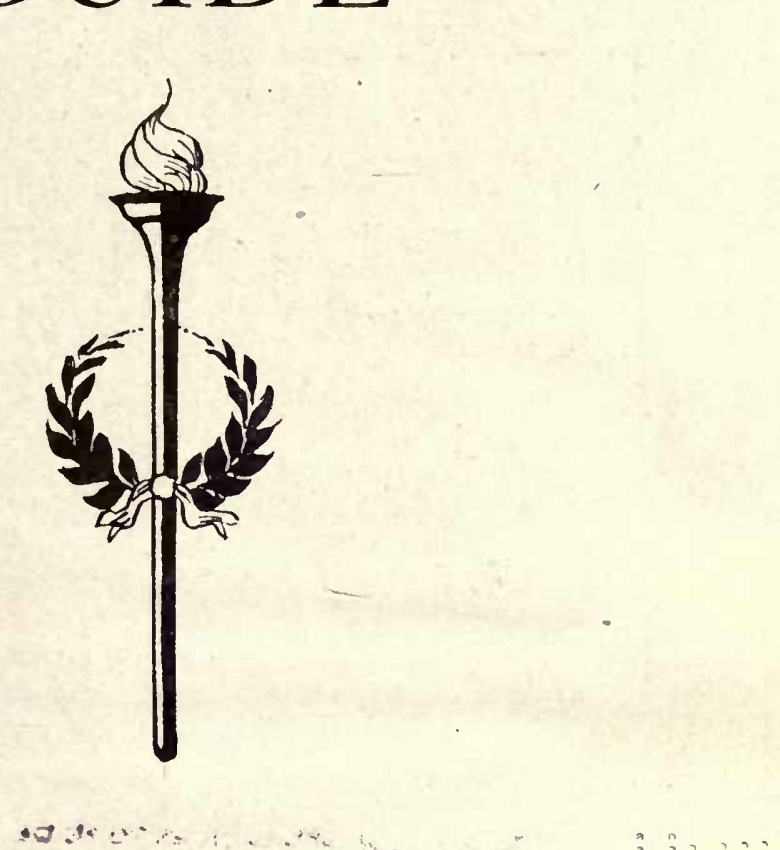

\author{
$B y$ GEO. C. ROEDING \\ FRESNO, CALIFORNIA
}




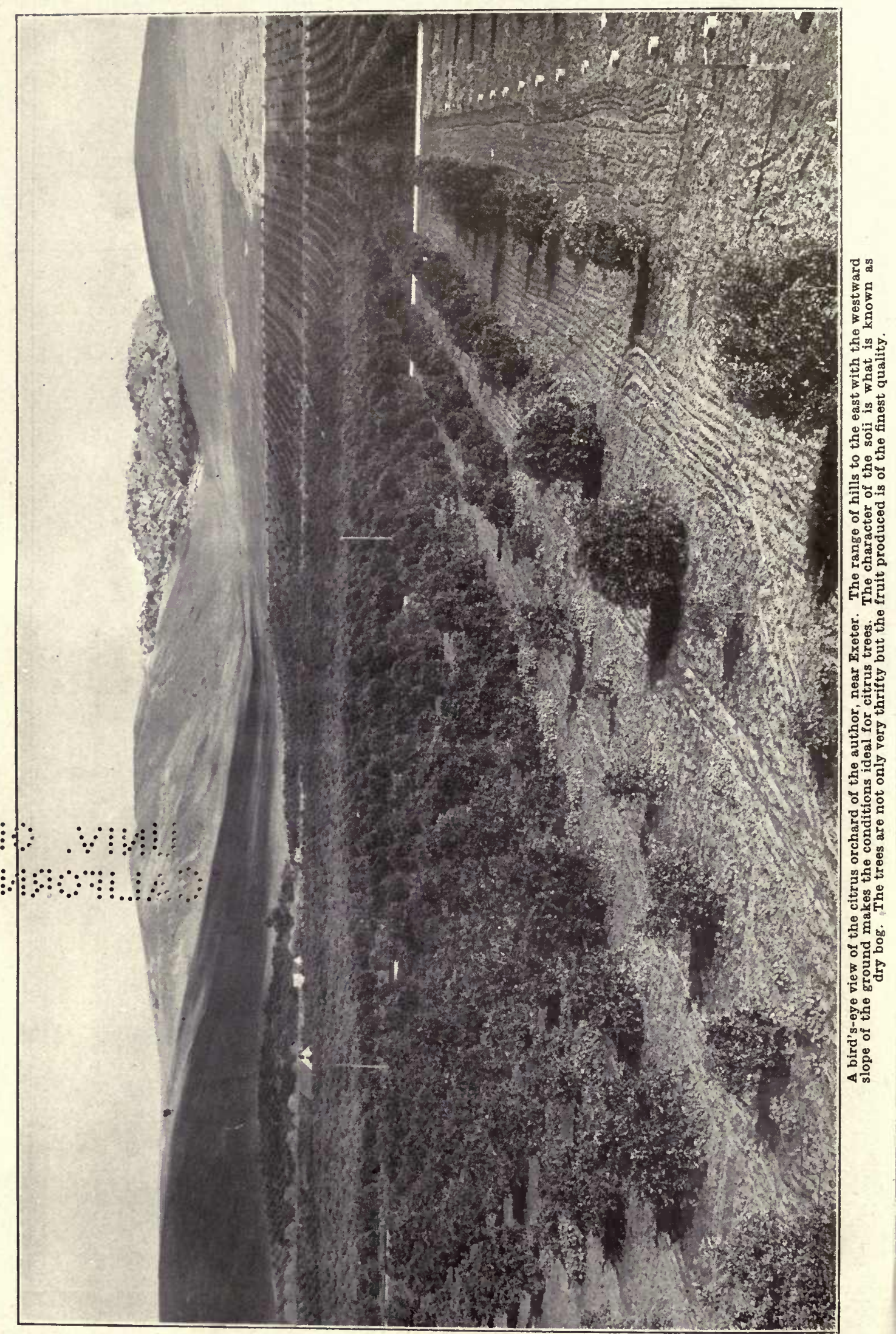




\section{Roeding's Fruit Growers' Guide}

\section{BEGINNING RIGHT}

Fruit growing is a business, pure and simple. It had a very important bearing on our winning the war. The purchases of dried fruits in California alone, exclusive of canned goods for the men who were at the front, aggregated $\$ 25,000,000$ of the crop of 1918 . Vegetables, canned and dried, formed another very important adjunct in the diet of our men, and the purchases ran up to millions of dollars. Intensity in farming operations is being encouraged now more than ever before. A man who planted fruit trees and intercropped with vegetables during the period of the war certainly fulfilled his obligation to the Government. He not only provided for the future when he planted his orchard, and increased the value of his land, but in addition to this he was encouraged to go to the expense of installing a pumping plant for developing water, building ditches and, where necessary, cement pipe lines, with much more care and thoroughness than he would have done were he devoting his attention merely to the raising of vegetables alone. It is becoming more and more apparent in these days that a fruit grower should specialize. This does not mean that a man living on a farm should not have a small orchard, berries, vegetables, alfalfa, a cow, poultry and hogs. It is being demonstrated, however, that with our diversified climates and soils certain localities are better adapted to one variety of fruit than another. 'This point should never be lost sight of. There is far too great a tendency on the part of many people to plant the fruit which has been bringing the highest prices for several seasons, utterly disregarding the fact that both soil and climate may not be conducive to make the venture a success.

\section{PREPARATION OF THE SOIL}

It is of the utmost importance that the land be put in first-class condition to receive the trees. Too great an emphasis cannot be laid on this one point. The subject is worthy of careful analysis. If the orchand is to be planted where irrigating is to be practised, careful attention must be given to grading so as to permit the water to run in furrows or to be properly distributed in checks around each tree to be irrigated. When scraping the land great care should be exercised not to remove the surface of the soil to too great a depth, for where this is done it causes the trees to grow poorly and neither thorough cultivation nor irrigation will overcome this trouble for years to come. Where it is necessary to take off the surface soil to a foot or more in order to permit a high piece of land to be irrigated it is far better. to pump the water to the higher elevation and distribute it in this manner. In other words, in preparing land which is to be irrigated, bear in mind that every point of the field should be graded, not leveled, to permit every foot of it to be eovered with water. Nothing will do so much to promote the success of an undertaking as to commence the work of leveling, plowing, and the installation of the irrigating system early in the fall months. One point I want to be very emphatic on and that is, do not attempt to plant trees and vines on a commercial scale, where irrigation is to be practised, without knowing where the supply of water is to come from. If the water is to be supplied by a canal system, have the main and lateral ditches large enough to carry a sufficient volume of water to permit the irrigating of the land as expeditiously as possible. Many people make the mistake, where they do not understand engineering, of attempting to do the work themselves without any expert advice, thus causing themselves an endless amount of trouble through the fact that their ditches are not properly located, the banks not having sufficient slope and, in many instances, caving in. It is important to have the weirs, where there happens to be a heavy fall in a ditch, properly located to prevent washing of the banks. Where a cement pipe system is to be installed, even greater care must be exercised to have the pipe lines on a grade and the stand-pipes properly located to get the best results. The diameter of the pipe is determined by the volume of water to be carried and by the fall it has. Far better to err on the part of having the pipe system too large than to make the mistake of having it too small and not be in a position to convey the quantity of water which is available to the trees. If the water is to be pumped the engineer should determine the location of the plant and see to it that it is large enough to provide the necessary water for the piece of land to be irrigated. An engineer is an important factor in a case like this and his charges for services rendered will be many times repaid in having the plant installed in such a manner as to secure a maximum of efficiency at a minimum of expense. There is probably no other institution in the world which has more reliable and authentic data on the installation of irrigating systems or, for that matter, any other subject pertaining to agricultural and horticultural work, than the United States Department of Agriculture. Bulletins may be obtained therefrom at from five to ten rents each on any subject pertaining to farming operations by writing to the Division of Publicatiors, Washington, D. C. After all the details relative to the irrigating of the land to be improved have been carefully considered, its preparation for planting is the next step in line. Deep plowing and particularly subsoiling will do much to promote the rapid growth of trees and vines. It may not be practical during the fall months to plow deeply, due to lack of rain. However, if possible after the leveling is finished, plow the land and finish with a buck-scraper. The Fresno scraper is probably the best all-around implement for rough grading, but for the finer work, filling up small holes and for smoothing, there is nothing like the first-named tool. Shallow plowing should always be done when conditions are 
most favorable. By all means plow and harrow the land just before planting.

Drainage should be given consideration, particularly if the land is low and liable to have water stand too closely to the surface during the spring and summer months. In California, where, as a rule, there is no substrata of clay, tile drains are the best. In soils where there are stratas of hardpan with intervening spaces of soil between, it becomes necessary to lay the tile on redwood boards which are grooved out to hold the tile in place. Should this not be done in soils of this character, when there is a superabundance of water in the ground it becomes a loblolly and the tile sinks out of place. It is necessary to have sump boxes (not less than five hundred feet apart) made out of two-inch redwood boards, to take care of the deposits of silt and sand from the drain pipe. If made of cement, they should not be less than three feet in diameter, the redwood boxes should be three and one-half feet square. The bottom of the sump should be at least two feet below the pipe. Where the pipe line is within three to four feet of the surface of the ground and is laid to within twenty-five to thirty feet of the trees or vines, it is necessary to clean this pipe line out frequently during the summer months. A steel brush will have to be dragged through it to remove the roots, which are sure to enter between the sections of drain tile. The brush also stirs up the silt, which will invariably collect in the bottom of the pipe. The practical way to handle this is to keep a No. 8 galvanized wire in the drain at all times. When the cleaning operation is to be carried out this wire is used to draw a three-eighths inch woven wire cable through the drain. To this is attached the steel brush. A windlass is placed in the next box and the brush is drawn through. There should be a swivel on each end of the brush. It is necessary to attach the galvanized wire to the brush to pull it back, as it may be necessary to repeat the operation of drawing it through several times before the drain is clean.

\section{SELECTING NURSERY STOCK}

One point should never be forgotten in purchasing trees, and that is, that as far as appearances go one tree may apparently be as good as another. A little thought on the part of the purchaser will convince him that, although nursery stock may be classed as merchandise in the ordinary sense of the word, there are many important factors that may mean the ultimate success or failure to the planter in his undertaking. California soils demand a variety of roots. To plant a prune on peach root, on soil which might be very wet during the greater part of the year, would mean the loss of the tree most likely just as soon as it came into bearing. The selecting of buds from the trees producing the very best quality of fruit and which are vigorous and healthy, should never be lost sight of. There are some stocks which may be apparently all right so far as growth goes, but which will die just about the time the orchard romes into its prime. This is very noticeable where any variety of citrus tree is budded on the lemon root. The tree dies without any apparent reason. It is a wellknown fact among experienced nurserymen that the lemon should never be used as a stock owing to its tendency to do this. A conscientious nurseryman fully realizes the responsibility resting on his shoulders and if he is going to fulfill his duties to the purchaser of his goods, he is going to strain every point to have them as represented. It is very easy to practise a deception, because it takes three years for the buyer to learn whether or not the trees delivered to him are true to name. Therefore, be as careful in the selecting of a nurseryman as you would be your physician. The personality and reliability of the firm with which you are dealing should never be overlooked when buying trees. The firm that never relaxes its attention to every detail, from the planting of the seed to the time the trees are properly packed and shipped, is the one to favor with your business.

\section{TIME TO PLANT}

Fall planting is never desirable in California, because the growing season often extends into the month of November. It rarely occurs that frosts are severe enough toward the latter part of the month to check the growth. The roots of trees dug before they have fully matured turn black, and the tree either starts very slowly in the spring or does not grow at all. The best time to set deciduous trees is from January to April 1st. All evergreen fruit trees should be planted from February to May 1st, although in many localities, particularly sections of the state where the summer climate is cool, planting may be continued later than this.

A safe rule to follow is to plant deciduous trees when dormant and those which are classed as evergreens as soon as the sap commences to rise in the spring.

\section{TREATMENT WHEN RECEIVED}

The trees when received at point of destination should be immediately unpacked and the roots laid in a trench and well covered with soil, which should then be thoroughly, wet down. If delayed in transit, thereby becoming dry and suffering from exposure (the bark showing signs of shriveling), it is a good plan to immerse the trees in a tank overnight and the following day bury root and top completely in damp soil for a few days until they become normal, when they may be with safety planted out. Should trees be frozen while in transit, place the package in a cellar or some other place free from frost until thawed out, when they can be unpacked and heeled in, preparatory to planting. Trees treated in this manner will not be injured by having been frozen.

It is quite practicable to ship trees when dormant to other localities where the weather or seasonable conditions might not make it advisable to plant on arrival. When the trees are received, place them in cold storage. The temperature should be maintained at from 32 to 35 degrees Fahrenheit. The shipment should be examined and if found to be in good condition, the contents should remain undisturbed in the case or bale until the time for planting arrives. This method of handling trees is thoroughly practicable, so much so that it is possible to ship trees to the antipodes during 
the winter season and have the shipment on arrival there placed in cold storage until the opening of the planting season.

\section{PREPARING TREES FOR PLANTING}

Just immediately before planting be sure to examine the roots carefully, and cut away to a smooth surface all bruised, lacerated and broken roots and rootlets with a sharp knife or pruning shear. The cut on the larger roots should be sloping and made on the lower side of the root. The tree can now be said to be ready for its permanent orchard home.

If planting is delayed through circumstances beyond the control of the orchardist and a warm spell should intervene in February or March, causing the buds of the trees or vines to start, remove them from the trenches, shake out all the dirt from the roots and expose thein for two hours in the early morning on a calm day to the rays of the sum. This will cause the small, white rootlets which have started, to dry up, and if the trees are heeled in (wetting them down, of course), in a shady place their dormancy may be prolonged several weeks.

\section{HOW TO PLANT}

Planting System.-There are a number of methods of planting an orchard, but vineyards are usually set in the square system. In order to eliminate much of the confusion that seems to exist in the mind of the planter when deviating from the rectangular or square system, we are submitting plans drawn to a scale and are outlining under each one of them the plan of procedure. It is very important in laying off the ground to have straight lines, not only for the purpose of retaining symmetry in the orchard but also for the many other advantages in cultivating, irrigating, etc.

Explanation of Diagrams.-The planting distances are represented by the figure 1 , all other related distances by multiple parts of 1 , so that any desired distance on any of the diagrams may be obtained by the simple process of multiplying the desired distance by the distance indicated on diagram.

Square System.-One of the advantages of this system is that it permits cultivation in both ways, especially when the trees become larger. The trees are not equally distributed over the ground, however.

The first step to be taken in this and the following plans is to have the base lines at right angles. In planting a large place, these lines should be obtained by a transit. By studying the plans and observing the directions herewith given, the method of procedure is readily understood.

\section{SQUARE PLANTING}

Rule: Square Method.-Multiply the distance in feet between the rows by the distance the plants are apart in the rows, and the product will be the number of square feet for each plant or hill; which, divided into the number of feet in an acre $(43,560)$, will give the number of plants or trees to an acre.

Lay off the base lines A B and A C along two sides of the planting field in such a manner that the angle at $\mathrm{A}$

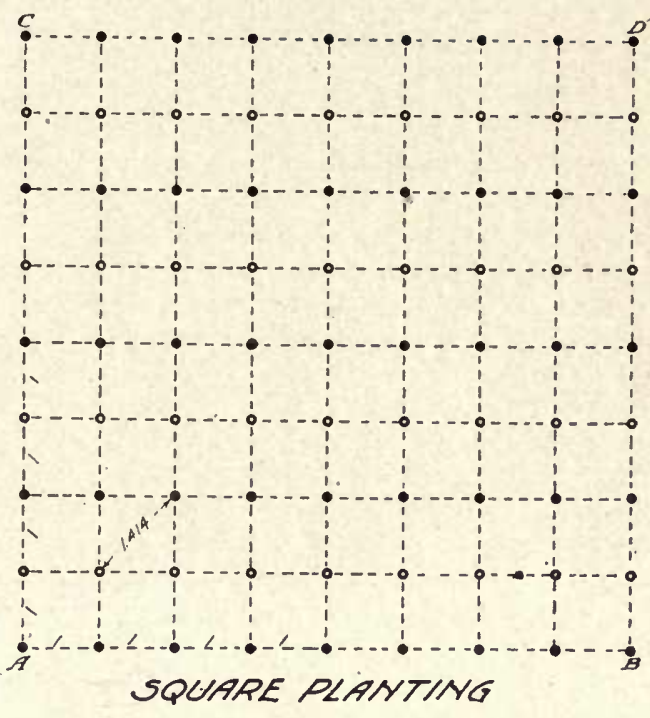

is an exact right angle (90 degrees), and set stakes on said base lines the desired distance apart. Care must be exercised to have all stakes on true lines.

A right angle can be formed in the field by the following method:

Lay off 30 feet from $\mathrm{A}$ along base line $\mathrm{A} \mathrm{B}$ on the diagram; then a point on base line $\mathrm{A} C$ will be 40 feet from $\mathrm{A}$ and 50 feet from the other end of the 30-foot length.

After setting the stakes along the base lines at planting distance apart, the next step should be to set stakes along secondary lines drawn parallel with base line A B, and such distances therefrom as will be multiples of the planting distance required, and at the same time no further apart than permitted by the length of the planting chain. This should preferably be of stranded wire No. 19 gauge and provided with numbered metal tags designed to be inserted at desired distances apart.

Experience has demonstrated that a 250-foot chain is the most serviceable. The chain should be stretched for several days before using to prevent too much variation in the field.

The chain should be provided with a ring and about two feet of surplus length of wire on each end for easy manipulation and stretching. - Iron stake pins should be used to hold the chain in position. To do this properly it is advisable to lay off a temporary base line B D from end $\mathrm{B}$ of base line $\mathrm{A} \mathrm{B}$ and at right angles thereto, setting flags on such temporary base lines at distances to correspond with the spacing of the secondary lines.

With the flags as a guide, lay off the planting stakes on the secondary lines, starting always from base line A C. Then all that is required to complete the staking will be to stretch the chain between similar points on the secondary lines and set the stakes at each tag on the chain previously adjusted.

Quincunx System.-The only advantage in this method of planting is in connection with using a filler temporarily, to be dug up as soon as there is any indication of crowding. This permits of double the amount of trees to the acre than in the square system. 


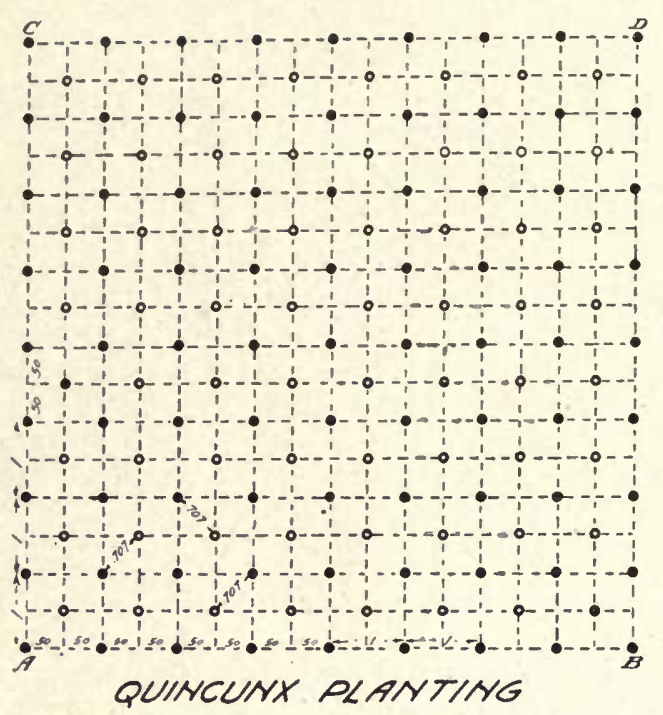

Proceed to stake the field in squares. Then without the aid of a chain, place a stake in the center of each square. This is readily determined by sighting along the two diagonal rows of stakes at right angles to each other.

Rule: Quincunx Method.-Multiply the number required to the acre "Square Method" by 2 . The result will be the number of plants required to the acre by this method.

Hexagonal System.- This is the only one in which the trees are equidistant in every direction, every tree being at one point of an equilateral triangle.

The name "Septuple," sometimes applied to this system, refers to the fact that the number of trees in each group unit is seven. Note hexagon on diagram.

To illustrate the plan to be followed, we will consider that the trees are to be set 24 feet apart. Then on base line A B set stakes 24 feet apart. On base line A C set stakes 0.866 times the planting distance apart or every 20.784 feet (or 20 feet 9 inches).

The first stake on the intermediate line, shown by the hollow circle on the diagram, should be 12 feet from the base line $\mathrm{A} \mathrm{C}$ and 20 feet 9 inches from base line $\mathrm{C} \mathrm{D}$.

In using this method of staking, tags of two different colors should be used, one starting at zero and the other .50 times the planting distance from the zero end of the chain.

For the convenience of the planter we are giving herewith the distances between rows of trees, parallel with base line A B on the diagram, to correspond with various planting distances:

As an illustration, if trees are planted 18 feet apart on base line A B, the following row would be 15 feet 7 inches and correspondingly greater distance where the trees are to be planted further apart.

Base line A B $18 \mathrm{ft}$. Secondary line $15 \mathrm{ft} .7 \mathrm{in}$. from A B Base line A B $20 \mathrm{ft}$. Secondary line $17 \mathrm{ft}$. $4 \mathrm{in}$. from A B Base line A B $22 \mathrm{ft}$. Secondary line $19 \mathrm{ft} .1 / 2$ in. from A B Base line A B $24 \mathrm{ft}$. Secondary line $20 \mathrm{ft}$. $9 \mathrm{in}$. from A B Base line A B $28 \mathrm{ft}$. Secondary line $24 \mathrm{ft}$. 3 in. from A B
Base line A B $30 \mathrm{ft}$. Secondary line $26 \mathrm{ft}$. 0 in. from A B Base line A B $36 \mathrm{ft}$. Secondary line $31 \mathrm{ft}$. $2 \mathrm{in}$. from A B Base line A B $40 \mathrm{ft}$. Secondary line $34 \mathrm{ft}$. S in. from A B

Rule: Hexagonal Method.--First, figure the number of trees required per acre by the "Square Method," using the same planting distance; then divide by the decimal .866 . The result will be the number of plants required to the acre by this method.

Alternate System.- We will assume that the planting distanee is to be 24 feet apart, and then all stakes on base line A B will be 24 feet apart. The alternate stakes on this line will be for temporary use only. In setting stakes on lines parallel with base $A \mathrm{C}$, the tags of one color should be spaced 24 feet apart, commencing at the zero end. Tags of another color (for use on alternate lines) should be spaced 24 feet apart, commeneing at a distance of 12 feet from the zero end of the chain.

Rule: Alternate Method.-The number of plants required per acre by this method is the same as that required by the "Square Method" with similar planting distances.

\section{Planting Distances. Distance}

apart each way

Standard Apples

25 to 30 feet

Standard Pears. ...............24 to 30 feet

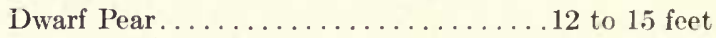

Strong-growing Cherries............24 to 30 feet

Duke and Morello Cherries...........18 to 24 feet

Standard Plums and Prunes...........24 to 30 feet

Peaches and Nectarines............24 to 30 feet

Aprieots..................24 to 30 feet

Figs.....................25 to 40 feet

Olives...................... 30 to 35 feet

Citrus trees.................22 to 30 feet

Walnuts.....................40 to 60 feet

Almonds....................24 to 30 feet

Grapes..........6.6.6. $6 \times 12,8 \times 8$ and $8 \times 10$ feet

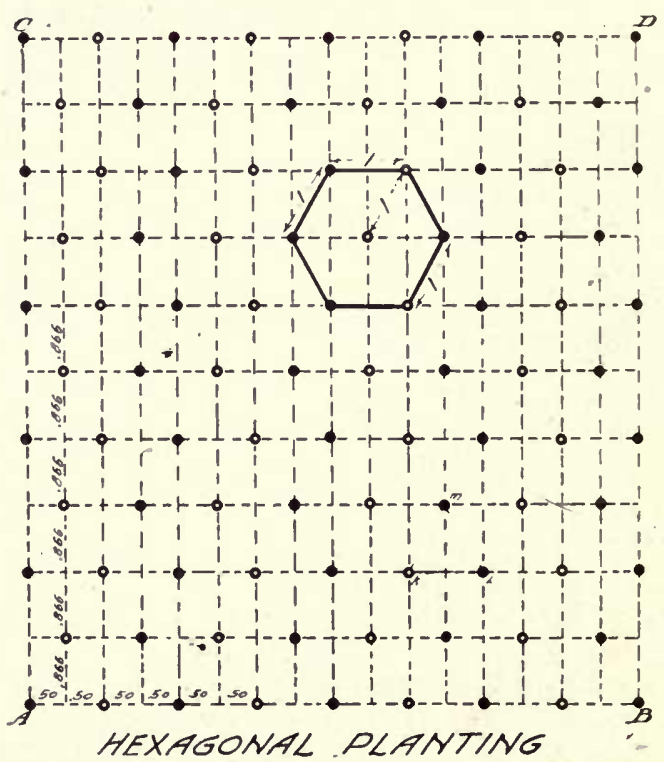




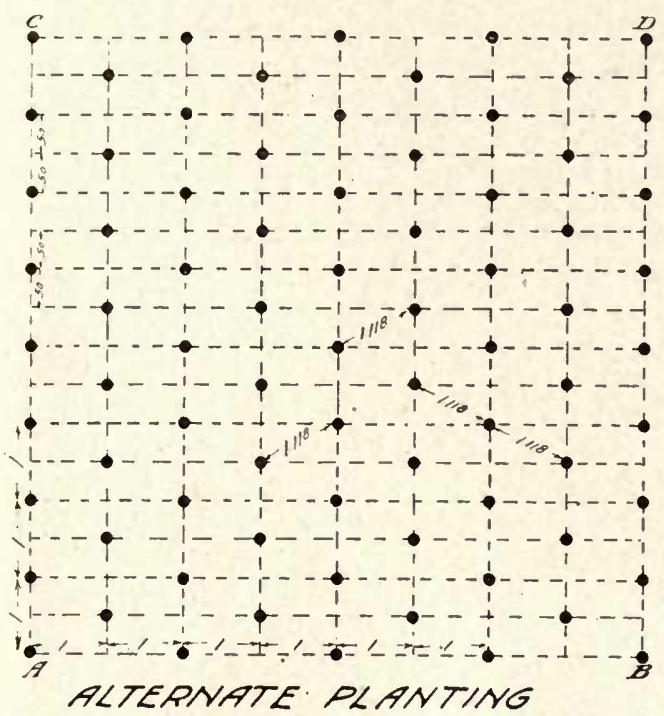

NUMBER OF TREES TO THE ACRE

$\begin{array}{rrrrr}\text { Distance } & \text { Square } & \text { Quincunx } & \text { Hexagohal } & \text { Alternate } \\ 8 \mathrm{ft.} & 680 & 1360 & 785 & 680 \\ 10 \mathrm{ft.} & 435 & 870 & 500 & 435 \\ 12 \mathrm{ft} . & 302 & 604 & 349 & 302 \\ 14 \mathrm{ft} . & 222 & 444 & 255 & 222 \\ 16 \mathrm{ft} . & 170 & 340 & 196 & 170 \\ 18 \mathrm{ft} . & 134 & 268 & 154 & 134 \\ 20 \mathrm{ft} . & 109 & 218 & 124 & 109 \\ 22 \mathrm{ft} . & 90 & 180 & 104 & 90 \\ 24 \mathrm{ft} . & 75 & 150 & 87 & 75 \\ 25 \mathrm{ft} . & 70 & 140 & 80 & 70 \\ 26 \mathrm{ft} . & 64 & 128 & 74 & 64 \\ 28 \mathrm{ft} . & 56 & 112 & .64 & 56 \\ 30 \mathrm{ft} . & 48 & 96 & 55 & 48 \\ 32 \mathrm{ft} . & 43 & 86 & 49 & 43 \\ 36 \mathrm{ft} . & 34 & 68 & 39 & 34 \\ 40 \mathrm{ft} . & 27 & 54 & 31 & 27 \\ 45 \mathrm{ft} . & 22 & 44 & 25 & 22\end{array}$

Note.-All of these figures are not exact for planting one acre, but are intended for the planting of a multiple of acres.

\section{BLASTING THE HOLES}

Much interest has been manifested of late years in dynamiting the holes prior to the planting of the trees. It is absolutely necessary to do this in hardpan soils in order to plant trees at all.

It has been the practice not to blast where the hardpan came within three feet of the surface. Actual experience has demonstrated that not only striking and remarkable development in the growth of trees had been secured by blasting where hardpan was found, but in any soil of a heavy, compact nature. It does not take much of a stretch of the imagination to comprehend the fact that a thorough disintegration of the soil, permitting the roots to ramify in every direction, will promote a rapid root and top growth. The drilling of the hardpan is rarried on very expeditiously nowadays by the use of a power drill mounted on a wagon.

\section{IMPORTANT DETAILS}

As has been suggested previously, above all things have your ground in the very best condition of tilth. The importance of this one point cannot be dwelt upon too forcibly, for it not only insures more rapid work on the part of the men setting your trees, but in addition to this, not having any clods to contend with, the fine loose soil packs around the roots, when tramped in. If for any reason there should be no water available for settling the trees there is less likelihood of their drying out.

A stake about half an inch square and one foot long, split out of redwood, will be found to be a very convenient size as a marker for the setting of the trees. Dip about six inches of one end in whitewash. They can then be readily seen, and should any of the stakes be out of line it will be noticed at once. Before digging the holes it is necessary to have a tree setting board. This is easily made out of a piece of $1 \times 4$ six feet long with an inch hole at each end and a notch in the center. Place the notched center against the stake where the tree is to be planted and push a stake into the ground through the holes at each end of the planter and remove the center stake. The hole may now be dug and this should not be less than 18 inches in diameter and 18 inches deep. After the hole is dug, replace the board over the end stakes in its former position, then plant the tree with the trunk end resting against the center notch in the board and it will be in identically the same place as the stake which was removed to dig the hole.

In setting out, one person should hold the tree in an upright position against the notch in the tree setter, while another shovels or fills in the loose soil around it, first spreading out the roots and rootlets in as natural a position as possible. The surface or friable soil should be put in first among the roots, care being taken to fill in every interstice, thus bringing all the roots in direct contact with the soil. When the hole is two-thirds full, firm the earth thoroughly about the roots, but before doing this draw the tree up to its permanent position. The top three to four inches of soil should not to be tramped.

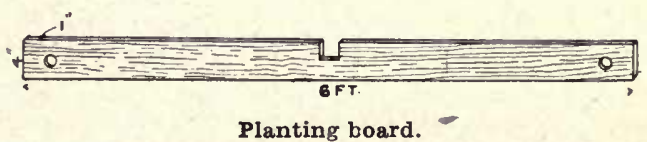

A basin should be scooped out around the tree which will hold at least fifteen gallons of water, and unless heavy rains should intervene to fill it up, water should be applied either by bucket or by irrigation. The following day draw in loose soil to fill up this basin, reducing it to a fine condition of tilth and do not tramp in. Guard against setting too deeply, but allow for the settling of the soil, so that when once established the tree will stand about as it did at the time of removal from the nursery rows, or at the outside not more than three inches below the surface of the soil. In the hot interior valleys of this state, it is also very important to protect the trunks with tree-protectors until they can supply their own shade. 


\section{BRINGING AN ORCHARD OR VINEYARD INTO BEARING}

Just in the proportion that the orchard receives intensive and intelligent care, will it give corresponding returns on the investment of capital, time and labor. Above all things, do not plant too many varieties if you desire to be a factor in the business. As an illustration, it is a mistake to have a different variety on each acre, for when this orchard comes into bearing there are so many varieties and so limited a quantity of each that the commercial packer of dried or canned fruits does not feel inclined to pay what the fruit is worth, because there is not enough of any one kind to make it an object for him to handle it.

The handling and marketing of fruit has assumed such vast proportions that there are always commercial institutions eager enough to enter a new field and exploit it as soon as the production is large enough to encourage the building of packing houses for the handling of any particular product. Another serious mistake on the part of many growers is to endeavor to harvest big crops when their trees are only two years old. This is an unwise policy and in many cases sacrifices the tree, resulting in its not producing profitable crops when it should be in its prime, and in consequence of this requiring extraordinary care to restore it to its proper vigor. The care bestowed for the first two or threc years in cultivating, pruning and irrigating, where the rainfall is insufficient to carry the trees through the long dry summer months, is the foundation for the upbuilding of an orchard which will redound to the credit of the owner and give him ample returns for his intelligent care and years of hard work.

Next to the thorough cultivation there is nothing which is more vital to the life of a trec than proper irrigation. It is difficult to lay down specific rules on this point, but there are basic ones which can generally be observed in the handling of most deciduous trees, with some exceptions, and instructions pertaining to such cases will be.dwelt on under proper heads.

\section{MUST BE CUT BACK}

After a tree is set never fail to cut it back. This is now the general practice among the most successful orchardists throughout California, and is the result of years of experience. The following winter from three to four branches, properly distributed around the body of the tree, should be allowed to remain to form the head, and each one of these branches should have at least one-half of their growth removed, cutting away all laterals from them also. These leaders will eventually form the framework of the tree. The first year's pruning will result in the trees making an immense growth and also induce them to grow stocky. The second winter heavy thinning will have to be followed and the pruning should be done with a view of causing the framework branches to spread out. 'There may be some variation from these instructions, therefore it is advisable to read carefully the information given under each head. The many advantages of this method of pruning are: (1) it makes a low-crowned and a more stocky tree, affording an umbrageous head, and thus protecting it from the hot rays of the scorching summer sun; (2) it enhances the carrying capacity of the tree, thus avoiding artificial props when maturing a crop of fruit; (3) it expedites the harvesting of the crop by rendering it more accessible to the pickers, thus economizing time and expense; (4) it prolongs the life of the tree by reason of conserving its vital forces and rendering it less liable to damage in the breaking of limbs and taxing its strength by carrying its fruits "close in."

\section{IRRIGATION}

During the first season for deciduous trees in districts where irrigation is practised, water should be applied not less than four times during the year. For the first two years it is not necessary to irrigate all of the ground between the rows. A space six feet wide will answer the necessary requirements in nearly all cases.

The planter should never lose sight of one important fact, and that is, if the orchard or vineyard ean be maintained in a thrifty, vigorous condition thorough cultivation is recommended as being preferable to an irrigation.

\section{THE APPLE}

In the temperate zone no variety of fruit is so widely distributed or has been more extensively planted than the apple. The list of varieties is amazing. "Downing's Fruits" alone lists about 3500 sorts.

Varieties are variable as to localities, and in planting in sections where apple culture is pursued commercially the advice as to the best varieties to plant should be sought from experienced growers. Broadly speaking, the hot interior valleys are not suitable for commercial apple culture on a large scale, as the very rapid and early maturing of the fruit does not seem to be conducive to long-keeping, as found in tried localities where conditions are favorable for perfecting fruit having long-keeping qualities. Nevertheless, it is a fact that where moisture is readily maintained in a soil by either irrigation or by sub-irrigation, many varieties are of such exceptionally large size, present so fine an appearance and are of such excellent flavor that more attention should be given to their culture.

\section{SOIL AND SITUATION}

The best soil for this fruit is a deep, rich loam which will allow the free extension of the roots and is exempt from stagnant water. An extremely light soil should be avoided. Apples do exceedingly well in all the coast counties, as well as in the upper foothills and inountains of the Sierra Nevada. In adjacent states and territories to the north and east, apple culture is more general, and may be safely followed wherever the soil and climate is favorable. The keeping qualities and the flavor and coloring of our mountain-grown apples at elevations of 3000 to 5000 feet or more, are indeed hard to surpass.

California's great apple center is located in the vicinity of Watsonville. There exists in that section a combination of soil and climate which causes apples not only to be of good quality but excellent keepers. 


\section{POINTS TO BE OBSERVED}

It is the consensus of opinion among commercial growers that trees should be planted from twenty-five to thirty feet apart in orchard form. Crab apples may be planted closer. Trees should be eut back to twenty inches from the top of the ground after being set, except in the higher altitudes, where the snow in settling would cause the branehes to break off, thus making it advisable to head the trees at not less than two feet from the ground. Apples are very much subject to sun scald and to the attack of the flat-headed borer the first few years after trees are set out. When headed low, protected with tree protectors, permitting of free circulation of air, and by giving the stem a coating of whitewash to which has been added soap and crude carbolic acid, little danger need be apprehended from either of these evils. The wash is made in the following manner: Dissolve one-half gallon of soft soap in one-half gallon of hot water, adding one-fourth pint of crude carbolic acid. When mixing add five gallons of hot water and enough lime to make a mixture the consistency of paint.

\section{SHAPING THE TREE}

In forming the head of the tree no branches eloser than one foot from the surface of the ground should be allowed to grow. The following winter they should be cut back at least one-half and thinned out so as not to leave more than four branches to form the framework, and these should be distributed in such a manner as not to crowd one another as the tree develops. Each one

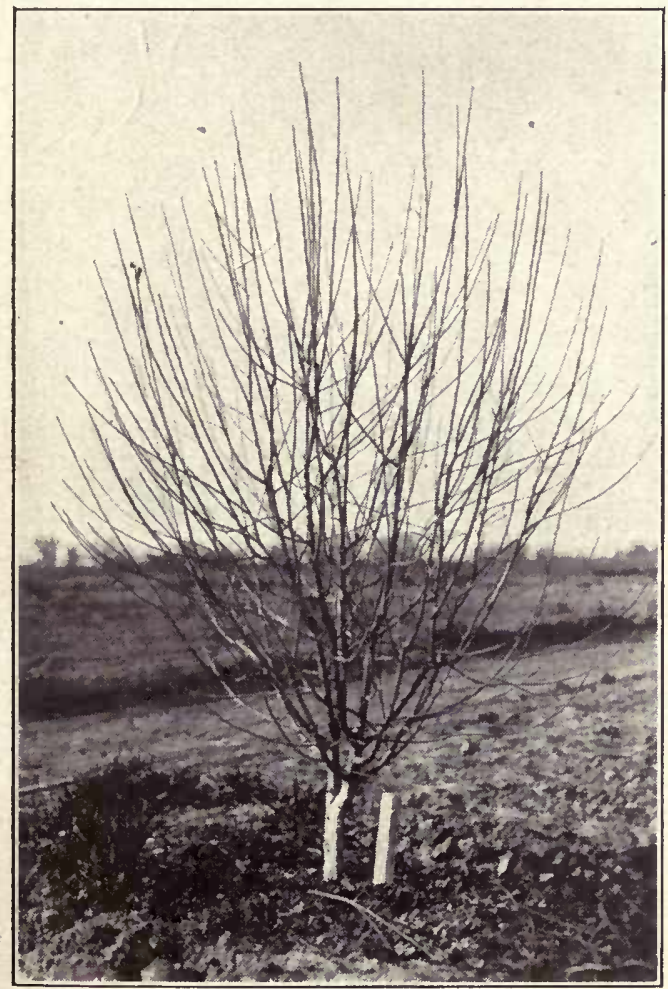

A four-year-old Apple tree with a well balanced head.

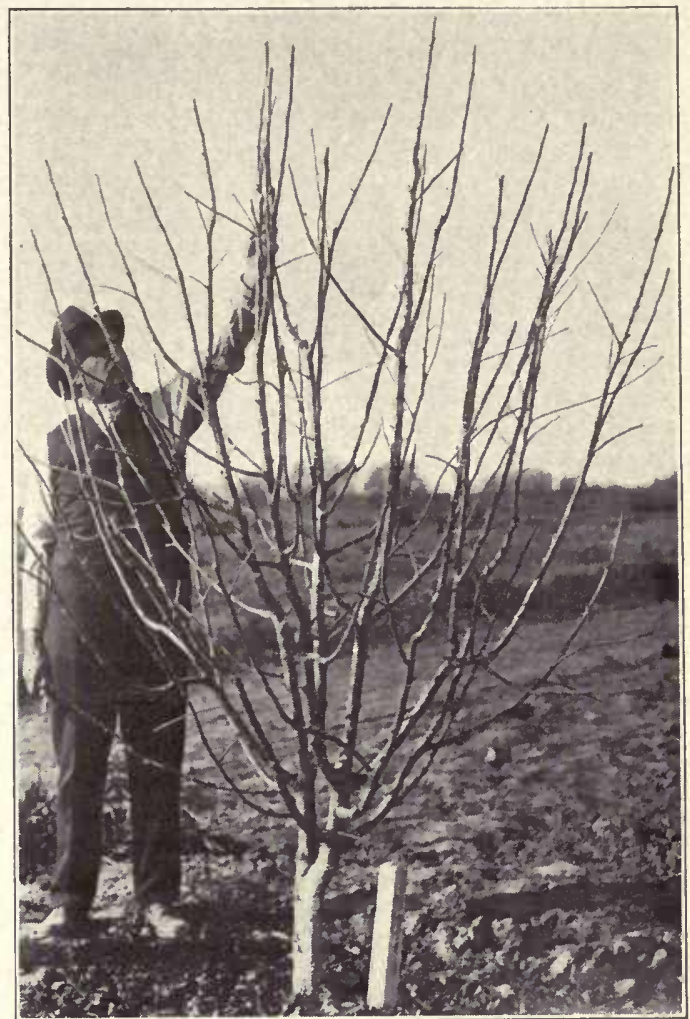

The same tree with the leaders and laterals shortened in. It has reached the point where it is in shape to produce a crop of fruit.

of these branches should be regarded as a subdivision to maintain the wood supply to eventually form a perfectly vase-formed tree. The second winter not more than two laterals should be allowed to grow from the framework branches, and if there is a tendency to crowd, not more than one, and its growth should again be shortened very severely. The tendency as far as possible should be to prune to an outside bud for the first two winters' pruning. With the head now practically formed, the orchardist must shape the tree in accordance with its development, leaving and shortening in the inside laterals if they show a tendency to spread out, or if the inclination is to assume too upright a form, cause them to spread by leaving the outside laterals. The cutting back of the trees and judicious thinning prevent the long bare branches so noticeable in trees which have not been systematically pruned every winter. The effect of this method of pruning is to eause the structural branches to be sturdier, the load of fruit is carried closer to the trunk and even with a very heavy crop of fruit the necessity of propping is eliminated very largely. Props are an expensive item and they also interfere very materially with the harvesting of the erop, so that a method of pruning which will dispense with them is worthy of very careful consideration.

\section{ROOTS}

The stock generally used for budding or grafting the apple is Malus communis, common apple. These stocks 
are raised from seed. Much interest has been manifested in the Wooly Aphis resistant roots. After twenty years of careful experimental work, it has been fully demonstrated that the Northern Spy root is absolutely resistent to the attacks of this insect. Trees growing in badly infested districts are entirely free from it, thus proving conclusively the value of the Northern Spy root. It is only reasonable to suppose that these trees should command a higher figure than those budded on the seedlings, when the additional expense incurred in handling is taken into consideration. In the first place it is necessary to have mother trees growing in the nursery to supply a crop of roots. They are permitted to grow for several years, when they are dug up and all the roots fit for grafting are cut off and the trees are again planted for the purpose of supplying another crop of roots. These roots are in turn grafted with Northern Spy scions and the grafts are planted in beds. The following year they are transplanted to nursery rows and the Northern Spy stock is budded. The several operations, therefore, extend over a period of three years before the trees are marketable. It is practicable to produce dwarf apple trees by budding them on dwarf apple stocks, commonly known as Paradise or Doucin stocks. These are produced by layering. The demand for apples on this stock is very limited. Trees grown on this root may be planted as close as six feet apart. They come into bearing within three years after planting. For gardens or for suburban homes they will prove to be a valuable acquisition.

\section{THINNING}

Fruit growers fully realize that it is just as important to thin their apples as any other class of fruit. Where apples are allowed to grow in bunches many of them are undersized, and in addition to this, the difficulty of thoroughly spraying the fruits touching each other gives the codlin moth a good chance to get in its work, thus causing a good part of the crop to be wormy. If there was no other incentive, this alone should be a sufficient inducement to thin. The life of the tree is conserved by relieving it of its heavy burden of fruit.

\section{GATHERING AND STORING}

This is a problem which confronts every grower of fruit. The safe rule is to gather summer and early fall apples when they have attained full color and before they become soft. Care should be exereised not to break out the stem. Winter apples should be mature but not ripe. When the seeds show that they are turning slightly brown, it is a safe indication that the fruit is ready to pick. The external appearance of the fruit is usually a good guide as to the time of gathering. All late winter varieties should be gathered when too hard to yield to the pressure of the thumb and always before heavy autumn frosts. An old plan, and one which is followed even to this day by many orchardists, is to pile winter apples under the trees covering them with leaves, allowing the rains to fall on them. For family use there is no serious objection to this method, for in nearly all eases the apples when taken from their coreling are smooth and plump. The commercial practice is to pick and sort the apples, carefully removing all diseased and inferior fruits, place them loose in boxes and then transfer to a fruit house. This should be constructed so that a fairly uniform temperature is maintained. The ventilation should be good and the boxes should be stacked so that there is a eirculation of air. In the mountains, where stone is to be had readily, there is no better material than this for an apple house, as it resists any sudden changes in temperature.

It is quite true that the apple will withstand rough handling far better than many other fruits, but even admitting this fact, it is nevertheless just as much to the interest of the grower to give every attention to all the details necessary to the careful handling of apples as with any other class of fruit.

\section{COMMERCIAL VARIETIES}

Alexander, Arkansas Black, Black Ben, Delicious, Early Harvest, Esopus Spitzenburg, Gravenstein, Jonathan, Red Astrachan, Rome Beauty, Smith's Cider, Stayman's Winesap, White Astrachan, White Winter Pearmain, Winesap, Yellow Bellflower, Yellow Newtown Pippin.

Period of ripening of varieties in an average apple section. Listed in the order in which they ripen.

June

Red June, Red Astrachan, White Astrachan, Duchess of Oldenburg.

July

Early Harvest, Alexander, Gravenstein.

August

Maiden's Blush, Red Beitigheimer.

\section{September}

Fameuse, King of Tompkins County, Bismarck.

\section{October}

Jonathan, Rhode Island Greening, Rambo, Red Bellflower or Marshall Red, Yellow Bellflower, Winter Banana, King David.

\section{November}

Ben Davis, Gano or Black Ben, Arkansas Beauty, Arkansas Black, Baldwin, Delicious, Esopus Spitzenburg, Grimes Golden Pippin, Lawver, Mammoth Black Twig, Missouri Pippin, Northern Spy, Rome Beauty, Smith's Cider, Stayman's Winesap, White Winter Pearmain, Winesap, Yellow Newtown Pippin.

\section{CRAB APPLES}

August

Red Siberian, Hyslop, Yellow Siberian.

\section{September}

Whitney No. 20, Transcendent. 


\section{THE PEAR}

The pear is a fruit cultivated throughout California and the Pacific States generally, extending into Mexico. Like the apple, there is an endless list of varieties. Unlike any other variety of fruit we grow, there is one variety, the Bartlett, which may well be termed the King of Pears, because it meets every demand for shipping, canning and drying. It has held its sway as the leading, all-purpose pear for a great many years, and where it can be grown successfully, it will undoubtedly continue to do so for many years to come. It is of English origin and dates back to the year 1770 . Its correct name is Williams' Bonchretin, which name was lost after it was introduced into the United States. Enoch Bartlett, of Boston, Mass., cultivated and distributed it and it took his name.

There are other desirable varieties, of course, many of which are very meritorious and worthy of being cultivated. As fruit growing develops, experience and market conditions will cause a number of varieties to be recluced to a point where only those having qualities that will make them valuable commercially will be grown to any extent. The elimination of all varieties of pears not up to a standard perfection, making it profitable for the commercial fruit grower to produce them, is the order of the day.

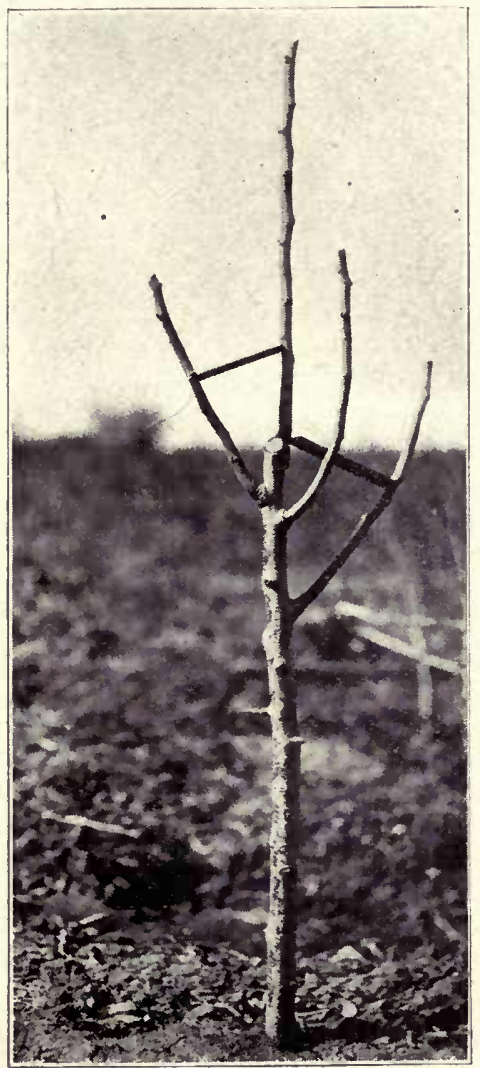

The method of pruning a one-year-old orchard pear tree. Note the simple device used for pushing the framework branches away from the body of the tree.

\section{SOIL AND SITUATION}

It does well in all soils with the exception of those which are extremely sandy. It thrives better in alkali soils than probably any other variety of deciduous fruit and therefore is being planted in vineyards and orchards where the vines and trees have been killed. If there is any one thing that has militated against the planting of pears on an extensive scale in the great interior valleys of California, it has been the blight. Like all fungus diseases, its control has been a very difficult matter and it is only by the utmost care and vigilance on the part of the grower in cutting out the diseased sections of the trees and by the disinfection of the pruning tools that the disease can be controlled. In all the

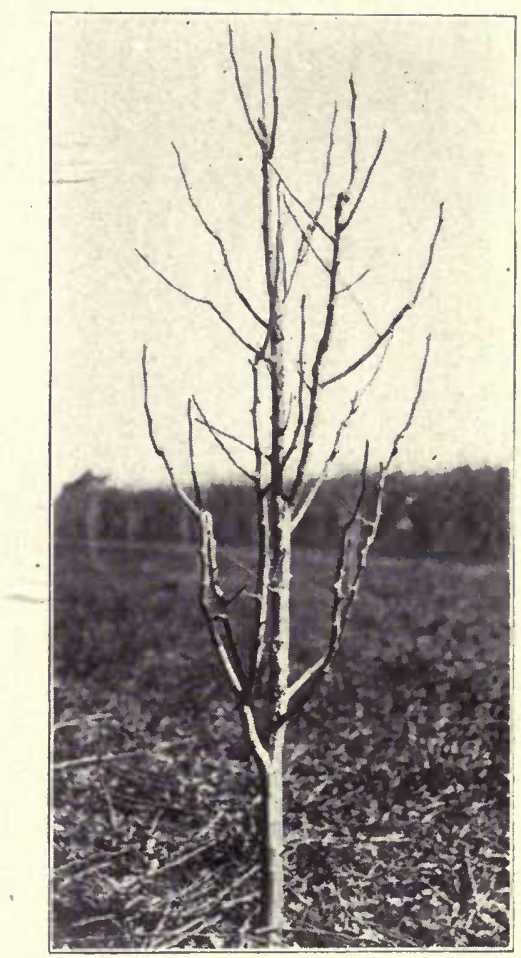

A three-year-old Bartlett Pear tree. Note the strong leader three-year-old Bartlett Pear tree. Note the strong, when in center and numerous laterals. In later years, when the tree is heavily laden with fruit, the laterals are prefastened to the strong leader.

coast counties of California, from the County of Monterey northward and west to the Coast Range, climatic conditions are very favorable for the growing of the very finest pears, bounteous crops being harvested annually. In these sections the blight has never been considered a menace, because there are orchards in the Counties of Alameda, Santa Clara and Solano, fifty years old which are vigorous and healthy. Experience and actual demonstration are, after all, the best answer to any argument that might be presented against the growing of pears in the sections referred to.

By planting varieties which ripen in succession in the early summer months until the late fall one may have pears on the table during the entire year. 


\section{DISTANCES APART AND STOCKS}

Trees must have ample room for development if crops of any consequence are to be harvested from them when they reach a bearing age.

Growers are becoming more impressed with this fact than ever before. Crowding a lot of trees on an acre does not mean more fruit. As an actual fact it not only means less, but in addition to this the vitality of the tree is impaired to such an extent that it never reaches its prime vigor. Twenty feet apart is entirely too close to plant pears on pear root; never closer than twentyfour feet is better, and in very strong, deep alluvial soils, well supplicd with moisture, there will be no objection to even planting thirty feet apart. Pears on quince root may be planted much closer, because the quince has a decidedly dwarfing tendency on the tree. . Not only has it this effect but it also causes the trees to come into bearing when three years old and holds them in check to a great extent without impairing their vitality. Trees worked on quince are well adapted for use in small gardens where there is not much room. For orchard planting trees should not be set closer than fifteen feet apart. That the trees are long-lived and that a crop failure is almost unknown is aptly illustrated by the famous A. Block orchards in Santa Clara, where the old monarchs, fifty years old and two feet in diameter, still con-

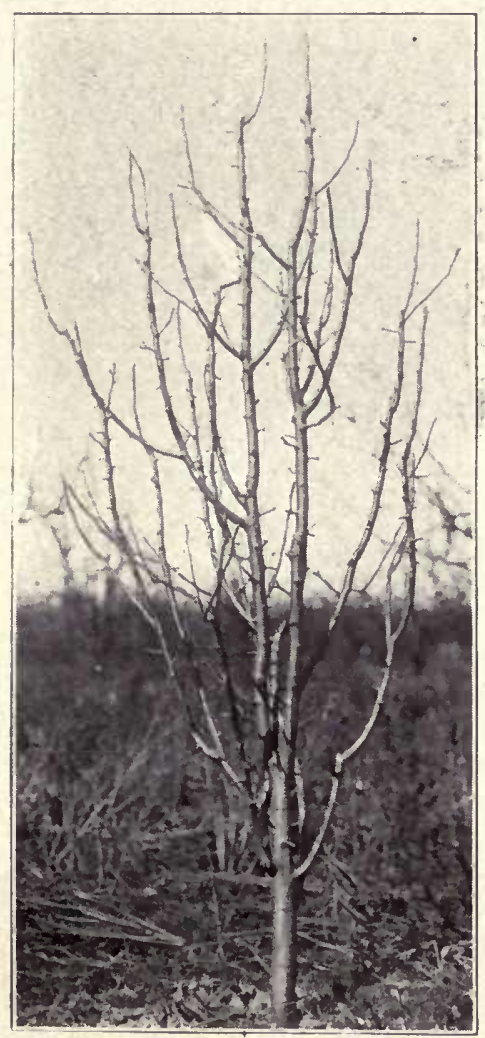

A five-year-old Bartlett Pear tree with head formed and well supplied with fruit spurs.

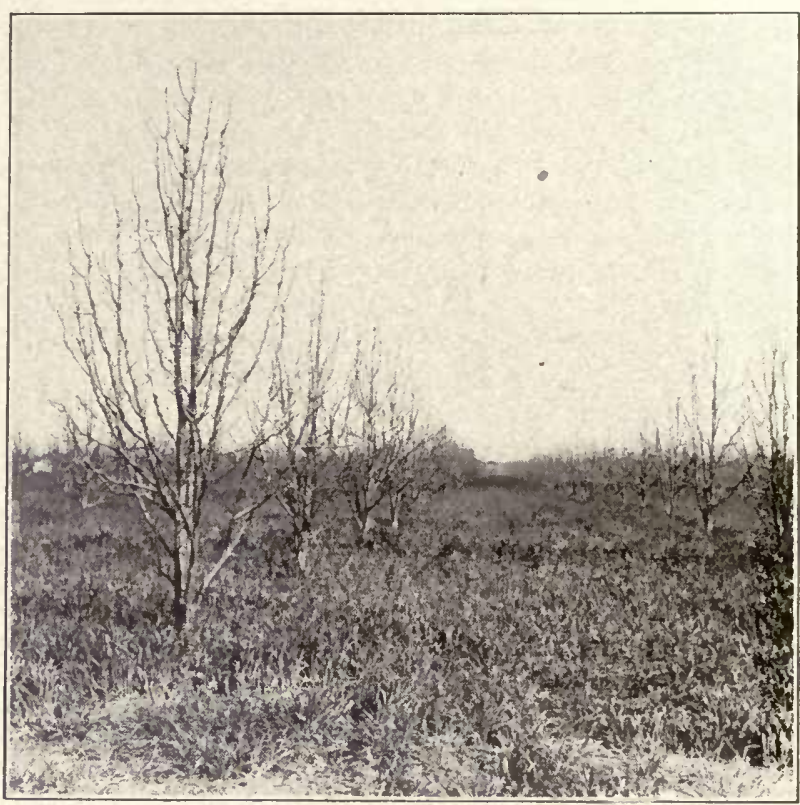

A general view of an eight-year-old Bartlett Pear orchard, pruned along the lines recommended.

tinue to bear heavy crops of fruit annually. Pears on quince root are very much more expensive to grow than a pear on pear root. First of all, the quince trees must be grown from cuttings. These are planted in beds and the following winter they are planted in nursery rows. Many varieties of pear lack affinity with the quince root and if budded directly on it, the bud will frequently break off in the nursery rows should there be a high wind. When planted in the orehard, the trees may fall over at any time. The only safe plan, then, to follow, is to secure trees that have been doubleworked. This means that the Beurre Hardy, which makes a better union on the quince than any other variety of pear, is first budded on this stock and when the tree is grown it is in turn budded to any variety of pear desired. Four years of constant care are required, therefore, before the trees are ready for sale.

All the old pear orchards in California are on the French pear root. This is being superseded very rapidly by the Japanese pear, because of its wider adaptability and on account of its being less subject to the attack of blight. Even the root of the French pear is attacked by blight. This is, in itself, a bad feature which should discourage the use of this stock in all future plantings.

\section{PRUNING AND SHAPING}

The very marked tendency of the pear to send its branches straight up requires a method of pruning which not only holds the tree under control but will promote fruit spurs from the point where the framework branches diverge from the body of the tree to the very top. It goes without argument that this is the desideratum which every pear grower would like to achieve.

For a number of years, while passing in the train from Lawrence station to San Jose on the Southern Pacific 
Railroad, my attention was direeted to the Bartlett pear orchard of Bracher Bros., two miles from the aforesaid station. The symmetry of the trees gave evidence that the pruning was being earried on along lines which not only maintained active growth in the trees but strong, vigorous fruit spurs, capable of carrying very heavy crops. The oldest orchard is over twenty-five years of age. It is in the very best of condition, as far looked; in other words, the branches should be forced outward without interfering with their upward course. In 1920 the current season's growth on these branches should be pruned back at least one-half, with the exception of the terminal, which should have its growth shortened one-third. A few side limbs should be allowed to remain, not overlooking the fact that they should be shortened in. In 1921 the same method

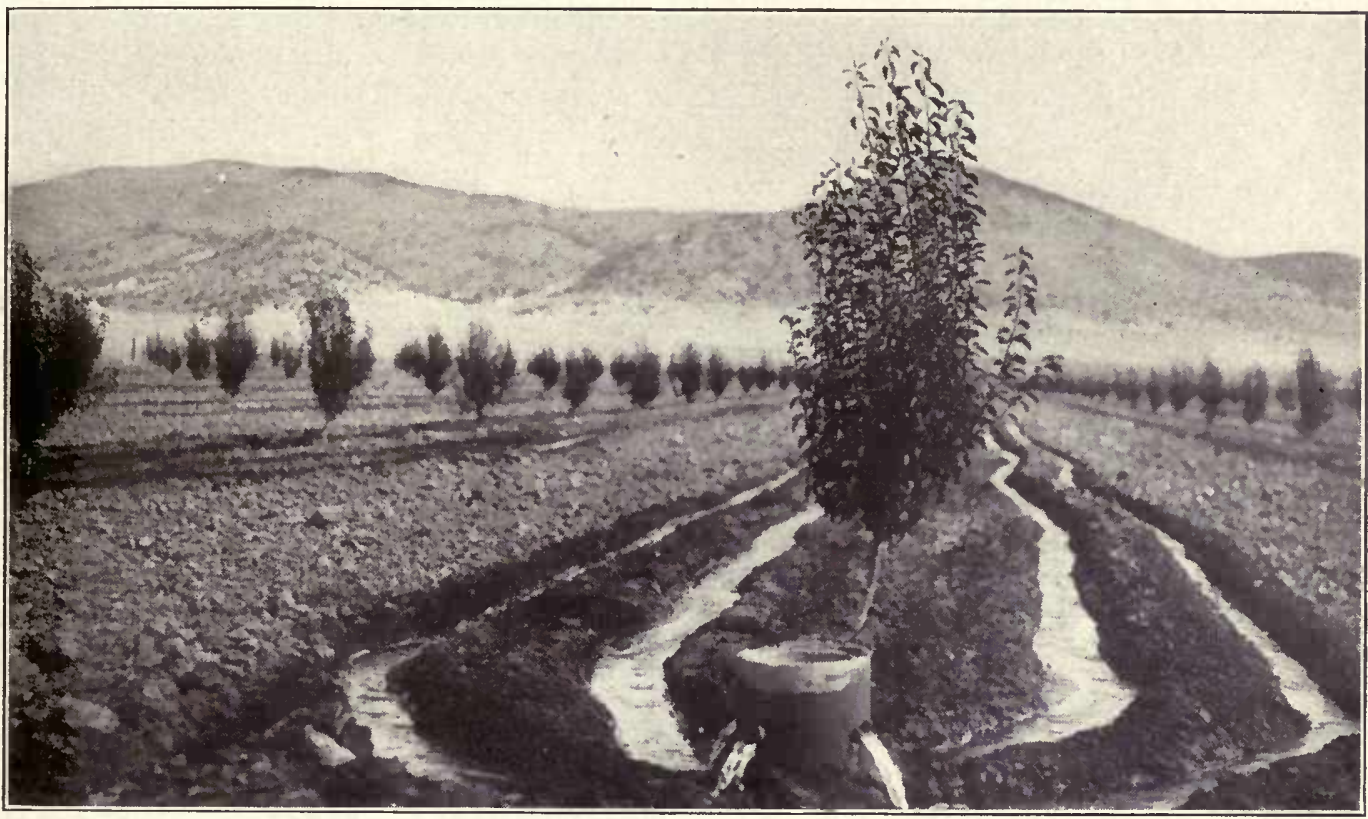

Irrigating a young pear orchard by the furrow system. This method of only partly covering the ground with water answers the purpose very well while the trees are young.

as vigor and fruitfulness is concerned and fully exemplifies the rare good judgment exercised in pruning. It is not uncommon for the one-year-old budded pear trees in nursery rows to attain a height of ten feet. Cut off this top, so that when the tree is set it will not stand more than twenty inches from the ground. Wellgrown pear trees have plump buds all the way up the stem, every one of which will start. This, therefore, should eliminate any doubt in the mind of the grower that the tree will not start if cut back as severely as this. In midsummer just before the wood begins to harden, from four to five branches, well distributed around the tree, should be selected and strips of wood slightly notched and from three to six inches long, should be used to push the branches away from the body of the tree. These will eventually be the framework branches, and the idea of pushing them out is to open up the tree tc develop the goblet form.

For the sake of argument let us consider that the orchard to be pruned was planted in February, 1918. In January, 1919, four branches regularly distributed around the stem of the tree should be selected, counting from the terminal one at the tip end to constitute what will eventually be the head of the tree. All of these branches must be cut back to at least six inches. If any of them show a tendency to hug too closely to the body of the tree, the wooden braces should not be over- of shortening in the leaders and thinning them where necessary should be followed, increasing the side limbs to balance the tree, and shortening them in. In 1922 the same method of shortening in and building up the frame of the tree should be followed. In later years the general policy of pruning continues, with the only alternative that its extent is regulated by the growth of the tree. This method of pruning and thinning results in making a fine symmetrical, vigorous tree with an even distribution of fruit spurs throughout. The fruit is evenly distributed over the entire tree and in years of enormous crops the leader is used as a support to string wires to the lateral branches and to prevent them breaking down with their load of fruit.

\section{THINNING}

Practically the same reasons for thinning the apple are applicable to the pear. It is of the utmost importance to thin pears because of their very marked tendency to grow in bunches. Another point, particularly with the Bartlett, which is shipped more largely than any other variety, is the very decided advantage of having early fruit because it has attained its size, thus securing the benefit of the very highest prices. Less wormy fruit, greater longevity of the tree, because its vital forces are not drained, are most excellent reasons 
for doing this work whenever it is necessary. Bear in mind that it is not advisable to thin until the fruit is well set.

\section{GATHERING AND RIPENING}

Pears, to secure the very best in them and high-elass delicious fruit, should never be allowed to ripen on the tree. Tree-ripened fruit is mealy, without juice, and is, in fact, entirely lacking in quality. The time to gather is indicated by the change in color from the decided green stage and the fact that when the pear is elevated slightly its stem parts readily from the branch to which it is attached. One of the great advantages in favor of the Bartlett is the fact that it can be picked as soon as it reaches the standard size of two and a quarter inches, packed in boxes, and shipped to the eastern markets, maturing en route and being ready for sale as soon as it reaches its destination. It is out of the question to handle winter pears like apples. They must be wrapped and packed tight in boxes, or placed in drawers closed tight in a room where the temperature only ranges from sixty to seventy degrees Fahrenheit. The pear, not having the oily skin of the apple, will shrivel up instead of ripening when exposed to the air. Pears which have been properly ripened are exceedingly melting, buttery and juicy.
The drying of pears is a very important industry in many sections of California. The fruit is allowed to remain on the trees until it has attained its largest size. The pears are then placed on trays or shelves under cover, and as soon as they show color, they are halved. A loaded car of trays is run into the sulphur house, where they are exposed to the fumes of burning sulphur for four hours. The fruit is then exposed to the sun for a period of ten days, depending on the weather. The finest product is very inviting. The flesh is white while the skin is of a light golden eolor. Lake county has a reputation for producing the finest dried pears in California. One of the advantages of drying pears is that fruit unfit for shipping or eanning ean be used for drying by cutting out the defects.

\section{IRRIGATION}

No absolute rule ean be laid down for irrigating. Where irrigation is practised at least from two to three irrigations, starting in May and continuing up to September, should be given to maintain good aetive growth in the trees for the first few years. For the first three years, where the roots are confined to a narrow space, a back furrow on each side of the row and three feet from the trees, with a cross check six feet below to back up the water, will provide all the water that is necessary

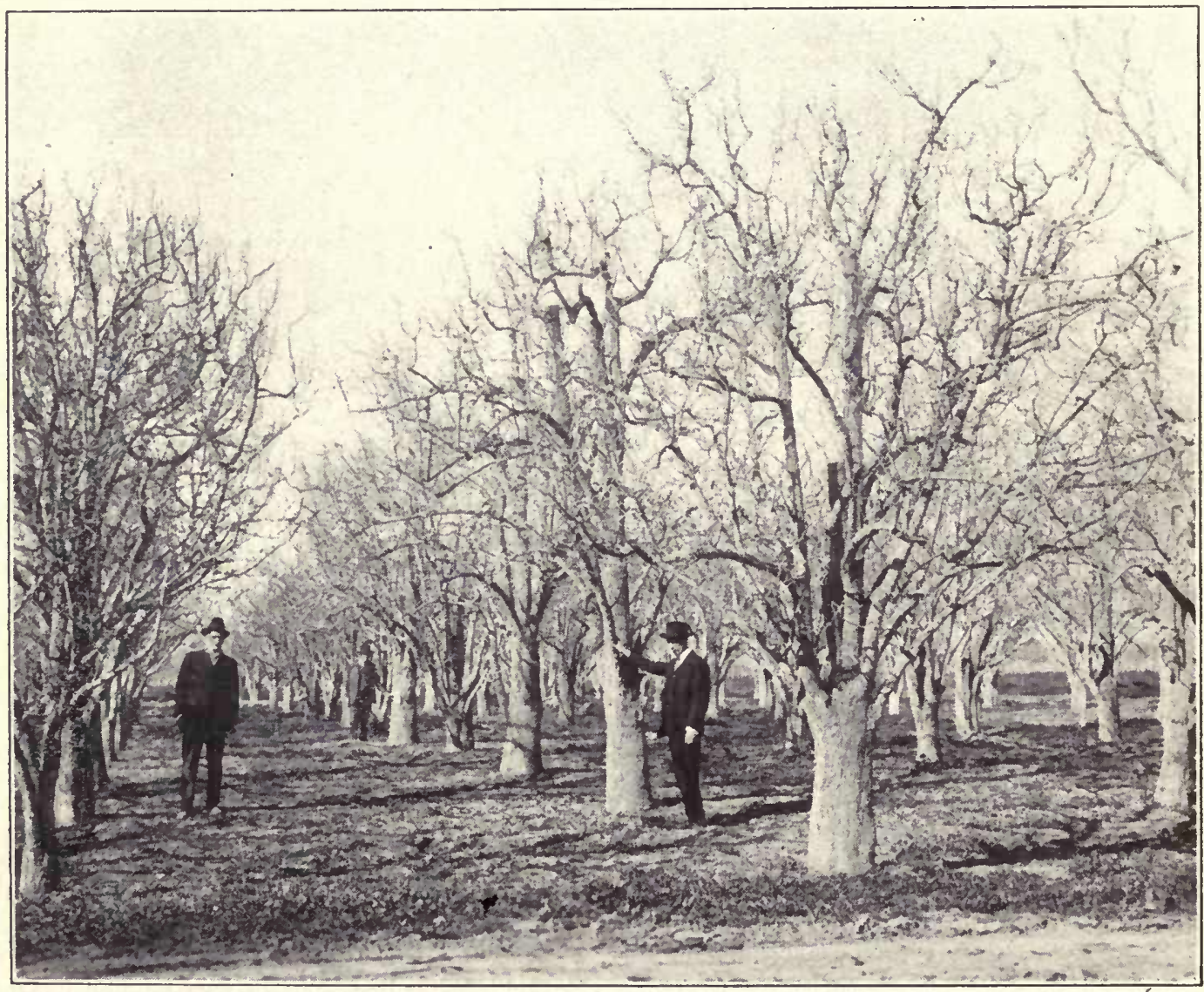

These old monarchs are pear trees on the A. Block place near Santa Clara These trees on quince root are only fifteen feet apart, nevertheless they are still in their prime and are constant and regular bearers. 
if the check is filled up. Thorough and frequent cultivation is much more important than resorting to irrigation. Cultivating and stirring the soil causes the roots to penetrate deeply for moisture, a very important and vital point. As the trees become mature, all the ground will have to be covered when irrigating, either by checking or by having the water run in furrows and seeping into the surrounding soil.

\section{COMMERCIAL VARIETIES}

Bartlett, Beurre Clairgeau, Beurre Hardy, Doyenne du Conice, Easter Beurre, Forelle or Trout, Glou Morceau, Howell, Lawson, P. Barry, Winter Bartlett, Winter Nelis"

\section{TIME OF RIPENING}

July

Madeleine, Lawson.

\section{August}

Bartlett, Bloodgood, Calpp's Favorite, Howell, Śouvenir du Congress, B. S. Fox.

\section{September}

Beurre Hardy, Le Conte, Duchess d'Angouleme, Scckel, Flemish Beauty, Beurre Clairgeau, Rossney.

\section{October}

Beurre Diel, Doyenne du Comice, Kicffer, Beurre Bose, Louis Bonne de Jersey, Beurre d'Anjou, Emile d'Heyst, Forelle, White Doyenne, Winter Bartlett.

\section{November}

Dana's Hovey, Winter Nelis, Pound, Easter Bcurre, P. Parry, Glou Moreeau, Crocker Bartlett.

\section{THE CHERRY}

Strictly speaking the sections in which eherries ean be grown seem to be limited to the counties adjacent to the San Franciseo bay region, although there is no doubt that in many of the eounties north of the bay and receiving the benefit of the tempered sea air, the growing of eherries will prove to be a profitable undertaking. The enormous profits realized from cherry orchards and the popularity of the fruit in the east, the very excellent keeping qualities of many of the varieties even when picked quite ripe, present a series of reasons for extending the field for the planting of cherries over a greater territory.

Being the initial stone fruit of the season probably accounts in a way for its popularity.

Exceptionally fine cherries are grown in Oregon and Washington. California's advantage over these two states is not so much in the quality of the fruit as it is in the time of ripening. Our season is from May 1st to June $15 \mathrm{th}$, while in the more northern states the season opens on the latter date and eloses about July 15th. In the upper San Joaquin valley, notably around Stockton, in many sections of the Sacramento valley, and in the foothill sections adjacent thereto, eherries are grown quite suecessfully in the alluvial soils. In the south half of the San Joaquin valley cherries should only be

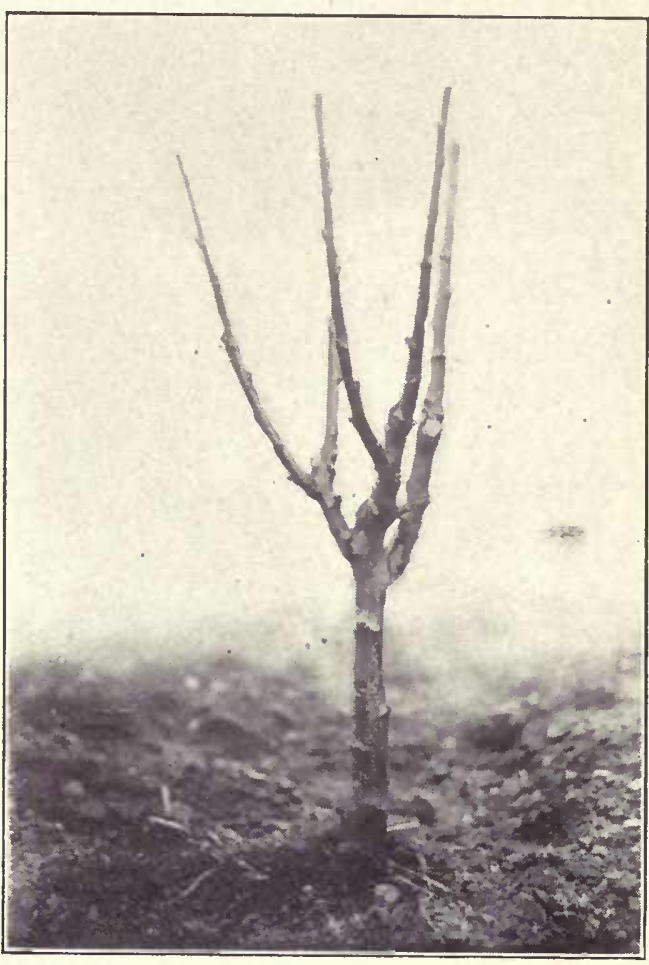

A two-year-old Cherry tree cut back to illustrate method followed of thinning and cutting back the leaders to secure a well balanced head.

planted for home use, giving the preference to the Morello types. Cherry trees should be planted twentyfour feet apart at the very least, and on exceptionally rich soils, thirty feet would be better.

\section{STOCKS FOR THE CHERRY}

For years it has been absolutely fixed in the minds of planters, and many of them experienced growers, that the only root for the eherry in California is the Mazzard (Cerasus avium).

According to all reports, the Mahaleb root (Cerasus odorata), which is extensively used in the east for growing eherries, would not do in California, and nurserymen, because of the prevailing prejudice, have hesitated to use it. While on a tour of investigation in Solano county, I found to my surprise in the Vacaville district several young orchards and one old orchard of forty years or more where the sweet cherries were not only very thrifty, but were producing very heavily on the Mahaleb root. One of the most experienced growers in the valley, Mr. H. A. Bassford, said that his preference for this root was due to the trees being longer lived, greater prolificness and the evident influence of this root on the growth of the tree.

The dwarfing tendency so often attributed to the Mahaleb is not borne out by observation: on the eontrary, its effect is to give the tree a greater bearing surface and its influence is more in the direction of preventing the excessive growth of the branches. Possibly the loss of trees which many growers have sustained through sour sap may be due to the use of the Mazzard 


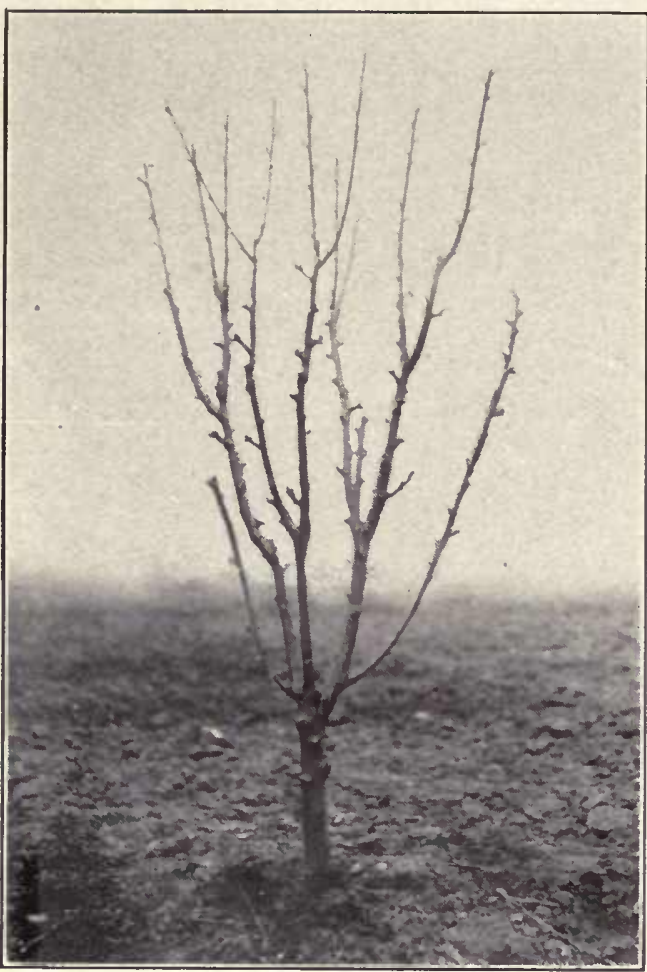

A four-year-old Cherry tree illustrating method of pruning. A typicalvase-formed tree well supplied with fruit spurs.

root. That the Mahaleb is a more vigorous grower and has a much better root system is generally recognized by all nurserymen.

\section{PRUNING}

It is simply disheartening to see some of the unpruned cherry orchards in Solano county, which stands out pre-eminently as the most important cherry section in the state today. Compare the quality and quantity of fruit produced with the trees that have been systematically pruned, and the whole fallacy not to cut a cherry tree after the head has once been formed falls to the ground.

The trees should be headed back to twenty inches. Three to four branches should be allowed to grow to form the head of the tree, and these should be distributed in such a manner as to prevent forks, as the tree has a tendency to split as it grows older. The first winter these branches should be cut back one-half and the following season not more than one to two branches should be allowed to grow from those left the first year. The third season the new growth should be shortened in about the same, depending on the growth, and some of the laterals appearing near the point of divergence from the main stems should not be eut off but nerely shortened in, for the shade they furnish is one of the essential features in the development of the young trees. This same method of pruning should be followed until the fifth year. In after years the cutting should be less severe, but pruning, unless the trees should show too much of a tendency to spread out, should continue every year. This promotes fruit spurs on the large as well as on the smaller branches, and in harvesting a crop the even distribution of the cherries from the bottom to the top of the tree cannot but help bring about a feeling of pride in the mind of the grower over the results obtained. There are cherry trees in the Ulatis Ranch Property near Vacaville, managed by Mr. H. A. Bassford, where with one or two exceptions, one of the cherry orchards now fifteen years old, consisting of Bing, Lambert, Royal Ann, Black Tartarian, has been pruned annually. The trees in this particular orchard are simply beauties. The Gummosis, a gum disease, has been overcome in this orchard by slashing the body and framework branches every other year in Norember.

The placing of a colony of bees in this orchard has had a decided influence on its bearing qualities. Not only do they benefit the cherries but undoubtedly are responsible for the splendid crops of other fruits which are harvested annually on this large fruit ranch.

I believe the placing of a colony of bees in any orchard will be found a splendid investment.

\section{GATHERING}

Great care should be exereised not to pull the clierries from the stalks when gathering. Several hundred carloads are shipped from California to eastern markets annually. The cherries are either packed in pound cartons or in rows in flat boxes of ten pounds each. The fruit is picked when it is mature and, if carefully handled, invariably reaches its destination in prime condition. When gathered for market or transportation on distant shipments cherries should be gathered only when perfectly dry. For table use the flavor is very much enhanced by placing the fruit for an hour or so in a

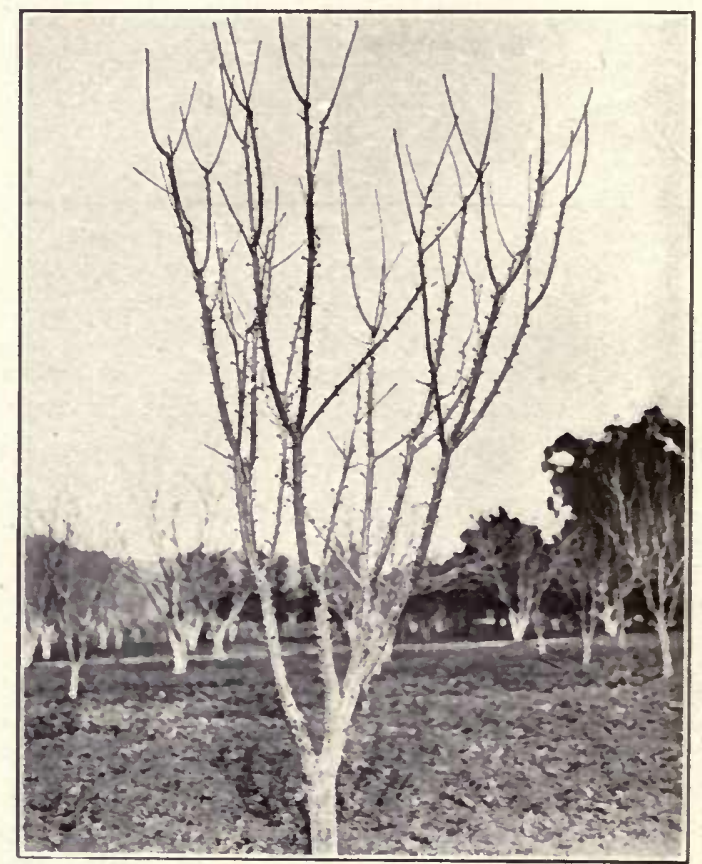

This Cherry tree is six years old. Numerous fruit spurs on the well balanced tree fully demonstrate the advisability of pruning the Cherry annually. 


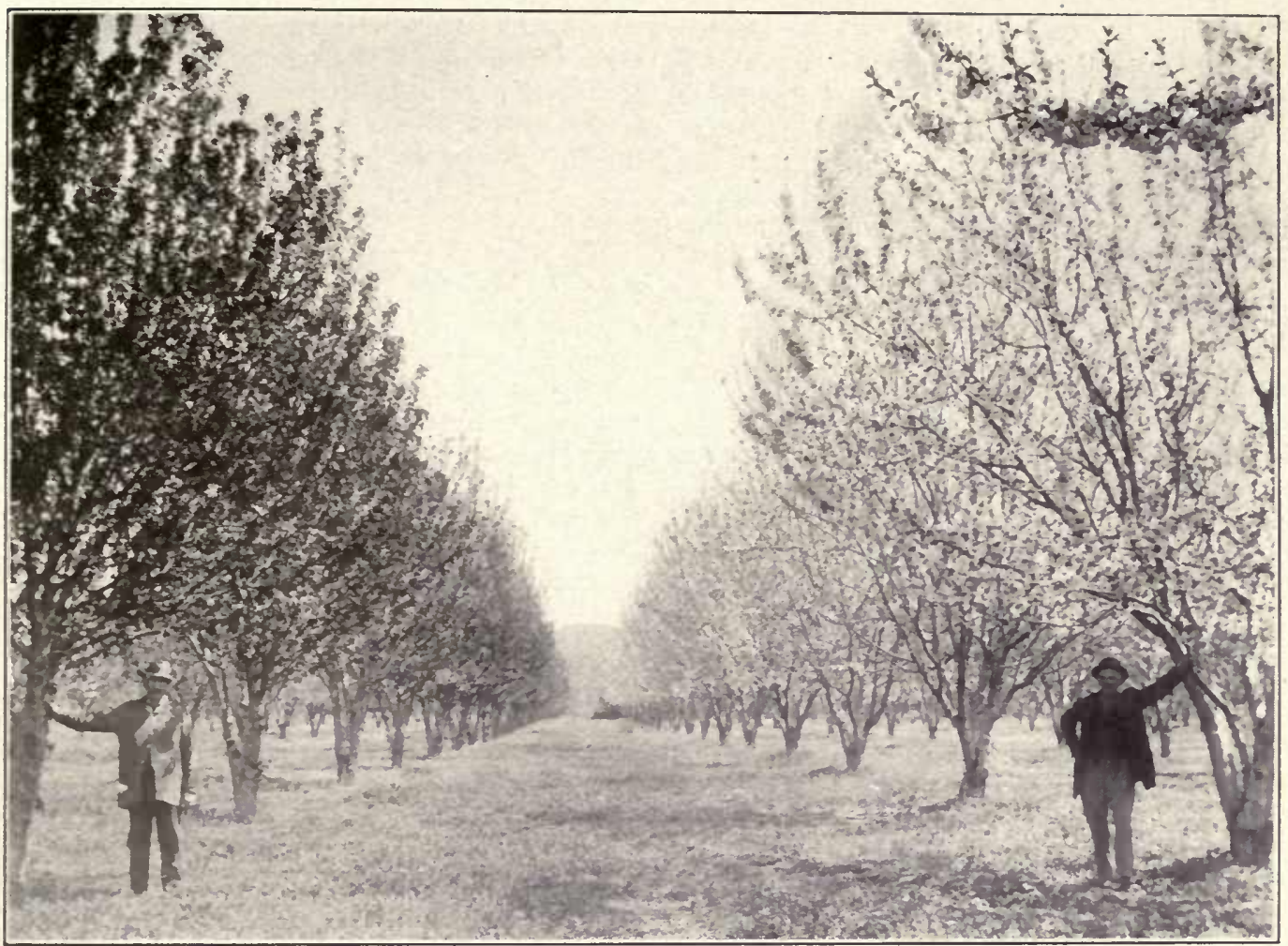

Trees like these make one envious of the owner of this magnificent orchard. Note the even distribution of blossoms.

refrigerator and bringing them on the table cool with dewdrops standing upon them.

\section{IRRIGATION}

Irrigation is a very important factor in the development of a cherry orchard. In California, in the very

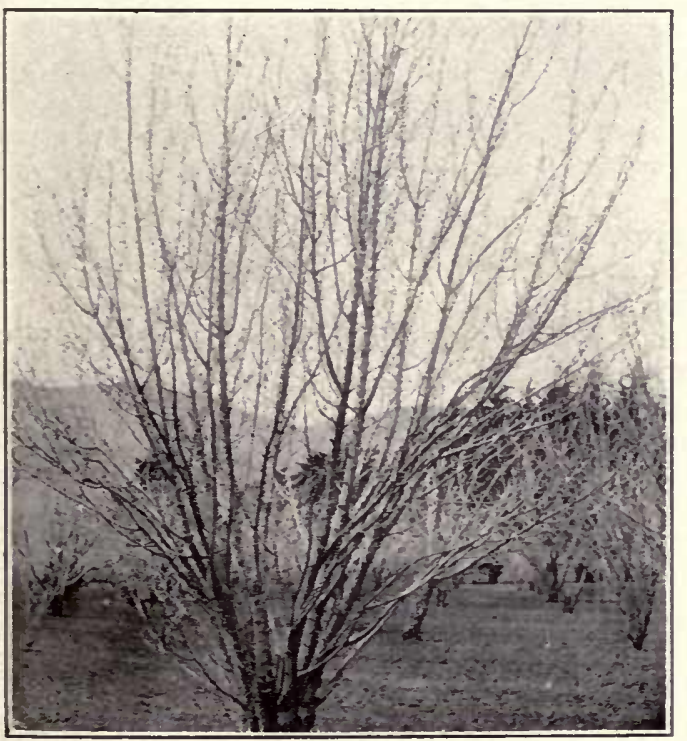

This is the result of allowing the Cherry tree to grow without checking the framework branches. They are badly crowded where they started from the body of the tree. crowded where they started from the plainly the mistake The long, straight stems indicate very plainly the mistake of growth. best cherry sections, in years of limited rainfall, if the necessary moisture to sustain the trees is not supplied to them, they may suffer so severely that they may die. The cherry is an extremely sensitive tree but where soil and elimatic conditions are favorable, it is exceedingly profitable if given proper care.

The lack of rainfall in California is a problem which frequently confronts the fruit grower. In such seasons, in order to maintain the trees in thrifty condition, it is necessary to apply water artificially during the growing season.

\section{COMMERCIAL VARIETIES}

Bing, Black Tartarian, Early Purple Guinge, Lambert, Lewelling, Napoleon Bigarreau.

\section{TIME OF RIPENING IN A CHERRY SECTION May}

Early Purple Guigne, Abundance, Chapman, Burbank, Knight's Early Black.

\section{June}

Belle d'Orleans, Rockport Bigarreau, Black Tartarian, Reine Hortense, Burr's Seedling, Elton, Black Eagle, Centennial, Governor Wood, Great Bigarreau, Napoleon Bigarreau, Yellow Spånish, Ostheimer Weirhsel, Bing, Lambert, Schmidt's Bigarreau.

\section{July}

Early Richmond, Lewelling, Montmorency. 


\section{THE PLUM}

The plum in its geographical distribution on this coast, particularly in California, eovers a wide range of soils and elimates, being both thrifty along the coast regions and the interior valleys, and well up into the foothills. Indeed, so wide is its range that it is safe to say that every county in the state boasts of its plum orchards. The very fact that the plum has such a wide range of usage should cause plums to be more widely planted than they have been in recent years. It is very rarely indeed that there is a failure of a crop, and this is largely accounted for by the fact that practically all the varieties, with the exception of some of the Japanese types, flower late in the spring when all danger from frost is over.

There are two distinet lines in the elassification of plums: those which are especially shipping sorts and the other types which are primarily used for canning. The very fact that plums may be picked considerably riper than many other fruits makes them very valuable for long distance shipments, due to their fine shipping qualities. Plums need not be peeled when canned, a great point in their favor as a preserving fruit. Under no consideration should plúm trees be planted closer than twenty-four feet apart. This, of course, refers to planting in orchard form. For gardens or in small

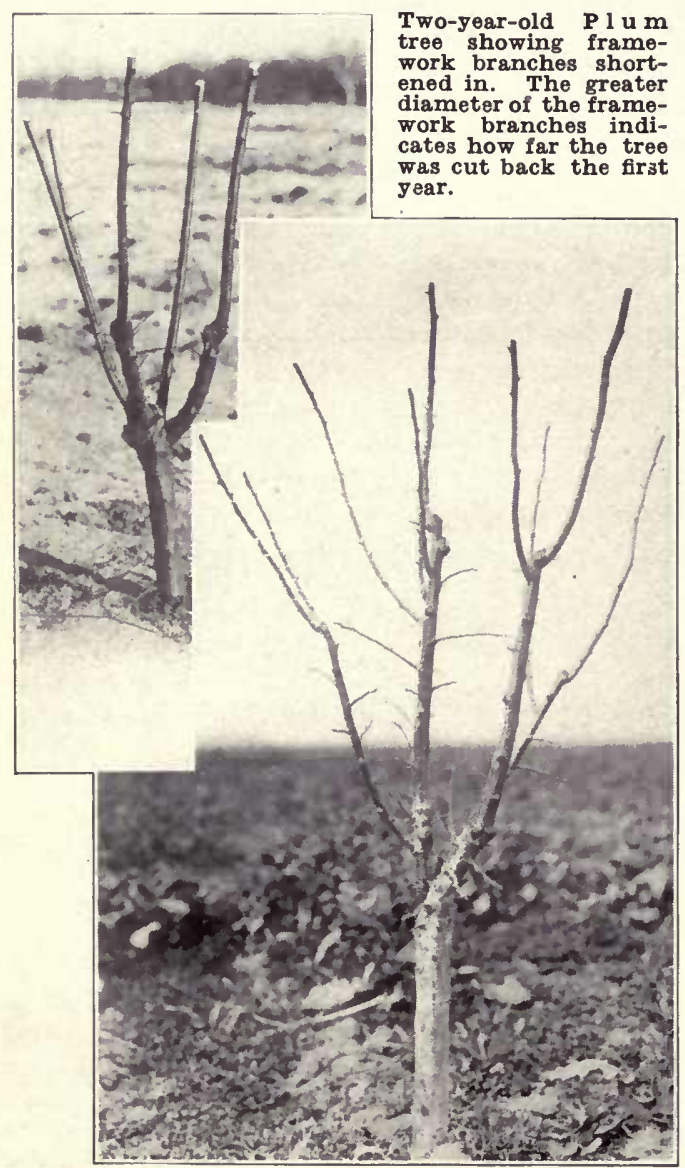

A three-year-old Plum tree already giving evidence of the much desired goblet form. plots of ground, the trees may be planted very much eloser than this. By pruning regularly every year and then holding the annual growth of the trees in check, it is not only practicable to have trees as close as twelve feet apart, but to harvest very good crops of fruit.

\section{STOCKS}

The peach and myrobolan root are the standard stocks for the plum and these two roots seem to meet practically all the conditions where the plums are raised, the peach root being given the preference on the sandy, loamy soils, and the myrobolan on the heavier and damper soils. It is quite possible within a few years that other roots, such as the Mussel, so extensively used in Great Britain and on the continent of Europe for so many of the stone fruits, will find conditions equally as congenial with us. The only way to raise this stock is by layering, making it rather expensive. Several varieties of plums including the following, lack affinity for the peach root: Yellow Egg, Jefferson and Washington. On very gravelly soils the almond root could be used to advantage, nearly all varieties doing well on this root. It has not been used to any extent, however.

\section{PRUNING}

To deliberately say that a plum tree should be pruned regularly every year would be just as nonsensical as a recommendation never to prune the plum. No absolutely fixed rule can be adopted when it comes to pruning, whether it be a plum or anything else, for in the final analysis the grower must study his conditions and decide for himself the poliey to pursue.

There cannot possibly be any argument, however, in shaping the trees when they are young and training the branches which will eventually be the main supports of the tree I have no patience with the man who will not cut his trees back to at least twenty inches after they are planted and who will not endeavor to have the framework branches properly distributed around the body of the tree. If, in after years, larger crops are produced by allowing the trees to grow at their own sweet will, except to cut out interfering branches, this is a matter of judgment.

The planting and the bringing of an orchard into bearing is no small undertaking. It not only taxes the average man's purse strings to the limit but in addition it means the employment of every resource at his command in labor and brains to reach the goal for which he is aiming.' Therefore he must have returns for the combination of forces which have eaused him to build vigorous, substantial trees.

If $I$ were growing the orehard my decision would be to prune the trees regularly every year even after they reach the four-year age linit.

It is not possible to say definitely how much of the annual growth should be removed, but that the trees should be pruned to promote fruit spurs, according to my idea, is the only practicable and sensible plan in the handling of a plum tree. As I see it, a tree with fruit from the very crotches to the tip ends and evenly distributed throughout, is preferable to having a total 
absence of laterals and to have all the fruit spurs on the upper limbs. Where the trees are not eut back this is just what happens. After a number of years, depending on the vigor of the tree, practically no new wood is being made, there is apparently a lacking in vitality, the blossoms are weak, and there is a general debility in the tree. There is only one recourse then-cut the tree back and build a new top and be out of a crop for at least three years until the tree is again back where it belongs.

\section{THINNING}

As a rule it is not customary to thin plums. Commercially, very good fruit can be grown without doing this work. Nevertheless, there is no use denying the

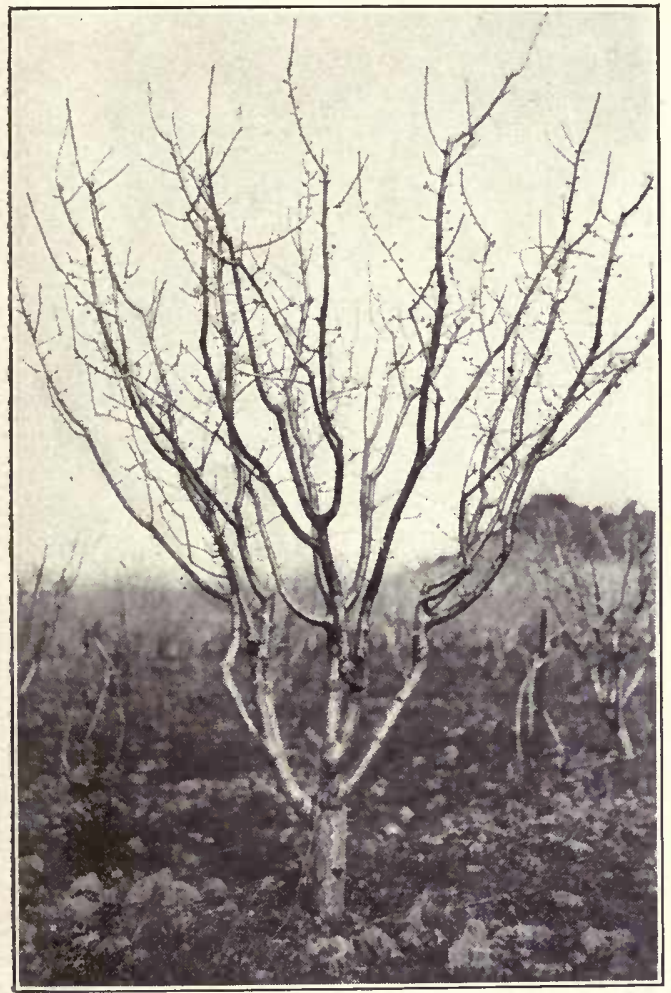

A six-year-old Plum tree. A fine type of a tree.

- fact that much finer and more uniform fruit will be produced where this is resorted to. For the man who wishes to maintain a degree of quality and establish a standard for his fruit, it is very essential that thinning be done.

\section{GATHERING}

For shipment to distant markets, plums should be picked while they are still hard and have taken on some color. For local shipments or for table use they should be mature, well colored but not soft.

\section{IRRIGATION}

While the trees are young, the same care in the matter of irrigating should be given to them as to any other young trees. Just bear in mind that in the interior valleys they must have more water than is necessary in the coast counties, where there are fogs, more moisture in the air and less evaporation from the soil because of the difference in climatic conditions. Plums are very much subject to the attack of a minute red spider, which weaves a web on the under-side of the leaves. When they become very numerous, and they propagate very freely in the warm weather, the leaves turn brown and finally drop off. This, of course, retards the growth of the tree. All that is necessary to control the pest is to spray the trees with water and then apply, powdered sulphur. To hold it in check it may be necessary to attend to this several times during the summer months, but under no consideration should the work be delayed later than the middle of June.

\section{COMMERCIAL VARIETIES FOR SHIPPING}

Beauty, Burbank, Climax, Clyman, Diamond, Giant, Grand Duke, Formosa, Gaviota, Kelsey Japan, President, Santa Rosa, Satsuma, Wickson, Yellow Egg.

\section{COMMERCIAL VARIETIES FOR CANNING}

Jefferson, Imperial Gage, Washington, Ycllow Egg, Bavay's Green Gage.

\section{TIME OF RIPENING}

Maturing in Each Month in About the Order Named

\section{June}

Clyman, Cherry, Beauty, Apex Plumcot, Climax, Rutland Plumcot, Bartlett, Santa Rosa, Burbank.

\section{July}

Abundance, Bartlett, Formosa, Gaviota, Simon, Anita, Satsuma, Wickson.

\section{August}

Washington, Diamond, Apple, Grand Duke, Jefferson, Giant, Yellow Egg, Bavay's Green Gage, Kelsey Japan, Red Egg.

\section{September}

President, Bradshaw, Shropshire Damson.

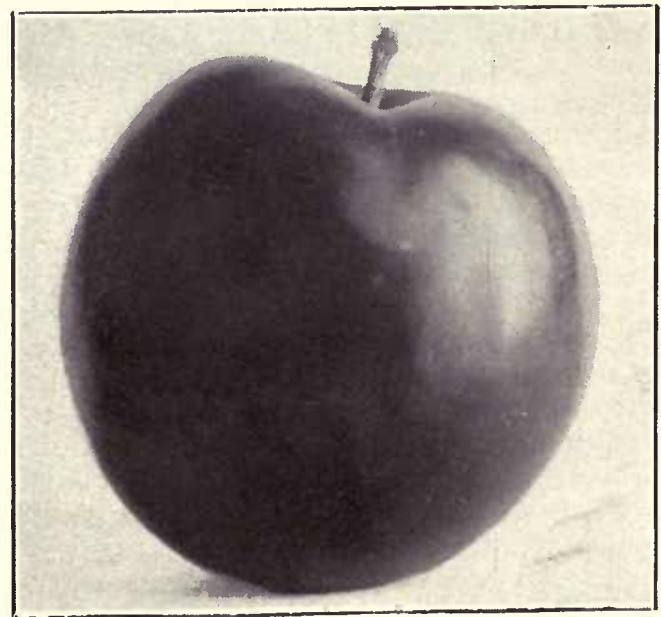

The Santa Rosa Plum, one of the leading varieties of shipping plums-a Burbank introduction. 


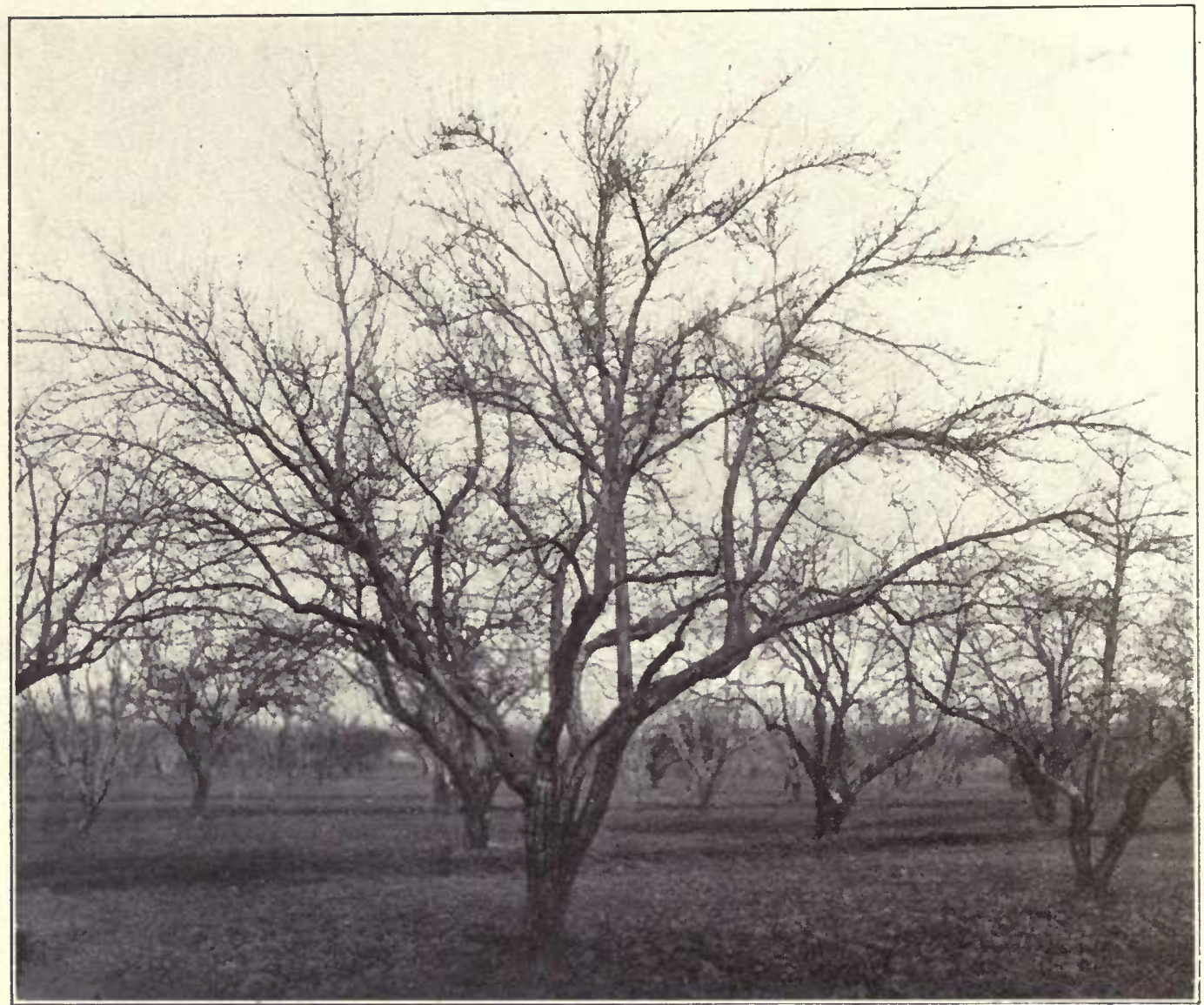

An improved French Prune tree. Note its tendency to spread out and that the branches are inclined to hang down. This is characteristic of this tree. Except to thin out interfering branches this tree has had very little pruning in recent years.

\section{THE PRUNE}

Prunes and plums are so closely allicd that remarks pertaining to one fruit are equally applicable to the other. Practically speaking the prune is characterized by its sweet firm flesh and has the property of drying and curing without the seed being removed.

The varieties of prunes having their origin in France seem to find conditions more congenial in the counties clustering around San Francisco bay than in any other part of the state. There are certain favored spots, more particularly in the silty soils of the river bottom in the Sacramento and San Joaquin valleys, where the prunes not only are very thrifty but are very dependakle in their production of crops. From a standpoint of quality the dried product from the interior is inferior in quality to the prune from the coast counties. One of the strange anomalies in connection with the growing of the French prune is that in the coast counties, even with their much lower average of temperature units in the summer months, the harvesting season commences at least two weeks earlier than in the interior, while the apricot in the same section is six weeks later in maturing than the apricots in the interior valley counties. Trees should be planted from twenty-four to thirty feet apart.

\section{STOCKS}

It is very difficult for nurserymen outside of California to grasp the situation concerning the demand which exists for trees on different roots to meet soil conditions. The answer is that in California the growing of fruit is just as much a great commercial business and is just as much a staple as the growing of cotton and sugar in the Southern States.

The stability of the tree and its fruitfulness must be guarded by the selection of a root best adapted to the particular soil in which the grower contemplates planting, therefore the extreme care in securing the right root. The Myrobolan root is preferred by most growers, although there are many soils on which this root is - used where the peach could be used to advantage. In behalf of the peach root it may be said that the trees are stronger growers than on the Myrobolan, although not quite so long lived. There is another point which must not be lost sight of and that is that there is a lack of affinity of some varieties of prunes for the peach root; among them may be mentioned Robe de Sargent, Imperial Epineuse, and Sugar.

The Roke de Sargent lacks affinity for the almond root, while the other two take well on this root and make good unions. 


\section{PRUNING}

Instructions about pruning given for the plum will serve equally as well for the prune.

\section{GATHERING AND DRYING}

The prune should never be picked until it is fully ripe. This is indicated when it is soft to the touch. The trees are shaken slightly, although with many growers it is customary to make a number of pickings during the season from time to time as the fruits drop to the ground. Unless the prune is dead ripe, it makes an inferior dried article. The first step in curing is to dip the prunes in boiling water in which lye has been dissolved, using one pound of lye to ten gallons of water. It is very important to maintain the temperature of the water at at least. 200 degrees Fahrenheit, if the best results are to be obtained. The purpose of this dipping is to erack the skin to facilitate drying. As a rule the fruit is immersed for about a minute but this may be

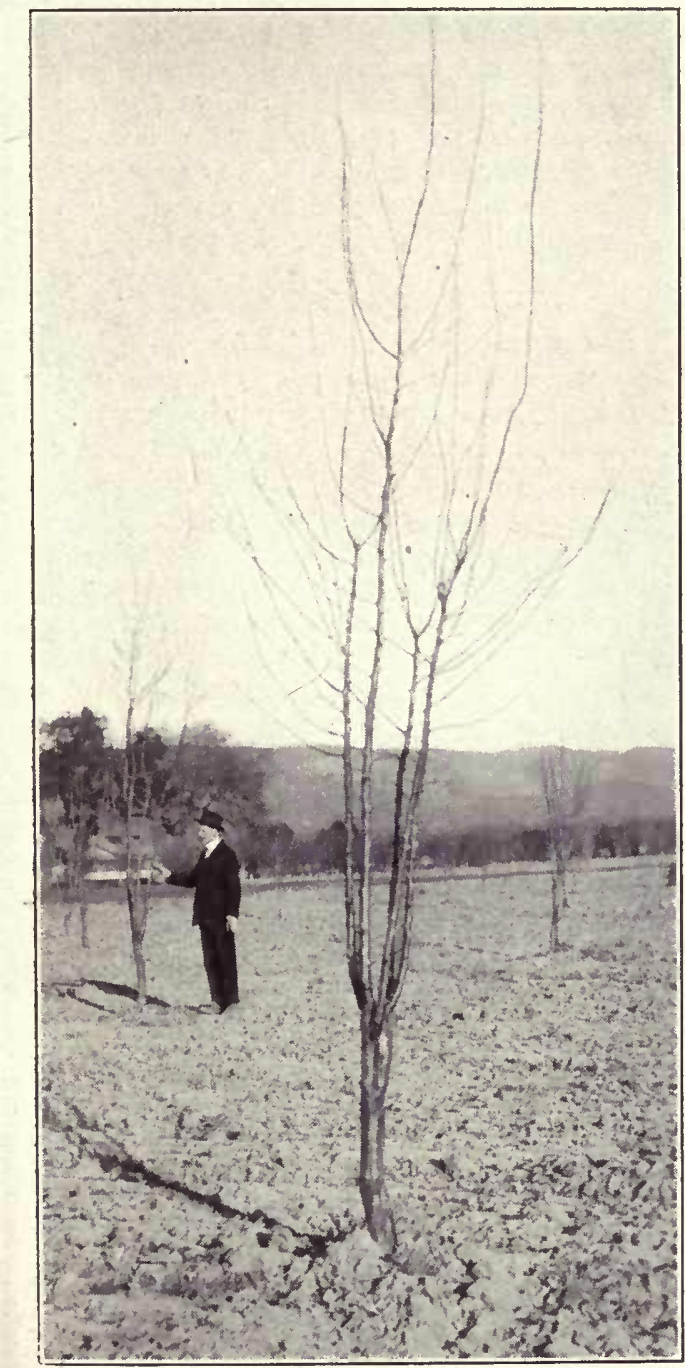

The owner of this three-year-old French Prune orchard does not agree with me in my recommendations of pruning.

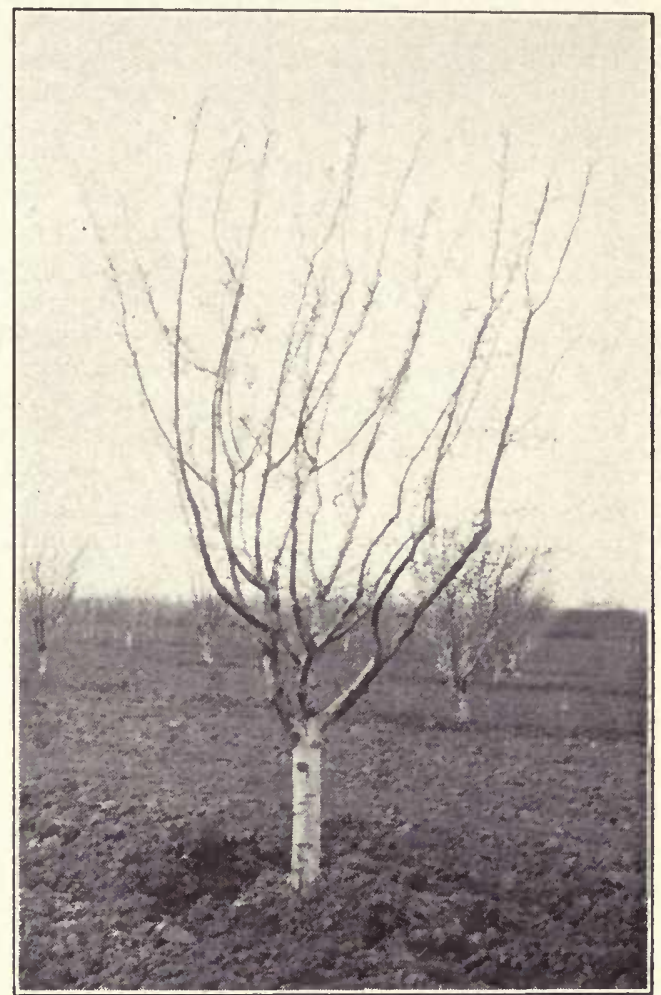

But this man does. The reader must draw his own conclusions as to which plan is preferable.

varied, and final experience is the best teacher as to the strength of the lye solution and the length of time of dipping. Carelessness in dipping, that is, not having the water to the boiling point, causes fermentation in prunes, which are termed "bloaters." The Imperial Epineuse is very much subject to this trouble. Mr. C. F. Fleming, manager of one of the prune packing plants of the California Packing Corporation in San Jose, claims that by allowing the prunes of this variety to remain on the trays for two or three days until wilted, before dipping, nuch of this difficulty will be overeome. After the prunes are dipped in the solution, they are then rinsed off in cold water to remove all traces of the lye. There are a number of processing machines on the market devised for handling prunes. These are either operated by hand or by power, depending on the quantity of fruit to be handled. From the dipper the prunes are transferred to trays, which are three feet wide, eight feet long, with a two-inch cleat all around, made of one-inch lumber to prevent the prunes from rolling off. The drying is carried on in the open, the desiccating of the fruit being due entirely to the rays of the sun. It is very important to stir the prunes on the trays to prevent them from sticking. This causes them to dry uniformly. Clean trays play a very important part in preventing mold and the loss of the prunes in event of wet and sultry weather. There is a tendency on the part of beginners to over-dry, exhausting all the juices of the fruit, by too long exposure to the sun. Take a handful of prunes in the morning before they have been warmed up by the sun, and if, after 
squeezing them slightly, they fall apart readily, the trays should be stacked one above another, just as soon as the fruit has become slightly warmed up. After a few days the prunes should be placed in bins on wooden floors, where they have access to the air but covered in such a manner that they will not be rained on. There are a number of solutions for preparing prunes for packing commercially. Probably the simplest dip is a solution made by dissolving five pounds of salt to one hundred gallons of water. As a result of this dip the fruit takes on a bright, dark, glossy hue. The solution should be used hot and the prunes should have the surplus moisture dried off before packing in the boxes.

\section{COMMERCIAL VARIETIES FOR DRYING}

French, French Improved, Imperial Epineuse, Robe de Sargent, Sugar.

\section{COMMERCIAL VARIETIES FOR SHIPPING}

Conquest, Fellenberg, German, Hungarian, Silver, Tragedy, Standard.

\section{PERIOD OF RIPENING June}

Tragedy.

$$
\text { July }
$$

Sugar.

\section{August}

Conquest, Fellenberg, German, Hungarian, Standard.

\section{September}

French, Improved French, Imperial Epineuse, Robe de Sargent, Silver.

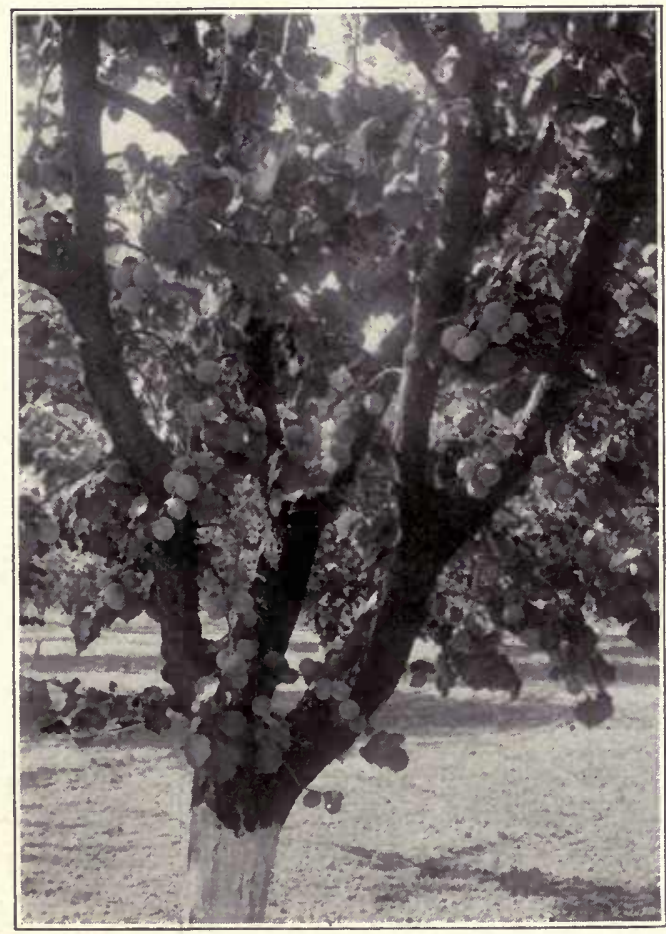

When you get a tree to produce fruit from a point close to the main body, to the very tip ends, the demonstration of successful pruning is complete.

\section{THE APRICOT}

The apricot is a native of Asia Minor and the higher regions of Central Asia. As a commercial proposition California has practically a monopoly of the apricot culture. No other section of the Union produces it in quantities at so small an expense and so little risk of failure in a crop. In appearance it is the handsomest of all stone fruits and contains less acid. For canning, evaporating and drying purposes, and for use in the fresh state, the fruit can hardly be excelled. It scems particularly adapted to the coast counties, where the fruit attains the largest size and the highest flavor. In the interior valleys it has a distinct advantage, in that it ripens its fruits fully a month earlier than in the cooler sections of the state. A few years ago the only value the apricot pits possessed was for fuel, but today there is no waste of any part of this all-around fruit. The pits sell readily at $\$ 40$ per ton. Special machinery has been devised for cracking the pits and extracting the kernels. A very fine edible oil is made from the kernels. During the period of the war the shells came into use for the manufacture of gas masks, the United States Government taking the entire available supply. These were carbonized and then subjected to a secret process. Apricot pits, peach pits and cocoanut shells were in great demand because of their effectiveness in absorbing the noxious vapors better than any other known material.

\section{STOCKS FOR THE APRICOT}

It is not surprising that in California, where such great strides have been made in commercial fruit growing, that the stocks best constituted to certain soils and locations should be in demand by growers. In order to meet these conditions it has been found necessary to bud the apricot on peach, apricot and myrobolan roots. Some growers even go so far as to want the apricot on almond root. The apricot has no affinity for this stock and it would be dangerous practice to use it, because the trees are liable to break off on the slightest provocation. On deep well-drained loamy soils the apricot makes a fine vigorous tree. The peach root has a much wider adaptability and will do well on a greater variety of soils, even those which may become very wet during the early spring months. In soils which are heavy and very retentive of moisture and where the water may stand for any length of time the Myrobolan root should be used exclusively. The trees do not attain so great a size on this root but they are longer-lived, which is a good point in their favor. For commercial planting the apricot should never be set closer than twenty-four fect apart and on deep rich soils, due to its faculty of being a strong, straggly grower it would seem advisable to plant the trees either twenty-eight or thirty feet apart.

\section{PRUNING}

The very fact that the apricot trees are strong growers obviously makes it necessary to prune the trees carefully for at least the first four years of their existence. The trees should be cut back to twenty_inches after they are set. It is safe to cut trees back to this 
height even if they are extra large and devoid of any lateral branches below where the tree is nipped off, because of the plump, well developed buds on the stem of the tree. Not more than four branches should be left the following year after planting, having them as carcfully distributed around the stem as it is possible to get them. In the second year these branches should have at least two-thirds of their growth cut off. This severe cutting promotes not only a stocky well-balanced trec but insures a vigorous growth and encourages a compactness that cannot be secured in any other way.

In the third year the pruning should be far more moderate, otherwise there is a tendency to make the tree brushy to such an extent that many of the laterals starting from the framework branches just above the point where they diverge from the main body of the tree are smothered out. In the fourth year the pruning should be more a matter of shaping and controlling the branches, making a rampant growth. The tree in its fourth year should have a pronounced wide-open goblet form and it will unquestionably, if the pruning has been properly done.

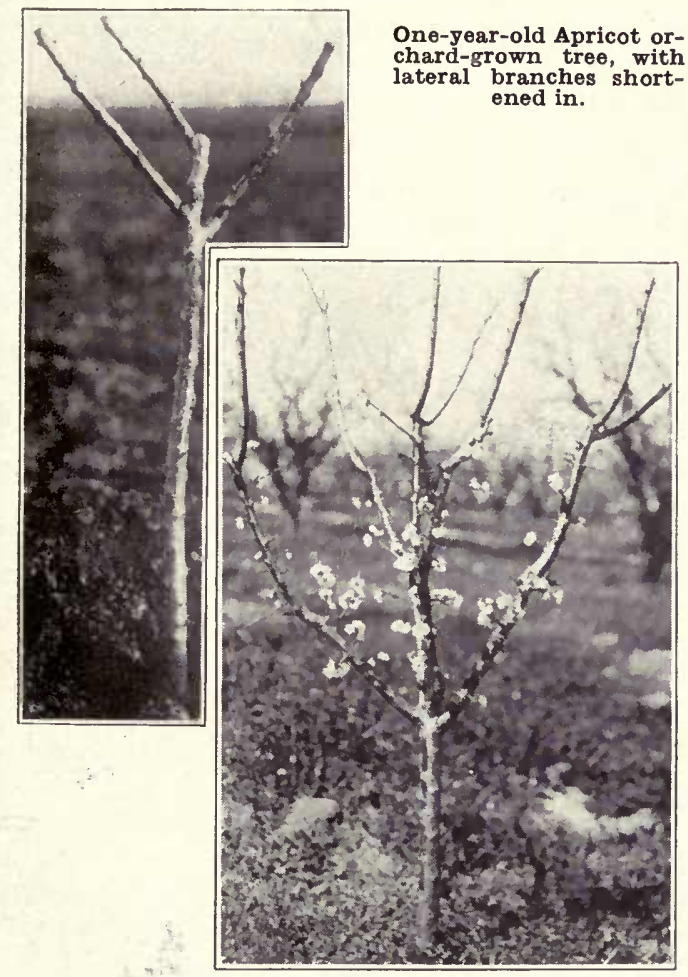

This two-year-old Apricot tree is already giving evidence by its numerous blossoms on the main branches what may be expected of it when it reaches bearing age.

There is no use denying the fact that the apricot is distinctly a creature of environment. It is an open question as to whether or not any benefit is derived, as far as fruitfulness is concerned, from summer pruning. A grower must determine this for himself. The results obtained must be his answer. Some varieties after they have reached bearing age if pruned heavily every year

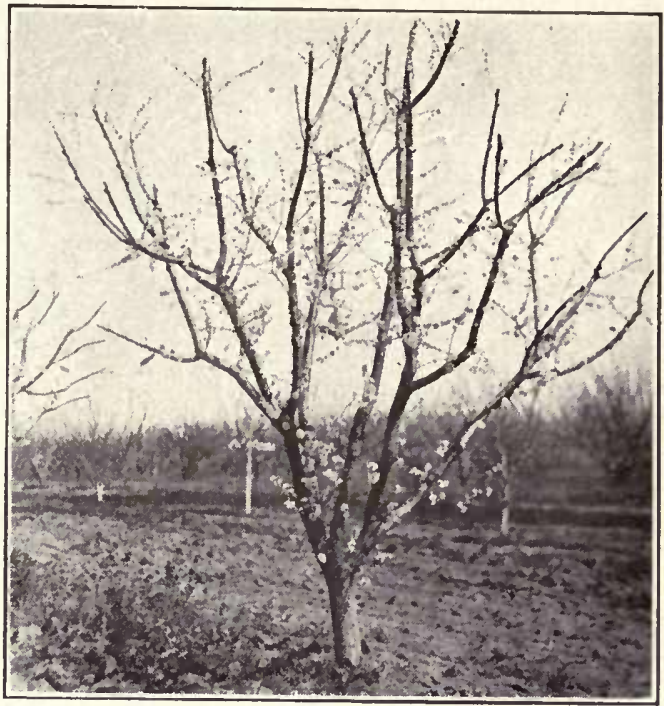

A six-year-old Apricot tree with a well developed head, the result of regular and systematic pruming.

will not produce sufficient fruit to pay for cultivation. This has been demonstrated to be a fact in the handling of the Hemskirke, which if pruned heavily is a very shy bearer. For size and flavor there are few apricots that will compare with it, unless it is the Moorpark. This variety has thoroughly identified itself as being so shy a bearer that commercially it is no longer seriously considered. As stated in the introduction, I am solely responsible for any recommendations concerning pruning in this booklet; at the same time, if I have any egotism it is not so pronounced that I am not willing to give credit to the successful men who practise the very methods which I champion. Furthermore, in my opinion, although my suggestions may be of value to the reader, nevertheless, wherever it is possible for a planter to personally visit a property and absorb from the owner the methods that have been followed, there is nothing to my mind which will be more conducive to success than to follow along the same lines as the man who demonstrates by an actual example that he is on the right track. Possibly the largest acreage in apricot trces is found in Santa Clara county. It is the exception to find an instance where trees are not pruned. There are very few, if any, properties in the valley in which thorough and intelligent management is more manifest than in the 500 acres under the control of Mr. H. E. Losse, recently deceased. He had 120 acres of fifteenyear-old apricot trees equally divided between Blenheim and Hemskirke. The annual production varies from 750 to 1000 tons of green fruit. No finer example of pruning could be found anywhere, for the trees are loaded with fruit annually which is of the largest size and evenly distributed from the framework branches to the extreme top of the trees. The trees are never summer pruned. Up to four years ago the treatment of both varieties was the same, with the result that the Hemskirke variety produced very light crops. Now that the pruning of the Hemskirke has been confined to the removal of interfering branches the yield has been 
exceedingly satisfactory. It will be necessary after a period of years to head in these trees very severely to develop new wood in the trees handled in this manner.

\section{THINNING}

The proper time to do this is just before the kernel gets hard. It is a very important piece of work, which should be religiously performed, when the trees give evidence of carrying more fruit than they should. The fruit should be thinned to be from three to four inches apart.. Sometines the ground under a tree may be literally carpeted with green fruit, but even this should not deter the owner from his task if he wants first-class fruit.

\section{GATHERING}

The time to gather apricots for eanning is when they have reached their size, are firm and show a slight tinge of green elose to the stem end. For drying they should be somewhat further advanced. The canneries prefer fruit which will run twelve apricots to the pound and less. The larger the size, the higher the price. For drying it is necessary to halve the fruit first and extract the pit. Prune trays are used for drying apricots. The very fact that apricots ripen so far in advance of prunes and that there is very little danger from rain, should cause prune growers to confine at least part of their acreage to apricots. One year with another, there is comparatively little difference in the profits realized. The filled trays are run into the sulphur house on trucks designed for this purpose. They remain in the fumes for at least four hours. A good rule to go by is to wateh the fruit and whenever a good part of the cups are filled with juice it is an indication that the fruit has been sulphured sufficiently. The sulphuring brightens up the fruit, causes it to retain its color and prevents it from being infested by insects. The time of drying varies from six to eight days, depending on the weather. Whenever the fruit shows that the moisture is practically out of it and is still quite supple, stack the trays and permit the drying to continue from this point in the shade. After the fruit is cured it is shoved off the trays with wooden paddles into sweat or lug boxes.

\section{IRRIGATION}

Even in the coast counties, where there is an abundance of rainfall during the winter months, it is very important indeed to be in a position to irrigate an apricot orchard. Our climate is so arid, there being no rain from May to October, that it is necessary to supply moisture artificially to maintain vigorous thrifty trees. While the trees are young from three to four irrigations are necessary. One, and at the outside two, irrigations will be all that will be required when the trees have reached a bearing age. Winter irrigation, or rather applying water in the late fall, has a very beneficial effect, and this, if followed by an irrigation just before thinning, will be the means of eausing the fruit to run into larger sizes. Cultivation following an

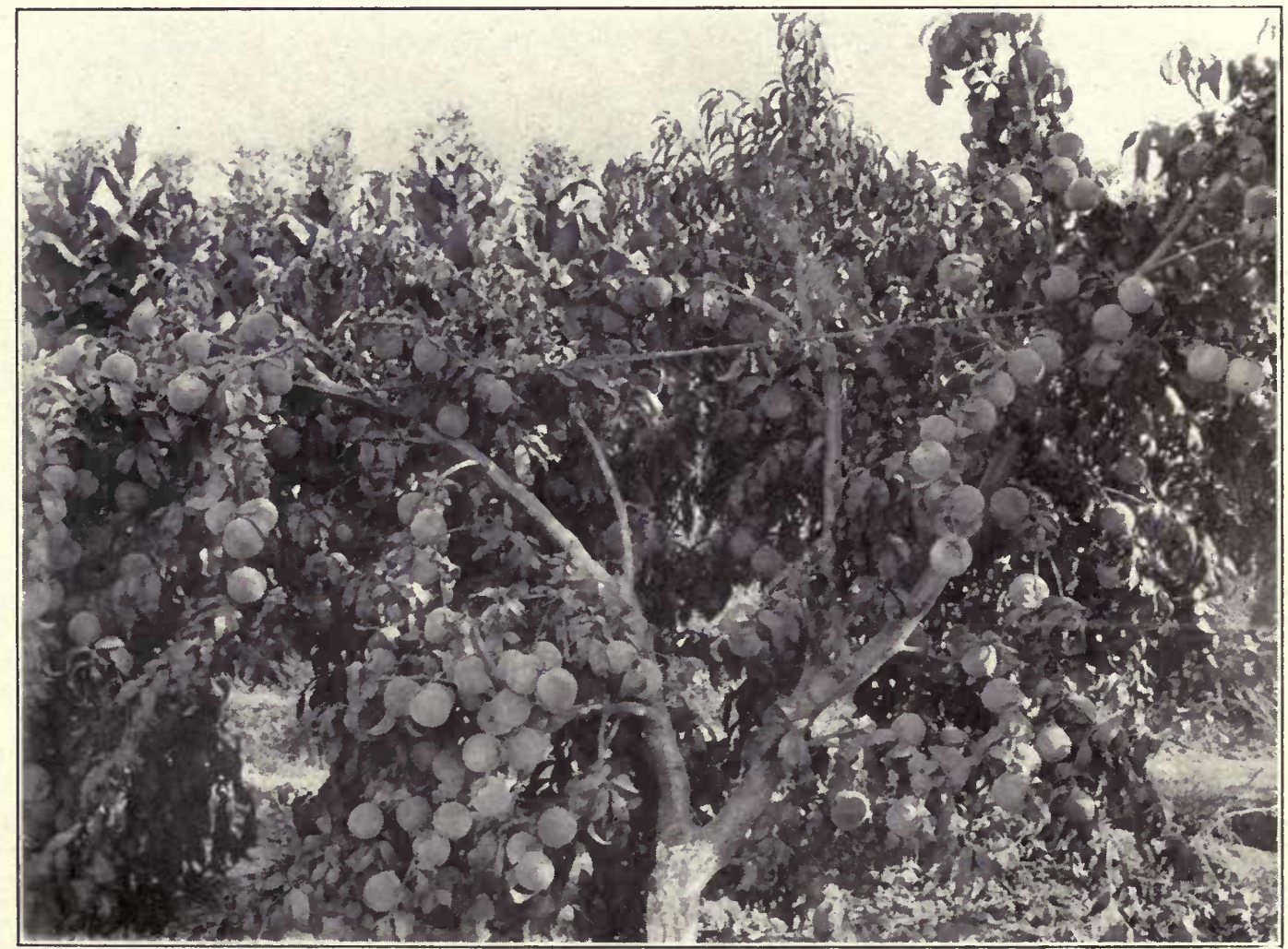

A four-year-old-Peach tree with the leaves stripped off from one side. It is loaded down with a heavy crop' of uniform sized peaches. Pruning and thinning combined are responsible for such results. 
irrigation, not once but several times over, is even more important than irrigating. Anything that will develop sound, healthy roots seeking into the lowest stratas of the soil for sustenance and moisture, is the right course to pursue.

\section{COMMERCIAL VARIETIES}

Blenheim, Hemskirke, Newcastle Early, Royal, Pringle, Tilton.

\section{RIPENIING PERIOD}

Pringle, Newcastle Early.

\section{June}

Large Early Montgamet, Royal, Routiers Peach, Smyrna, Blenheim, Tilton.

July

Hemskirke, Moorpark.

\section{THE PEACH}

The peach, like the prune and apricot, is indeed a fruit of commercial importance, and finds wide distribution not only in California but throughout the length and breadth of the Pacific slope. For size, flavor, color and shipping qualities the peaches grown in this state have a national reputation. The tree prefers a light, deep, sandy loam, preferably inclined to be dry rather than too moist, but well drained. It should be not less than three or four feet deep, the more depth the better.

Fresno county is the peach center of California, having a total, according to reliable estimates, of not less than 21,000 acres. The Libby, McNeil \& Libby Cannery, located in Selma, the great peach center of the
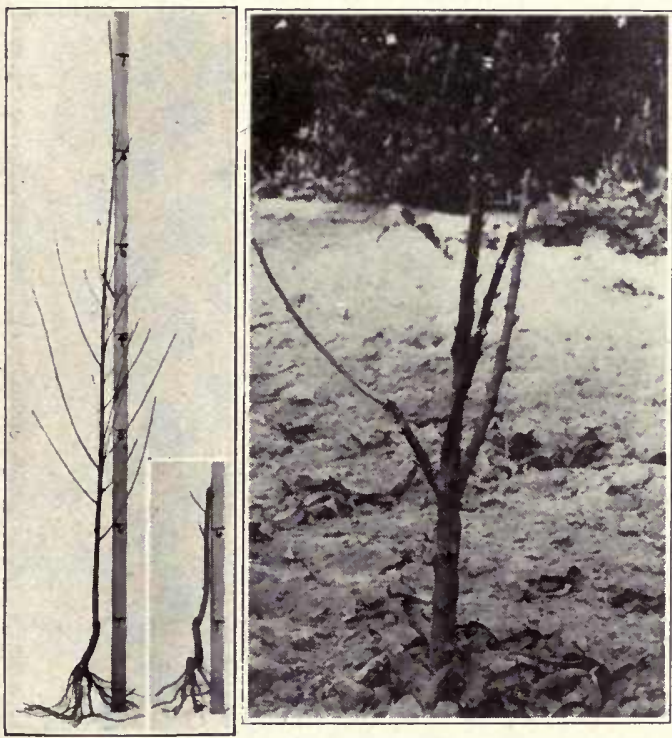

Left-A one-year-old nursery-grown Peach tree and the same topped and the root pruned before planting.

Right-A one-year-old orchard-grown Peach tree with its branches cut back and well distributed around the stem.

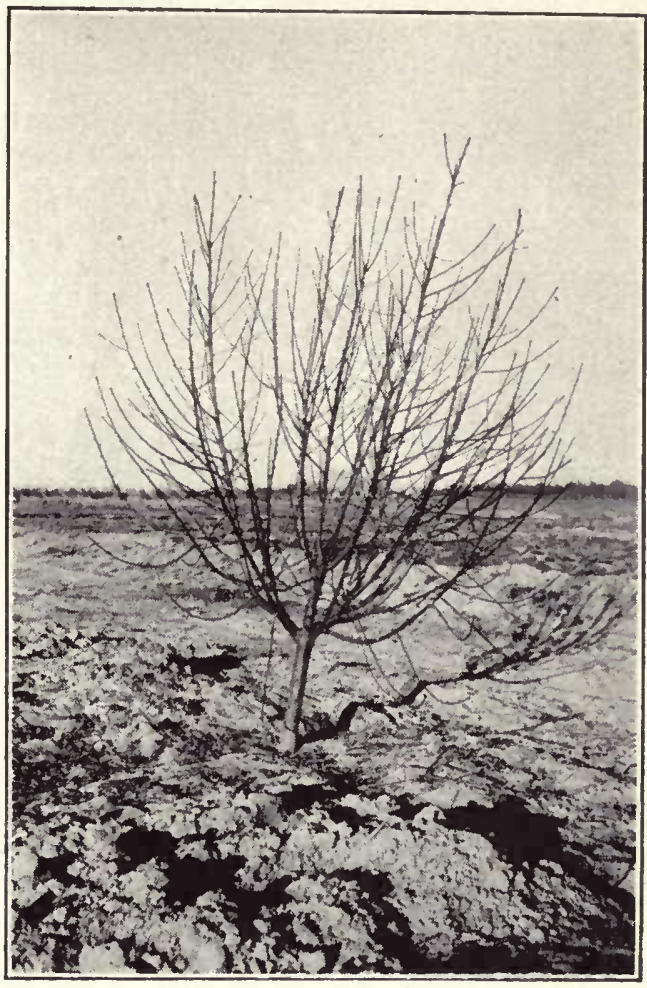

A two-year-old Peach tree.

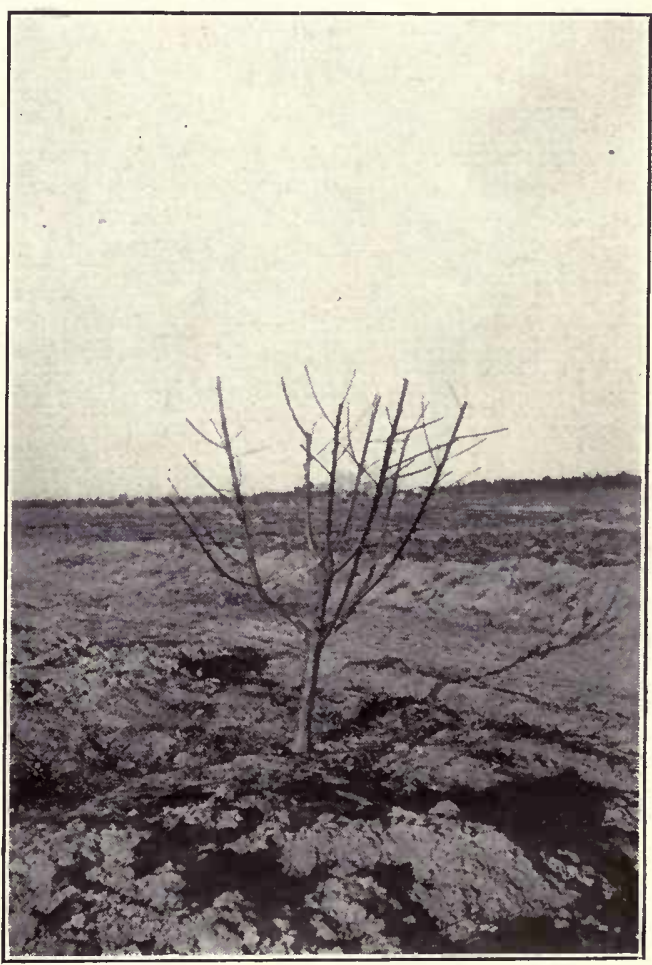

Same tree as above pruned. This tree will produce a light crop of fruit without impairing the vigor of the tree. 


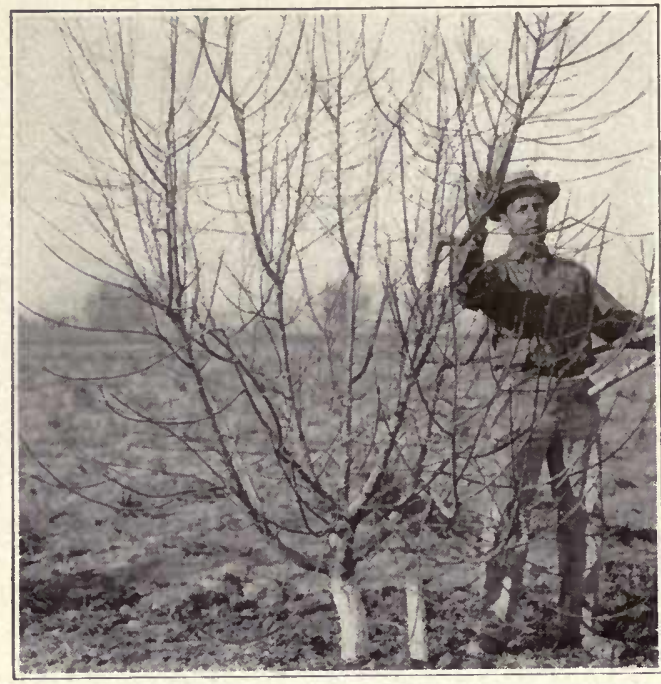

A four-year-old Peach tree with fruit-bearing laterals from the point where the main branches diverge from the main body of the tree to the very top.

county, handles no less than 8000 tons of peaches annually in its plant, and this is only a very small part of the canning peaches raised yearly in Fresno county.

The commercial importance of peach growing cannot be estimated in dollars and cents, for the great territory over which the peach thrives with the practical certainty of a crop one year with another makes the field a very promising one.

\section{STOCKS FOR THE PEACH}

Without exception the peach root is used exclusively for growing peaches. For several years I have been carrying on experiments with different varieties to determine their value from a standpoint of growth and general freedom from crown gall, and taking it all in all, the Salway comes first, and the trees produced from Lovell and Muir seed next. Within the last few years I have been carrying on experiments with Tennessee natural pits and am already convinced of their value as to the vigor of growth. If the rcot system is found to be healthy and of a fibrous character, this stock will be given the preference.

\section{DISTANCES APART}

In former years it was customary to plant peaches twenty feet apart. The trees grew so rapidly that it was only a question of a few years when the branches were interlacing. On sandy soils from twenty-four to twenty-five feet is a very satisfactory distance to plant, while on heavy soils twenty-eight to thirty feet is better.

\section{PRUNING}

The general cultural directions for the handling of deciduous fruit trees in the introductory chapters should be closely followed in the case of the peach tree. Nothing will bring a peach tree to a premature end quicker than not to prune. The trees as they stand in nursery rows have the limbs removed to a point about twelve inches from the ground. Instead of removing all these limbs when topping the tree at twenty inches, they should be cut back to about two inches long, so in case the buds on the main body do not start in the spring the buds on the smaller branches will. If the buds do start on the main bcdy, the branchlets may be clipped off with a shear.

All growers are practically in accord that peach trees must be pruned. How to do it, brings up an endless amount of argument. They say "A confession is good for the soul"; I am not going to argue this pro or con except to say that I am now firmly of the opinion that the ideas that I have had for a number of years relative to the pruning of the peach, while they may not be absolutely wrong, do not bring the trees into bearing as early and as prolifically as it should. There is no argument about heading the trees to twenty inches after setting and resorting to very severe pruning the first year, cutting off at least one-half, or better still two-thirds of the current season's growth. Not more than four branches should be used to make the head of the tree, and they should be distributed to secure as symmetrical a tree as possible. Heretofore my recommendation to prune back severely in the second and third years has resulted in developing an immerse amount of woody growth, producing a fine umbrageous head, which was a sight to behold in the summer months and which to all appearances, judging from the general healthfulness of the tree, was the right policy to follow. Careful observations have now convinced me that this severe pruning has promoted the woody growth of the tree to such an extent that it has militated against its fruitfulness. Instead of cutting the framework branches back so severely in the second and third years they should not be cut back more than one-third and the laterals distributed along their entire length at intervals of six to eight inches apart should be shortened in, of course, but not cut off. By following this plan a crop

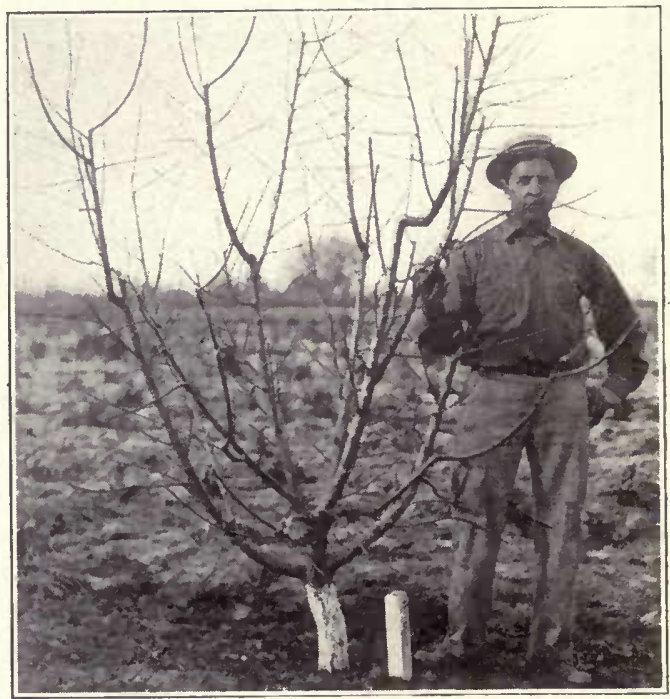

The same tree pruned. The young man, George Stephenson, standing beside this tree was one of the author's foremen, who sacrificed his life on the soil of France while fighting for his country. 
of peaches which will pay for cultivation may be harvested the third year, without in any way impairing the vitality of the tree.

In the fourth year and in subsequent seasons the method of pruning will be self-evident to the experienced pruner and requires no further elucidation here. This is the very idea whirh I hoped to bring about by the old method, but it was invariably frustrated by the exuberance of growth of the tree, the fruitful laterals being smothered out.

\section{THINNING}

To obtain large, firm fruit, thinning should be done when the fruit has set well and before the kernel has hardened.

Most growers become frightened when they find the ground under a tree literally covered with fruit, and get cold feet. Forget your imaginary troubles and keep at it until your peaches are not closer than four inches apart, and try to have most of them six inches from each other, and then your crop will be heavier, no doubt, than your tree will carry, without having a prop to support the overburdened branches. Less pits and more pounds of actual fine, large, luscious, perfent peachy peaches should be the purpose for which every grower should strive.

\section{GATHERING}

For shipment to distant markets it is necossary to pick peaches just as soon as they show a slight color. At this stage they are far from being ripe and this may account for their lack in flavor when they reach the eastern markets. Climatic conditions are very favorable indeed in California for not only developing highly colored peaches but fruit of the highest flavor as well. For canning purposes, the Clings are given the preference, because of their greater firmness and the fact that they stand up better under the cooking process. The standard size for canning peaches is fruit which will just pass through a two and onequarter-inch ring. Smaller fruit than this is very rarely accepted by the canners, unless it happens in years of a light erop. Care should be exercised in gathering peaches to be canned to avoid bruising. The fruit should be well colored but not soft.

\section{DRYING PEACHES}

For drying the peaches must be ripe to make a firstclass dried article. To dry peaches to advantage, it is necessary first of all to have a drying yard, or if arrangements can be made to have a plot of ground to be used for this purpose in alfalfa, so much the better. A great point in favor of an alfalfa field is its freedom from dust. To handle the fruit to advantage, it is necessary to have tracks not only running to the sulphur houses but also to the field where the trays are to be exposed to the sun. In former years it was the practice to use $2 \times 4$ Oregon pine scantling and to screw down heavy iron strapping to the two-inch edge to wheel the trucks over. Portable tracks are now to be had, made entirely of steel. They will last for a great many years and can be moved very quickly from place to place. They are so constructed in sections that several hundreds of feet can be put together very quickly. The same trays used for apricots and prunes answer equally well for peaches. The sulphuring of peaches is carried on in a shed-like structure, constructed of tongue and grooved lumber and lined with building paper. The peaches, after being halved, are placed in the trays, cups up. In sulphuring it is necessary to place cleats between the trays to permit the fumes to penetrate in every direction. The exposure should not be less than four hours. When a good part of the halved peaches have the cups partially filled with juice, it is a sign that the fruit has been in the sulphur bath a sufficient length of time. If the trays have been placed in the house late in the afternoon, let them remain overnight and take them out the next morning. If taken out in the evening they will have a dark color and command a less price. As soon as the peaches on the trays are no longer mushy the trays should at once be stacked, the curing from this time on taking place in the shade. This not only conserves the weight of the peaches but makes a far better dried product. After the peaches are cured they are scraped off the trays with wooden paddles into sweat boxes for delivery to the packing house. It takes from ten to twelve days, depending on the weather, to dry peaches.

In the last analysis it presents the finality in the industry, for all the fruit is cared for and there is no wastage. There has been more or less prejudice to dried peaches due to their fuzzy skin. This has been overcome now by a process for which the Lovell and Muir seem to have a decided advantage, by removing the peel by a recent invention even after the fruit is dried. That the consuming public appreciates this grade of fruit is demonstrated by the high prices which dried peeled peaches sell for in the market.

As a matter of fact the orchardist at a very small additional expense could easily do this himself. All that is necessary after the peaches have been halved, regardless of variety, is to immerse the fruit in a hot lye water maintained at a temperature of 200 degrees Fahrenheit for one minute. Dissolve one pound of lye in ten gallons of water. The peaches after being given the lye dip are then immersed in a tank of cold water, which not only removes every vestige of lye but causes the skins to slough off. It will pay the owners of large orchards to purchase a lye-dipping machine such as is used in the canneries and known as a "Grasshopper" for this purpose. The machine is not very expensive and would more than pay for itself in a single season.

Conditions may arise, through a failure to thin properly or because the orchard is not in a thrifty condition, where many peaches may run undersized. In the case of Freestones the peaches may be halved, although the expense is quite heavy. With Clings it is not practicable to do this, and it is not at all uncommon to have thousands of tons of fruit of this character go to waste, rotting on the ground because there seems to be no practical way of handling it. I have made experiments for several years now with such peaches and find they can be dried to good advantage by removing the skins by the lye process. The peaches are dipped into the lye 


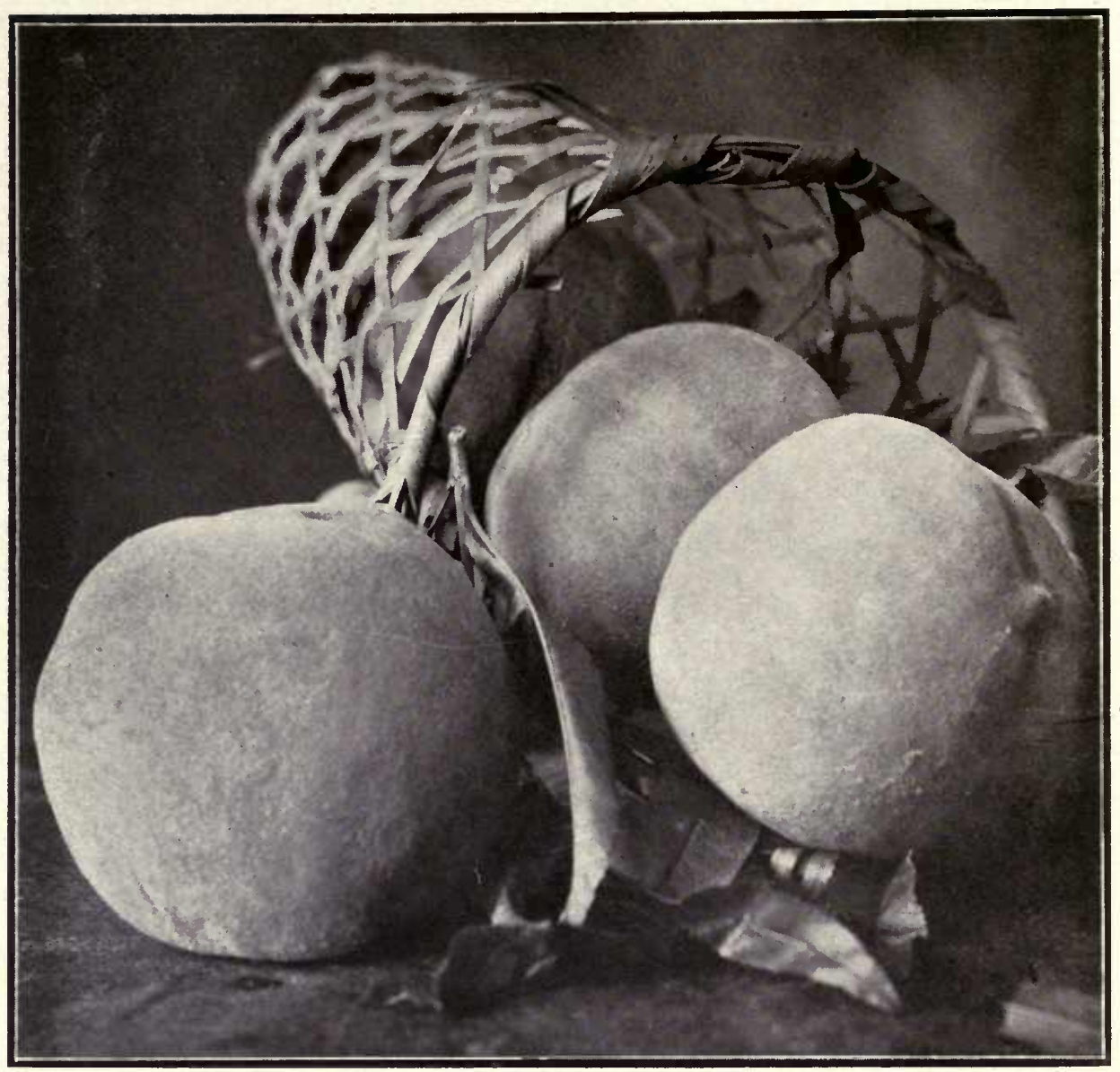

Selma Cling Peach, which gives promiso of standing in the lead of all other varieties for canning purposes

just as they come from the field. The method of procedure is as follows: Dissolve one pound of lye to ten gallons of water. Place the peaches in a perforated bucket and immerse them in the solution for about a minute. The length of time is easily determined by the manner in which the skins peel off in the cold water dip which they must be given to remove traces of lye. The temperature of the water must be at boiling point. The fruit is then placed on trays, exposed to the sulphur fumes just like the fruit which has been halved, and then placed in the sun to dry. In order that the fruit may dry uniformly the trays should be shaken occasionally so that all sides of the fruit will be exposed to the sun's rays. Peaches handled by this process have a distinct character, for it is found when the fruit is cooked that the pit imparts a very delicate flavor to it.

\section{IRRIGATION}

To promote a healthy, vigorous tree during the first three years it is necessary to irrigate the trees unless they have been planted in a district where the annual rainfall, with thorough cultivation, is sufficient to cause the trees to grow vigorously. When the trees have reached hearing age they should be irrigated just after thinning and again a short time before the fruit is gathered. Never forget that thorough cultivation is very necessary indeed after each irrigation to conserve the moisture in the ground.

\section{COMMERCIAL VARIETIES}

Admiral Dewey, Alexander, Brigg's Red May, Elberta, Foster, Greensboro, Hale's Early, Heath Cling, Levy's Late, Libbee Cling, Lovell, Mayflower, McDevitt's Cling, Muir, Phillips' Cling, Salway, Selma Cling, Sims' Cling, Sneed, Tuscan Cling, Wheatland.

\section{NAMED IN THE ORDER IN WHICH THEY RIPEN}

\section{May}

Sneed, Greensboro, Mayflower, Oklahoma Beauty, Oklahoma Queen.

\section{June}

Alexander, Brigg's Red May, Hale's Early, Admiral Dewey, Triumph, Early Imperial, Yellow St. John.

July

Foster, Early Crawford, Sims' Cling, Strawberry, J. H. Hale, Elberta, Tuscan, Blood Cling.

\section{August}

Morris White, Selma Cling, Muir, Lemon Cling, Lovell, Royal George, Runyon's Orange Cling, Seller's 
Orange Cling, Wheatland, Susquehanna, Late Crawford, McDevitt's Cling, McKevitt's Cling, Libbee Cling, Sims' Cling, Phillips' Cling.

\section{September}

George's Late Cling, Heath Cling, Salway.

\section{October}

Bilyeu's Late, Ward's Late, Levy's Late.

\section{THE NECTARINE}

There is a mistaken idea that the nectarine is a cross between the peach and something else. As a matter of fact it is nothing more or less than a smooth-skinned peach. Nectarines can be grown in any section where the peach thrives. The nectarine bears fully as well as the peach, and for canning, drying and shipping it has so many points in its favor it is difficult indeed to comprehend why planters have not engaged in nectarine culture more extensively than they have. In England and on the continent of Europe the nectarine can only be grown to advantage under glass. It is prized there more highly than any other variety of stone fruit. The prices realized are exceedingly high. As the nectarine has identically the same habit as the peach the cultural directions are the same, therefore any additional instructions would be superfluous.

\section{SEASON OF RIPENING} June

Early Newington.

\section{July}

Gower, New White, Boston, Advance, Lord Napier.

August

Hardwick, Humboldt, Victoria, Stanwick.

\section{THE QUINCE}

The quince comes in at a season of the year when practically all other fruits for preserving purposes are disposed of. California conditions, both in the interior valleys and through the coast sections, are well adapted to its culture. The trees are enormous bearers and in the fall of the year when loaded down with their heavy crops of large, light, lemon-colored fruits, they are strikingly ornamental. For delicateness of flavor there is no jelly superior to that of the quince. The fruits when cooked are very desirable for table use. In California the demand even in our largest cities has never been heavy. The inspiration to plant more quinces is evidently coming from our Middle West and Eastern neighbors. They are taking the few carloads which are now being produced and paying fancy prices to the growers. Quince culture has a future in California and those growers who are far sighted enough will not fail to plant a few quince trees in connection with their plantings of other fruits. The Smyrna quince is particularly well adapted to the interior sections, due to its very heavy foliage. The quince does remarkably well in alluvial soils, and even on soils which are inclined to remain wet a considerable length of time during the growing season. As the trees are of a dwarf habit they should be planted from fifteen feet to twenty feet apart. The quince is grown on its own root. The general practice is to plant the Angers quince cuttings and bud the named varieties on this stock. The trees should be trained to a single stem and headed at about twenty inches. As the tree is of a low, spreading habit, it should be trained to a wide goblet form. To secure a well shaped tree it is very essential to thin out and prune the trees back severely for the first three years. To develop fruit spurs and to keep the heavy fruits close in and to help the trees to sustain their large crops without breaking down under their burden, the cutting back and thinning out of the young growth should be an annual winter's job. The trees are very much inclined to sucker from the root, and if their vitality is to be conserved these suckers must be removed. Quinces should be gathered as soon as they are matured. They will keep for several months without any particular attention if stored under cover where there is a circulation of air and where the temperature is fairly uniform.

\section{TIME OF RIPENING}

September

Apple or Orange, Champion, Pineapple, Meech's Prolific.

October
Rea's Mammoth, Smyrna.

\section{THE ALMOND}

In normal times we import nine thousand tons of almonds and our annual production is three thousand tons. It requires no great amount of discernment to fully understand that almond culture in California is only in its infancy. It has had many conditions to contend with which have held it in check. The European varieties introduced in the early days ncver bore well, and then again many orchards were planted in localities subject to cold weather in the spring months where, on account of the tendency of the trees to bloom early the crop was severely curtailed. The introduction of the Hatch varieties in the early eighties overcame the first problem, and the second one has been mastered by the choosing of localities suited to their culture. The trees do well even in heavy soils if well drained. The tendency has been to plant almond orchards on soils more or less loamy but well mixed with gravel. The trees are rapid growers and attam large size in time, therefore they should be planted from twenty-five to thirty feet apart. There are many sections in the great interior valleys and in many of the Coast counties, noticeably San Luis Obispo, thirty miles inland, where almonds are an assured success. Thousands of acres have been planted in recent years in this county. The very fact that the rainfall is ample, combined with the necessary elevation, overcoming the danger of injury to either the blossoms or nuts when in their formative stage, has had much to do with the extensive acreage planted to almonds in the aforesaid 


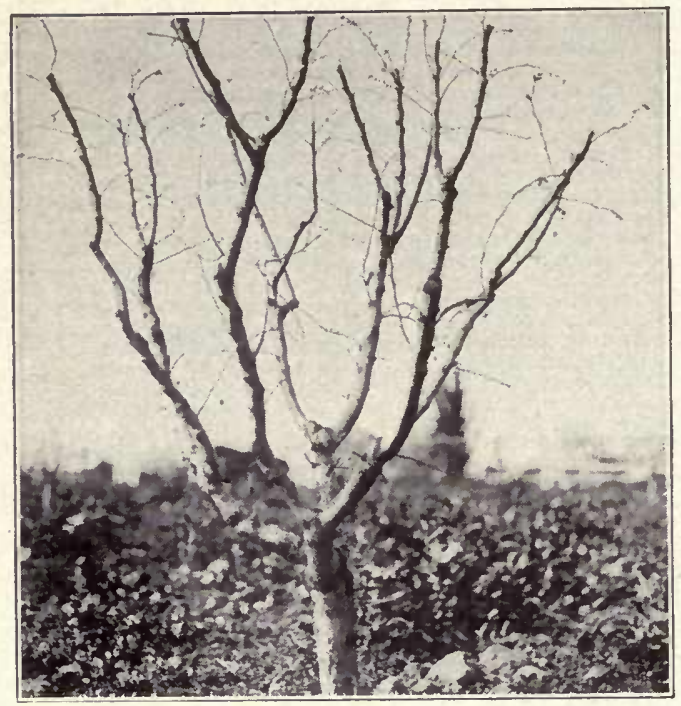

Three-year-old Almond tree, illustrating method of pruning. Had the tree not been pruned in this manner the wide-open top could not have been secured.

county. A well drained, warm soil and a locality where there is not a too frequent occurrence of frost are the necessary requisites to make almond culture a success.

\section{STOCKS}

The almond and peach roots are used exclusively for the growing of almonds. There is a preference for the almond root, because it sends its roots down deeper into the ground and the consensus of opinion is that trees are not only strouger growers but live longer on the almond than on the peach. The almond is really a very long-lived tree, and whether on peach or almond, providing the soil conditions are right, I have never observed any great difference in the longevity of the trees on either root.

\section{CLASSIFICATION}

The sweet almonds are divided into the following grades: hard shell, soft shell and paper shell. The hardshell variety has no commercial value except for raising stocks for budding and grafting other varieties. These have six ounces or less of kernel to the pound of nuts. The soft shell has six to eight ounces of kernel to the pound of nuts and the paper shell ten ounces or more. There is one exception, viz., the famous Jordan, which is a hard shell with its fixed type of elongated kernel and a flavor superior to all other almonds. Cross-pollination is one of the interesting phases in connection with almond culture, and although no exhaustive experiments have been made to determine how far-reaching this is, alternating three to six rows of a variety has a very marked effect in improving the yield.

\section{PRUNING}

When planting almond trees the instructions relative to other trees as given in the introduction should be followed. The trees after being set should be headed to twenty inches from the ground. During the first year allow the numerous shoots to grow without any interference and in the early winter months thin out the laterals so that the lowest ones will not be closer than ten inches from the ground, not leaving more than four to form the head of the tree. Even if they have made a growth of from three to four feet, cut them back severely. Because almonds should not be pruned much in later years, do not hesitate to prune when they require your trained eye and hand to shape them properly and create a form and a head which can only be secured by severe cutting. If there is any one object I have in view, it is to impress the man who aspires to be a fruit grower to remember that his success for at least the first eight years of his undertaking is dependent absolutely on a few essentials, and the pruning of his trees is one of the most important for at least the first four years of their existence.

The second and third winters cut off at least from oue-third to one-half of their growth. The fourth winter, the tree now having become sturdy and assumed the goblet form, which is ideal, confine your pruning to the thinning out of objectionable branches, and remove laterals where there is a tendency to overcrowding, so as to permit light and air to circulate through the trees.

\section{GATHERING}

In Europe there is quite a trade established in the sale of "green almonds." Such almonds are sôld just as soon as the kernel has passed from the glutinous stage to the white meaty form. As a dessert nut it is very delicious and I have every reason to believe when the value of the nut for table purposes is more generally known that the local demand will not only increase very rapidly but shipments will be made to the Eastern markets. Almonds should be harvested as soon as the hulls commence to split open. Much time and labor is saved by spreading a canvas under the tree and shaking the branches. All the nuts which do not fall should be jarred off by using a light pole. In orchards of a considerable size the hulling is done by machinery. Where there are only a few trees it can be done by hand. After the nuts are taken from the hulls they are placed on trays and exposed to the sun to dry. Care should be exercised not to over-dry the almonds. The proper degree of dryness is readily determined by taking $\mathbf{a}$ kernel between the fingers and if it breaks readily without bending, the almond is cured. To meet the trade requirements it is necessary to bleach almonds. This is done by sprinkling them with water and exposing them to sulphur fumes for thirty minutes or longer. The color should be yellowish white. In order to secure the proper shade it is advisable to get some samples from a dealer as a guide to obtain the right color. A few hours' exposure to the sun after being bleached is all that is necessary and they are then ready to be sacked.

\section{IRRIGATION}

The almond sends its heavy roots very deeply into the soil searching for moisture. For that matter the peach will do this also, but thorough cultivation is very 


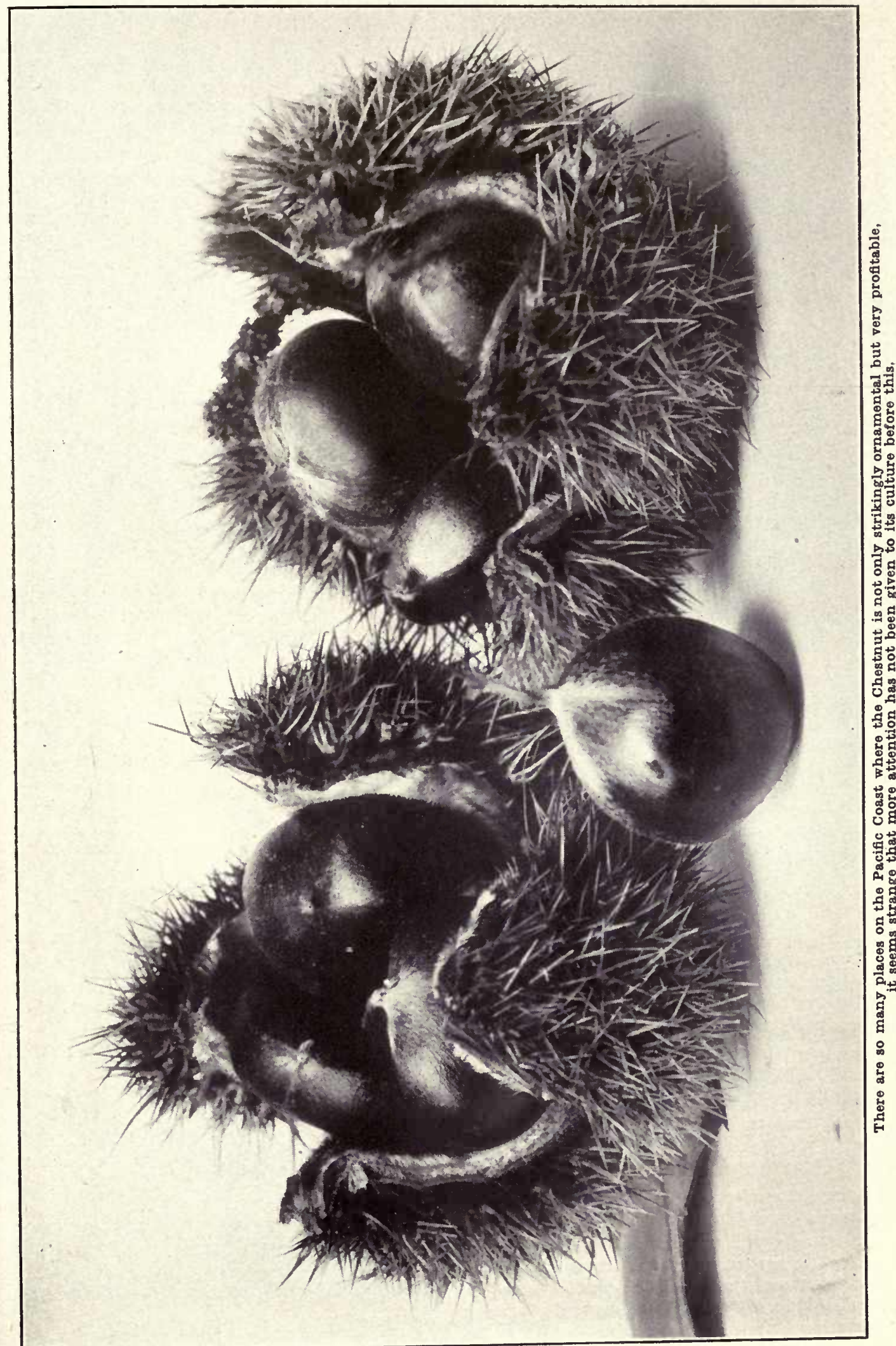




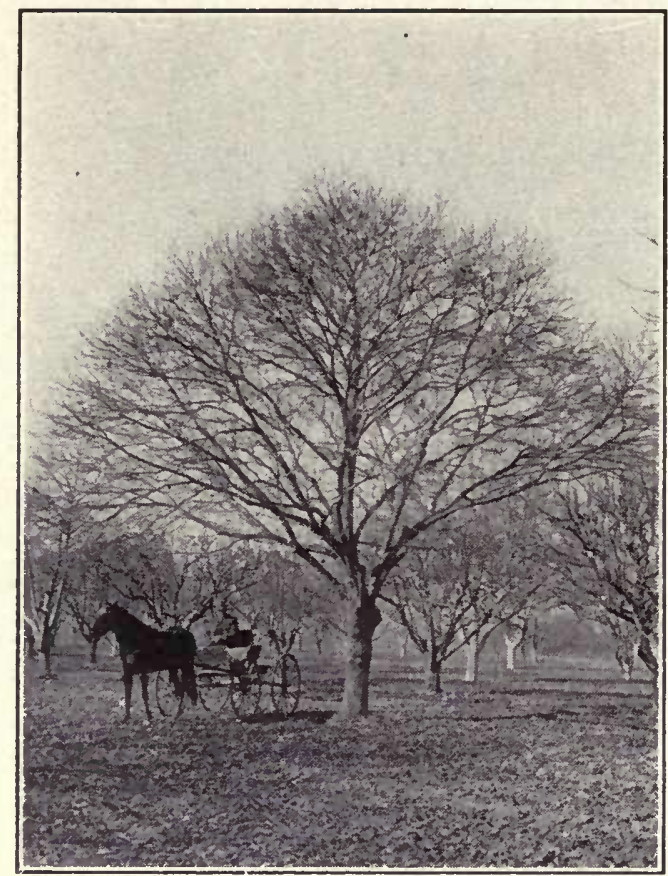

The Chestnut possesses the distinction of not only being a a very profitable fruit tree, but is equally adaptable as an avenue or border tree. Once the head is formed all it tree is the Marron Combale in the trial orchard of the California Nursery Company.

necessary to bring this about. Almonds will thrive under conditions as far as water is concerned which would be fatal to many other varieties of fruit trees. This does not mean that they will grow without irrigation, for in localities where the average rainfall does not exceed eight inches per annum to attempt to grow almonds without irrigating the orehard would be foolhardy. When the trees are young, that is up to the fourth year, they should receive the same care that is bestowed on any other deciduous tree. When they have reached the age of bearing, an irrigation in the month of June followed by thorough cultivation is sufficient. In the fall of the year if the trees show signs of wilting, an application of water is very beneficial to the tree, for it causes the leaves and fruiting buds to fill out and adds to its vitality when it takes on its new growth the following spring.

\section{COMMERCIAL VARIETIES}

Drake's Seedling, I. X. L., Jordan, Ne Plus Ultra, Nonpareil, Peerless, Texas Prolific.

\section{PERIOD OF RIPENING}

The harvesting commences in August and ends in the early part of September.

In recent years the interest which has been manifested on the part of growers in the planting of almonds, has been very marked indeed. Conditions prevail in California which should eause the industry to advance very rapidly and eventually make it the center of production for the entire world.

\section{THE CHESTNUT}

There are so many points in favor of the chestnut that it is very diffeult indeed to understand why the culture of this nut has not long before this become one of our leading industries. Aside from the fact that the trees are very ornamental, the eertainty of a crop one year with another should have eaused them to be planted on an extensive scale. By heacling the trees low it is practical to grow them in the interior valleys. However, from a standpoint of profit they should only be planted in the deep, alluvial, silty soils found in our river bottoms. Strictly speaking the chestnut should be planted in the Coast sections, where there is an abundance of rain and where the temperatures never run up very high due to the influenee of fogs and cold air from the ocean. The chestnut grows vigorously in such sections and where in addition to this there are frequent oceurrences of rain during the summer months, so inuch the better. The trees will withstand extremes of cold weather during the winter. They do not bloom until May, when all danger from late frosts are over with. The great coastal regions of Oregon and Washington are so well suited to their eulture it seems very strange indeed that some enterprising horticulturist lias not exploited the possibilities of this industry long before this. In my travels in the great Northwest section I became impressed a number of years ago with the opportunity so much in evidence there for growing chestnuts. I have seen trees growing in pastures and on hillsides

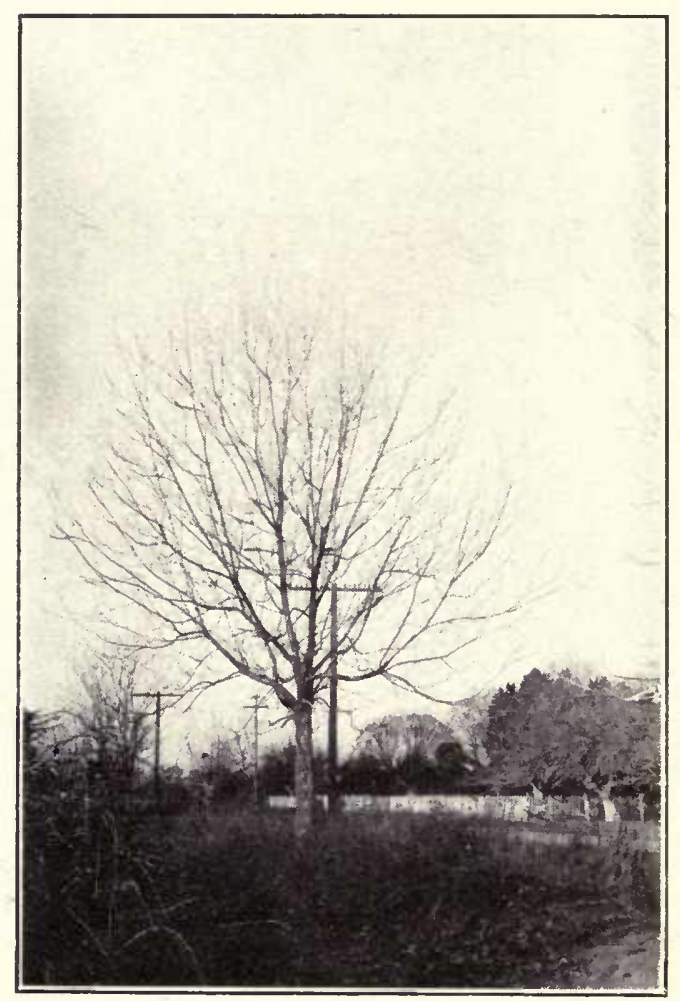

The Pecan must be shaped while it is young, but after it is started properly, the only pruning required is to remove interfering branches. This tree is the Stuart, one of the paper-shell varieties. 
with no care and still they were loaded to the guards with nuts. Chestnut culture has always been a problem in the Eastern States when it came to growing European and Japanese types, and now that the blight has made such a serious invasion into the great chestnut forests of the East, there can be no possible excuse for the Pacific Coast States not engaging in this industry which is so promising. The trees attain a very old age and a great size. The grafted varieties should always be given the preference, for they not only come into bearing earlier but in addition to this the nuts are of uniform size and shape. For orchard planting the trees should never be planted closer than thirty feet. As an avenue or border tree there is nothing more beautiful than the chestnut.

\section{PRUंNING}

After the head of the tree is once formed its pruning in subsequent years should be confined to the removal of interfering branches and to the checking of the growth of a branch which may be drawing the tree out of shape.

\section{STOCKS}

Seedlings for budding and grafting the Improved French and Japanese varieties are raised from seeds of the Italian chestnut (Castanea vesca).

\section{GATHERING AND STORING}

Chestnuts are gathered in October. In the warmer sections, where during the summer months there is no rain, they ripen earlier than this. As soon as the burrs begin to split open they are knocked off the trees with poles. The nuts that do not come out of the burrs in falling from the tree are picked out by hand. They are then packed in barrels and shipped to market. They will keep for some time if handled in this manner without deteriorating. To keep them in good condition for a number of months they should be placed in a receptacle and have boiling water poured over them. After being immersed for fifteen to twenty minutes, spread them out on trays until they are dry.

\section{VARIETIES OF COMMERCIAL VALUE}

Marron de Lyon, Marron Combale, Numbo, Paragon, Ridgely.

\section{THE PECAN}

Of the eight or nine species of hickories the one which produces the most marketable fruit and in the most profitable quantities is the pecan. A native of the Southern States, it is today the only nut (which has any commercial importance) which is grown there, and to a limited extent in the Middle States. Texas is probably the largest producer of pecans, the crop aggregating several millions of pounds. Gathered largely from seedling trees. The business of cracking pecans and selling the meats put up in attractive packages has created a demand for the nuts which is increasing at a very rapid rate. It is largely due to the impetus the industry has received in recent years that has encouraged the planting of trees on a commercial scale of the improved paper-shell types. The diff.culty of extracting the meat from the hard-shell seedling nuts has been one of the causes for their not being more popular as a dessert fruit. The thin shells of the improved types, the ease with which the meats are removed, and the noticeable absence of the fibrous segments found in the hard-shell nuts, which possess a peculiar acrid taste, will do much to make them popular.

Old seedling pecan trees are found growing and producing heavy crops annually in the Sacramento and San Joaquin valleys. A number of seedling trees, two feet and over in diameter, are growing one mile north of Fresno, bearing abundant crops.

It is only within the last ten years that pecans have been regarded of sufficient commercial importance to cause groves to be planted in the Middle and Southern States, and the condition of affairs has been brought about by the unexcelled merit of the paper-shell pecan. In California only a very few paper-shells are to be found; none of these are over fifteen years old, with the most complete assortment of varieties growing on one of my properties.

\section{CONDITIONS FAVORING ITS GROWTH}

The trees thrive in a great variety of soils, doing well in a stiff clay or porous sand, and in Texas they are said to do well on soils underlaid with hardpan, provided proper precautions are taken to blast it before planting. The planting of trees should be confined to soils where moisture is either supplied by natural means or irrigation. Pecans will prove a valuable acquisition to our list of nut fruits in the warm interior valleys of Califorria, Oregon and Washington. In the coast counties, although the tree grows well, it does not mature its nuts, due to the cool, foggy weather, which does not seem conducive to the proper development of the nuts before the dormant season sets in.

For planting along irrigation ditches, the pecan is the ideal tree, as it will thrive without cultivation and ripens its nuts after the water is turned out of the ditches.

The advisability of planting only named varieties of grafted or budded trees is conceded by experienced planters. When trees are grown from selected papershell seeds, they are liable to produce nuts of variable character in shape, size, thickness of shell and quality of meat. The additional cost of growing named varieties either by budding or grafting is caused by the very small percentage which a nurseryman succeeds in growing. If the orchardist will only bear in mind that the increased outlay for budded or grafted trees is offset by the fact that they will come into bearing in less than half the time that seedlings do, and that the nuts will sell for four times as much on the market, their economy is at once obvious.

The pecan, like the walnut, is unisexual; that is, the male and female organs are not in the same blossom. It sometimes happens that the male blooms (catkins) mature and release their pollen grains before the pistillate or female bloom is in the receptive stage, and when this occurs the nuts are hollow shells and it is therefore advisable in planting a pecan grove to plant two or 


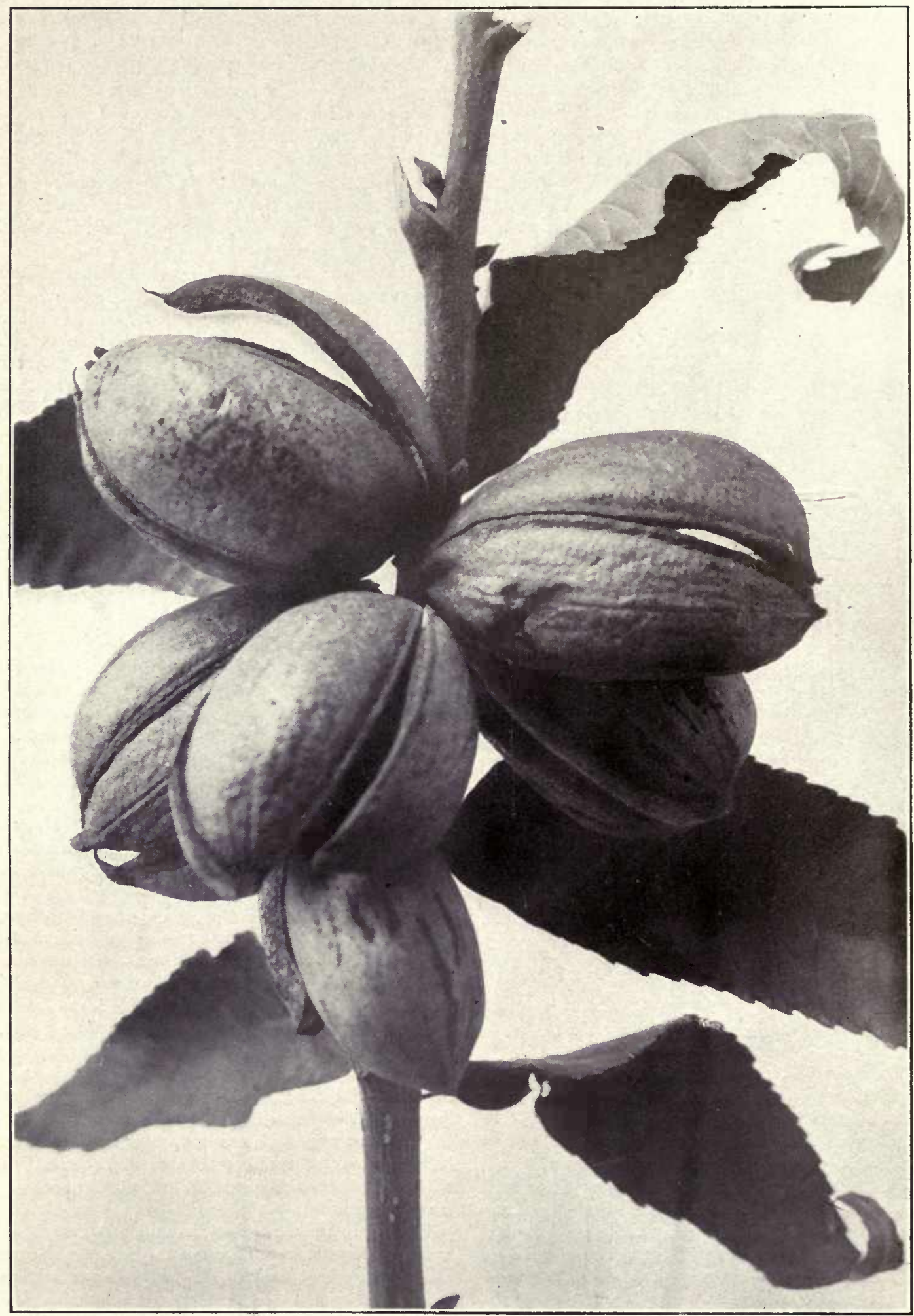

There are many sections in California where the Pecan will be extensively grown. The grafted Paper Shell Pecans have so many points in their favor that they should be given the preference over the ordinary seedlings. 
three varieties and alternate with several rows of each. Trees should be planted not closer than forty feet, and on rich bottom soils fifty feet apart. It is entirely practicable to plant some other fruit between temporarily until the pecan commences to bear profitable crops, when the other trees can be dug up. The oft-repeated remark that only trees which have never had their tap root cut will bear, has time and again been shown to be a fallacy; in fact, no harm will result from the shortening in of the tap root, for the tree is really benefited by the more spreading root system. The difficulty of securing a uniform stand and protecting the trees from injury; the marked variation in the size of the trees when the nuts are planted in the orchard where the trees are to grow, has further discouraged this method of procedure. Remarks pertaining to the pruning of walnut trees are applicable to the pecan. Much difficulty has been met with in transplanting pecans. This can be overcome by cutting the tree down to within six inches of the bud and hilling soil around the tree until it starts to grow, when the soil may be drawn away.

\section{THE HARVESTING}

The pecan ripens its nuts in October. No attempt should be made to gather the nuts until the hulls show a tendency to split open When this occurs the nuts may be knocked from the tree with light poles and gathered up from the ground. Spread them out on trays and expose them to the sun until, when the nuts are cracked, the kernel is found to break readily when pressed between the fingers. This is an indication that the nuts have been dried sufficiently. The nuts may then be stored in a dry place, where they will keep in the very best of condition for a number of months.

\section{VARIETIES WHICH HAVE PROVED MERI- TORIOUS IN CALIFORNIA}

Frotscher, Pabst, Russell, Schley, Stuart, Success Van Deman.

\section{THE PISTACHIO}

Comparatively little is known about the pistachio, or green almond. It is particularly well adapted to the warm interior valleys. The nuts have a flavor which makes them very inviting when eaten out of the hand. They must be processed, however. This is done by soaking them in a brine made by dissolving four pounds of salt to a gallon of water. They are then roasted and this causes the shells to open slightly. Of all the candy we buy, there is none more expensive than that which is flavored and colored with the pistache nut. It is known as pistache candy and it possesses a delicacy of flavor found in no other sweetmeat. The trees are dioecious; that is, the male flowers are produced on one tree and the female on another. The tree is of a spreading habit and low-growing. This is particularly the case with the Pistacia vera, which is the variety producing the nuts of commerce. For commercial planting it is necessary to have one tree of the male type to ten of the female. The latter trees when loaded down with their large grape-like clusters of nuts are strikingly

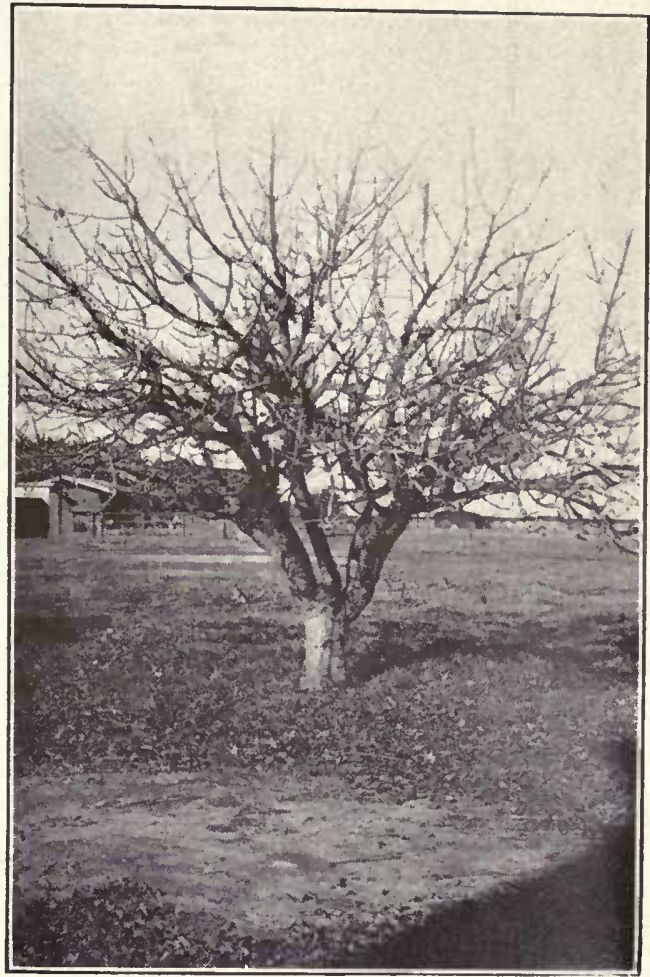

As the Pistachio tree is very hardy and is not particular in its requirement of soil, its culture will undoubtedly develop into a very important industry. This treo is twenty years old.

beautiful. The trees are of very easy culture, thrive on a great variety of soils and are, as a matter of fact, very much hardier than the fig and the olive. As border trees they are very attractive, and I have every reason to believe they will prove quite profitable. They would be used by the foreign population much more extensively than they are if the price at which they are sold, from sixty to eighty cents per pound, was not so high. The importations are estimated to a verage $\$ 200,000$ per annum. There is no question about the future of this industry, though up to the present time it is still in the experimental stage. It is largely through the efforts of the Bureau of Plant Industry of the United States Department of Agriculture that varieties of merit have been introduced in recent years. I am giving now, and have given for several years, considerable time and thought to the culture of this nut, and I am confident that the time is not far distant when it will become another valuable acquisition to our list of horticultural products.

\section{THE WALNUT}

This tree prefers a rather loamy, deep, rich soil, and when so planted no nut yields larger and more profitable returns. The tree is practically free from insect pests, and when once established requires little care as far as pruning is concerned. Good and thorough cultivation is necessary for activity in the growth of the trce, causing it to respond with bountiful crops. The planting of seedling walnut trees has been generally abandoned on 
account of the many advantages of grafted trees, which may be summed up as follows: (1) they usually commence to bear protitable crops much earlier than seedlings; (2) they reproduce the variety from which buds and grafts were taken, so there is an absolute certainty that the character of the parent tree will be transferred to the young stock; (3) perpetuation of the bearing qualities of the parent tree with nuts of identical quality. These points form the basis of success for the grower, and the extra prices realized for the product of the grafted trees in connection with their early bearing qualities more than offsets the additional first outlay. In addition to other facts mentioned, the California Black Walnut (Juglans Californica) root, which is used as a stock, has a decided influence in causing the graft to grow more vigorously and it will also adapt itself to a wider range of soil conditions than trees on their own roots.

\section{HOW TO PLANT}

For commercial planting, trees are usually set forty feet each way, although in some instances, where the soil is exceptionally fertile, trees are set fifty feet apart, for as the tree matures it makes a wide-spreading top, so that it is no uncommon sight to see branches even at the latter distance interlacing.

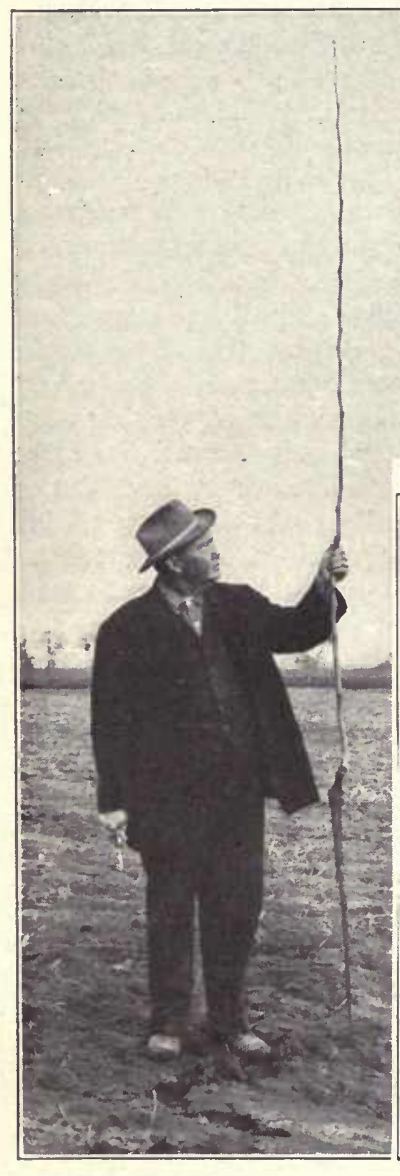

A grafted Walnut tree just from the nursery.
All the talk that the cutting of the tap root of the walnut interferes with its bearing qualities is mere twaddle. Practically all the orchards in California are transplanted trees.

\section{PRUNING}

Even if the trees are ten feet high, they should be cut back to three and one-half feet from the ground after being set. In the interior valleys growers have even found it expedient at times to cut trees down to twelve inches and train up a new stem. If there are any advantages in this plan of procedure, they are evidenced by the tremendous vigor and the prevention of sunburn of the new shoot, which must of course be staked the first year. The coined expressions that this tree or that should not be pruned because it would be ruined, has had the tentacles of misapprehension more closely interwoven around the walnut than possibly any other tree. Which is preferable, the tree with all its fruit-bearing wood in the very top or the one that is liberally supplied with laterals as nearly as it can be obtained from the point from which the head is started? If you can secure a more striking tree with a broad-bearing surface, is it not common sense to suppose that you are not going to reach the goal you are aiming at, if you don't do something to check the growth of the framework branches?

No person of intelligence will deny the fact that one's arm held at length has not the strength to resist the same strain as when the forearm is held at right angles to the arm.

The same principle applies to the main limbs of the tree. The development of elbows promotes strength, increased bearing surface and a perfect tree. Cut back the framework branches one-half the first winter after planting in the orchard. Cut back the leaders but not quite so severely the second winter, and thin out if there is a tendency toward overcrowding. The treatment should be more moderate in the third winter, and in the fourth year the checking of rampant limbs which have a tendency to outstrip their neighbors is all that is necessary.

\section{SPECIAL FEATURES}

The holes for planting should not be less than three feet deep and two feet in diameter.' Cut the tap root off at about twenty-four inches and trim off all bruised and broken lateral roots before planting. A liberal application of thick whitewash, in which some salt or glue has been dissolved, is very beneficial to the body of the tree, as it prevents sunburn.

The walnut, like the pecan, is unisexual; that is, the flowers of both sexes although produced on the same tree, do not occur in the same flower. The male flowers are called catkins and in the spring are distributed throughout the tree and look like tassels; the female flowers are like two little horns at the terminal ends of the new growth. 
One of the striking peculiarities of the French type of walnuts is their late blooming. This peculiar feature of these walnuts was no doubt developed in Grenoble, France, where the Chaberte, Franquette, Mayette and Parisienne originated. When the French walnuts are planted among such varieties as Santa Barbara, Placentia Perfection and others, the difference is very striking, for they rarely have a bud swelled by the middle of April, while the varieties which have been developed in California will be clothed with all their foliage.

Deep alluvial soils should always be selected for planting walnuts, and a liberal supply of water should be available, either by surface irrigation, or the soil in which the trees are planted should be of a moist nature.

It is only recently that the San Joaquin and Sacramento valleys have been found to possess climatic and soil conditions, making the culture of the walnut a very profitable undertaking, particularly of the French varieties grafted on California Black Walnut root.

\section{GATHERING AND CURING}

Walnuts are gathered during the months of September and October, depending on the locality. The time of maturity is indicated by the cracking of the hulls. The nuts drop to the ground and are gathered up at intervals. Any nuts sticking to the hulls may be easily dislodged by jarring the tree or knocking them off with light poles. The nuts are taken from the field to the drying ground and spread out on trays. Prune trays may be used to good advantage for this purpose. They should be stirred occasionally to cause them to dry uniformly. After the nuts are dried, for commercial purposes it is necessary to grade them into several sizes. This is done by passing them over a revolving screen having meshes three-quarters of an inch square at the

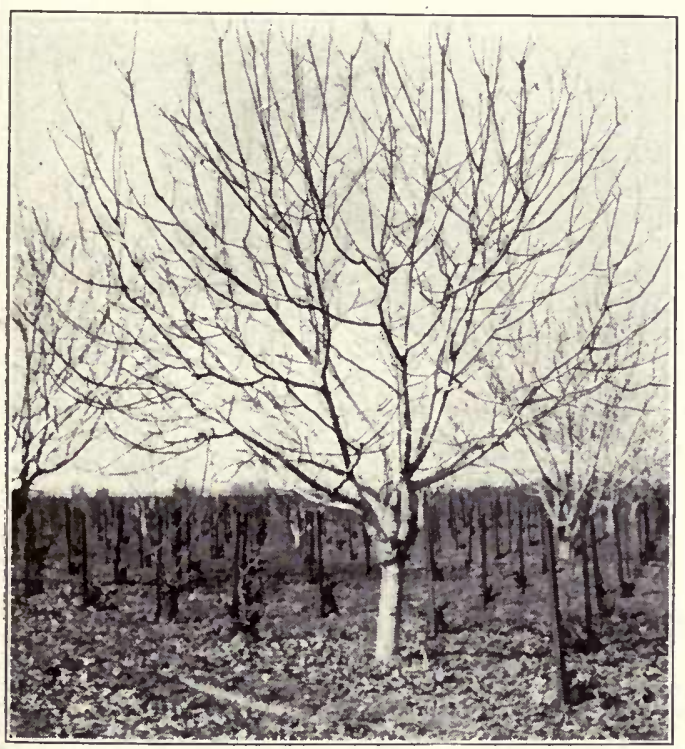

This tree has been pruned for several years to secure a symmetrical head. This having now been established, pruning in the future will be confined to cutting out interfering branches and checking the growth of those which might cause the tree to be drawn out of shape.

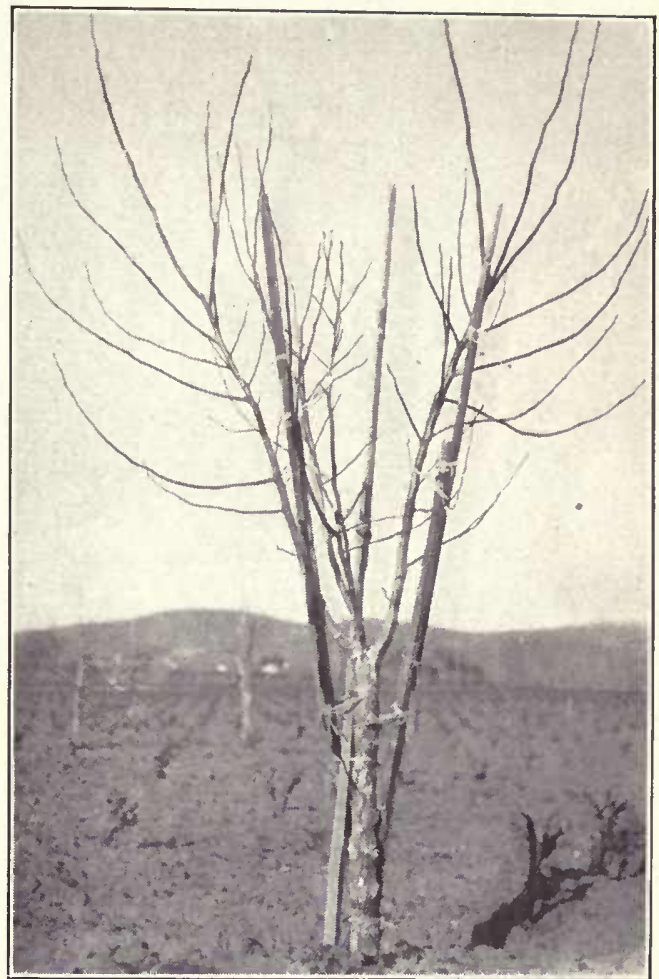

A top-worked Walnut. Note the long sticks tied to the grafts to keep them from breakilig off. A much better and well balanced tree would be secured, and a much stronger union at the point of secured, and a much stronger been cut back severely the first year of their growth, and then following this up by shortening in and thinning out then following this up by shortening in and thinning out the laterals for a couple of yeal thereafter, until the head the walnut is a detriment is responsible for just such nonsensical methods as shown in this illustration.

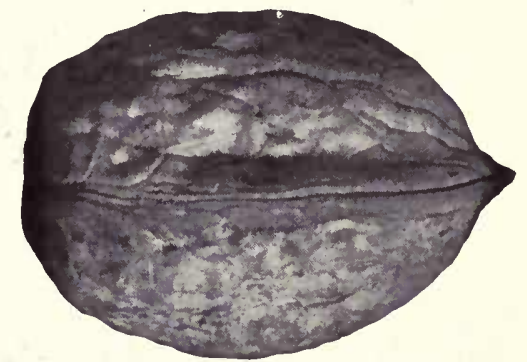

Franquette Walnut, one of the most popular of the French introductions

upper end and one inch square at the lower end. The small meshes take out the dirt, and the inch meshes take out the small nuts, which are called No. 2 nuts, while those going over the screen are known as No. 1 nuts. The drying, as a rule, is done in the sun, although some growers resort to evaporators, intimating that by this method the pellicle, which is the covering over the kernel, does not become discolored to the extent that it does when the nuts are dried in the sun. As far as my observation goes, unless the weather is inclement, walnuts under California climatic conditions may be dried without any detriment to the nut or its quality in the open. As soon as the kernel is firm and cracks readily, the nuts are dry. After the nuts are graded 


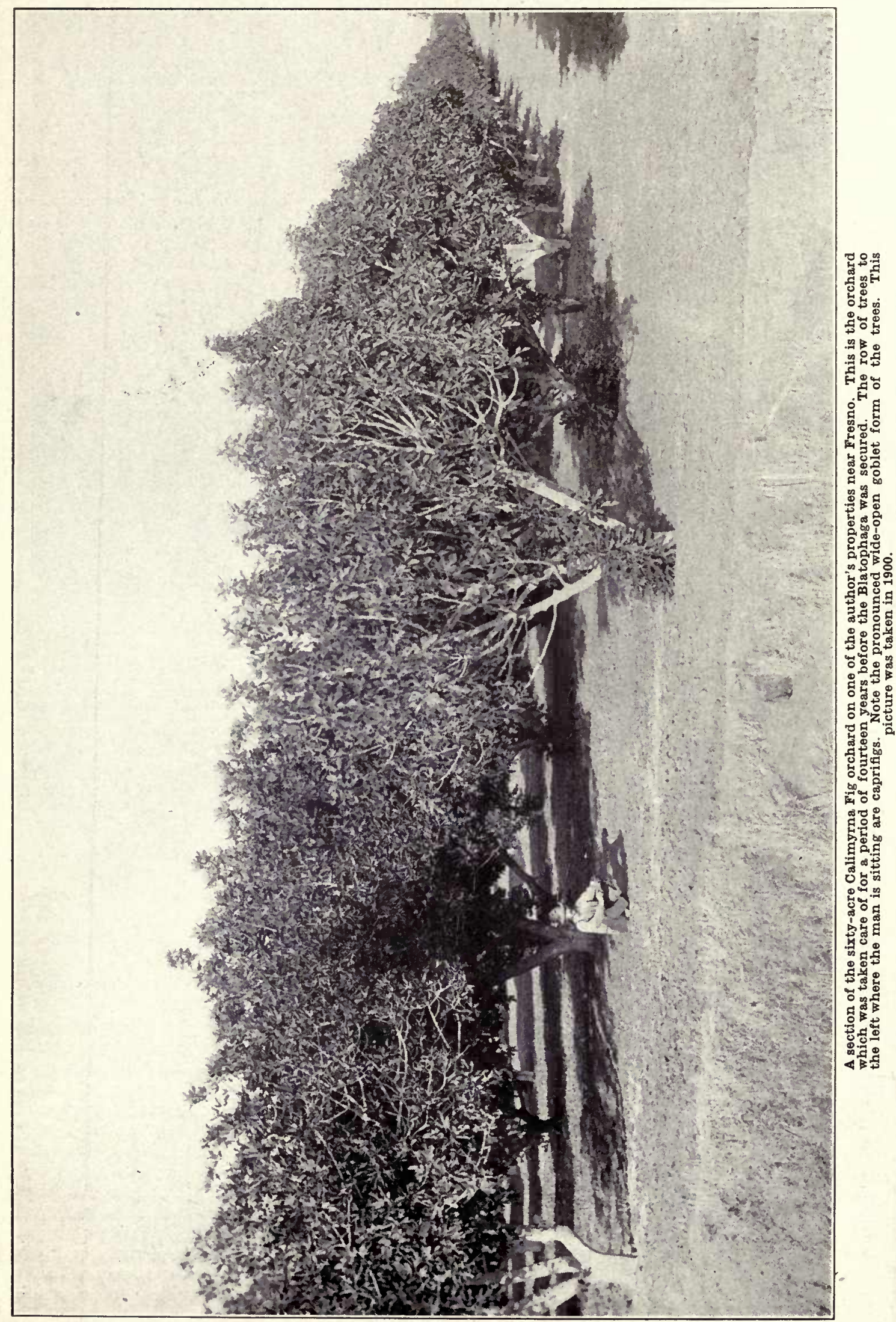


and washed, they are sulphured for about thirty minutes. After passing through this last process, they are again transferred to trays, which are stacked one above another, the nuts remaining on them until the moisture from the processing has dried off. They are now ready for market. The commercial package consists of a good strong burlap sack, holding one hundred pounds. Great care must be exercised in sulphuring walnuts to be sure that the kernels are dry and not allow them to remain in the sulphur fumes too great a length of time, otherwise the kernels will taste of sulphur, which will unfit then for market. In the leading walnut sections of California the curing of walnuts is carried on by the use of bleaching powders. The process is very much quicker and eliminates all danger of having the kernels contaminated. On groves of some size, graders, dippers, sulphuring and bleaching contrivances are constructed to facilitate all the operations referred to, with a view of not only holding down the expense of handling but also to turn out a more uniform product.

\section{COMMERCIAL VARIETIES}

Concord, Eureka, Franquette, Mayette, Placentia Perfection, Santa Barbara Soft Shell.

\section{VARIETIES WORTHY OF TRIAL}

A'Bijou, Chaberte, Cut-leaved, Mayette Rouge, Monstreuse, Neff's Prolific, Parisienne, Praeparturiens, Vourey, Willson Wonder.

\section{TIMBER TREES}

American Black, California Black, Paradox, Royal.

\section{THE FIG}

Figs grown in the United States either for eating fresh or for drying are of one species, viz.: Ficus carica. There are an endless number of varieties of figs. In many instances, on account of the wide distribution of this fruit throughout the world, the same variety may be blessed with any number of synonyms. This is the case with many sorts grown in California today. Not over six varieties comprise the list of commercial varieties for all purposes in California.

\section{LOCALITIES FAVORABLE FOR THE FIG}

It is safe to say that no deciduous tree grown in the semi-tropic and temperate zones will adapt itself to a wider range of climates and soils than the fig. Figs can be used for such a variety of purposes, namely: drying, canning, preserving, shipping in the fresh state and for home use, that a wide range is open for their successful exploitation. To produce the finest dried figs, with the thinnest skin and rich in sugar, a warm, dry climate is an important factor. They will withstand a temperature of 18 degrees Fahrenheit in the winter months without being injured; hence their geographical distribution is very wide.

\section{BRIEF HISTORY}

Many of the countries whose shores are.washed by the Mediterranean sea are producers of figs commercially, but the recognized fig center of the world today

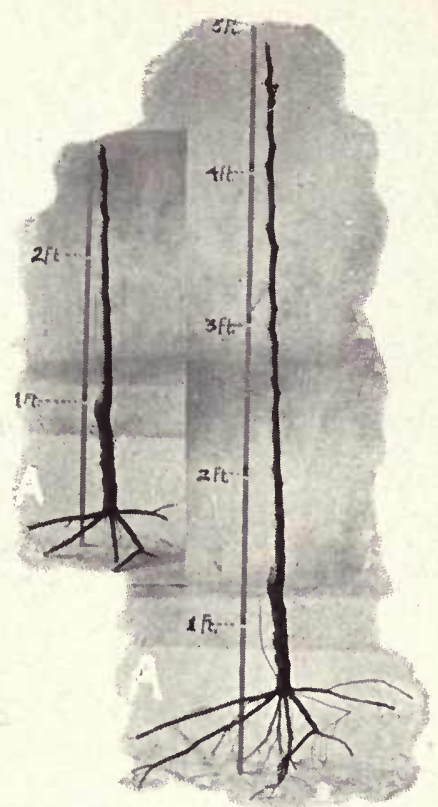

A Fig tree as it comes from the nursery. The one to the left shows the method of cutting back and root-pruning before planting.

is in the Meander valley about forty miles distant from Smyrna, Asia Minor. It is here that the Smyrna fig of commerce has been grown for centuries, and the secret of their culture was so closely guarded. It was only after fourteen years of constant and persistent effort on my part that I succeeded in 1890 in producing the first Smyrna figs in the United States by artificial pollination, and ten years later, having succeeded in establishing the Blastophaga grossorum, with the assistance of the United States Department of Agriculture, the first Smyrna figs were produced in a commercial way.

The first figs introduced in the United States were brought, as nearly as can be determined, by the Spanish Padres from Mexico in 1769 . They were planted at the San Diego Mission. This fig is still a standard in California. The tree is a great grower and produces an abundance of what is known as the Breba, or first crop, maturing in late June, and the second crop ripening from August to October. The very fact that this and other varieties of figs were grown in California, from which abundant crops were being gathered annually, caused the whole subject of caprification to be branded as an idle dream. It is now conceded that the Smyrna type of figs are in a class by themselves, and unless the pollen is conveyed by the Blastophaga to the edible fig, all the figs drop off prematurely when about the size of marbles. I knew this to be a fact, for in my orchard of sixty acres of Smyrna figs, which I cared for over a period of fourteen years, all the figs dropped off until the Blastophaga was established in the caprifig trees.

The fundamental difference between the Adriatic and Smyrna class of figs is that the former matures its fig without the fig wasp, while the latter does not. The Adriatic figs seem to possess all the qualities of the 


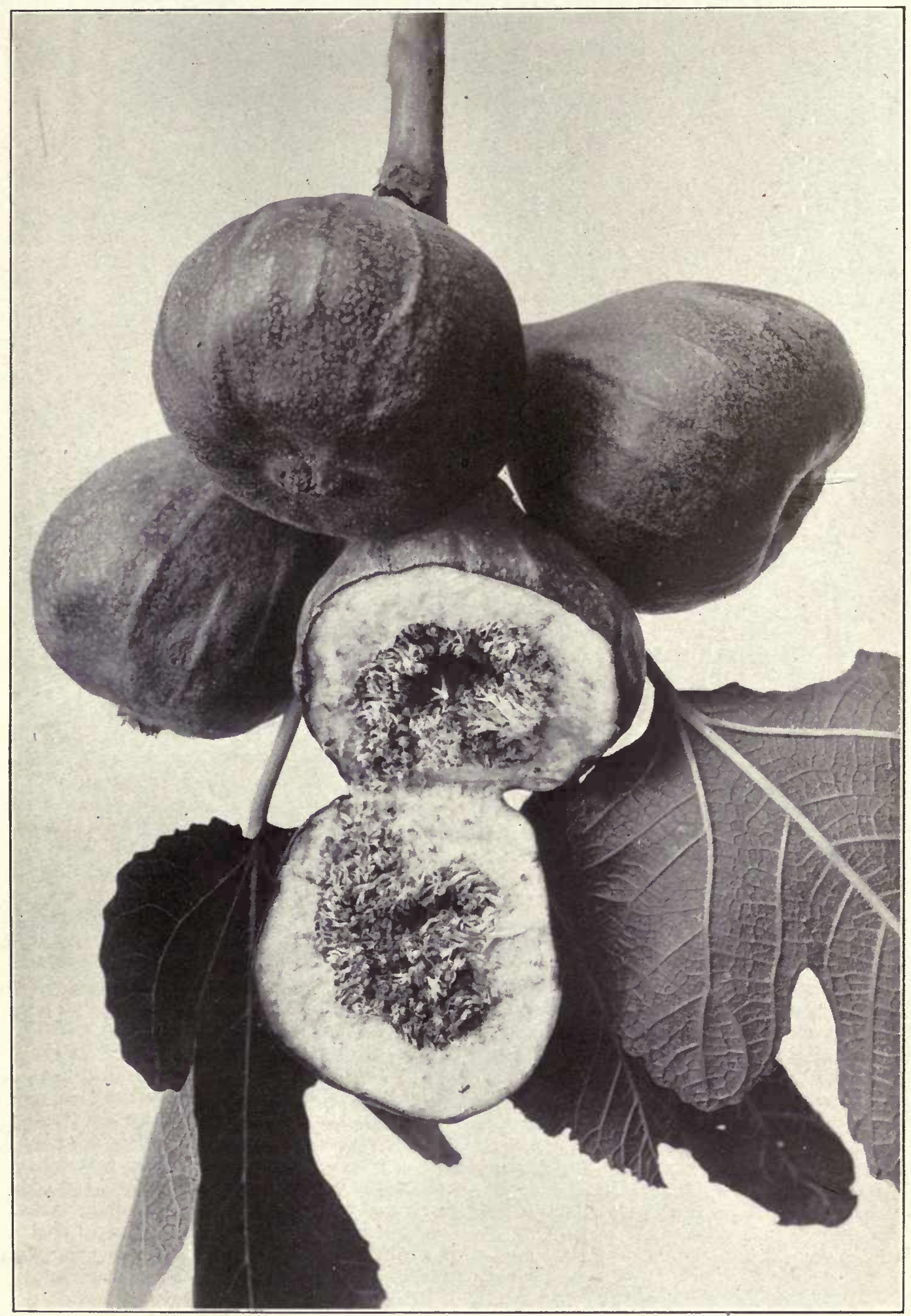




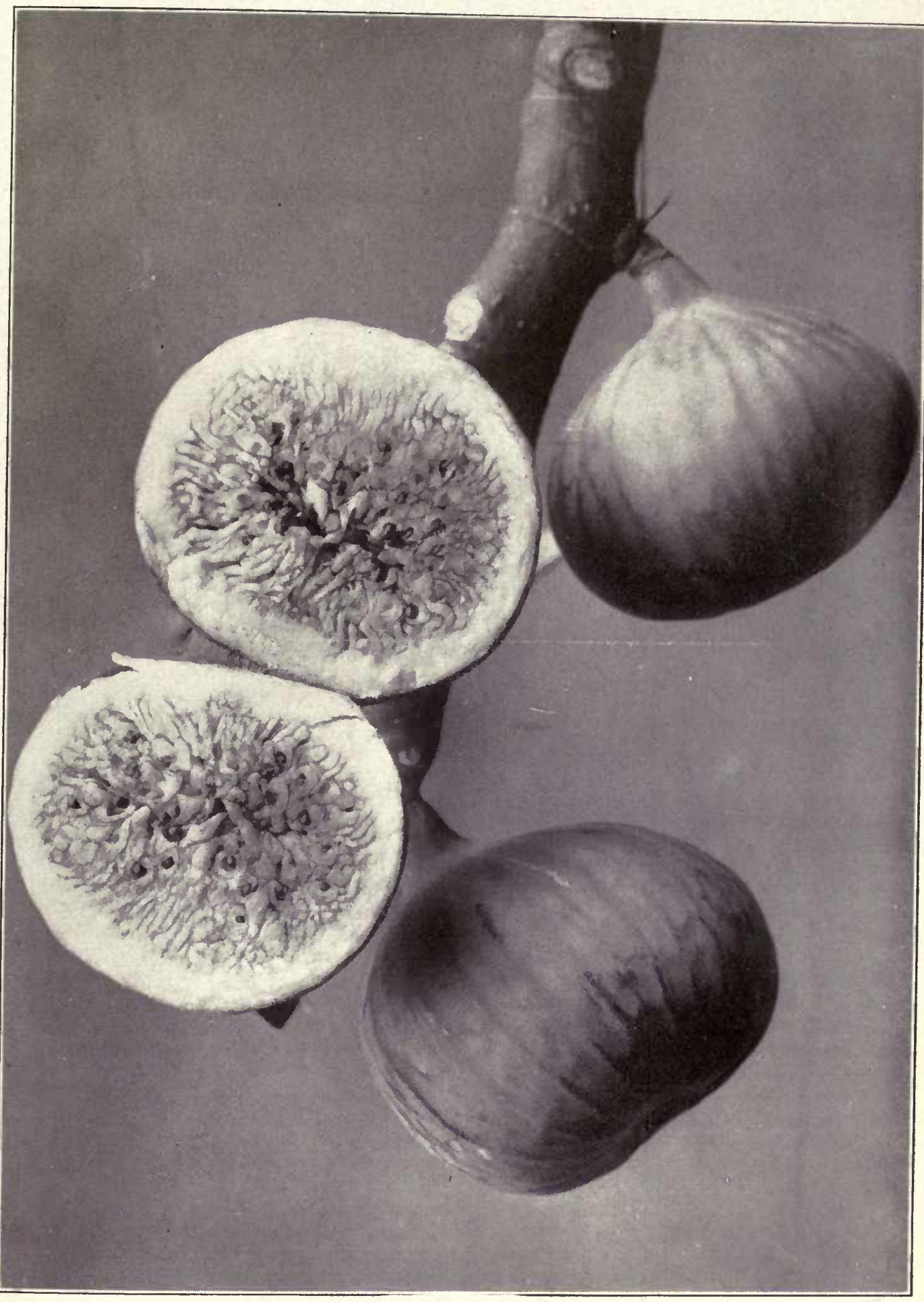

The Calimyrna Fig. 


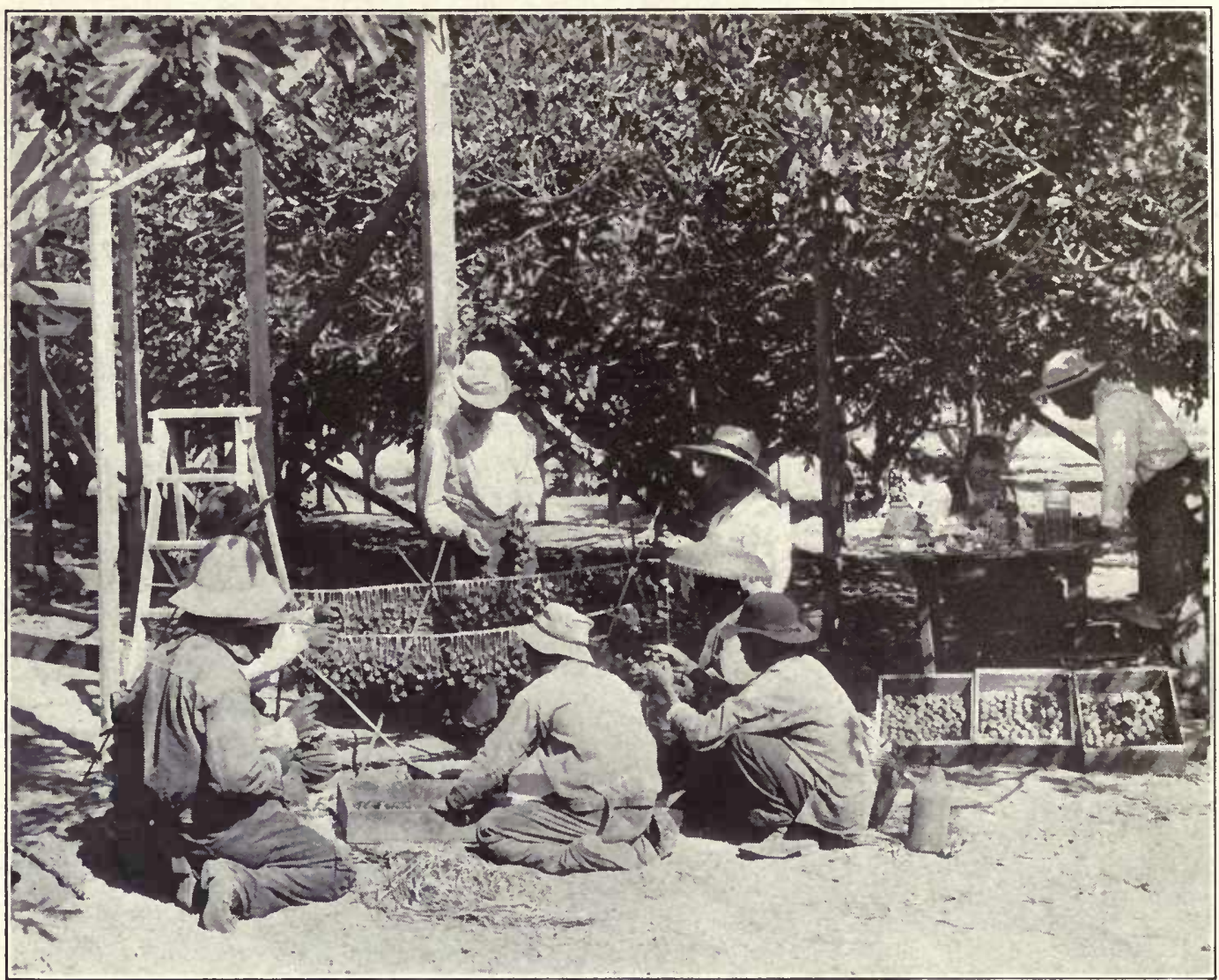

Under the Caprifigs; stringing the Capris on raffia fibre preparatory to suspending the figs in the Calimyrna trees. This picture was taken in 19c0, the year prior to the author's trip to Smyrna, Asia Minor. Today the figs are placed in wire baskets, or grape baskets, eliminating the heavy labor expense and securing equally as good results.

Smyrna so far as general appearances go, but on investigation it will be found that all the seeds are hollow, while in the Smyrnas each seed contains a kernel, giving the fig a nutty flavor and a delicious syrupy sweetness found in no other fig. The great interior valleys of California, with theirfavorable climatic conditions (there being no rain in the summer months, and the air being both warm and dry) present possibilities which are not equalled in any other part of the world. The output of Smyrna is in the neighborhood of 30,000 tons annually. California produces about 10,000 tons of dried White Adriatic, Mission and Calimyrna. The United States imports from 10,000 to 13,000 tons annually. The demand for figs for shipping, preserving and drying is growing by leaps and bounds, and it is up to the growers to embrace their opportunities and engage in this, one of California's most promising industries.

\section{CAPRIFICATION}

To give even a short review of caprification would occupy pages of a book several times as large as this one. I merely wish to say that for years the subject was regarded as an illusion by prominent horticulturists, and I was subjected to criticism and met with discouragements too innumerable to mention, before I finally after many years of persistent effort, succeeded in con- vincing the skeptics that Smyrna figs could not be grown without caprification. Plant life has just as many intricate problems as human existence. We have in the fig a problem which is beyond human ken. It is very difficult indeed to give any explanation why the edible fig, Ficus carica, has within its range so many hundred varieties of figs which do not require fertilization of their flowers to produce edible fruit, while in the Smyrna type of figs unless the flowers are pollinated the figs drop off and never mature. The fig is a fleshy receptacle to which is attached thousands of minute flowers. Botanically, flowers grouped together like this are characterized as an inflorescence. The fig differs from practically all other classes of plants in that no ordinary insect can reach its flowers, berause the receptacle in which they are enclosed has only one small opening in the apex of the fig, which to all appearances, as far as human intelligence and eyesight can discern, it would be impossible for any insect to enter. Fortunately for the thousands of people who enjoy eating figs, a great many varieties mature their fruits and are perfect from the standpoint of the consumer, although scientifically imperfect, because the flowers have not been fertilized and the seeds are hollow shells.

When California, twenty years ago, began to engage in the business of drying figs and shipping them to the east, it did not take long to discover that there was 

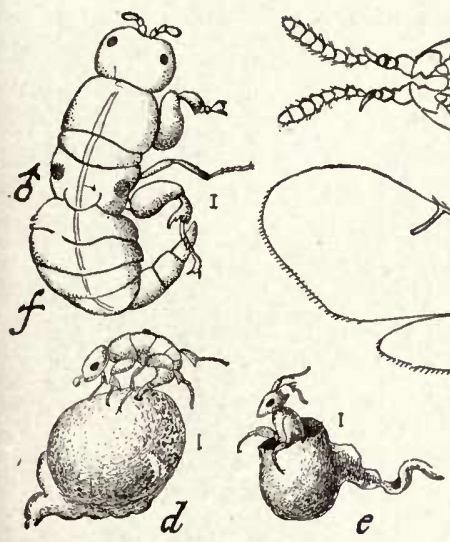

e

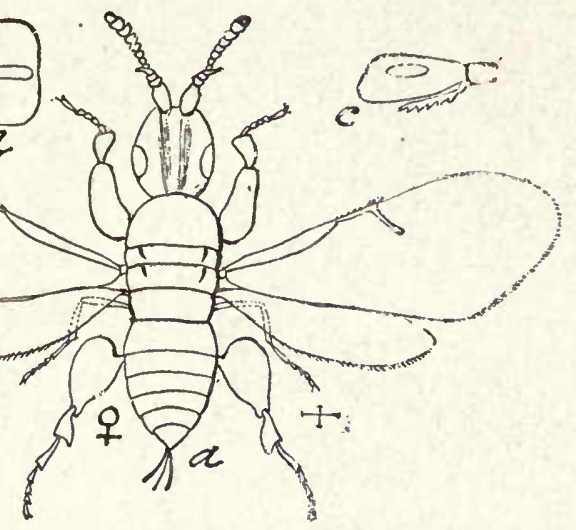

Blastophaga grossorum. A, adult female, very much marnified; $B$, head of same from below: $C$, head of same from side; $D$, hale sam irom female; $E$, female issuing from the gall; $F$, adult much enlarged. The narrow lines close to each figure indicate the actual size of the insect. something decidedly lacking in our product when compared with the famous fig of commerce from Smyrna. The very decided difference in quality was attributed to soil and rlimatic conditions, and those who were ready to concede that a little wasp could so completely change the character of a fruit, were in the abject minority. Although it is not necessary to have the fig wasp for the White Adriatic, nevertheless there is a decided improvement in this and even in other varieties of figs where the wasp has made its entry.

This is due to the fact that although the greater part of the flowers in the Adriatic type of figs are malformed and therefore cannot be pollinated, there are some flowers in such figs which do take the pollen, and these have perfect seeds.

One point must not be overlooked-that the edible fig grows on an entirely distinct tree from the caprifig. The caprifig serves as a home for the several generations of the wasp, and its figs are not edible. The caprifig produres three distinct crops annually, the first one pushing out on the wood of the previous year's growth in March; the second crop comes on the new wood in July; the third in September. These several crops are designated as follows: Profichi, or spring crop; Mammoni, or summer crop; Mamme, or overwintering crop. The Mamme figs remain on the trees all winter, from September until into the April of the following year, the wasps during this period being in the larvae stage. When the caprifig starts to grow in the spring the wasps pass out of the larvae into the pupae stage, and finally when the Profichi figs are about the size of marbles, which usually occurs in April, the female wasp passes from the Mamme figs and forces her way through the scale of the orifice into the Profichi figs (which to the naked eye is closed) and deposits an egg in the ovaries of the gall flowers. The life history of the wasp in this crop is the same as in the others, the only difference being that the metamorphosis takes place more rapidly. When the erops reach maturity there are both males and females. The males are wingless and are readily distinguished by their reddish tinge; the females are of a lustrous black color and are winged. The male wasp crawls out of the gall first, intuitively locates the female in the gall in which she is confined, gnaws an opening with its powerful mandibles and impregnates her. She then enlarges the opening made by the male and starts on a tour of exploration. Her sole object in life is to perpetuate her species and to do this she must find the flower of another fig to deposit her eggs. As the Profichi crop bears the most important part, in her relation to mankind, for the sake of argument we will take it for granted that the female wasp is coming out of the Profichi crop. As she prepares to take her departure she passes through the zone of male or staminate flowers, surrounding the orifice of this fig, and her body is completely dusted with the pollen grains. In the great fig-growing districts this flight occurs in the month of June. It is in this stage of her existence that the hand of man steps in.

The Profichi figs are gathered from the trees and are distributed in oval baskets made of three-quarter-inch poultry netting or placed in small strawberry or fruit baskets which have been previously hung on wire in the Smyrna fig trees. At this time the Smyrna figs vary in size from a small pea to a large size marble. The wasp forces its way between the scale of the orifice of the edible fig, going into it for the avowed purpose of laying its eggs.

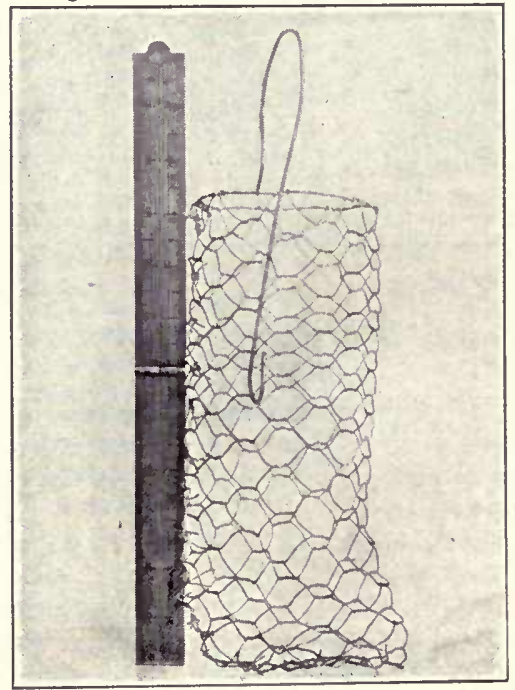

The wire basket which is suspended in the Calimyrna fig trees. In an exceptionally large tree two of these baskets trees. In an excerd be used. 


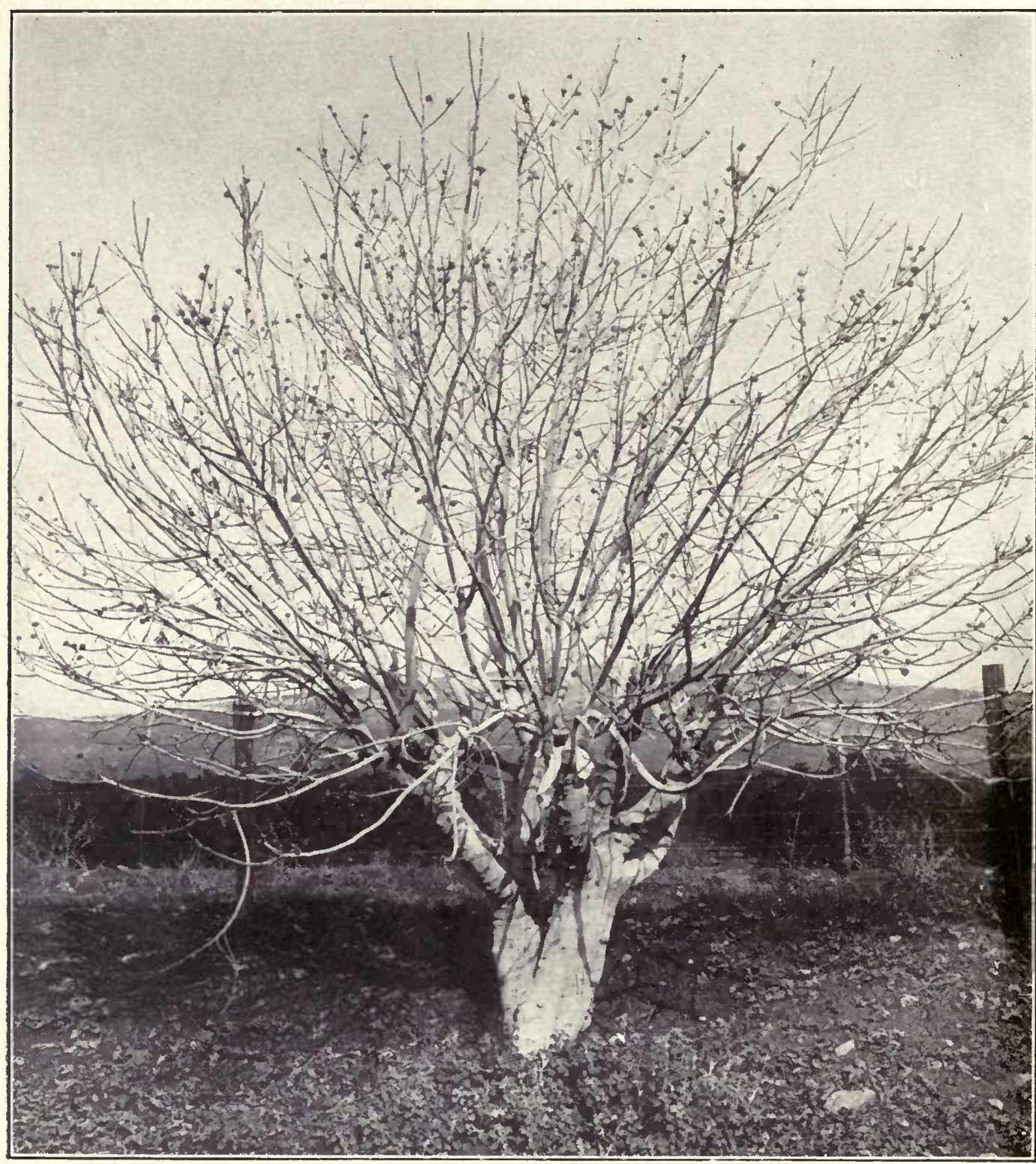

Roeding's Capri No. 3. It has a magnificent crop of Mamme or winter figs. This picturewas taken in December. This was originally a Calimyrna fig tree which was grafted over to this variety of Caprifig three years ago. The handkerchief placed in one of the limbs indicates where this grafting was done.

Fortunately for the fig industry it is frustrated in its efforts to reach the ovaries of the female flowers with its ovipositor, due to their long styles. In its persistent and determined effort to find a receptacle for them it crawls around the inside of the fig and dusts the pollen on the pistillate organ of the female flowers. The insect is exceedingly small and it finally perishes within the fig, being absorbed by its juices, or it crawls out and dies. One wasp is sufficient to pollinate the numerous flowerets on the inside of the fig, but it very often occurs that on breaking open a fig, three to four insects will be found crawling around. Within a couple of days after the wasp has penetrated the fig, its entire appearance changes; it becomes plump and firm and of a deep green color, while the figs on the same tree which the wasp has failed to reach turn a sickly yellow, shrivel up and drop off. Nature again asserts herself in behalf of man, by delaying the pushing out of the Mammoni erop of figs until the season for caprifying the edible figs is practically over. The Mammoni is the lightest of all the crops, and it is very difficult to find any figs of this crop in the caprifig tree until July. There are just enough of the late Profichi figs on the tree at this time to supply wasps for the Mammoni crop.

Growers who fail to secure a good crop of figs on their Smyrna trees have only themselves to blame for not studying their problem, for a light crop is traceable to 
an indifference on the part of the grower in caprifying. There are several varieties of caprifigs, some of which ripen their fruit early, while others are later. As the edible figs are not in the receptive stage at the same time, this is a fortunate coincidence. In order to know how many caprifigs to place in a tree to secure the best results, multiply the age of the tree from its fourth to its ninth inclusive by five, and from ten years and up by ten, and you will not go very far wrong in placing enough figs in your trees to secure the very best results. From three to ten figs should be placed in the trees every third day or even oftener than this. The frequency with which this is done being determined by the rapidity with which the caprifigs ripen.

\section{PLANTING AND PRUNING}

Although the fig will stand all kinds of neglect after it is established, too great emphasis cannot be laid on the close attention which must be given in transplanting the trees from the nursery to the orchard. The roots of a fig tree are very susceptible to exposure, hence they should be carefully covered in transferring from the trenches to the field. It is surprising what effect the puddling of the roots will have in preventing their drying out even in cases of severe winds, and I cannot emphasize the importance of this too strongly. To make a puddle, dig a hole eighteen inches deep, two feet in diameter, fill it partly full of heavy soil, mix with water until you have a muck the consistency of a heavy paint. Dip the roots into this, and give no further concern about their drying out even if exposed to the direct rays of the sun for a short period.

Before planting cut off all bruised and lacerated roots and make a fresh cut on all other roots, so they have a smooth, clean surface. The tree when planted should not stand over three inches deeper than it stood in the nursery row. Never neglect to settle the earth around the trees with not less than fifteen gallons of water. After the water has soaked away fill in with fine soil without tramping. No greater mistake can be made than to wait for rain or for water to be turned into the irrigating ditches. After the tree is planted, cut back to twenty-four inches from the ground, and cover the wound with rubber paint or grafting wax.

The first winter cut the branches of the one-year trees back to about twelve inches, leaving not more than four to make the head of a tree. Have these distributed in such a manner that there will be sufficient room for them to expand without crowding as the tree grows older. The second season cut not less than two-thirds of the new growth, leaving not more than two shoots on each of the framework branches. Any branches on the underside of the limbs having a tendency to droop to the ground should be removed. The third season shorten in the new growth about half, leaving the same multiple of branches on each of the previous years' shoots as were left the year before. In after years the pruning is limited to the removal of branches which cross or interfere with each other and cherking the growth of branches, making an excessive growth. Young trees should always be protected with tree protectors to prevent sunburn.
None of the edible types of figs, whether they be of the Adriatic or Smyrna class, should be planted closer than thirty feet. In Asia Minor orchards which have been planted within the last forty years are set in the square system and none of the trees are planted closer than thirty-five feet apart.

\section{FREEZING TO THE GROUND}

If the trees have made a very strong growth during the summer months and they should (due to severe cold weather) berome so badly injured that they freeze down to the ground, the entire top should be cut off to a point

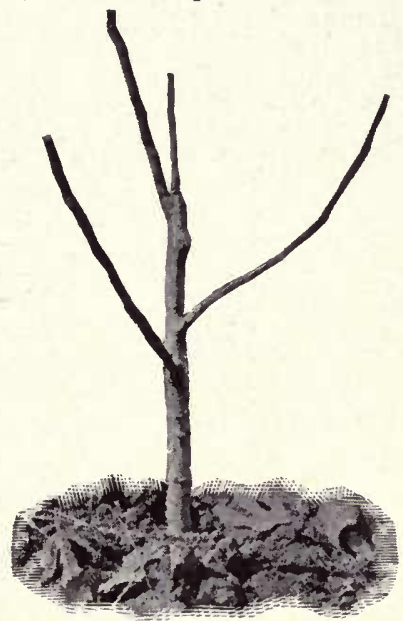

A one-year-old orchard grown Fig tree with the framework branches properly distributed around the body of the trec and cut back to promote sturdiness and develop a head.

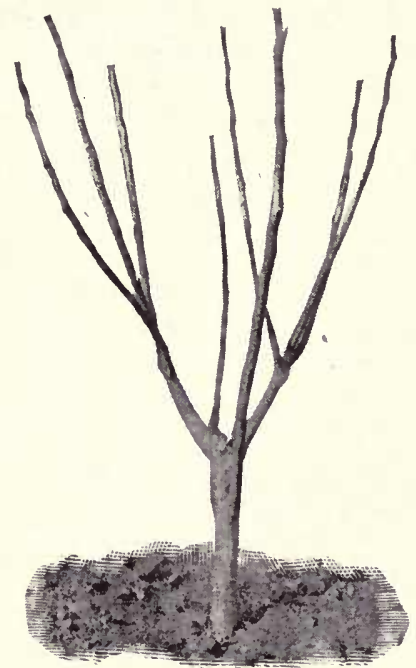

A two-year-old tree with laterals cut back. Note that_this tree is already assuming a shapely head.

where the body shows no injury, just before the new growth starts out in the spring. A number of suckers will start from the body and all of them should be permitted to grow. In June all excepting the strongest ones should be removed and these should be tied to a 2 in. $x$ 2 in. $x 6 \mathrm{ft}$. stake, and whenever the sucker reaches the height of three fcet cut the top off to two feet from the 


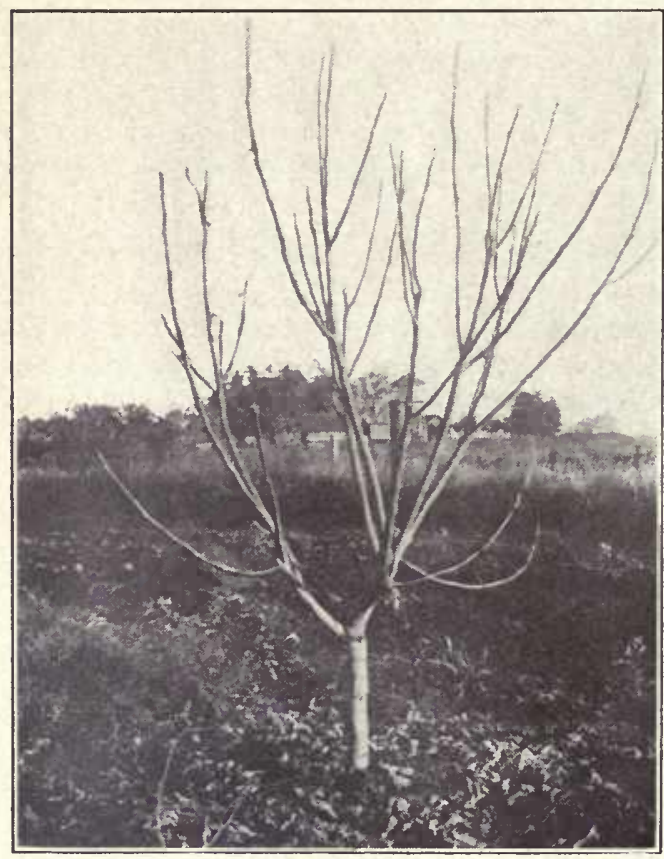

A three-year-old tree showing its current year's growth.

ground. This will cause it to send out lateral branches and the head will be formed at this point. Bear one point in mind-that fig trees are always grown from cuttings and, therefore, when they start again from a sucker growth the variety will be the same. Much of the difficulty from freezing may be prevented by cutting off a third of the tops of the trees in November, and then wrapping the tree with corn-stalks or tule. This should be done first by driving a stake not less than six feet long, a foot into the ground. Then make a circular trench three feet in diameter around the tree. Place the butt ends of the stalks in this trench and fill in with soil. This holds them in place. Bring the ends of the material used to protect the tree at the top of the stake and then tie them together by means of a rope. This covering should remain until about the middle of February, when it may be removed.

\section{PLANTING CAPRIFIG TREES}

It requires one caprifig tree, when planting an orchard in a commercial way, to twenty-five Calimyrna trees. These should be planted in a group by themselves in a protected part of the orchard and never closer than twenty-five feer apart. They may also be used to advantage as border trees. In planting it is a very good plan to mix the varieties, for by doing this, in the event of one variety being short of infested figs and another one immediately adjoining having a good crop, the supply of insects for any succeeding crops necessary to perpetuate the wasp will be available. In explanation of this I desire to call attention to the fact that it frequently happens that Roeding's Capri No. 2 is short of the Mamme or overwintering figs, and in order that Profichi crop appearing on the tree in the spring should become colonized with wasps, it is necessary to suspend figs from either the Roeding No. 1 or 3 for this purpose, in the No. 2 variety. If either one of these varieties of figs happens to be in elose proximity, it is not necessary to go to this trouble. The caprifig makes a very desirable shade tree, and as there is no mess from the d:opping of the figs, growers will make no mistake in planting them around their homes. The additional protection from the buildings is a valuable asset in years when low temperatures prevail during the winter months. The Mamme crop will stand a temperature of twenty degrees Fahrenheit without injury, but anything lower than this, particularly over a protracted period, will freeze the figs on the outside branches.

\section{GATHERING}

Whenever you see figs and cream on the menu, does it not make your mouth water? There is probably no place in the world where figs may be harvested over a longer period than California. This is made possible by the diversity of climate and lack of rainfall from May to October. The first crop of figs is gathered in June. These figs are not as well adapted for drying as they are for shipping fresh. The second crop which commences to mature in the fig sections in the latter part of July, continues to ripen its figs until quite late in the season. In the southern part of the state ripe figs may be picked as late as December. One of the advantages of localities where temperatures are moderate is that the figs ripen more slowly and for this reason shipments may be made for a much longer period. Figs for shipping purposes must be gathered when they are still firm and are cut off the tree. They are shipped in crates, either packed in single or double layers with papers between. These should never exceed ten pounds in weight, and years of experience leads me to believe that single layer packages are by far the most satisfactory. I have demonstrated to my own satisfaction that it is entirely practicable to pack figs in kegs using redwood sawdust as a preservative.

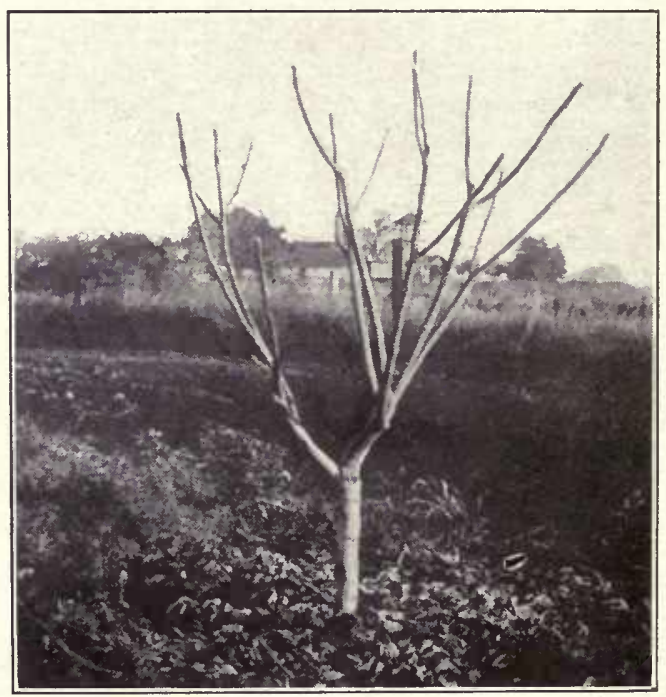

The same tree cut back and thinned. This method of pruning develops trees such as you see in the picture in the introductory chapter on the Fig. 


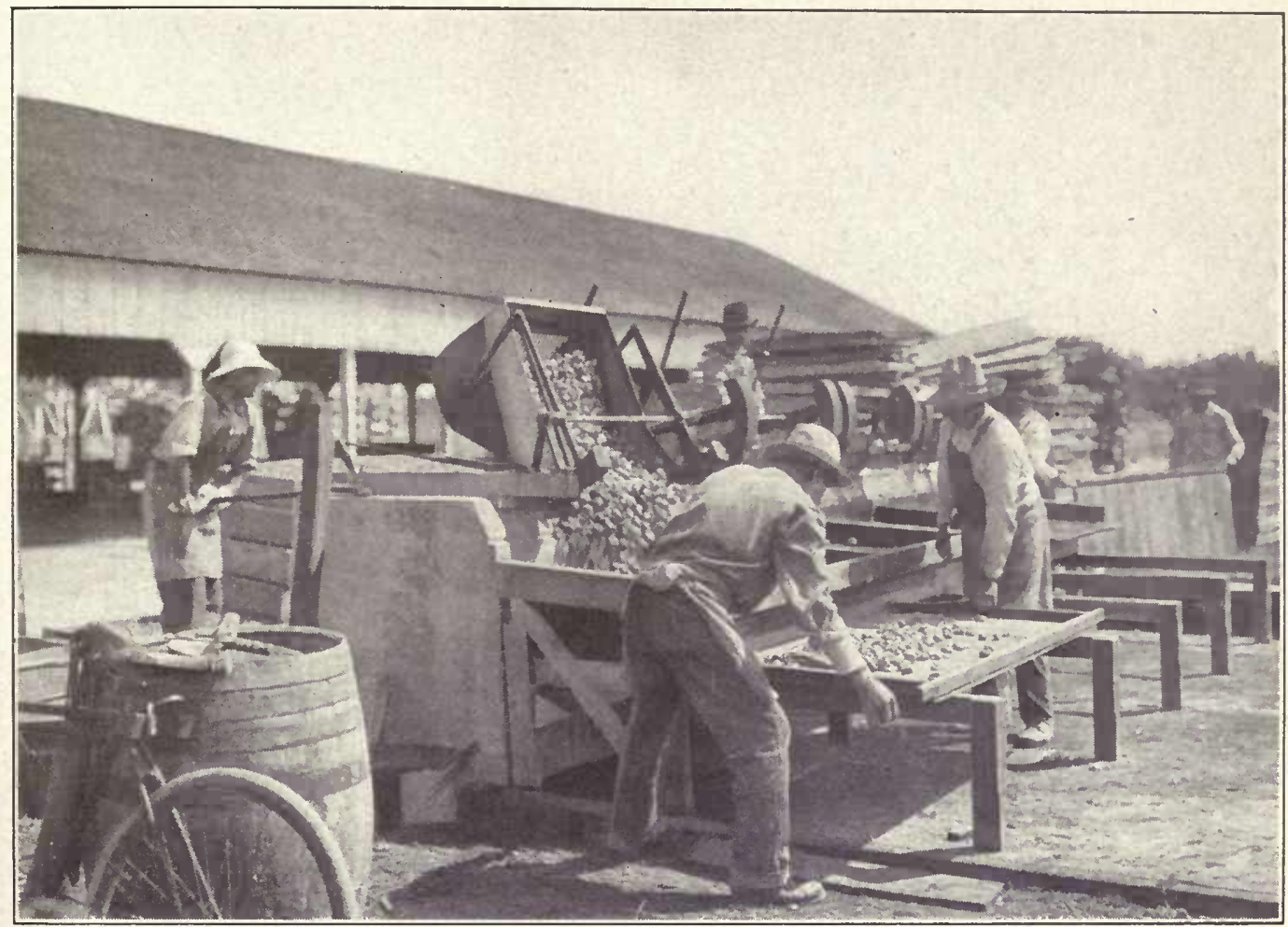

Washing and cleaning the dried Calimyrna Figs in a salt and baking soda solution.

The advantage of handling figs by this method is that they may be picked much riper than when shipped in crates. They will keep from four to six weeks in prime condition if placed in a refrigerator, where the temperature is maintained from 32 to 36 degrees Fahrenheit. This method of handling has many advantages for restaurant or hotel use, because the figs may be taken out as required from the package without disturbing any more of the figs than are actually needed. The sawdust has a tendency to lacerate the skin, so before placing them in the packing material, they should be wrapped with tissue paper, the same as is used for other classes of fruits. California will be the Mecea for preserved figs some day. Texas, with its many disadvantages for growing figs, has been marketing preserved figs for years. Practically all the preserved figs sold in California come from Texas. It is hard to understand why the canners of this state have not engaged in this industry. I predict the time is not far distant when Californian preserved figs will be as famous as our canned peaches, apricots, and other fruits. Figs for preserving should be picked in the same condition of ripeness as those used for shipping.

\section{GATHERING AND DRYING FIGS}

Go through the entire category of dried fruits and the fig stands in the lead of being the most inexpensive one of all the fruits to handle. Figs that are to be dried are:allowed to drop to the ground. The trees are given a good shaking and all the figs ripe for drying drop off. When the fig is fully matured, it loses its shape and hangs down in a more or less shrivelled condition. The figs are gathered from the ground in buckets by either women or children and are then dumped into the lug boxes holding from forty to fifty pounds. These are hauled to the drying ground and the figs are spread out on trays. There is no better place for drying figs, or any other fruit for that matter, than a section of an alfalfa field. As the figs are almost half-dried when they drop to the ground they require but very little exposure to the sun when placed on trays. At the outside they are not exposed for more than a couple of days, when the trays are stacked so as to permit a circulation of air through them. The drying proceeds in the shade from this time on. Whenever the fig feels leathery when squeezed between the fingers, it is dried enough. Avoid over-drying, as this more than any other one thing, causes the skins to be tough. The next step is to dip the figs in a salt brine made by dissolving four pounds of salt and one-half pound baking soda in a gallon of water. The solution should be cold. If hot water is used it darkens the figs. A cement trough equipped with perforated iron buckets, with a lever to raise these buckets up and down, is used, and the figs are dumped on the trays after they have been rinsed. This is by far the best and most economical equipment. The washing of the figs continues over a period of ten to fifteen minutes, depending on the condition of the fruit. The figs are now placed on trays and sulphured. Calimyrna and Mission figs should be sulphured for three hours, the White Adriatic from five to six hours. After sulphuring, the trays, loaded with figs, are again 


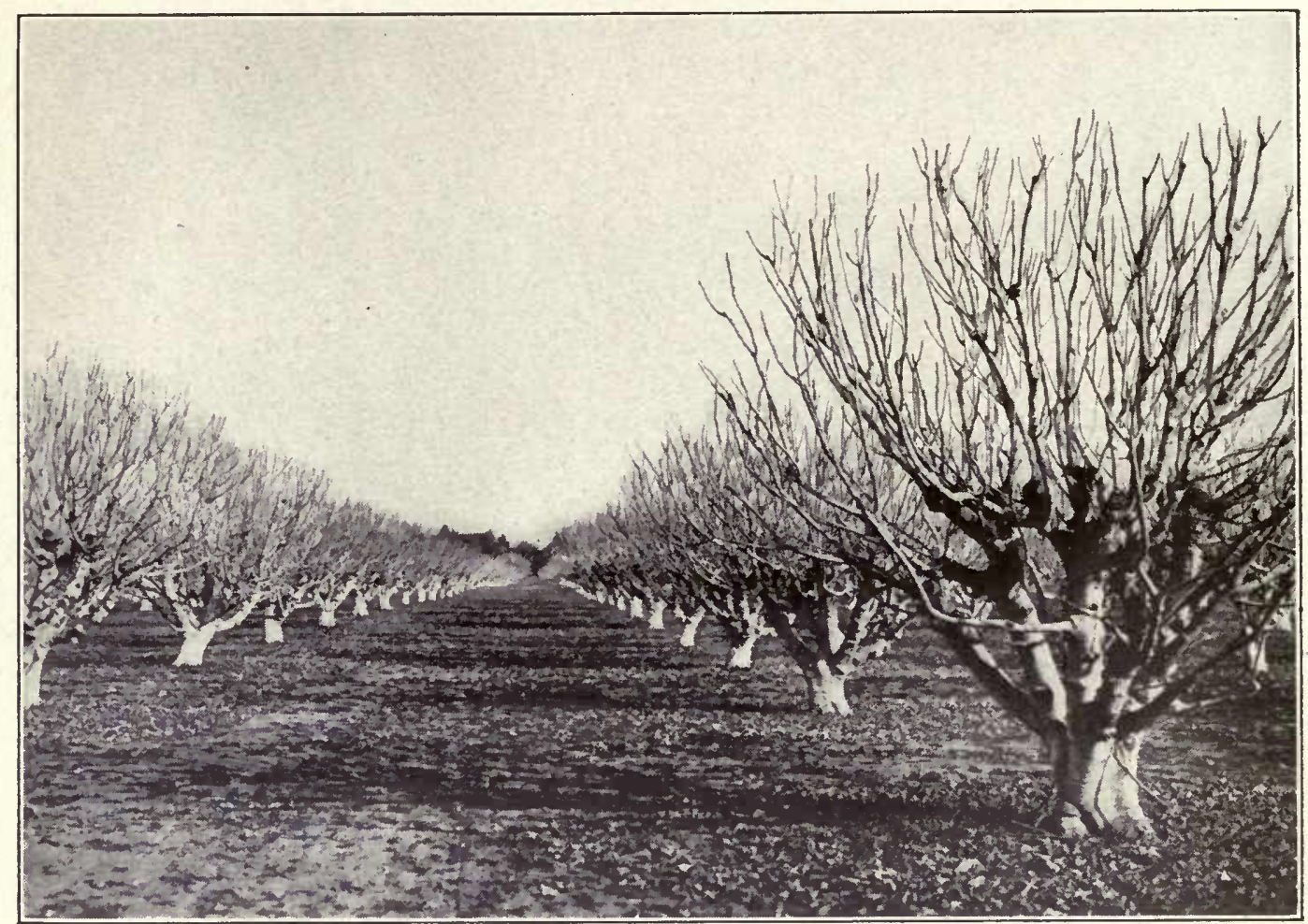

Note the tree in the foreground. These trees were beheaded four years previously. This picture was taken just after pruning. Notice the sturdiness and the thrifty growth of the lateral branches. The figs produced on these trees are all of the largest size and finest texture.

placed in the sun for a few hours until the moisture on the fruit has evaporated, when the trays are again stacked. Within two days, if the weather is warm, the figs are dumped into sweat boxes and are hauled to the nearest packing house. Here they again go through a series of processes consisting of grading, washing, steaming, for the purpose of cleansing them and destroying all insect life. Under normal conditions the expense of gathering the figs, hauling them to the drying ground and putting them through the several processes described, does not exceed fifteen dollars per ton for the dried product.

\section{IRRIGATION}

A furrow plowed on each side of the trees and about three feet from them, will carry all the water and will irrigate all the ground which it is necessary to cover during the first two years after planting. The trees should not be irrigated more than four times and not less than twice during the growing season. Cultivate well after each irrigation. Never irrigate after August unless the tree gives indications of drying up. Late irrigating promotes new growth to such an extent that the trees do not harden up as early in the fall as they should, and in consequence of this they are damaged by frost. When the trees are five years old two irrigations is all they require during the growing season. The time to do this is in May and then again in July. The latter irrigation may be dispensed with if the trees are making a thrifty growth.

\section{CROP SURE-NO FAILURES}

The certanty of the crop is indicated by the policy pursued by the packers of dried figs, who make it a practice to purchase the entire output of an orchard extending over a period of years at a fixed annual sum. The prices paid depend largely on the size of the trees. The contractors assume all the expense of harvesting, the grower merely prunes and cultivates his orchard under this arrangement. The importations of Smyrna figs are constantly increasing, the annual amount averaging not less than 13,000 tons. This fact in itself, with the favorable conditions existing in many sections of the Pacific Coast states is sufficient indication of the possibilities of this great industry.

\section{VARIETIES OF FIGS OF COMMERCIAL VALUE}

Calimyrna, Mission, San Pedro White, White Adriatic, White Endrich (Kadota.)

\section{VARIETIES WORTHY OF TRIAL}

Agen, Bardajic, Black Ischia, Bourjasotte Panache, Brown 'Turkey, Brunswick, Col di Signora Nigra, Dauphine, Doree, Drap d'Or, Kassaba, Lardaro, Pastiliere, Ronde Noire, San Pedro Black, Verdal Longue, White Celeste, White Genoa, White Ischia, White Marseilles.

\section{VARIETIES OF CAPRIFIGS}

Magnissalis, Milco, Roeding No. 1, Roeding"No. 2, Roeding No. 3. 


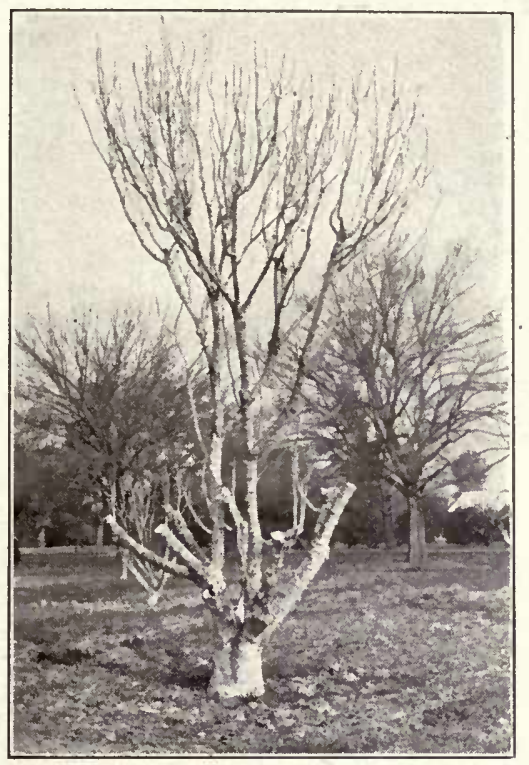

An old Fig tree cut back for the purpose of developing a new head. The branches in the center are left to shade the cut-back section. They are eventually cut off in the same manner as the others were. The new growth appearing on the framework branches must be shortened in very severely for several years. The stumps should be sawed off as far as possible to a common point from which several new branches have started. Be sure to paint the stumps new branches have started. Be sure to paint the stumps over with coal tar. Cutting these stumps close to where the new growth starts causes the cambium layer the sap wood. The trunk of the tree should be given a coating of thick whitewash not later than May. It is a good plan in addition to this to wrap the body and main branches of the tree with burlap to prevent sunburn.

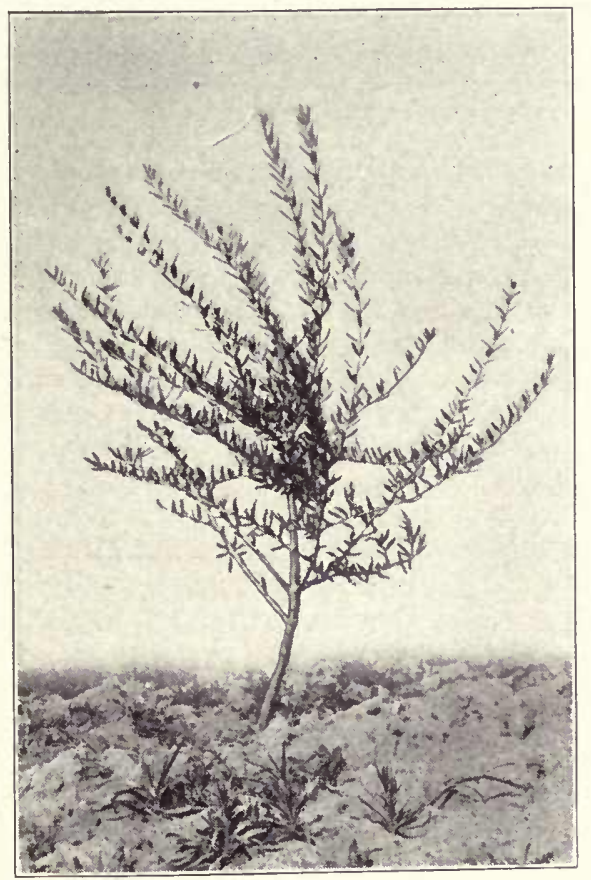

A one-year-old Olive tree with its entire seasonal growth.

\section{THE OLIVE}

In California the olive has long since passed the experimental stage and is now being produced in quantities for pickling and oil purposes. The important position that it is destined to occupy as one of our leading horticultural industries can no longer be questioned.

California possesses the same soil and climatic conditions in which the olive thrives in the countries of Europe, Asia and Africa, and there is absolutely no obstacle to prevent our supplying the demands of not only this country, but becoming exporters of the numerous products for which the olive is noted.

The two countries which stand out most prominently as producers of olives are Italy, famous for its oil, and Spain, for its green pickled olives. In Italy there are $2,688,738$ acres planted to olives, and according to reliable statistics Spain has 3,546,515 acres. There are many insect pests threatening the olive in those two countries, which frequently curtail the output. There is very little likelihood of any of these pests or diseases gaining entrance into California, because we have all the leading and best European varieties growing here already. We have hundreds of thousands of acres, extending almost from the northerly to the extreme southern part of the state, in which olives can be successfully grown.

\section{PICKLING THE OLIVE}

The ripe pickled olive is pre-eminently a California product. People who never eat the green olive, and those who do, have to acquire the taste for them, take to ripe olives as a duck does to water. Those who are engaged in the manufacture of olive pickles. encounter only one difficulty, and that is to secure sufficient of the ripe olives to satisfy the demand of the consumer.

Every home should have an olive tree where there is sufficient ground, for one tree will supply all the olives which the average household will use for several months.

\section{PLANTING}

Today the transplanting of olive trees is comparatively an easy matter to what it was twenty-five years

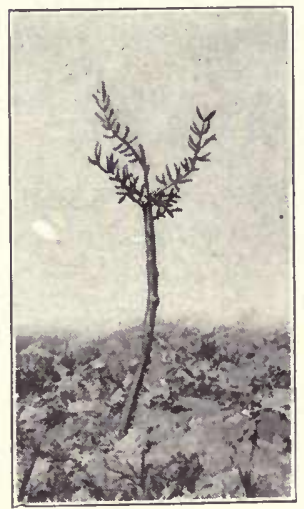

Same tree with branches shortened in, permitting shoots with an upward tendency to remain ago, when the industry was just beginning to attract the attention of horticulturists. At that time the trees invariably died unless they were potted plants. After years of experimental work the cause of the trees failing to grow was found to be due to not topping the trees and shortening in the lateral branches when digging. This method of trimming overcomes much of the evaporation and loss of vitality through the foliage and much of the trouble formerly experienced has been overcome. In nearly all cases where trees fail to grow the 


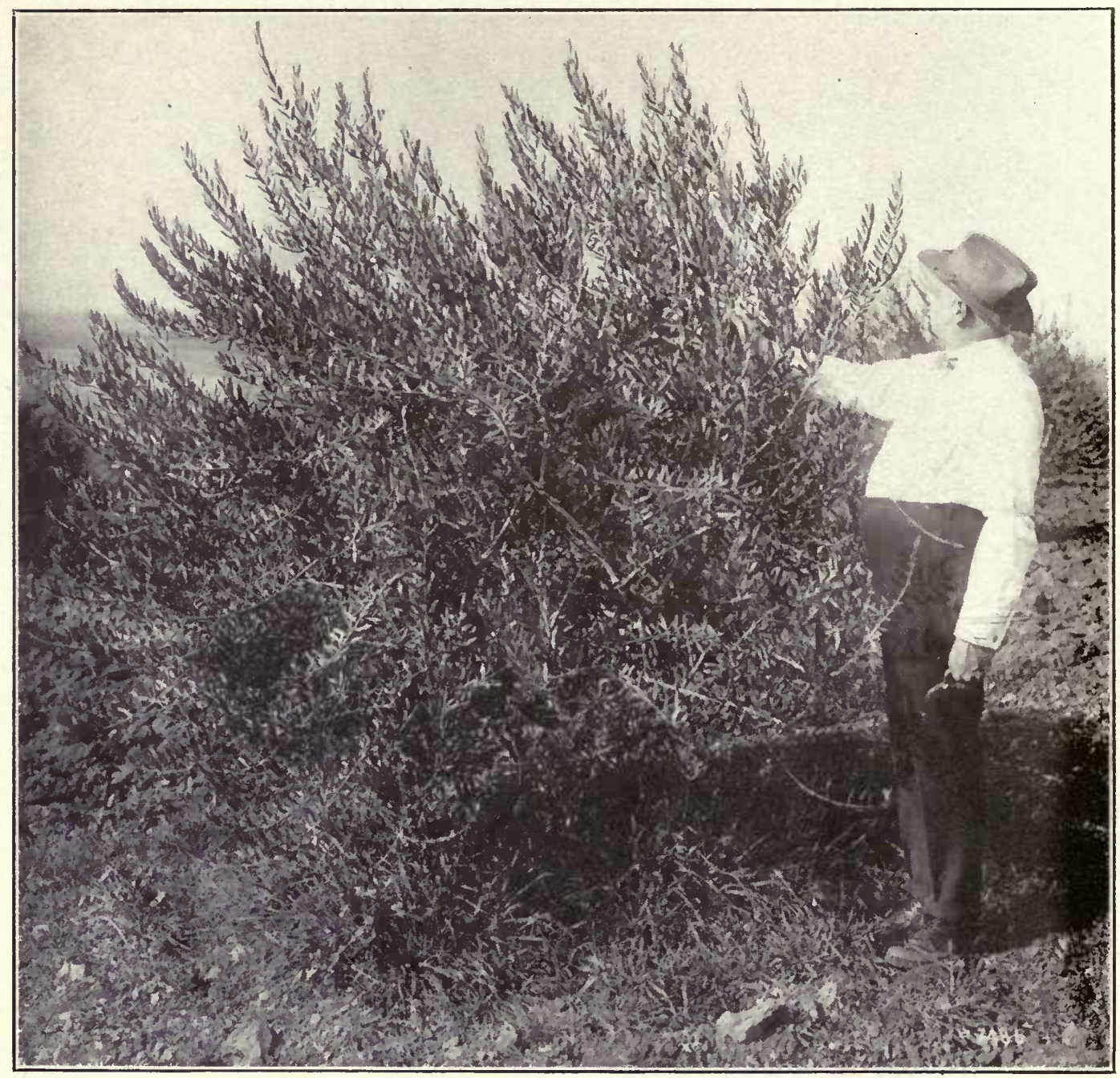

A three-year-old Ascolano Olive tree, making a fine, uniform and healthy growth.

trouble can be traced back to not again cutting the trees back after they are set or to careless handling on the part of the planter after the trees are received.

In order to insure the best results for the orchardists, the trees should be top-pruned and all the lateral branches should be shortened before shipment from the nursery. This method of trimming overcomes the evaporation and loss of vitality through the foliage, and is a very important point.

Olive trees should not be transplanted until the middle of February, for it is only in a few places that the growing season starts in earlier. When received at destination take them out of the receptacle in which they are packed and heel them in a sandy, warm soil and then turn a hose loose in the trench so that the soil will fill in all interstices and exclude the air. After the soil is settled fill in with loose soil and tramp it down. The trench should not be less than fourteen inches deep. The trees should stand upright rather than at an angle. Treated in this manner they will remain in perfect condition until the ground is in shape for planting. As soon as they are taken out of the trenches and prior to planting, all bruised and lacerated roots should be cut off and a new, clean cut made on all the other roots. Before taking out to the field, puddle the roots in the same manner as is recommended for the fig. This particular phase of the operation must not be overlooked. Dig the holes to receive the trees as recommended for the general run of deciduous fruit trees and follow the other directions faithfully. Do not fail to cut the trees back to two feet after being planted and shorten all laterals to two inches. If there should be no laterals, cut the trees back anyway, for the olive will always force out its blind buds.

Olives may be taken up in the late fall or in midwinter, provided they are dug with a ball of earth. The trees start more quickly than those taken up with naked roots and almost a perfect stand of trees is assured. There is considerable additional expense entailed in digging and packing and in railroad charges, for a balled olive tree will weigh at least thirty pounds.

The theory that olives can be grown successfully on poor, rocky soils has been exploded long ago. It is a fact that olive trees are found growing in such soils in 


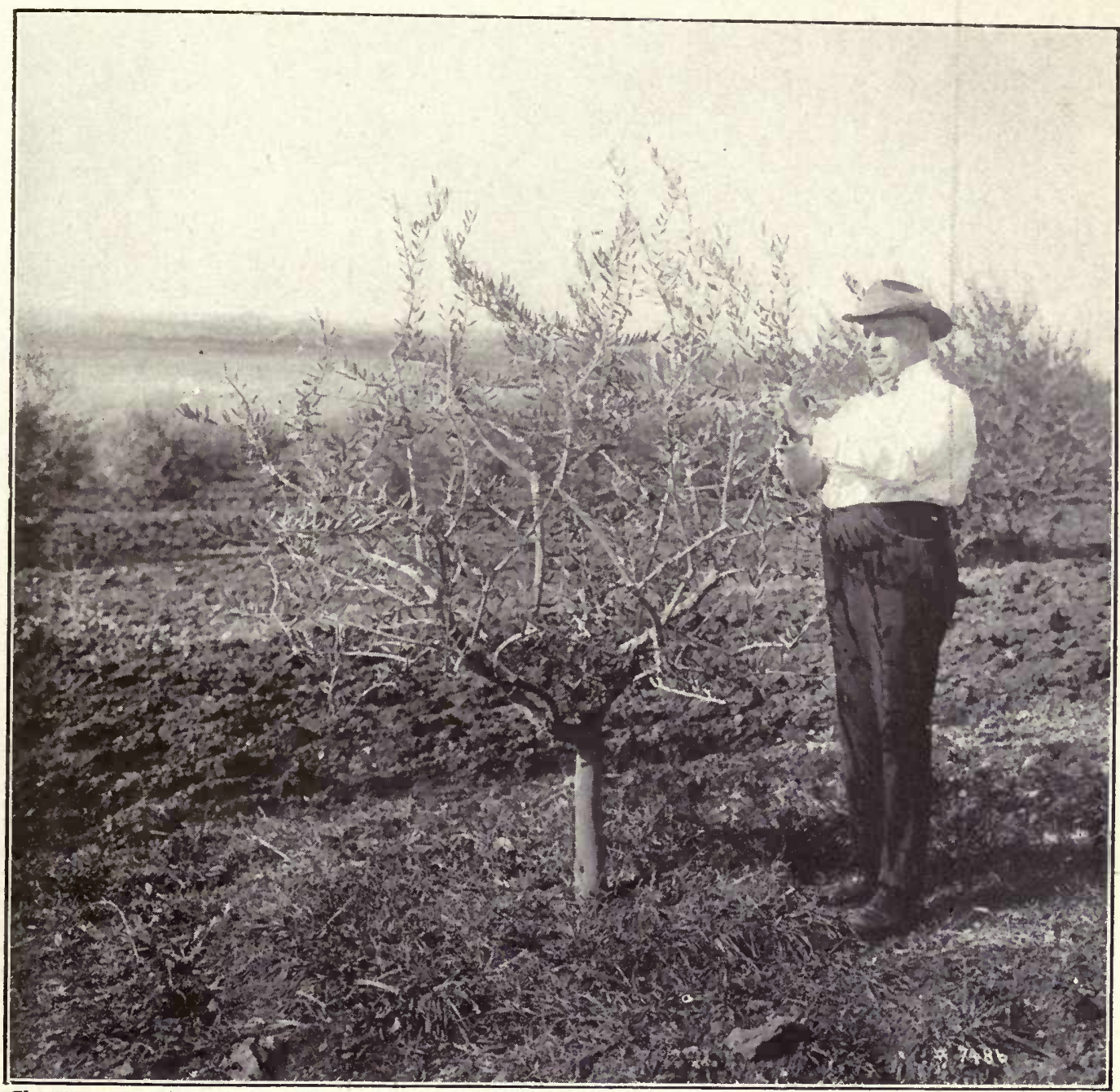

The same tree with many of its branches thinned out, and the laterals and top growth properly pruned to develop an ideal tree.

many countries of Europe, as I know from personal observation, but this does not indicate that olive culture is a success in such soils. The trees usually are scrawny, entirely lacking in the essentials which go to make a perfect tree, and would cause the orchardist accustomed to the fine, luxuriant trees grown in California, to have heart failure if he had such prospects before him.

Do not make the mistake of planting the trees too closely together. The olive is a gross feeder and sends out a mass of small surface roots. Never plant closer than thirty feet in a good, loamy soil, and forty feet apart on rich deep soils. A deciduous tree may be planted between, at this latter distance if it is desired, with a view of taking it out as soon as the olives attain any size.

\section{PRUNING}

When the tree is planted it should stand at least four inches deeper than in the nursery rows. Allow the tree to grow without much interference the first year, for the more vigorous the new growth and the more of it, the stronger will be the root development. The first winter after planting trim all the growth off except four or five branches close to the head, and have these properly distributed, as they will ultimately form the main framework branches. Cut off two-thirds of their growth. The second winter trim the tree in such a manner as to leave from one to two laterals on the original framework branches, bearing in mind that these branches should have an upright tendency and cut them in turn back at least one-half. In subsequent years this same method of thinning out and shortening in should be followed, and this cutting should be quite severe for at least four years. The workman should not always prune to an outside lateral, but should exercise some judgment to balance the tree by causing some branches to slope inwardly and force others to have an outward tendency as illustrated in the cuts. Pruning promotes sturdiness in the tree, a healthy, uniform growth and a broad-bearing surface. This last fact is shown by the growth of many lateral fruit-bearing branches. A tree with its growth unchecked would consist of several upright shoots with the fruit-bearing branchlets in the top. 


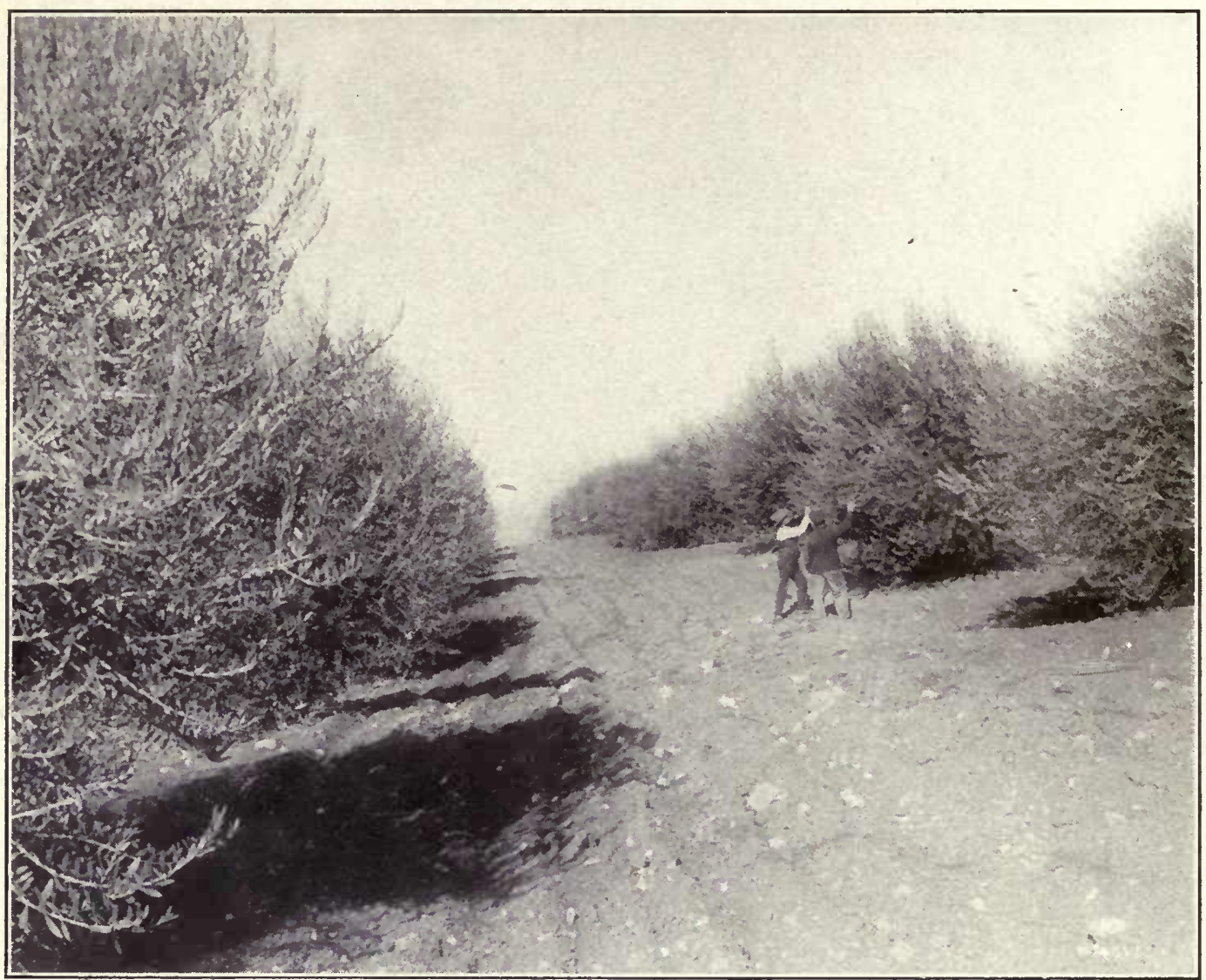

This is a section of a sixty-acre Mission Olive orchard, belonging to the author, located near Exeter, Tulare County. These seven-year-old trees amply illustrate the results obtained by a systematic method of pruning.

In case of a heavy crop these branches, being without any natural braces, which would have developed by pruning, will bend over and in many instances break off. After a number of years the shearing off of the small laterals will cause many so-called "crow's-nests" to form in the trees, and the new growth will be rather weak. It will be at least fifteen years before the trees will reach this stage, but when they do there should be no hesitancy in cutting them back severely and thinning vigorously, to promote a strong, new growth. Even before this age the trees will have a large amount of inside growth, which, when it is no longer productive, should be cut out entirely. This does not mean necessarily that the trees should be thinned out like a peach, for this would be a mistake, but that wood which indicates by its appearance that it has lost its vitality should be removed, for it will soon be replaced by new wood.

\section{STOCKS}

It has been the prevailing practice since olives were planted in California to raise them from cuttings. The trees planted by the Mission Fathers in San Diego in the year 1769 were undoubtedly started from cuttings or possibly from truncheons. What is a truncheon? It will be observed that old olive trees have large protuberances on the body of the tree. If these are gouged out with their woody fiber ard planted with the rough- wood side down and about eight inches below the surface of the soil, every one of them will grow. Numerous sprouts will start from this knob, all of which after they are three feet high should be removed, leaving one. Cut this back to two feet from the ground for the purpose of starting a head at this point. The same method was unquestionably followed in growing the trees in later years. They were not, I am quite sure, started from seeds, although some writers claiming a great variation in the Mission olive say it is due to this fact. The same statement might have been made in behalf of the Mission fig. As a matter of fact the seeds of all figs were hollow until the fig wasp was introduced and established in the author's caprifig trees in 1899 . In my many years close study of the olive, I have never seen but one variety of Mission olive. The practice in California for over twenty-five years has been to grow olive trees from soft tips, which are rooted in a greenhouse in sand. Practically all the commercial orchards in California have been started from trees grown in this manner. Quite a number of varieties are difficult to root by this method. In fact, with the Sevillano and Ascolano it is next to impossible to secure a stand with cuttings. Whether the trees grown from the seed of the Redding Picholine and Chamlaly and budded, are any better is an open question. The claim is made that the trees have a better root system 
and will withstand heavy winds better than those raised from cuttings. I have my grave doubts about this, but as the rooting of many varieties under the old method is fraught with so many difficulties the plan of raising seedlings and either budding or grafting them will appeal to every nurseryman.

\section{GATHERING}

For making the green pickles, olives should be gathered just as a change from a light greên to a yellow shade is seen. The development of the olive industry in California has been largely due to the remarkable success which has been made in the processing of the ripe olive. As there is quite an active demand and inore than likely there always will be in many parts of the world for green pickled olives, it will make it imperative for those engaged in the business in a commercial way for market to process them in any manner in which they may be demanded by the trade. One of the advantages of the green pickled olive from a grower's standpoint is that in years of very heavy crops, when the trees are overburdened with fruit, the olives are very slow in ripening, and this may be delayed so late in the fall that the olives become injured by frost and this unfits them for pickling purposes. If the trees are thinned by picking a good part of the olives early, those remaining will not only size up but will reach maturity within a few weeks, where it will extend over a period of several months if all the olives were allowed to remain on the tree. In picking olives care should be taken not to press them together when gathering. The bucket into which the olives are picked should be lined with burlap. The lug boxes which are used to carry them from the field should never be more than two-thirds full. If the olives are to be kept for any length of time before they are processed or are to be shipped by rail, they should go forward in barrels in a brine made by dissolving three ounces of salt to a gallon of water. When handled in this manner they will keep for several weeks in the very best of condition. "Whether green or ripe, this is the only practical way of shipping olives. An olive is ripe whenever it reaches the point where its surface is more or less diffused with red. It is not an invariable rule to follow, because in years of very heavy crops, when the olives are allowed to hang on the trees, the fruit may never rea.h a point beyond showing a light straw color on one side. Such olives are ripe. The expense of gathering olives for pickling purposes varies from eighteen to twenty-five dollars per ton, depending on the crop, labor conditions and so forth. For making oil it is not necessary to exercise the same care. The olives may be pulled off the trees and allowed to drop to a canvas spread under them. In shipping, it is practicable to forward them in sacks. Should they be on the road for any length of time, it is important to have the car well ventilated, otherwise they may mold. This may be overcome and the weight may be very materially reduced by spreading them out on a wooden floor under cover and turning them occasionally before shipping. They should never be spread more than six inches decp.

\section{METHODS OF PICKLING}

How to make our green olives when turned out as a finished product compare favorably with the imported goods was the desideratum we all aspired to thirteen years ago. Information from Spain and Algeria, the two points from which practically all of our green olives came, was so misleading that men who were experienced in this class of work knew that if the instructions given were followed the olives would be ruined.

In order to make green olives similar in appearance and flavor to the imported olive, the process extends over a period of several months. Briefly, the process is as follows: First the olives are graded and sorted, being reasonably careful to get the olives that are to be treated of a uniform size. The olives should be covered with a solution made by dissolving three ounces of lye in a gallon of water. It takes from eighteen to twentyfour hours to out the olives the desired depth-about one-third through. The rapidity of the cut depends on the condition of the fruit. Stir the olives occasionally while processing, to get them to cut evenly and to retain a uniform color.

The best implement for stirring is a shovel made the same shape as an ordinary shovel, except that the blade and handle are all of wood. After the olives are cut to the desired depth wash them in fresh water each day for about five days, or until all lye has disappeared. Then cover the olives with a brine made by dissolving four ounces of salt to the gallon of water for a period of, ten days, gradually increasing its strength. The olives will not shrink after they have taken a little salt. Fill the barrels full of olives, head up in a thirtydegree or ten-ounce brine and roll the barrels, bung up, into an open shed. Do not drive the bung too tight. Every few days following this, examine the barrels carefully and if the olives are not fully covered with brine, replenish with a thirty-degree brine solution. After the first month, the barrels will not have to be watched so carefully, but they should be examined at least twice a month and the brine solution should be replenished if necessary. As soon as fermentation is practically over, the barrels should be bunged up tight. They require no further attention after this except to examine them occasionally to see that the brine has not leaked out.

\section{HOW TO MAKE OLIVE OIL}

When the olives are received at the packing house they are run through a fanning mill or an aspirator to remove all dirt or leaves. The olives are next crushed between heavy corrugated iron rollers, operated by power machinery. In crushing, the pits as well as the pulp of the olives are reduced. It has been found impracticable to do otherwise, and the statement that has been made that an inferior article is produced when the pits are crushed is a fallacy, just as much so as that the virgin oil comes from the first pressing. This is good trade talk, but is never carried out in actual practice. The first pressing is usually light and the resultant produce is practically all water, very little oil. 


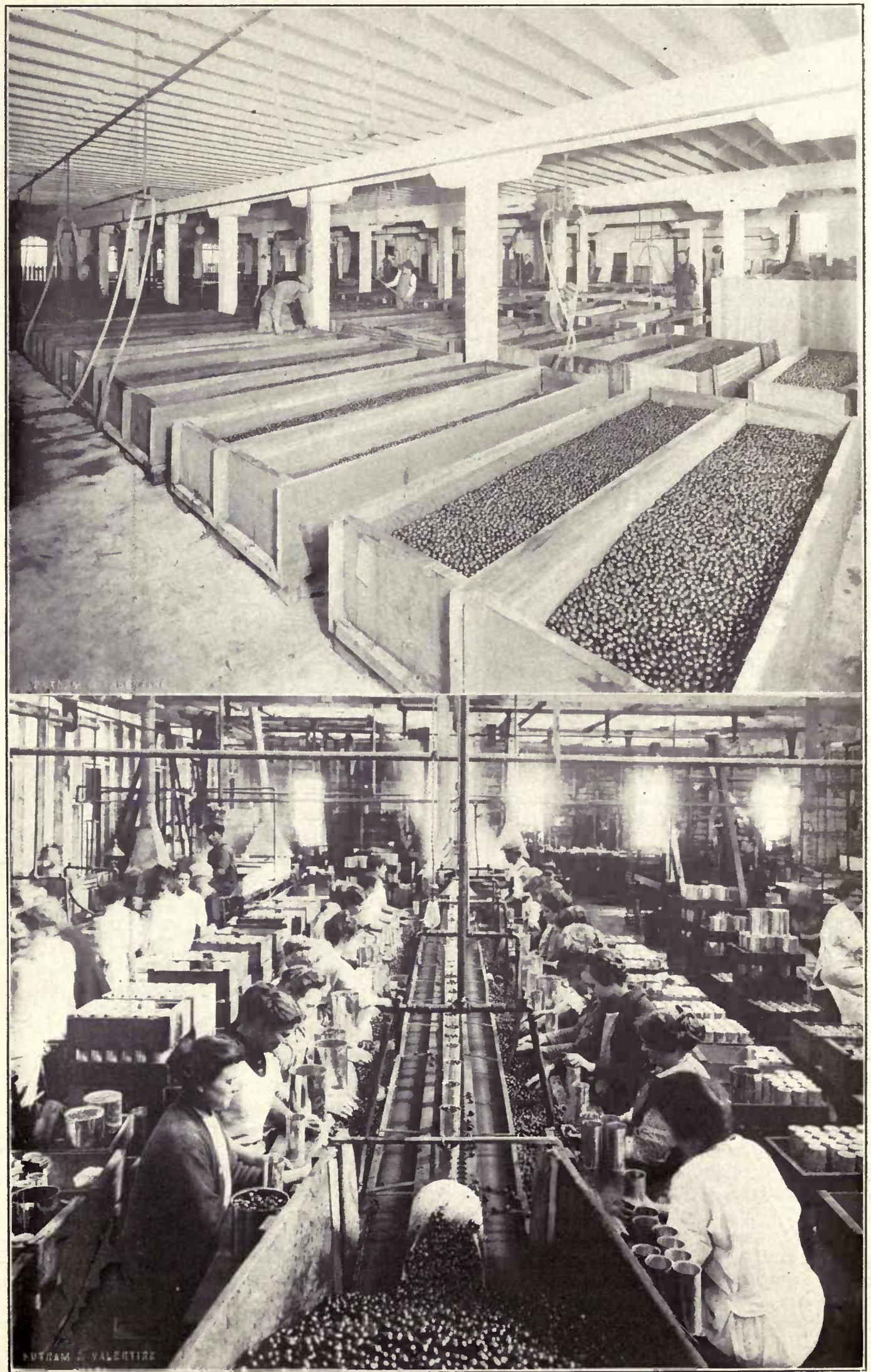

Upper Picture-The model olive plant of the Los Angeles Olive Growers Association, showing the vats used for pickling ripe olives.

Lo zer Picture-Women sorting olives, picking out all defective fruilt preparatory to processing. 
Before making the second pressing the romace is again crushed and is then placed in a large press which exerts a pressure of about two hundred pounds to the square inch. This is followed by another crushing and pressing, the pomace having been previously heated so as to cause it to more readily release the oil. Previous to placing the pomace in the press again, however, it is worked up by the rollers. The oil and water from the presses is run into settling tanks. Here the oil remains for forty-eight hours, when it is skimmed off into storage tanks, remaining in same until ready for racking. These tanks are usually built of galvanized iron, although some of the large olive oil concerns use glass lined tanks for storage purposes. After the oil stands in the tanks for six months it is ready for bottling. The oil goes through a sort of fermentation during this time, and all impurities settle to the bottom. Before marketing the oil is filtered through several thicknesses of filtering paper to still further clarify it. California oil makers take great pride in the purity of their goods, and the oil can be relied upon as strictly pure-just as represented.

\section{RIPE OLIVES FOR HOME CONSUMPTION}

Place olives in any wooden receptacle or earthen jar. Cover them with water, being careful to use water which has been cooled by the night air. After one day's soaking in this water draw it off and cover the olives with water in which two and one-half ounces of lye to the gallon of water have been dissolved. After pouring this over the olives stir them carefully for fifteen minutes, and after that every half hour. If after fourteen hours the lye solution becomes neutralized, slowly add lye at the rate of one-half ounce to each gallon of water. Allow the olives to remain in the solution until penetrated half way through. Draw the lye solution off and wash olives thoroughly until the water is clear. Change water twice daily for four days. Treat olives again as before until penetrated almost to the pit. Rinse as before, and immerse olives in fresh water, changing twice daily until all trace of lye is removed. Now, cover olives with a brine made by dissolving four ounces of salt to the gallon of water, changing the same every four days for twelve days, being careful not to increase the strength of the brine. Draw off old brine and replace with new, gradually increasing its strength until it is up to eight ounces of salt to the gallon of water, when the olives will be ready for the table. It takes fully six weeks to cure them by this method. Use a good grade of half-ground salt.

\section{COMMERCIAL PACK}

Olives are soaked in a three-ounce brine for a week; until fermentation sets in, as less time is then required in processing. This is followed up by placing them in a vat and covering with a solution containing two and one-quarter ounces of lye to one gallon of water. While in this solution the olives should be stirred occasionally and they should remain until the lye has penetrated to within one-third of the pit. This takes from ten to eighteen hours, depending upon the condition of the fruit. Draw the lye off and replace with a four ounce brine for forty-eight hours. Never use fresh water at this time of the processing. Draw off brine and expose to the air for a period of four days until the olives become darkened and the flesh takes on a brown shade to the pit. Now cover again with a solution containing one ounce of lye and three ounces of salt for a period of twenty-four hours, and stir as before. Draw off liquid and expose for two days until color is set. Should olives be bitter, treat again with the lye and salt solution about the same period, exposing as before. Follow this up, covering the olives with fresh water until the lye is out, changing the same five or six times the first day and daily after that until all trace of lye is removed. Then cover with a six-ounce brine for five days or longer without changing until by tasting they give indications of having taken the salt. They are now ready for canning. This brine should not be changed until the olives are canned, when a fresh brine, containing four ounces of salt to a gallon should be used.

\section{CANNING RIPE OLIVES}

After.the olives are in cans they are run through an open exhaust, lids off, registering 212 degrees Fahrenheit. Gallon cans are given eight minutes, two-pound cans three minutes. The olives are then placed in boiling water and are cooked as follows: gallon cans fifteen minutes, two-pound cans eight to ten minutes. If the olives are firm and can stand a longer cook, it is advisable to give them all they will stand, for if not properly cooked the cans will swell. The length of time for cooking depends on the fruit, so that no fixed rule can be laid down for their treatment. This must be determined by the man in charge.

\section{IRRIGATING}

It is quite true that olives do not require as much water as the orange; nevertheless, it would be the greatest mistake in the world to attempt to raise olives, for either pickles or for making oil, without irrigation. The first season irrigate the trees at least four times, and if they give indications of being dry, the leaves turning yellow and curling, do not hesitate to apply the water again. It is not necessary to irrigate the entire space between the trees but if a back furrow is thrown up, about three feet on each side of the row of trees and the water is run in the furrow and made to cover the ground confined within the furrows by checking, the trees will receive all the water they require. Thorough cultivation is essential after each irrigation; if growers would only give more attention to the cultivating, in many instances irrigating so frequently would not be necessary. After the trees are four years old the entire space between the rows must be irrigated. Under average conditions and with proper attention to the stirring of the soil, three irrigations are ample for a grove in the interior valleys of the state. There are two irrigations which are important after the trees come into bearing. The first one should take place in April just before the trees come into bloom. This occurs in the latter part of April or in early May. If the rainfall has been ample and the soil is well charged with moisture, this irrigation may be dispensed with. The olive commences to ripen in October. Therefore they should 


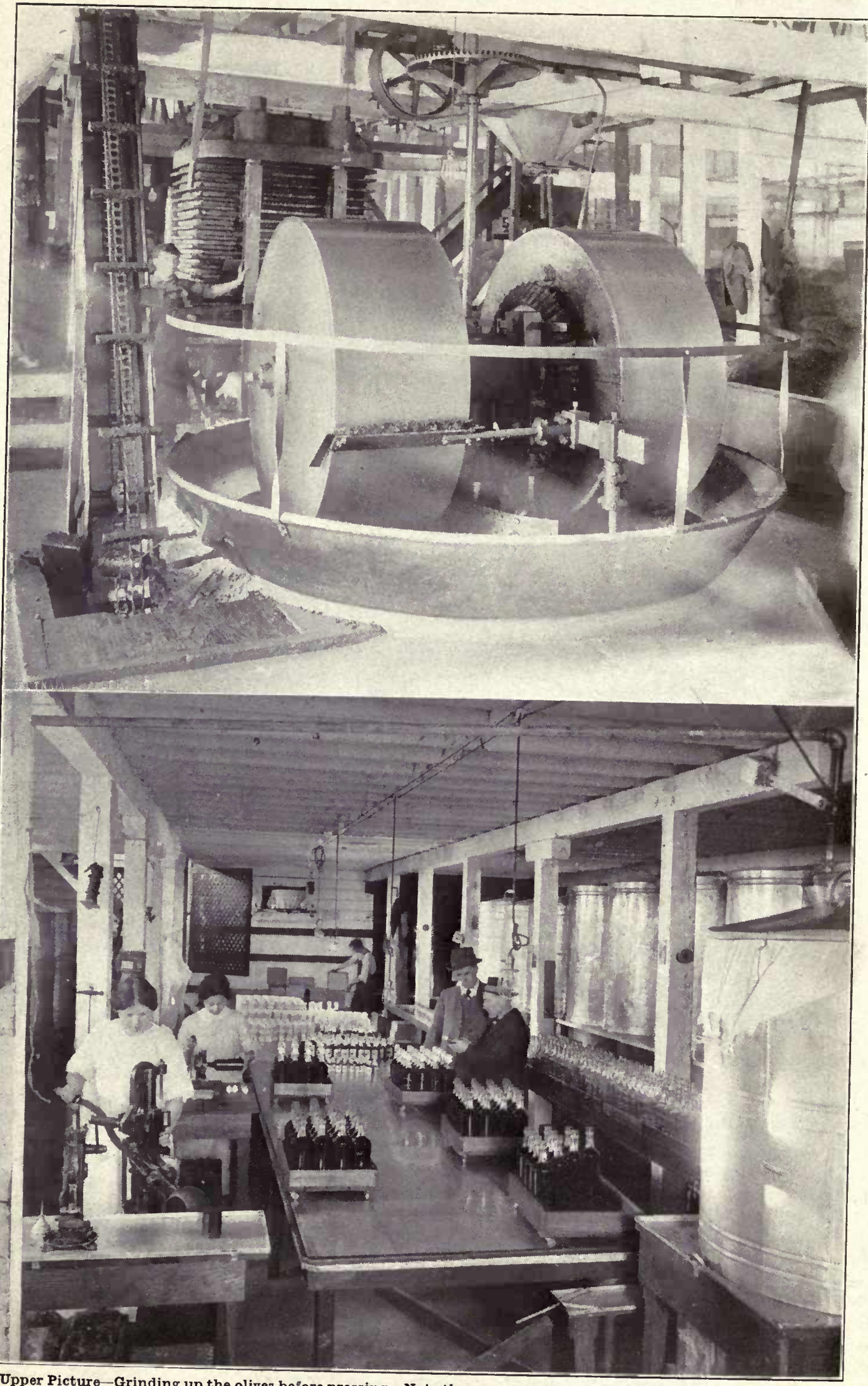

Upper Picture-Grinding up the olives belore pressing. Note the man standing close to the powerful press used for Lower Picture pressing out the oil. 


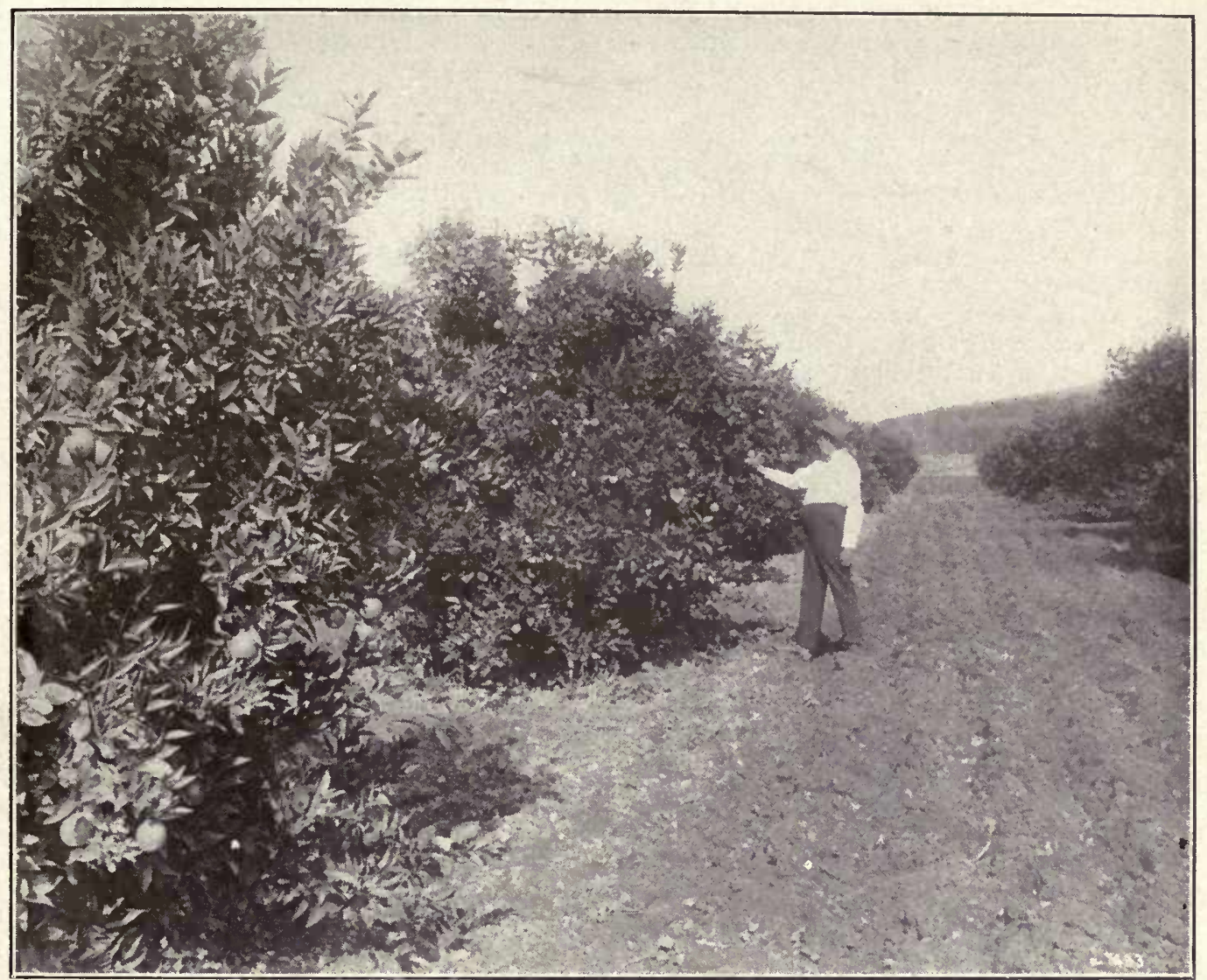

A section of the six-year-old Valencia Late Orange Orchard belonging to the author, located in Exeter. The trees are loaded with a very heavy crop of fruit. They have been pruned regularly every year.

fifteen to twenty feet apart. The tree likes a moist soil, and in California a lime grove should be liberally irrigated. The tendency to form a dense bushy head should be encouraged.

The citron is more tender than the lemon, therefore it should be planted where there is very little danger from damage by frost. The trees are very striking when loaded down with their long, roughskinned fruits in contrast with the large crinkled leaves of the trees. The only use for the fruit is for its candied rind. The method for preparing this fruit is as follows: Place the citron whole in strong brine for one month; take the fruit out and parboil it in clear water until it comes to a boiling point; then cut in halves lengthwise and remove the pulp and seeds. Place these halves in clear water for about three days until the salt is soaked out; then make a hot syrup of sugar and pour over the fruit, completely covering it. Allow it to stand in this for a period of twenty-four hours. Draw off the syrup, boil it as before, and again pour over the fruit. It remains in this syrup for a period of three weeks. The syrup is then again drawn off, the fruit is dropped into it and boiled for five minutes. It should remain in this syrup for a period of two days, when the citron is taken out, sugar is sprinkled over it, and it is allowed to dry. No one has ever deemed it worth while to engage in the business of pro- cessing the citron commercially, although very fine experimental lots have been produced. Experts have pronounced the local article as being very meritorious. The tree grows very much like the lemon except that it is of dwarf habit.

\section{SOIL AND SITUATION}

An ideal location for a citrus grove may be defined as a piece of land having a westerly slope with a range of hills to the east. The advantage of such a location is that in the winter months, when there is a spell of cold weather, the ground absorbs the heat more rapidly from the sun's rays (due to its slope), and in the morning, in the case of a severe frost, the shadow from the hills to the eastward causes a thawing out of the foliage and the fruit to be very gradual, thus reducing the injury to a minimum. The serious injury to tender plant growth, in case of a heavy frost, is due to the sudden changes in temperature when the sun's rays strike the trees, causing a sudden thawing out and thus injuring the sap cells. It is only within the last few years that we are beginning to appreciate the important part that air currents play in the growing of the tender fruits. Where such currents are known to exist they have a very important bearing in the development of a grove. For a number of years I have observed the difference in climate in Los Angeles, Orange and San Diego counties, 


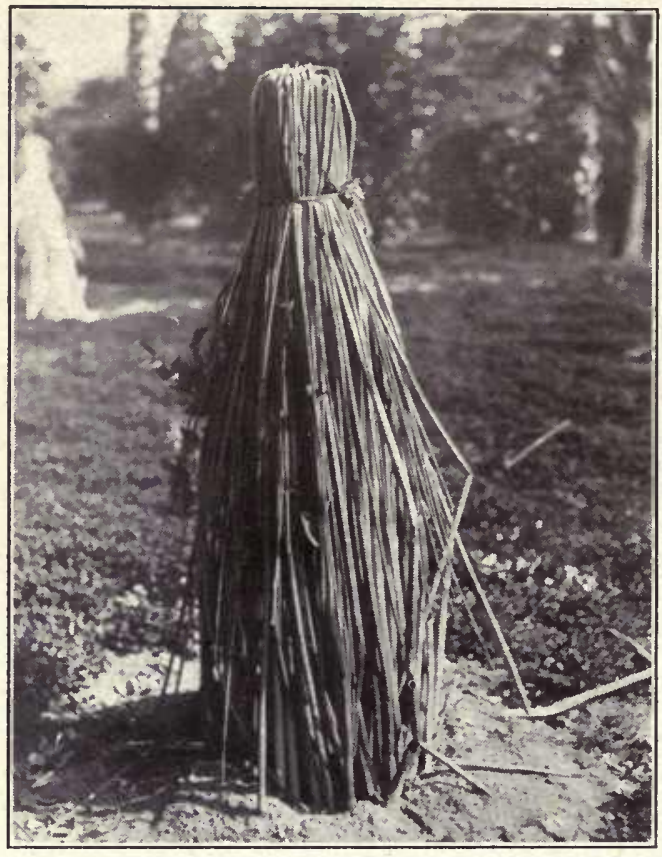

The method of protecting a young citrus tree from being damaged by frost. In the spring, as soon as there is a change in the weather, the tule or corn stalk covering should be pulled apart so as to permit the air to circulate through the trees and later be taken off altogether.

particularly in seetions lying between the low range of hills and the mountains to the east. That the Japanese current has a very decided influence on the climate and that the low-lying hills, in a way, pocket the air, there ean be no question. That vegetation is influenced by these conditions in the southern part of the state is evidenced by the fact that roses are in bloom practically all winter, that the young growth of lemons and oranges is very much in evidence, and that even tender palms like Kentias thrive outside with partial protection, all of which goes to prove the equableness of the climate. It is largely due to this condition that lemon culture has so many advantages over the great interior valleys, for here there is a chill in the atmosphere causing deciduous trees to go into early dormaney, and no young growth is ever noticed on citrus trees. Lemons are very profitable in the southern counties because they are frequently in full bloom in the dead of winter, thus producing an abundant crop in the summer months when lemons are in the greatest demand. Santa Barbara, possibly more than any other county, exemplifies this tropical climate, particularly so where the foothills rise up rather abruptly from the coast line. Here palms of the very tenderest character, which could only be grown in greenhouses with heat, in the region north of the Tehachapi, thrive and luxuriate without any protection. Oranges produce larger crops in the southern part of the state than in the interior valleys, but in quality they are inferior to the valley-grown fruit, grown along the foothills in either the red or black dry bog soils. Oranges ripen from four to six weeks later in the southern counties than they do in the more northerly sections. The early fruit invariably brings the highest prices, and as the Washington Navels in the valley distriets are all harvested before any severe cold weather oceurs, it has advantages worthy of consideration. I regard it as a grave mistake to plant the Valencia Late in any other location than the foot-hills, because this orange is never ready for shipment until April. I have seen entire crops ruined by cold weather during the winter months. There are very few soils in California where the eitrus trees will not thrive. Even in hardpan they do well if the ground is blasted. Never plant in alkali soils.

\section{SELECTING THE TREES}

It costs more to grow a eitrus tree than any other variety of fruit. The bud, after it has made a growth of a foot, must be staked, and to produce a straight tree the young shoot must be tied every two inches with raffia. Suckers must be kept off. When the tree has reached a height of three feet it is headed back to twenty-six inches; this causes it to send out laterals, and it is at this point where the hearl of the tree is formed. Whether to plant balled or naked root trees is a matter that should receive consideration. Balled trees are far safer than trees taken up with naked or open roots, for they may be placed under cover, the balls being placed in shavings, and if dampened occasionally they will keep in good condition for several months. It is, of course, practical to handle trees with naked roots providing certain fundamentals are observed. Before taking up such trees, it is necessary to cut the tap root at least eighteen inches below the surface and defoliate the trees. The effeet of this treatment causes the tree to become dormant. Within a short time the buds begin to swell, indieating that the tree has recovered from the shock of cutting the tap root and defoliating, when it may be dug up. Great care must. be exereised not to expose the roots to the sun. They are packed in damp moss for shipment. Before using the moss it is first

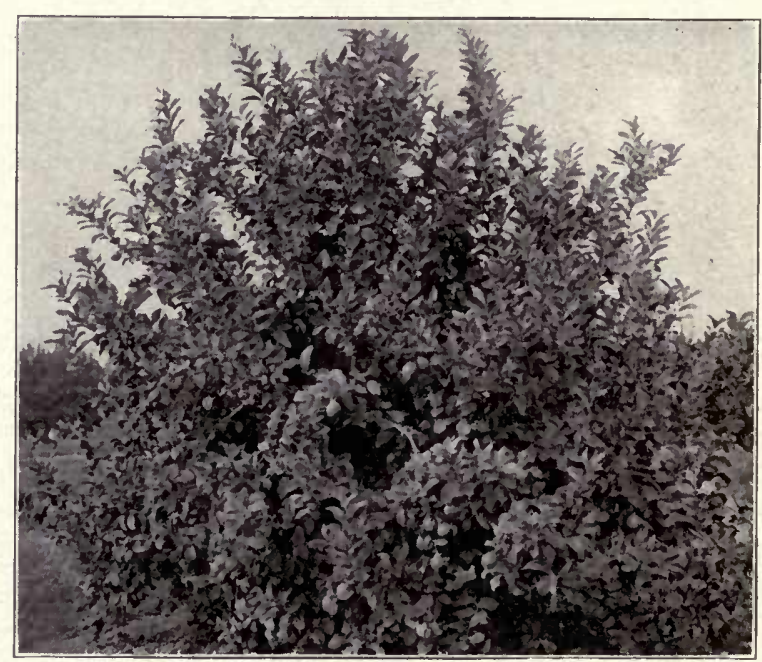

A four-year-old Eureka Lemon tree in the great lemon séction of La Habra, Orange County, California, taken in December when the tree had blossoms and fruit in all stages of development and with mature fruit ready to gather. 


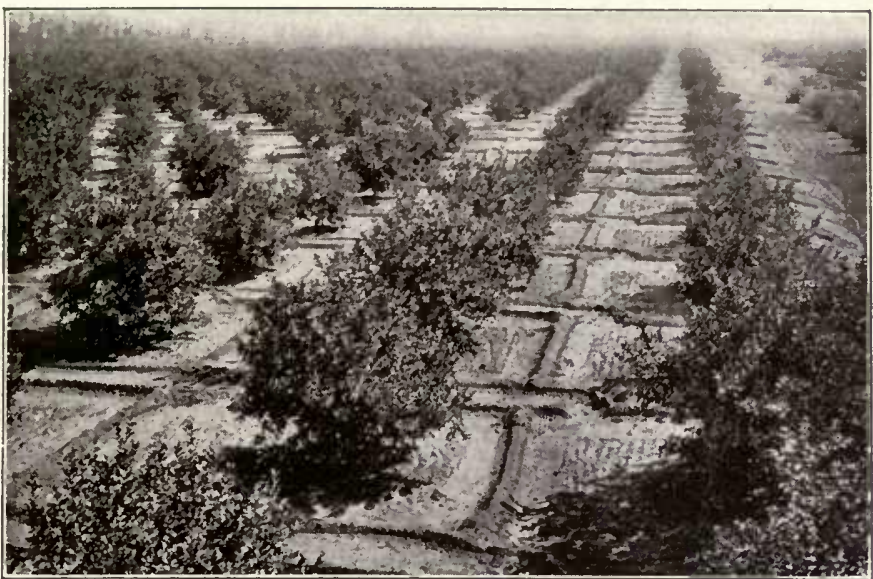

The check method of irrigating.

soaked in water and the surplus of moisture is either squeczed out of it with the hands or by passing it through a clothes wringer. If the trees are properly packed they will carry several months in the very best of condition.

\section{METHOD OF PLANTING}

Set the tree so that when the soil settles, the union of the bud with the stock will be at least a couple of inches above the ground. Be sure to settle the soil around the tree with water whether planting nakedroot trees or balled. This should be done as soon after planting as possible, and if the weather is warm it is best to have the water following the planting, so that but a few minutes will intervene between the time of planting and the time the water reaches the tree.

When planting naked-root trees have the water in the holes first, then settle the tree and fill in with earth gradually and spread out the lateral roots with the hands, so that they will be in about the same position as they grew in the nursery. It is often best to use a tank wagon for the first irrigation of naked-root trees.

In filling in the hole around a balled tree never tramp on top of the ball, as it will break it and dislodge the fibrous roots, and in many instances cause the tree to die. After the hole in which the balled tree is planted is partially filled, cut the cord at the top of the ball and turn down the burlap, so that it will be completely buried when the remainder of the hole is filled in. If this is not done the cultivator teeth are apt to catch on the burlap and will oftentimes pull the tree out of the ground or disturb it to such an extent that it will die before the trouble is detected. It is not necessary to remove the burlap from the ball; if properly turned down it will soon rot.

After the trees are planted and irrigated and before the earth has become firm around them, they should be carefully gone over, as more or less of them will settle to one side or the other, and unless straightened up right away will give the orchard a bad appearance. It will also be found that some of the trees have settled more than others; these should be raised before the earth becomes firm around them.

Newly planted trees should be given a light irrigation every ten days or two weeks until they begin to make some growth. After that it is not necessary to irrigate quite as often. They may be left from three to four weeks, according to the weather.

Never allow young trees to want for water. If they should show signs of being dry, give them a light irrigation right away. After the trees have been planted a year they should not be irrigated quite so often. If properly cultivated, one irrigation every month or six weeks is sufficient. In fact, trees will do better if only irrigated once every six weeks, provided the ground is kept. thoroughly cultivated between irrigations. The planter should bear in mind the fact that thorough cultivation is just as essential as irrigation. Care should be exercised to prevent the water from standing any length of time around the stem of the tree. In heavy soil this is almost sure to cause gum disease. In addition to cultivation for the purpose of filling in the irrigation furrows, newly planted trees should be carefully hoed after each watering, so as to avoid the possibility of the ground baking or eracking.

\section{STOCKS FOR CITRUS TREES}

In order to meet soil and climatic conditions in different sections, eitrus trees are budded on the following stocks: Sweet Orange (Citrus Aurantium Dulcis), Sour Orange (Citrus Aurantium Amara) and Deciduous Orange (Citrus Trifoliata). On the first-named sort the budded trees outgrow those on any other root, and practically all the old groves of the state are worked on this stock and are thrifty and healthy, except when situated on soils where there is an excess of moisture during certain seasons. Sweet Orange seedlings are grown from the seed of the common sweet seedling orange. Sour Orange seedlings are grown from the seed

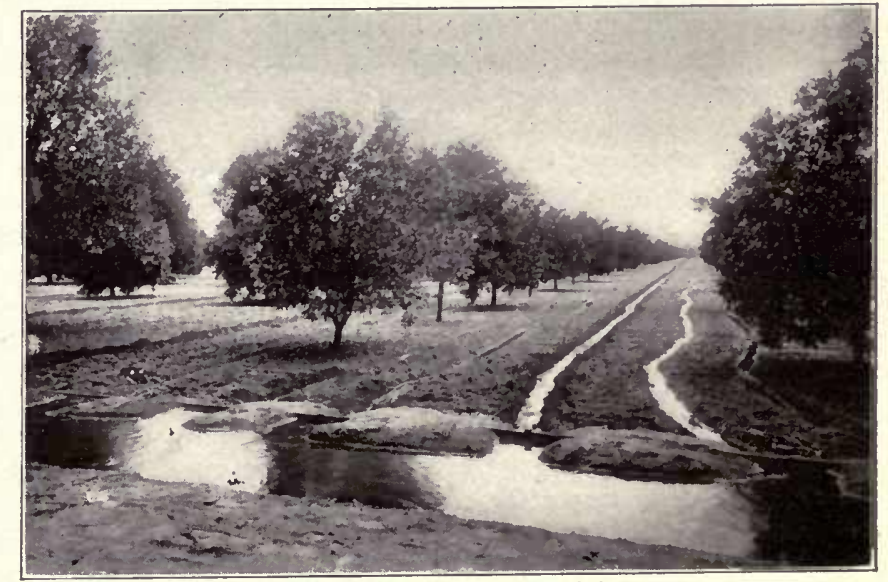

The furrow method of irrigating. 


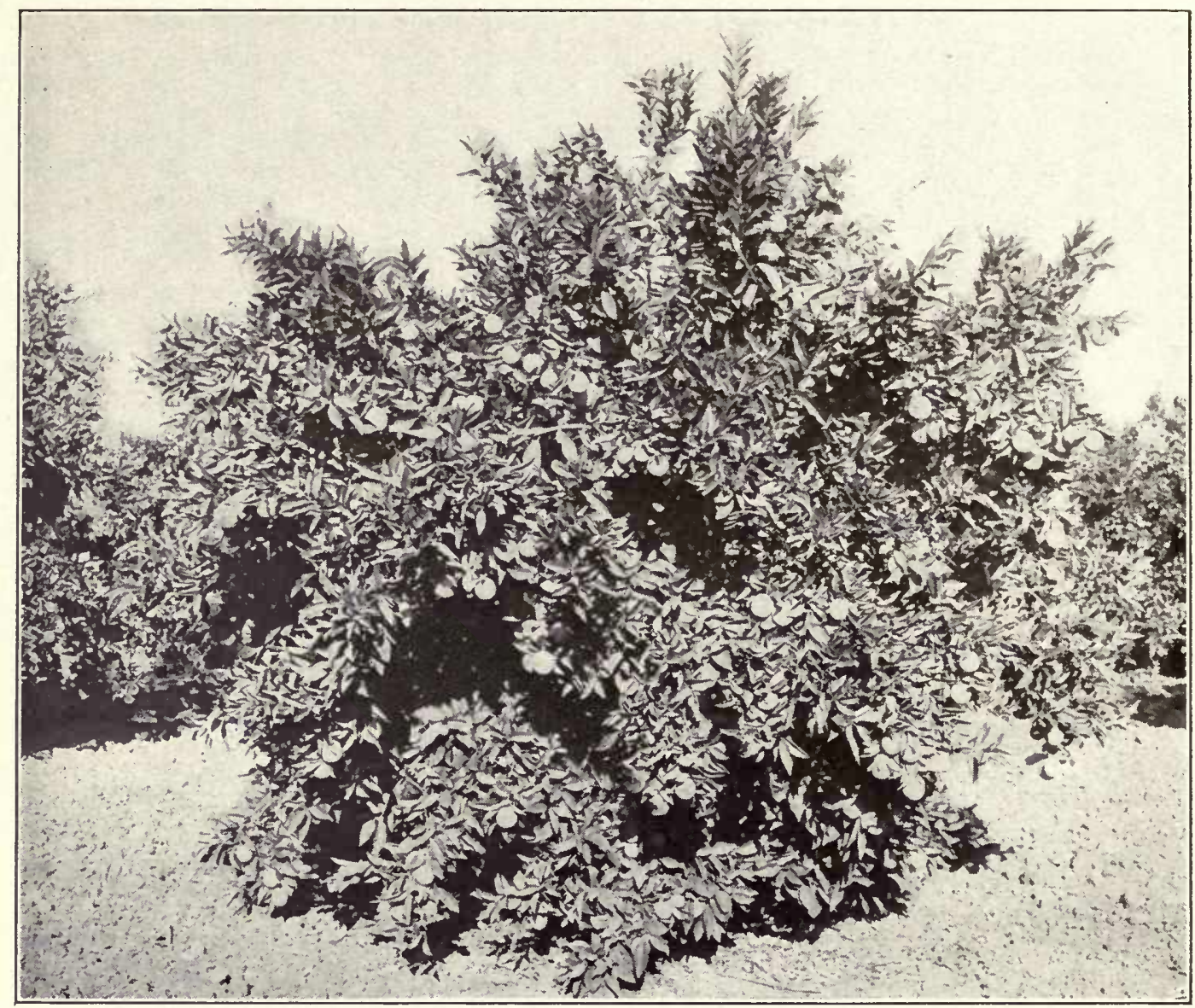

A model citrus tree. The interior branches of the tree are loaded with fruit. The exterior of the tree tells its own story.

of the sour orange so extensively grown in Florida as a stock for budding practically all types of citrus fruits. Although the buds do not grow as rapidly or attain as large a size in mature trees, this stock is much more resistant to gum disease; hence it has been in much demand in recent years for heavy soils, where water was apt to stand for any length of time, either because of summer irrigation or a heavy rainfall in the winter months.

The Citrus Trifoliata is a native of Japan and is the hardiest orange known. It is deciduous; its fruit is very bitter and has no commercial value, but its hardiness seems to exercise a decided influence on the budded tree. It is more resistant to cold than any other stock. It is also much prized as a hedge plant, making an impenetrable barrier to man and beast.

I have been experimenting with this root for orchard planting for a number of years now, and was under the impression, up to a short time ago, that it would adapt itself to locations in which neither the sweet nor sour root would grow well. The experiments I have made have convinced me that this root is not a satisfactory one for commercial planting. Its action is rather peculiar. In some instances the citrus budded on this root attain the same size as trees worked on either of the two roots referred to above. It is no uncommon sight, however, to see two or three trees, or even more, in a row not over five or six feet high, while other trees on this root in the sane row may be fifteen feet. This is a positive indication of the dwarfing effect of this root.

Another peculiarity about the root is that it differs from any other stocks used for dwarfing fruit trees in that the stock has a greater diameter than the bud. Trees budded on this root are hardier than when budded on any other root.

The point which may be considered as favorable to this root is that it causes the fruit of the budded tree to ripen several weeks earlier than on the other roots. In Exeter, Tulare county, where I have a very large orange grove, I have found that the Marsh Seedless Pomelo fruit, when the tree is budded on trifoliata root, is much finer grained, has more juice and is, in every sense of the word, a very superior fruit. Even with these points in its favor I do not recommend trees on trifoliata root for commercial orchards.

\section{DISTANCES APART}

Taking it all in all, the square method will generally give the best results and I recommend it in preference to the equilateral. While the last named method gives a few more trees to the acre and apparently gives the 
same amount of space between the trees, as a matter of fact, as the trees develop, there is less room for cultivating and harvesting the crops. This is an important item, in caring for the orchard and its production. I would advise those wishing to plant trees by the equilateral method, to do so with the idea of giving the tree more room rather than of getting more trees to the acre.

The Washington Navel and other varieties of similar growth should not be planted closer than twenty-two feet apart. In such localities where the soil conditions are good and there is every indication that the trees will make a strong growth, plant twenty-four feet apart. The Washington Navel is not usually a rapid or vigorous growing tree. When planted in light alluvial soil it makes a much larger tree than when growing in heavier soils.

The Valencia Late should be planted from twentyfour to thirty feet apart, as it is a very vigorous and strong growing tree.

Lemon and pomelo trees, as they are both very strong and rapid growers, should be planted at least twenty-four feet apart. It is safe and probably advisable in most cases to plant them even a greater distance apart than this.

The slow-growing varieties, such as Satsumas, Limes and Kumquats, can be planted as close as fifteen feet apart, as they never make very large trees.

One idea should be borne in mind always, and that is, that it is far better to waste a little ground, if one might term it so, in getting an orchard planted seemingly too far apart, than to have it too close.

\section{PRUNING}

If a tree is headed at twenty-eight inches from the ground, all that is necessary to do is to cut the laterals forming the head back to about six inches. In case the tree in the nursery has been permitted to make a straight stem and has not been headed back as it should have been, then the top should be cut off to within thirty inches of the ground to cause the tree to form a head.

High-headed trees are always objectionable, for they not only expose much of the stem, causing sunburn, but in addition to this the tree is retarded in acquiring a sturdy, compact growth.

In pruning, above all things do not be deceived into the idea that the trees must be thinned out to admit air and sun. The tendency of nearly all budded varieties is to droop, so in shaping a tree cut to a lateral which has an upward tendency.

It seems too bad that there are thousands of acres of citrus orchard in California which are not pruned because the grower is afraid to apply the shear to hold rampant branches in check.

In order to develop a well rounded, symmetrical tree it is very important indeed to prune the tree regularly every year until it is six years old. To establish a compact, symmetrical orange tree, the straggling branches should be shortened in rather severely the first year after being set out, as this will cause the tree to force out a number of strong, vigorous shoots.

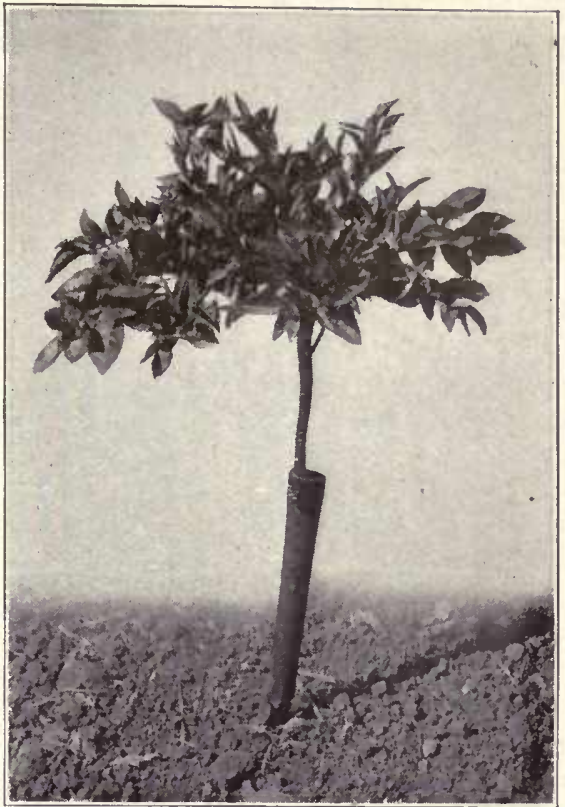

A one-year-old orange tree showing one year's growth in the orchard. If these branches are allowed to grow unchecked, the tree will be drawn out of shape.

In the second year it frequently happens that one or more of these shoots will grow to such an extent that the tree is pulled out of shape, and it is only by cutting this growth back severely that the shape of the tree will be retained.

The building up of the tree is secured by cutting branches having a tendency to grow too close to the ground, to an upper branch, and shortening this in. The result of this method of pruning, if followed carefully, causes ambitious shoots to send out numerous fruit-bearing laterals. The tree, when it reaches its fifth year, should apparently present a mass of foliage, with branches well distributed but not crowded. It is as important to cut out dead branches and branchlets, which will become very numerous, as it is to prune.

Suckers, if too numerous and having a tendency to draw the tree out of shape, should be removed entirely. If, however, the suckers apparently help to fill out the tree and build it up, they should be shortened in to conform with the natural growth of the tree.

In its finality, a well pruned orange tree should present a compact mass of foliage with none of the framework branches exposed to view.

\section{PRUNING THE LEMON}

The tree is a straggling grower and the branches must be held in check by a systematic annual pruning, for if the tree is permitted to grow at will the fruit will be at the ends of the long, unrestrained branches.

There are many systems of pruning, but the fundamental principle is to produce a compact but not too dense low-headed tree with a large amount of bearing surface on easily accessible branches.

When the tree is transplanted from the nursery to the orchard the same directions as given for the orange 


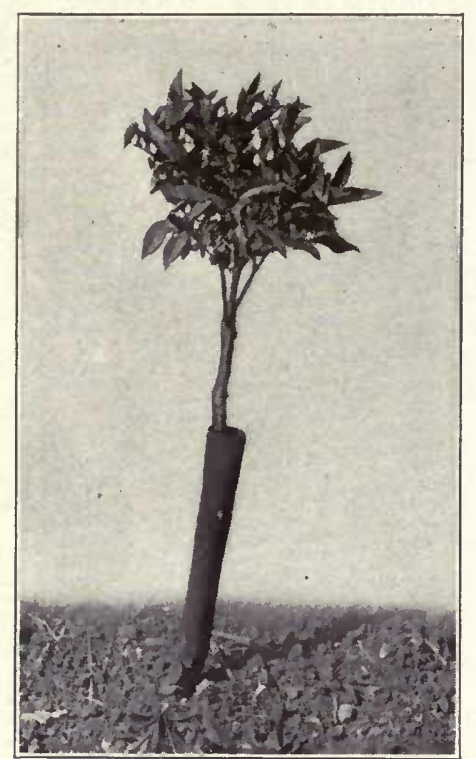

The same Orange tree correctly pruned to form a well shaped head.

should be observed, but in subsequent years the pruning is quite different. Not more than four branches are selected to form the framework of the tree. These in turn are persistently cut back and encouraged to assume an inclination to the horizontal rather than a vertical direction. Any branches showing a tendency to make a strong growth vertically should be cut down and forced to develop laterally. This continuous pruning back has a tendency to produce a dense mass of branches and foliage, and as the tree grows some thinning out is necessary. The results obtained by following out this system of pruning are a shapely broadened-out tree, liberally supplied with numerous fruiting laterals.

As lemons are picked a great many times during the year and the gathering of the fruit is no small item of expense, the advantages of having a tree with a lowspreading head, eliminating much of the expense of harvesting, must appeal to any grower.

\section{PRUNING THE POMELO}

The tree is a more upright grower than the orange. For this reason the method of pruning is somewhat different, but as a whole it is necessary to shorten in the growth and prune to a branch which shows a tendency to grow upright rather than down. The shaping of the pomelo is much simpler than either the orange or the lemon. The tree naturally assumes a well-rounded head, providing the shears are applied promptly whenever rampant branches have a tendency to draw the tree out of shape.

The pruning of the pomelo after it comes into bearing should be attended to just as soon as the crop is harvested. As the fruit sets in March and is harvested from January to August of the following year, the necessity of pruning as soon as the crop is taken off is quite evident. Taking it all in all, the plan outlined for pruning the standard varieties of oranges is applicable to the pomelo.

\section{PRUNING THE LIME}

I have already called attention to the fact that the tree is more tender than either the orange or the lemon and for this reason it should be planted only in such localities where there is not much danger of the tree being damaged by frost. Commercially, it is only practical to raise limes in sheltered foothill regions of the state. The seedless varieties of limes average much larger than the Mexican types, and as they come into maturity much earlier in the season they should be planted in exclusion to the other sorts.

The tendency of the lime is to form a dense, bushy head. The tree is really more of a bush than a tree. For this reason it should be pruned much more severely than the orange and the lower branches should be allowed to rest on the ground. To produce the best results it requires either a moist soil or a liberal amount of water.

\section{PRUNING THE CITRON}

The character of the tree is very much like the lemon, therefore the recommendations made for pruning the lemon should be observed in the handling of the citron.

\section{CARE OF THE ORCHARD}

The old adage that "what is worth doing at all is worth doing well," applies to citrus-fruit culture as well as to all other lines of horticulture and agriculture, and in no other line are the rewards greater.

While an orange or lemon tree will stand as much or more abuse than any other tree, yet no other tree will respond more quickly and more profitably to proper care and cultivation. The grower who is careful not to let his orchard want for care or for fertilization, is the one who always reaps a bountiful harvest.

It would be a difficult matter to lay down any hard or fast rule covering the irrigation and cultivation of a citrus orchard, as the soil and the climatic conditions have a great deal to do with the proper time and manner of these two necessary requisites.

Generally speaking, in California, citrus orchards should receive from three to four irrigations during the summer months. These should be given from four to six weeks apart. By irrigation I mean a thorough wetting; that is, the water should be run long enough to wet up the subsoil as deep and as far out as the roots penetrate. In light, sandy soils the penetration is rapid, but in the heavier soils it often requires several days to properly saturate the subsoil and the only satisfactory way to irrigate such soils is by the furrow method; that is, by running several furrows, according to the age of the orchard, between the rows and allowing very small streams of water to run down each furrow. These streams should be of such size that it will take them from twenty-four to forty-eight hours to run across a ten-acre tract, which gives the water time to penetrate the subsoil. In some of the heavier soils, if the water is allowed to run through the furrows too fast, it will coat over the furrow with a fine silt and it is then almost impossible to get the water to penetrate the soil. The result of this is that the water goes to 
waste and the trees remain in a dry condition. This condition is ouly apt to occur on the hillside lands where the fall is quite heavy.

On the lighter sediment lands it is not necessary to let the water run so long; in fact, some of these lands will become sufficiently wet by allowing the water to run only a few hours. Only on extremely sandy lands is it advisable to flood citrus orchards. Ordinarily no irrigation is required during the winter months, although in some seasons it is necessary to irrigate up to December.

The length of time required for the land to dry sufficiently for cultivation after an irrigation depends largely on the nature of the soil and weather conditions. A light, sandy soil will be dry enough to cultivate within thirty-six hours after the water is taken off, but the heavier soils require several days of sunshine before they can be properly cultivated. The soil should be dry enough so that it pulverizes or falls apart as it is turned up by the cultivator. If it is inclined to stick together and turn up in solid masses it should be left to dry another day or two. In some of the heavier soils where the drying process is very slow, it is oftentimes best to fill in the furrows with a harrow as soon as the surface shows signs of baking or crusting; then follow with cultivator a day or two later. This prevents the surface from getting too dry while that below is getting sufficiently so to cultivate properly, thus obviating the soil breaking up in large clods. Outside of the benefit of turning over and aerating the soil, the main benefit of cultivation is the forming of a mulch of finely pulverized soil, which keeps the subsoil from drying out. Unless the cultivation is done so as to properly pulverize the top soil a large part of the benefit of cultivation is

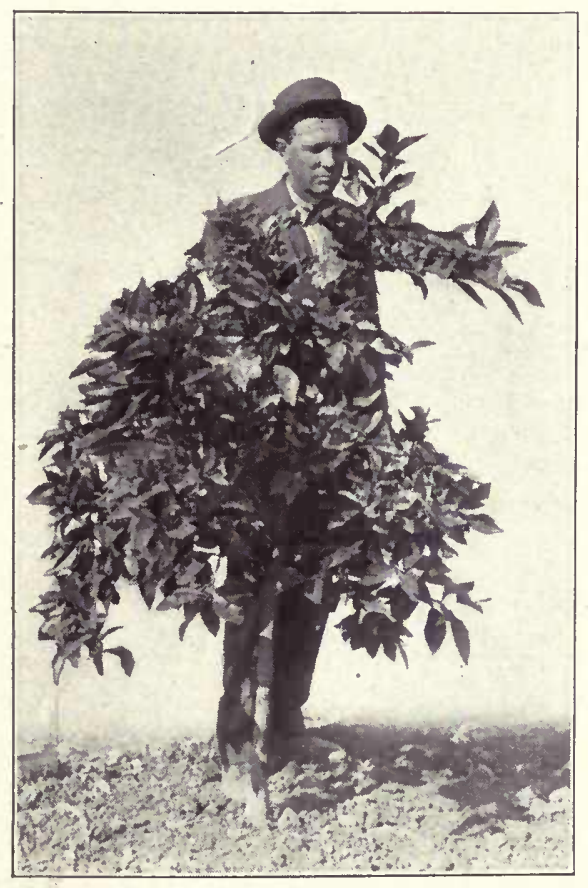

A three-year-old Orange tree rather one sided. This irregular development must be corrected.

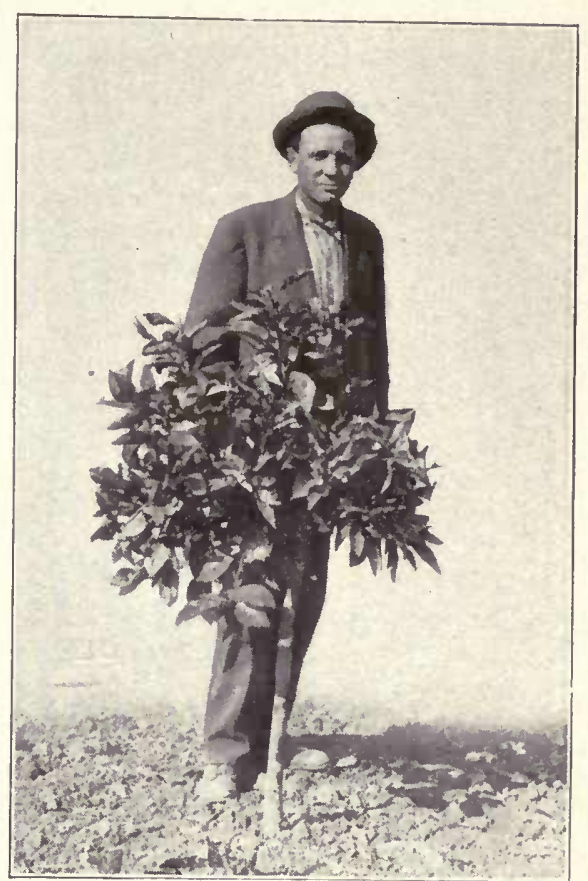

The same Orange tree pruned. The branch extending so far beyond the tree was cut back, while those branches having an upward tendency were shortened in. This method of pruning will cause a tree to round out uniformly.

lost, as loose, cloddy soil will dry out almost as fast as though uncultivated. The deeper and finer the top soil is stirred the less water the tree will require. I strongly recommend the thorough cultivation of eitrus trees to a depth of from four to six inches where it is possible, and not less than four times between each irrigation. It is at times impossible to cultivate more than two or four inches deep the first time after an irrigation without turning up mud, but by setting the cultivator a little deeper each time a greater depth can be attained. It is not best to do all the cultivating at once, as it should be distributed over the interval between the irrigations, for in this way it helps to conserve the moisture in the subsoil, thus preventing the tree from suffering.

\section{FERTILIZERS AND FERTILIZATION}

It is best to begin the study of soil fertility early, as it is far better to feed the soil before it is exhausted. How best this can be done is a question that has been puzzling our best orchardists for a number of years, and it will, no doubt, continue to do so for years to come, as there are so many different soil conditions to contend with that it is impossible to lay down any rule that will apply in all cases.

It is a well-known fact that nitrogen, phosphoric acid and potash are the three chemicals required in the soil to produce and sustain plant life, and chemists have figured out just how much of each of these are required for the different plants and trees, and how much the different crops will take from the soil; yet when it comes to analyzing the soil it will be found that most of the soil contains a sufficient amount of all these ingredients 


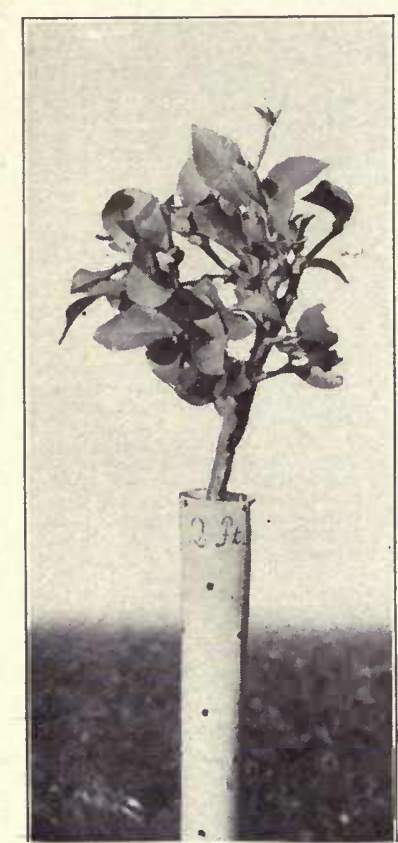

A Lemon tree just transplanted from the nursery to the orchard with its branches shortened in as they should be. The crown is started twenty-eight inches from the ground. to produce crops and still the tree may show that something is lacking. This is accounted for by the fact that any analysis of the soil will show what it contains but does not tell whether the plant food is available, and unless it is in such form that the roots can feed upon it, it is useless and other plant food will have to be furnished. For this reason the question of fertilization can only be determined by the growth of the trees; at the same time, it is not advisable to let the orchard go without any fertilization until it begins to show a starved condition. By applying about the same amount of plant food that the tree takes from the ground each year, one can prevent the soil from becoming exhausted. Then if the tree shows by its growth a lack of certain ingredients, it can be supplied accordingly. It has been my observation that barnyard manure applied in liberal quantities is one of the best fertilizers for the promotion of growth, as it not only supplies considerable plant food but assists in making that already in the ground more available by its action in loosening up the soil.

Cover crops of legumes, such as peas, vetch, fenugreek, burr clover and melilotus, are also quite generally used and are giving good results. They are sown in the late summer or early fall, and allowed to grow during the fall and winter, and are then plowed under in the spring. The value of a cover crop depends largely on the amount of growth it makes and the manner in which it is turned under. To get the best results a legume should be selected that will make a heavy growth and then it should be thoroughly turned under in the early spring. This is very important, otherwise it draws moisture to such an extent from the tree that it does more harm than good. No cover crop, fertilizer or manure is of any particular value on top of the ground. It must be turned under or placed in the ground where the rootlets of the tree can feed upon it.

Commercial fertilizers are used quite extensively and with good results, but on account of the cost, a good many growers do not use enough per tree to get the best results. It is necessâry to use some eommercial fertilizer in connection with the use of barnyard manure or cover crops, in order to supply all the ingredients necessary to properly feed the tree.
The planter should bear in mind that no matter what form of fertilization is used satisfactory results cannot be obtained unless the soil is properly eultivated, as the rootlets of the tree cannot take up the plant food unless the soil is kept in condition so that these feeders can continue undisturbed in quest of it.

\section{THE TIME TO PLANT}

Citrus trees being evergreen, they ean be planted at all seasons of the year, although the months of March, April, May and June are considered the most favorable. In the interior valleys, where it is extremely hot and dry during the summer months, it is advisable to plant as early as possible in the spring, although planting should not commence until the ground is fairly warm, so that the tree will immediately start to grow. Trees planted too early, while the ground is still cold and wet, will remain in a dormant condition until the ground gets sufficiently warmed up so that they can make a start. When this condition prevails for any length of time it causes the finer roots to decay; as a consequence of this, when the tree does start, it will make rather a slow growth until new rootlets are formed. For this reason it is advisable to defer planting until conditions are favorable for the tree to start to grow as soon as planted.

Along the coast where the summer cimate is more moderate, citrus trees are planted with good results all through the spring and summer months. In fact, the trees planted during June and July seem to make nearly as good a growth as those planted in the spring. Where planting cannot be done before this time, it is my opinion that July or early August planting is preferable to waiting over until the following spring. Even though the trees do not make quite as vigorous a growth as those planted earlier in the season, they make sufficient growth to become thoroughly established, in consequence of which, they are all ready to start with the

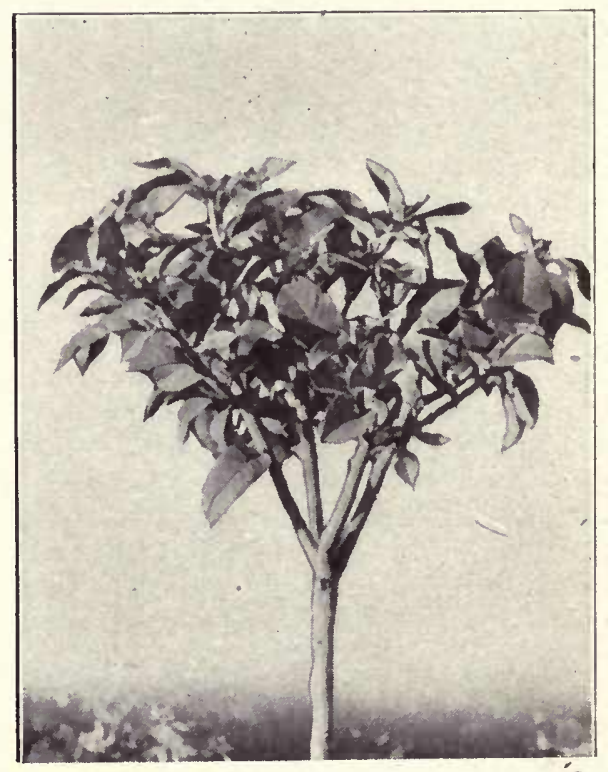

A one-year-old Lemon tree in the orchard, properly pruned. The importance of having a sturdy crown which will later on carry a heavy crop of fruit is illustrated here. 
first touch of spring and are far ahead of any that can be planted after that time.

The only thing necessary to successful summer planting is to see that the trees are properly handled from the nursery to the orchard and are sufficiently well irrigated and cultivated. The prompt application of water to newly planted trees is very essential in late planting.

\section{PACKING THE ORANGE}

The grower with five or ten acres of oranges usually does not consider it necessary to pack his crop.

It has been a practice of the small grower to deliver fruit to the packing house without noticing its condition and quality, whether above or below the average of his locality. Only when the returns come in does he realize that had the quality and size been better more satisfactory returns might have been had. It must be borne in mind that consumers are human beings like ourselves, and that unless the quality is such that it appeals to them they are going to pass it up in much the same manner as we do when we go into a store to purchase fruit or vegetables for our own use.

If the grower will begin studying packing and marketing conditions, noting the size and quality of fruit demanded, methods of properly handling and packing from orchard to loaded car, it will of ten not only assist to correct bad conditions in the orchard for the production of the best grades of fruit, but it will be a guide in determining what shipper to intrust with your crop, for the shipper who maintains the highest and most uniform grade of packing is bound to get the most satisfactory returns for the grower. It is necessary, first of all, to keep the orchard in such condition by proper methods of irrigating and cultivating that it will produce only the best quality of fruit. Size and quality cannot always be governed by cultural methods, for it often happens that climatic conditions cause the fruit to be small one season and large another, in spite of the care exercised. Taken one year with another, however, it pays to give intensive culture.

In picking and handling the fruit care is essential, as the carrying quality of the fruit depends largely on the manner in which it is handled from the orchard to the car. The practice of having fruit picked by day labor gives better results. It costs a little more to harvest a crop this way, but the results are much more satisfactory, as the loss from bruising is less, which more than offsets the additional cost.

Care must be exercised in picking to use clippers that do not cut or injure the fruit. The stems must be cut close, as one orange with a long stem may puncture or bruise a dozen or more while passing from the picking bags to the boxes, and from there to the packing house.

It was estimated that from eighty-five to ninety per cent of the heavy decay in California oranges a few years ago was directly due to the methods of picking and handling the fruit in the orchards, so that it is to the interest of the orchardist to personally see that the pickers are careful in cutting the fruit from the trees and placing them in the boxes. The picking bags used for this purpose are open at the bottom, and if the picker is careful, the fruit can be let out of these into the boxes without allowing it to drop or bump against other fruit in the box. Care must also be exercised in filling the boxes so that when stacked in the wagon on top of each other, the boxes will not be so full that the fruit will get bruised or smashed. All wagons for hauling the fruit should be equipped with springs so as to reduce the jar and jolting to a minimum.

The modern equipment in packing houses is calculated to reduce to a minimum the chances of bruising the fruit while passing from the receiving door to the car, and the old-time graders and elevators, whereby the fruit was subjected to drops of from six to eight inches, have been consigned to the scrap heap.

To those who have never seen an orange packing house in operation, a description of the methods employed therein will, no doubt, be of some interest. The fruit, after being taken in at the receiving door, is trucked to the grader, then dumped into a hopper and carried by a belt conveyor to the brushes; these are so arranged that, as it passes through, every particle of dust is brushed off. When the fruit is very dirty it is sometimes necessary to first pass it through washers, where the smut and dirt is washed off by brushes operating in water; it must then be thoroughly dried before going back to the grader. If the washing is not necessary, the fruit passes from brushes to the sorting table and is there selected as to quality. The regular grades are fancy, choice, standards and culls, although some packers put up an extra fancy and an extra choice brand. As the fruit is sorted, it is conveyed to the different graders. In large houses a grader is used for each brand, which are so arranged that the fruit passes over rollers adjusted so that the different sizes fall through into bins arranged on either side of the grader, and from which the packers take the fruit and pack it into boxes. Where only one grader is used and one brand of fruit runs at a time, the remaining fruit is taken from the sorting table before it reaches the grader and sent back to run over the grader later on. In the larger houses where several graders are in operation at the same time, each grade of fruit is passed from the sorting tables to a belt conveyor carrying it to the grader handling that grade of fruit; this does away with the necessity of passing any of the fruit over the sorting table a second time. In sorting the fruit, only such as is considered perfect, that is, free from blemishes, sound in quality and fairly smooth, is sorted out for the fancy or extra fancy grade. The next best goes to the choice grade, and consists of such fruit as may be only slightly blemished and possibly not quite so smooth as the fancy grade, but otherwise sound and of good quality; that which is quite badly scarred and with a rough skin, but of sound and good keeping quality, is packed as standard; and all fruit showing an unsound skin, either from being bruised in picking or handling, which tends to impair its keeping qualities, is thrown out as culls.

The standard box used for packing oranges is divided into two compartments $111 / 2 \times 11 \frac{1}{2} \times 11 \frac{1}{2}$ inches, and the sizes into which the oranges arc graded are $64 \mathrm{~s}, 80 \mathrm{~s}$, $96 \mathrm{~s}, 112 \mathrm{~s}, 126 \mathrm{~s}, 150 \mathrm{~s}, 176 \mathrm{~s}, 200 \mathrm{~s}, 216 \mathrm{~s}, 250 \mathrm{~s}$, and $324 \mathrm{~s}$, the bins being so arranged that each size is graded into a separate receptacle. After being packed the boxes 


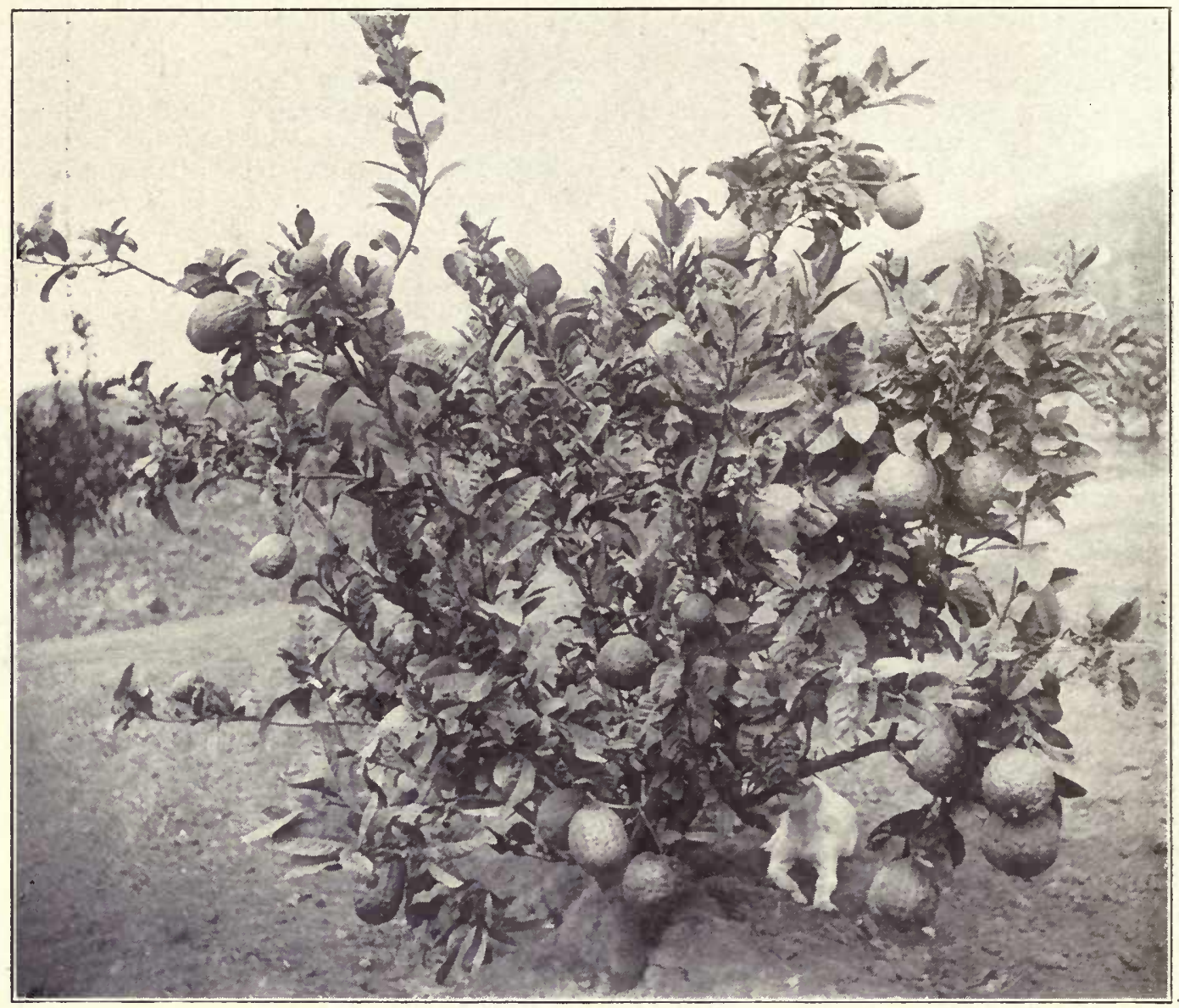

A Citron of Commerce loaded with fruit. Note how crinkled the foliage is and the rough skin of the fruit.

are earried to the press, where the tops are nailed on; they are then ready to be loaded into the cars.

A standard carload of oranges consists of 384 packed boxes of the following sizes: not more than 38 boxes of $96 \mathrm{~s}$ or $112 \mathrm{~s}, 76$ boxes of $126 \mathrm{~s}$ and 38 boxes of $216 \mathrm{~s}$ or $250 \mathrm{~s}$. The remainder of the ear to be made up of $150 \mathrm{~s}$, $176 \mathrm{~s}$, and 200s. All larger or smaller sizes, and any in excess of the above numbers of $96 \mathrm{~s}, 112 \mathrm{~s}, 126 \mathrm{~s}, 216 \mathrm{~s}$, and $250 \mathrm{~s}$, are considered off sizes and are discounted from 25 to 50 cents per box according to the market; $150 \mathrm{~s}$, $176 \mathrm{~s}$ and $200 \mathrm{~s}$ are standard and a car may be made up entirely of these sizes without discount, although most markets demand a certain amount of large and small fruit and packers usually try to load in accordance with the demand of the market to which they are shipping, as the buyer will always pay more for a ear that suits his trade than for one in which there are undesirable sizes.

\section{GROWING, CURING, PACKING THE LEMON}

Fruit should be picked as soon as it has attained its size and just before turning. For home use each fruit should be wrapped and placed in a box in a cool place. After a few months the lemon will have become quite yellow in color with thin skin and will be full of juice. Lemons allowed to ripen on the tree are thick skinned, deficient in juice, develop extreme bitterness and are in every way inferior. For commercial purposes lemons are curcd, before shipping, in specially designed houses.

In localities where the conditions are congenial for its perfect development, flowers, immature and mature fruit ready to pick will be found on the same tree. A few trees are always a desirable addition to the wants of every home, and by taking precaution to plant in a protected spot, a good supply of fruit is always available.

In picking lemons rings are used by the pickers to prevent the picking of undersized fruit. For winter picking $2 \frac{5}{16}$ inch rings are used and for spring and summer picking $2 \frac{1}{2}$ inch rings.

To obtain best results, both as to size and keeping quality, the orchard should be picked over every four or six wceks. Right here is where the grower eannot be too careful, as a large part of the success or failure of the lemon business is due to the methods of picking and handling of the fruit It should be borne in mind that every little bruise or bump affects the keeping quality of the fruit. When lemons are to be kept from three to six months before going on to the market, they should be handled as carefully as eggs.

Properly cured lemons may be kept for months, and they will improve in market qualities by a thinning and toughening of the skin and by an increase of juice content. 


\section{THE PERSIMMON}

In this country there are but two varieties in cultivation, viz.: the American and Japanese. The latter, on account of their attractive appearance and large size, are destined to be extensively planted as soon as their commercial importance is more appreciated. The impression that the fruits must be on the verge of decay before they can be eaten has militated against their sale. There is much variation in the character of the fruit. Some varieties are not astringent at all and are edible in early autumn, while still hard and green. Several kinds never soften at all until they decay; others are edible only when fully ripe and soft; still others lose their astringeney only after they have been dried, and some so abound in tannin that their juice, when expressed, makes a valuable varnish for preservation of all kinds of woodwork. There is quite a distinction between the dark and light fleshed varieties. The former invariably contain seeds, are crisp and meaty, and are edible before they soften, although their flavor is improved considerably when they reach this stage; the light fleshed kinds are seedless (or mostly so), and cannot be eaten until they soften.

Persimmon eulture commercially centers in Japan.

California offers great possibilities in the culture of this most delicious fruit. It will adapt itself to a wide range of localities. The fruit will very often hang on until January, providing there have been no heavy frosts and a tree loaded with this deep russet, golden fruit is a sight to behold when all the leaves are off.

There is an endless number of varieties, Japan holding the lead in this respect, and China being a close

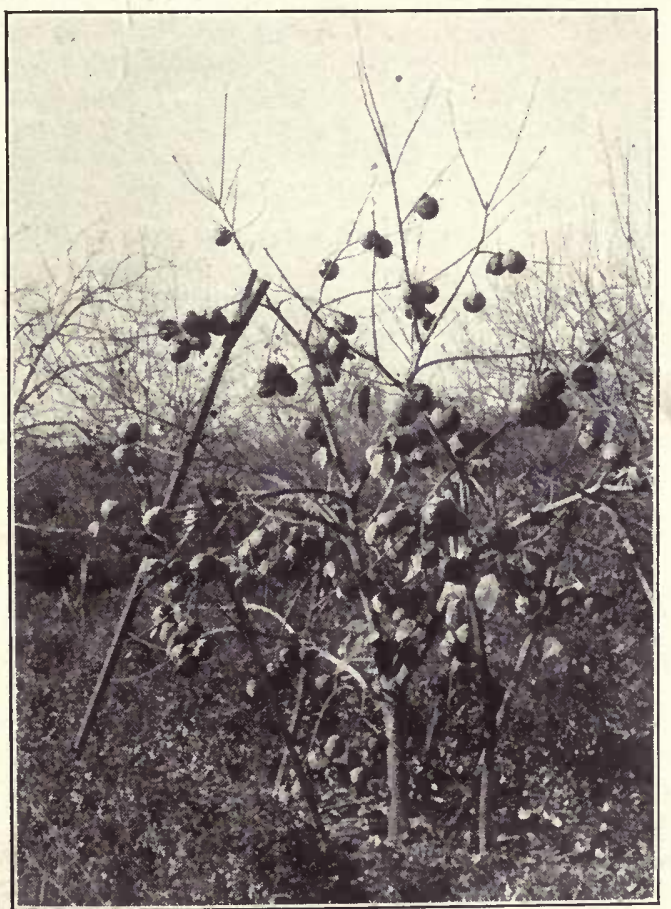

A Hyakume Persimmon tree four years old. It has a mag nificent crop of fine fruit. It would have been far better for the future of this tree if it had been pruned more severely while young.

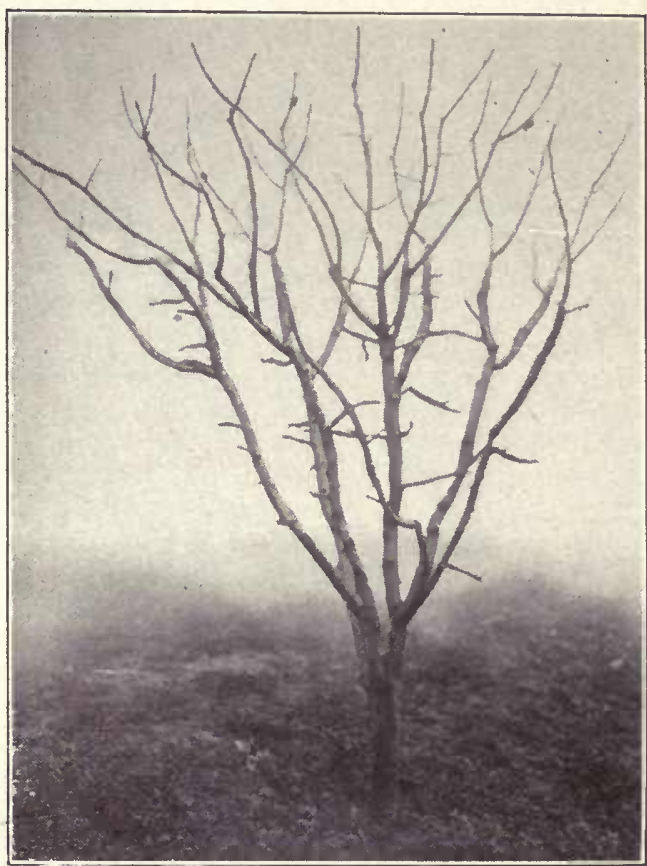

A well balanced Persimmon tree. This desirable shape is the result of pruning.

second. Through the very thorough and able efforts of the Division of Seed and Plant Introduction of the United States Department of Agriculture, it is hoped within the next few years that the almost hopeless confusion which seems to surround the nomenclature of the persimmon will be solved. It is of the utmost importance that nurserymen should grow their trees exelusively in this state, not only because of the difficulty of getting the imported trees to grow, but also because of their unreliability.

\section{PLANTING AND PRUNING}

Trees should be planted twenty-four feet apart. The persimmon has a rather decided tap root with numerous small fibrous roots. The tap root should be eut back to eighteen inches and fresh cuts made on all the fibrous roots. After the trees are set, head back to eighteen inches. The first winter thin out the branches not leaving more than four to form the head of the tree. Cut these back at least one-half. In the second, third and fourth years the pruning of the tree should be continued to fashion the tree into the typical goblet form. A better quality of fruit running into large sizes with a more regular distribution of fruit over the entire tree will be effected by pruning every year. The trees are quite hardy and fruit freely in all sections of the Coast.and in the Southern States, and as far north as Washington, D. C. Persimmons do not bloom until the middle of May; therefore, under average normal conditions the trees always bear fruit.

The astringency is readily removed by placing the fruit in Japanese tubs, from which saki (rice-beer) has been recently withdrawn. After the persimmons are placed in the tub, close carefully to exclude the air. In ten days the fruit will have lost all its bitterness. 


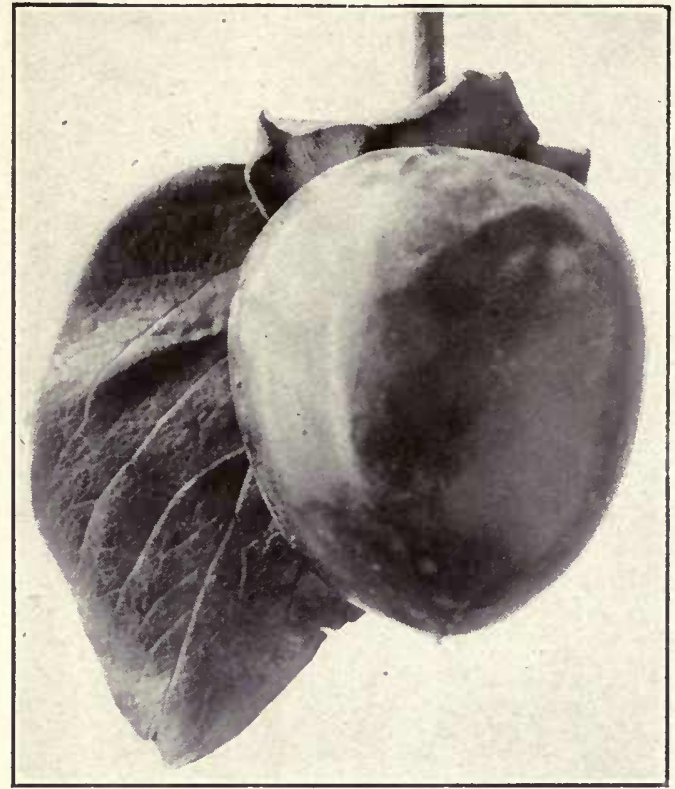

The Hachiya Persimmon, very much reduced. There is hardly a place in California where the Persimmon will not thrive well and produce heavy crops annually.

A new simple process of aleohol inoculation has been practis $\approx$ lately. Pierce the fruit at the bottom several times with a common needle dipped in alcohol and pack them in a tight box or eontainer lined with straw and with layers between the rows, keeping the box closed for ten days.

It is not generally known that the persimmon is delieious when dried. It is so sweet, so rich in sugar and has such a unique flavor that one who has never eaten the dried persimmon before immediately comes to the conclusion that the fruits have been crystallized. The method of drying is simple: the skin is pared off and the fruits are suspended by the stems, tying them with string to a rope or a stick and exposing to the sun; they gradually lose their original form, turn quite dark and are covered with sugar erystals: The dried persimmon is considered by many to be more delicious than the "date of commerce." Fruit should be picked for drying when yellow and firm.

\section{COMMERCIAL VARIETIES}

Dai-Dai-Maru, Hachiya, Hyakume, Tane-Nashi, Yemon.

VARIETIES WORTHY OF TRIAL

Delicious, Fuyugaki, Mammoth Gosho, Sato, Tamopan, Twentieth Century, Yami-Yemon.

\section{TIME OF RIPENING OF COMMERCIAL VARIETIES}

\section{September}

Tane-Nashi.

\section{October}

Hachiya, Dai-Dai-Maru.

\section{November}

Hyakume.
December Yemon.

\section{THE POMEGRANATE}

The fruit of the pomegranate will be remembered in connection with Seriptural history, where it is mentioned in conjunction with that of the vine, fig and olive. Its cultivation, therefore, dates back to remote antiquity. It is much prized in the south of Europe as an ornamental tree, and in countries around the Mediterranean it is volued very highly for its effective flowering qualities as well as for its delicious fruits. As our elimatic conditions in the interior valleys are very similar to those countries in the south of Europe where it flourishes so well, it is coming more and more into favor. The fruits are very showy, this being true more particularly of the Wonderful. As a table decoration there is no fruit which is more attractive. If there is any objection to the pomegranate at all it may be summarized as being due to the seeds in the pulp. It is said that there is a variety in which these seeds are entirely absent. In my travels abroad I endeavored to find a seedless variety in Asia Minor and in southern Europe, but met with no suceess in my quest. Numerous varieties have been introduced by the Division of Plant Industry of the United States Department of Agriculture and by private individuals, but thus far none have been found which are in any way superior to the well established varieties. As the pomegranate bears heavily and regularly every year, requiring very little care, and adapts itself to a great variety of soils, there is no reason why it should not eventually become a very important commercial fruit. A cooling drink known as grenadine is made from the pulpy seeds with the addition of water and sugar. This is used very extensively in the southern part of Europe. It is said to be especially grateful in fevers. The rind of the fruit, when boiled, has for many generations past been the remedy for taeniae, and a jet black, smooth writing ink is also made from it.

\section{SITUATION AND SOILS}

I have used the pomegranate for a number of years in depressions in my vineyard where the ground was so damp for a good part of the year that grape vines invariably died. The pomegranate luxuriates in these spots, and their spontaneity of growth is simply astounding. The pomegranate will thrive in any part of the state, but commercial planting should be confined to sections having comparatively high temperatures during the summer months. In such localities it reaches its highest point of perfection. It is not very particular as to soil and it will thrive in water-logged soils and those more or less impregnated with alkali in which other trees will fail entirely.

\section{DISTANCES APART AND PRUNING}

The very fact that the pomegranate produces so heavily with so little care has caused many growers to allow the shrubs to grow at their own sweet will. This is a mistake. To get the best results it should be started with a single stem about sixteen inches high. If allowed to throw out numerous suckers from the ground it is more difficult to keep the bush in shape and under control than when starting with a single stem. The 


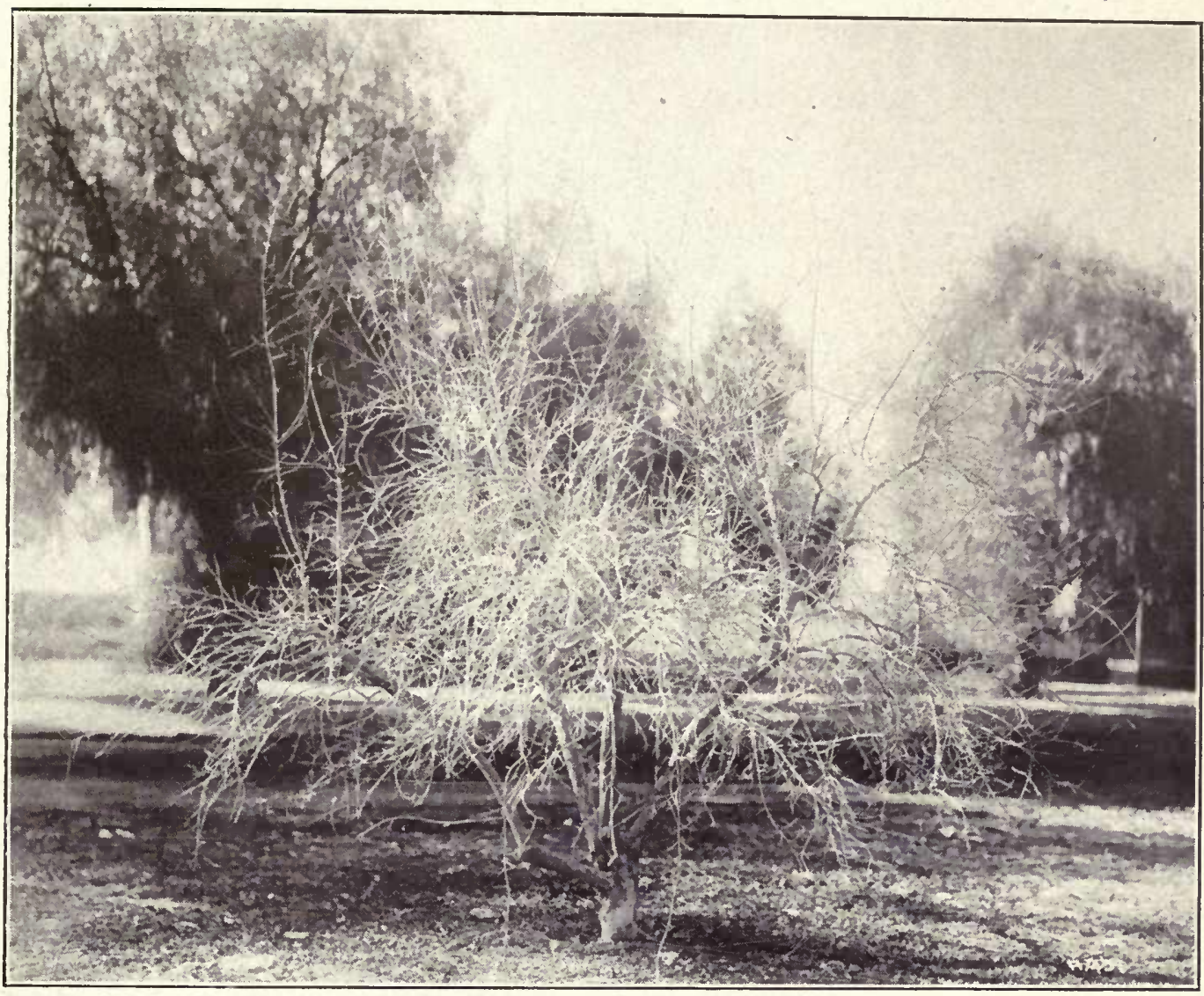

The Pomegranate should be started with a single stem. Enormous crops of fruit are gathered from trees shaped like this one.

body of the tree may well be termed a unit. With this unit fixed the shaping of the subject is by far a simpler matter than when having several framework branches coming out from just above and underneath the surface of the soil. For the first three years the shrub should be shaped by thinning out and shortening in the current season's growth. After the head of the shrub is formed the pruning resolves itself into thinning and shaping the plant to keep it within bounds. Never plant closer than twelve feet apart in deep, loamy soils; fifteen feet apart is preferable. The pomegranate is raised from cuttings. As far as I have been able to observe the varieties grown in California seem to adapt themselves to a great variety of soils.

\section{GATHERING}

On account of its rather thick skin the fruit will withstand quite a lot of abuse. The one point to guard against is to pick the fruits before they are rained on, for when this occurs many of them will split, making them unfit for shipment. After they are gathered the fruits if stored in a cool, dry place will keep for months; the skin loses its striking lustre, and the fruit shrinks some, but this in no way impairs the quality or the flavor of the pulp.

\section{MERITORIOUS VARIETIES}

Paper-shell, Sweet-fruited, Wonderful.

\section{THE AVOCADO}

It is very fortunate indeed for the fruit growers of California that the state, probably more so than any other in the Union, possesses such a variety of elimate and soils; otherwise avocado culture would have fallen by the wayside long ere this. In my travels throughout the state I have allowed no opportunity to pass not to observe the avocado where I noticed that a grower was devoting considerable of an acreage to its cultivation, probably the most valuable, from a dietetic standpoint, of any fruit grown in this state today. There is no denying the fact that the industry has a very great future. It must also be admitted at the same time that the successful growing of the avocado is going to be confined to those particular sections of the state where the lime grows to the best advantage. The avocado blooms and sets fruit at all seasons of the year; therefore it is a foregone conclusion that out of a very large number of varieties on the market now the list will finally settle down to a half a dozen sorts of real merit. When this time arrives we will begin to engage in the culture of the avocado in earnest. As one grower, F. O. Popenoe, who has probably had more experience and has given more thought and attention to the culture of the avocado than any other man in the state, tersely expresses it: "I believe it can safely be said that the most important problem which we avocado growers of 


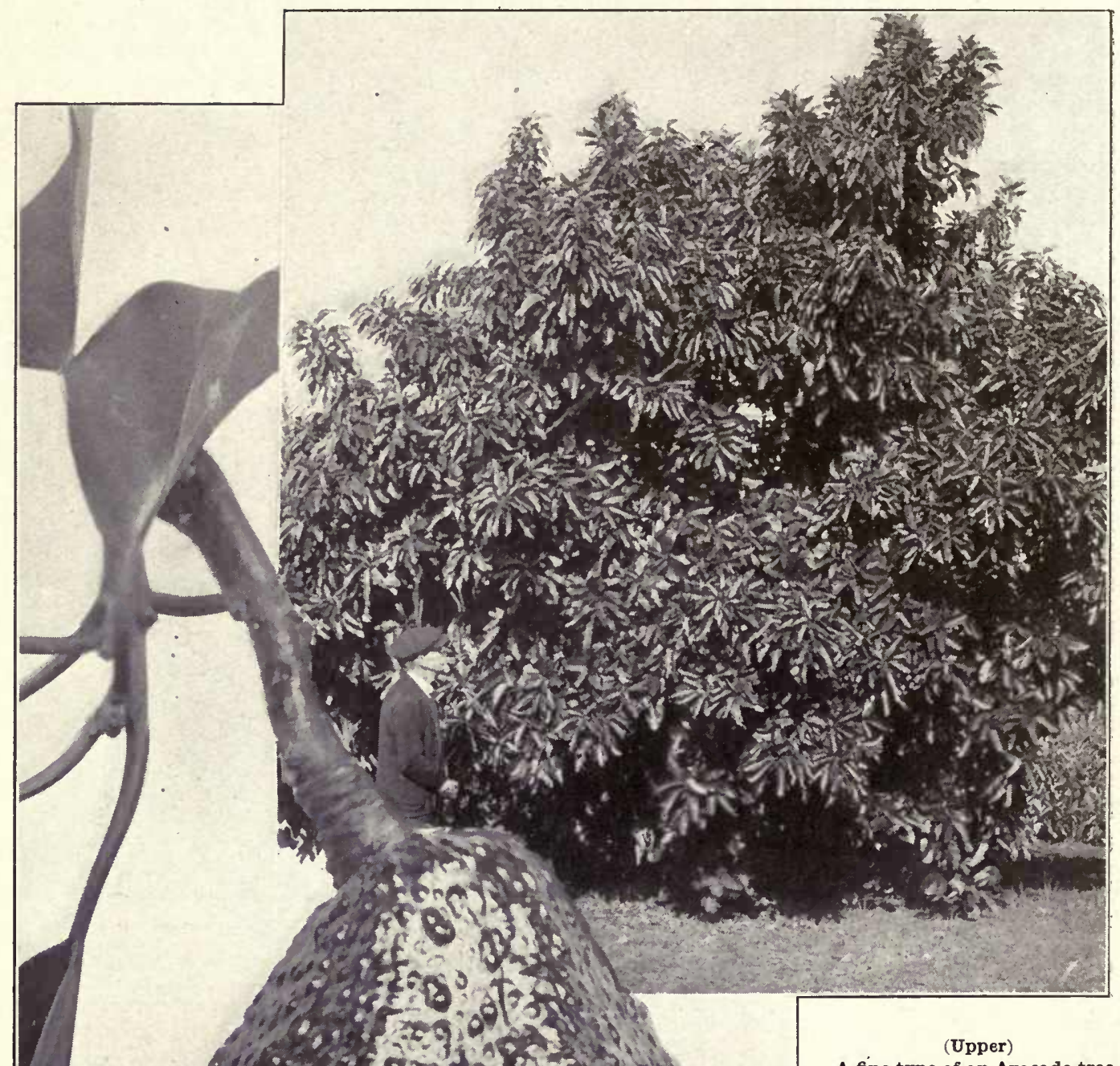

A fine type of an Avocado tree.

\section{(Lower)}

A hard-shelled Avocado.

Note the pebbly surface. 
California are facing at the present time is the question of varieties." Why do I contend that the culture of the avocado is going to be confined to a prescribed district? It is simply because I realize from my personal investigations that with very few exceptions ${ }^{\circ}$ the avoeado is more tender than the lime, and that it is going to reach its greatest perfection where as a rule there is very little danger during the winter months of any great extremes of cold. The alluring accounts which have gone the rounds of the great profits to be derived in avocado culture should be taken with a good sized grain of allowance. To succeed well the avocado must not only have an abundance of water but a good, deep soil, and in addition to this a climate where the air is tempered by the ocean breezes.

It is quite possible that this culture may be carried on successfully in the foothill districts of the interior valleys, but I would advise those who have the fad to exercise considerable caution in their efforts. Far better to plant fruits the success of which has been demonstrated by years of actual trial, than to be induced to engage in the growing of a fruit of doubtful value from a standpoint of making money.

\section{STOCKS}

The hardier Mexican types have been used for this purpose. As to what will finally prove to be the best stocks for the avocado is up to the present time just as chaotic as the numerous list of varieties. That ultimately there will be varieties having points in their favor for stock there can be no question. The seedlings are easily grown. They are placed in pots with the blunt end down and with the apex slightly exposed. After they have attained a growth of a foot they are transferred to larger receptacles and when the plants have attained a caliper of three-eighths to one-half ineh they are budded. The trees make such a very rapid growth in nursery rows that nurserymen are finding it far more satisfactory to produce the trees by raising them in boxes than by planting the seedlings out and balling the trees when they are ready for sale. The trees transplanted from boxes not only start out more quickly when planted in orehard form but in addition to this they can be trained to much better advantage.

\section{DISTANCES APART AND PRUNING}

The avocado is a rank growing tree and is also inclined to be of a very spreading habit, therefore the trees should not be planted too close together. Thirty feet apart is a good distance. In planting the boxed or balled plants observe the instructions given for planting balled citrus trees, and also the statements made under the heading of watering and irrigating. Each tree should be staked when it is planted, using a coast redwood stake 2 inch $\times 2$ inch $\times 6$ feet long. The tree should be trained to at least four feet from the ground before it is allowed to branch. Great care should be exercised not only to whitewash the body of the tree but also in addition to this to wrap it with burlap or use a tree protector to prevent sunburn. As the tree is very susceptible to sunburn every precaution should be exereised to prevent it. As usual, the old story that the avocado should never be pruned is going the rounds of the press. This has as much foundation as the recommendations which have been circulated throughout California in reference to the pruning of many other fruit trees. It is quite true that it is necessary to use proper precautions in the pruning of the tree and that it would be dangerous indeed to follow the course recommended for pruning deciduous trees, but nevertheless shaping is essential. There is a tendency on the part of most of the varieties to grow downward and it is no uncommon thing to have branches lying on the ground and loaded with fruit. It seems to be the very nature of the tree to do this. This is why it is necessary to start the framework branches high and allow them to droop to the ground rather than to permit them to shoot from the body of the tree close to the ground. The pruning should be done with a view of promoting an upward growth to bring about a series of elbows in the trees and to prevent the development of long straggling branches. Pruning and shaping should only be done when the tree is in its most active state of growth, and when a cut is made it should be carefully waxed or painted, otherwise there is a tendency toward die-back.

\section{GATHERING}

Under favorable conditions it is going to be possible to gather avocados at all seasons of the year. There are two distinct types: those with thin skins and the socalled hard-shells. The former must be very earefully gathered and picked when they have reached their size and before they commence to get soft, otherwise they will decay very quiekly. Whenever they show an indieation to soften somewhat (a condition which is readily determined by pressing between the fingers) they are ready for consumption. The thick-skinned varieties may be shipped long distance with every assuranees, if picked when they have reached their size, that they. will keep for several weeks in the very best of condition.

\section{EATING THE AVOCADO}

This fruit has well been named the poor man's food. In the countries of South America, Mexico and other tropieal countries where it grows wild, the very fact that the trees are such abundant bearers and that the fruits possess all the food ingredients to sustain the human body, are the combinatiors which have caused this fruit to be so designated. The fruits sell with us at very high prices, and it is more than likely they will continue to do so for many years to come. Many people must acquire the taste for the fruit, but once having done so it is difficult indeed to resist the longing for this most palatable and really wonderful fruit. There are many ways of preparing it for the table, but the usual method in vogue is to halve it, remove the seed, pour a little. oil or dinegar (lime juice is better), add a little table salt and pepper, and it is ready to be eakt.

\section{IRRIGATION}

Instructions given on this point for the citrus fruits are adaptable to the avoeado.

\section{MERITORIOUS VARIETIES}

Azusa, Carton, Fuerte, Harman, Iyon, Meserve, Northrop, Sharpless, Spinks, Taft. 


\section{CHERIMOYER}

There are grave doubts as to whether this fruit will ever attain any great commereial importance. Its culture has thus far been confined to the counties south of the Tehachapi, and in these only in sections where there was eomparatively little danger from cold weather. Botanically, it is known as Anona cherimolia. Its common name, Custard Apple, is derived from its having the consistency of custard with the blended flavors of the pineapple and the banana. Most of the trees which are sold are seedlings. If greater interest is manifested in this fruit, named varieties will undoubtedly be introdueed. It is quite variable in the size of the fruits produeed, running from an inch in diameter up to eight inches on the same tree. Where the trees do well they are very prolifie and attain quite a large size. The skin is overlapping and the fruit is shaped like a strawberry. They come into bearing when four years old. The fruit should be picked when matured and laid away for a few days in a ccol place before they are ready for eating. For shipping they should first be wrapped in paper and then packed in excelsior. The boxes in whieh they are paeked should be ventilated.

\section{THE FEIJOA}

Another of our semi-tropieal fruits possessing merit but one which was boomed to the limit by over-zealous nurserymen without testing out its value fully. This fruit is simply another example of having its merits extolled before determining some of the salient facts

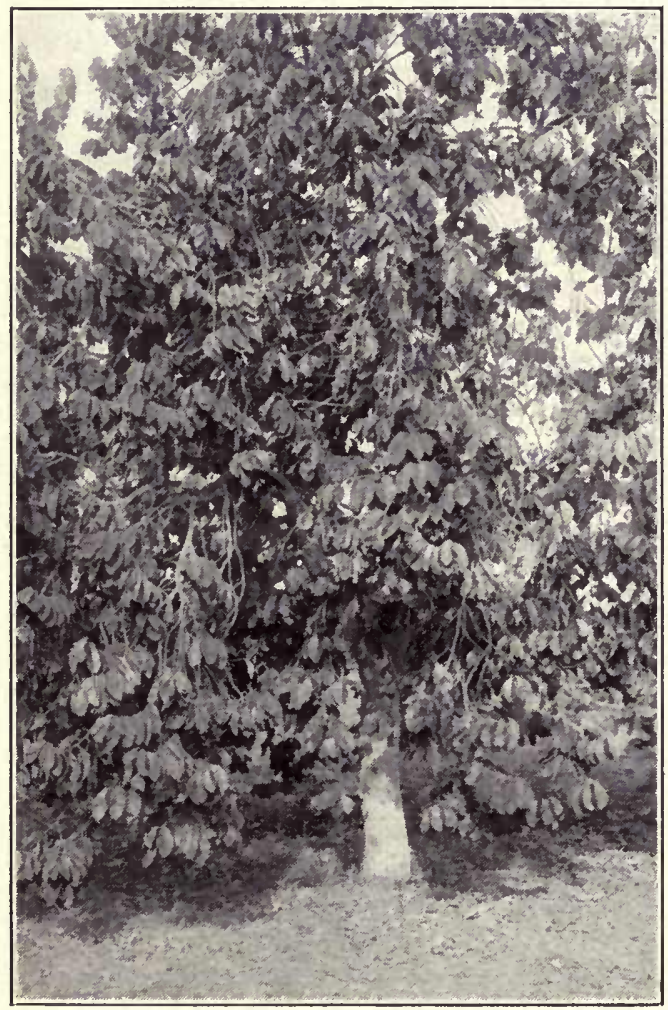

The Cherimoyer can be grown in many places in the southern part of California. Single fruits quite frequently weigh a pound or more. concerning it. It was widely distributed, and although it bloomed profusely the bushes failed in most instances to set fruit, and in eonsequence of this it lost its popularity. Varieties are now being introduced having fruits twice the size of a hen's egg, and are known to bear regularly and abundantly. The very faet that the shrub is very hardy, that the fruits have a mingling of flavors, all of which are attractive to the palate (the only objection being the numerous seeds), will eause it to be planted again on a limited scale. It makes a very fine transparent jelly. It should have a place in every garden, for it has a series of combinations which will make it a valuable addition to every home.

\section{THE GUAVA}

Guavas will only be grown to any extent in the counties south of the Tehaehapi. If planted elsewhere they will have to be protected, except perhaps in favored loeations in the foothills; otherwise they will freeze to the ground during the winter months. There are two varieties, the strawberry and the lemon guava. The former has been more widely planted. The shrub is very attractive both when in flower and when loaded with its crop of aromatic fruits. Its leaves are glossy green; the flower is snow-white with a decided jasmine scent. The fruits of the strawberry type are colored like a strawberry, hence the name; while the lemon guava has fruits of a lemon-yellow color. The strawberry guava is by far the better one to plant because it is very much hardier and bears much more abundantly than the other. As in some other fruits of this type the objectionable feature to it is its innumerable seeds. The guava makes a very superior jelly, and in localities where it thrives it grows with so little care it deserves receiving more attention than has been accorded to it.

\section{THE LOQUAT}

As an ornamental tree much may be said in its favor. Its wide adaptability, there being very few places in California where it ean not be grown successfully, and in addition to this its delicious fruits, coming in before any of the other table fruits in the spring, should cause it to be more widely planted than it has been. It blooms in November, the flowers appearing in large panicles. They are very sweet seented and suffuse the atmosphere when in full bloom with their delicious aroma. Botanically, it is known as Eriobotrya jabonica, and it is frequently eharacterized as the "date plum." Its native habitat is China and Japan. Preference should be given to the improved budded varieties, as the fruit averages much larger in size, the seeds usually varying from two to three in each fruit, being very much smaller than in the seedlings. The trees are either budded on loquat seedlings or on the quince. When grown on the quince it is practicable to transplant without balling in the winter months provided the leaves are stripped from the plant. Many budded varieties have been introduced from Japan and southern Europe, but none of them equal in size or compare in quality to the sorts introduced by C. P. Taft, of Orange, California. The fruit is produced in immense clusters and makes a striking contrast with the large, 


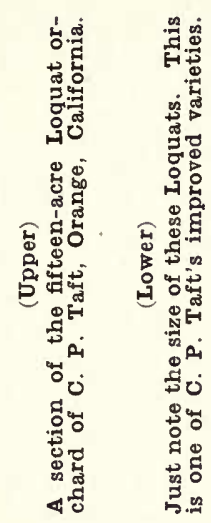
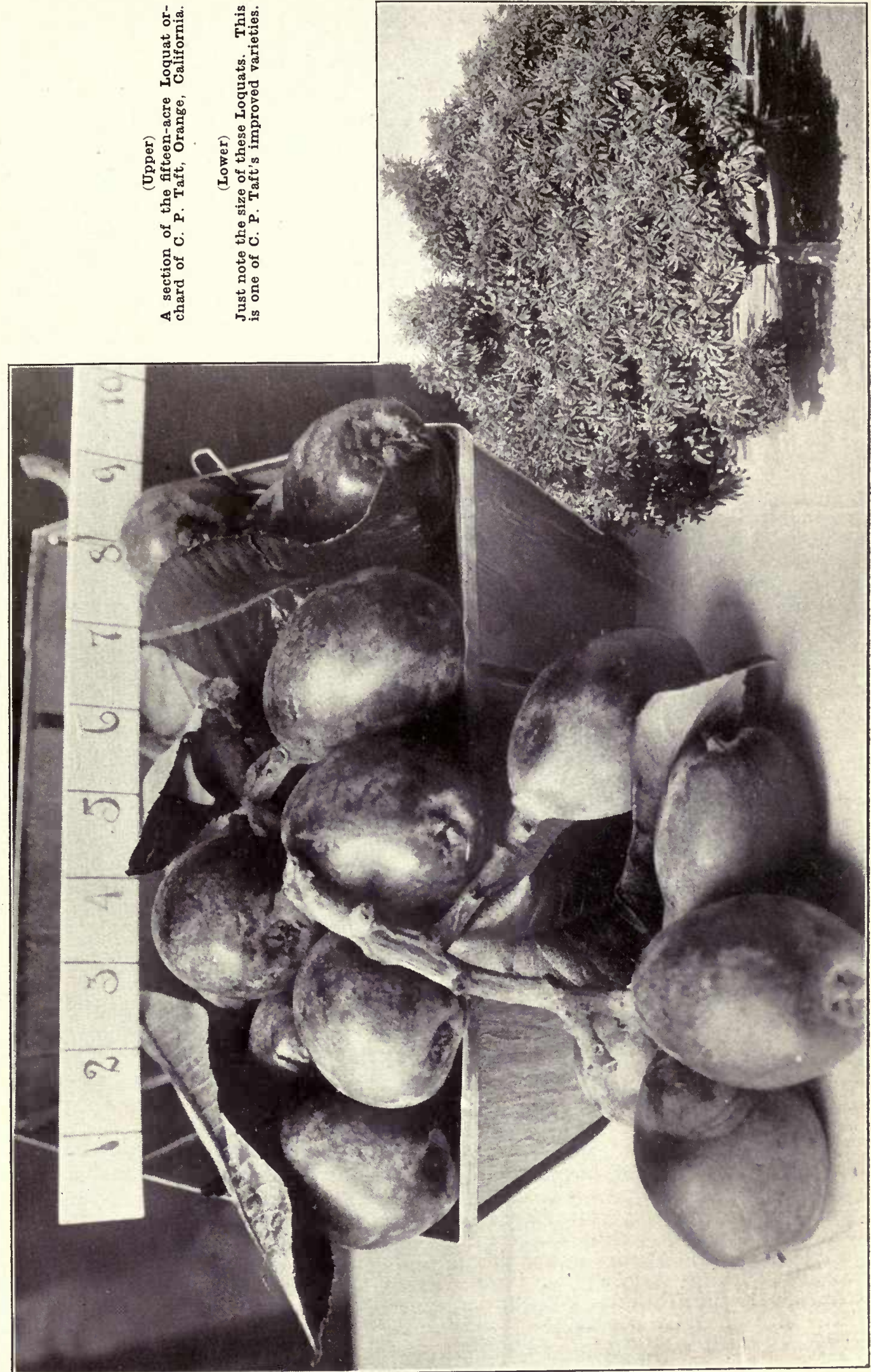
deep green, ruffled foliage. The improved types are as large as, or even larger in some instances than, a bantam egg. The trees have been planted in a limited way commercially: As they eventually attain a height of twenty feet and have quite a spread they should never be planted in-orchard form closer than twenty-four feet. The fruit should be allowed to ripen on the trees until it attains an orange-yellow color. If carefully handled it may be packed in strawberry or grape baskets and will carry a considerable distance when shipped by express. Outside of its value as an attractive and delicious table fruit it is made into jams, jellies and preserves. The pruning should be confined first of all to starting the branches about twenty-four inches from the ground. Outside of thinning the branches which may be overlapping or crowding it will take care of itself.

\section{VARIETIES TO GROW}

Advance, Champagne, Early Red, Premier.

\section{THE BANANA}

The only satisfaction that can be derived from growing the banana in California is based on the fact that this distinctly tropical plant can be grown and does produce very palatable fruits in very much favored sections in some of the southern counties of the state. It is a definite demonstration of how closely this climate approaches that of the tropics without having the enervating effect of that climate. The banana is grown from suckers. An abundance of water and fertilizer, consisting of rubbish, which should be spaded in around the plant, will promote a rapid and luxuriant growth. A sucker will invariably produce a bunch of bananas within twelve to eighteen months after it is planted. The bunch should be picked just as soon as the fruits have attained their size and while still green. By storing in a dark room, if the weather is warm, the fruit soon matures and it is ready for the table. If the weather is cold, when the bananas are handled commercially, it is necessary to store them in an artificallyheated room.

\section{VARIETIES}

Cavendishii, Orientum or Hart's Choice, Sapientum or Orinoco.

\section{THE JUJUBE}

The jujube (Zizyphus jujuba) has been growing in California for a number of years, having been introduced by G. P. Rixford in 1876, at that time a member of the staff of the San Francisco Bulletin, but now Physiologist of the Bureau of Plant Industry, U. S. Department of Agriculture. The oldest trees are said to be growing in Sonoma valley. Isolated specimens are to be found growing in both the Sacramento and the San Joaquin valleys. The climatic conditions of the interior valleys seem to be particularly favorable to its rapid growth. It is very extensively grown in northern China, where hundreds of varieties, it has been said, have been developed. It grows in the driest of locations and is very resistant to alkali. Many new and

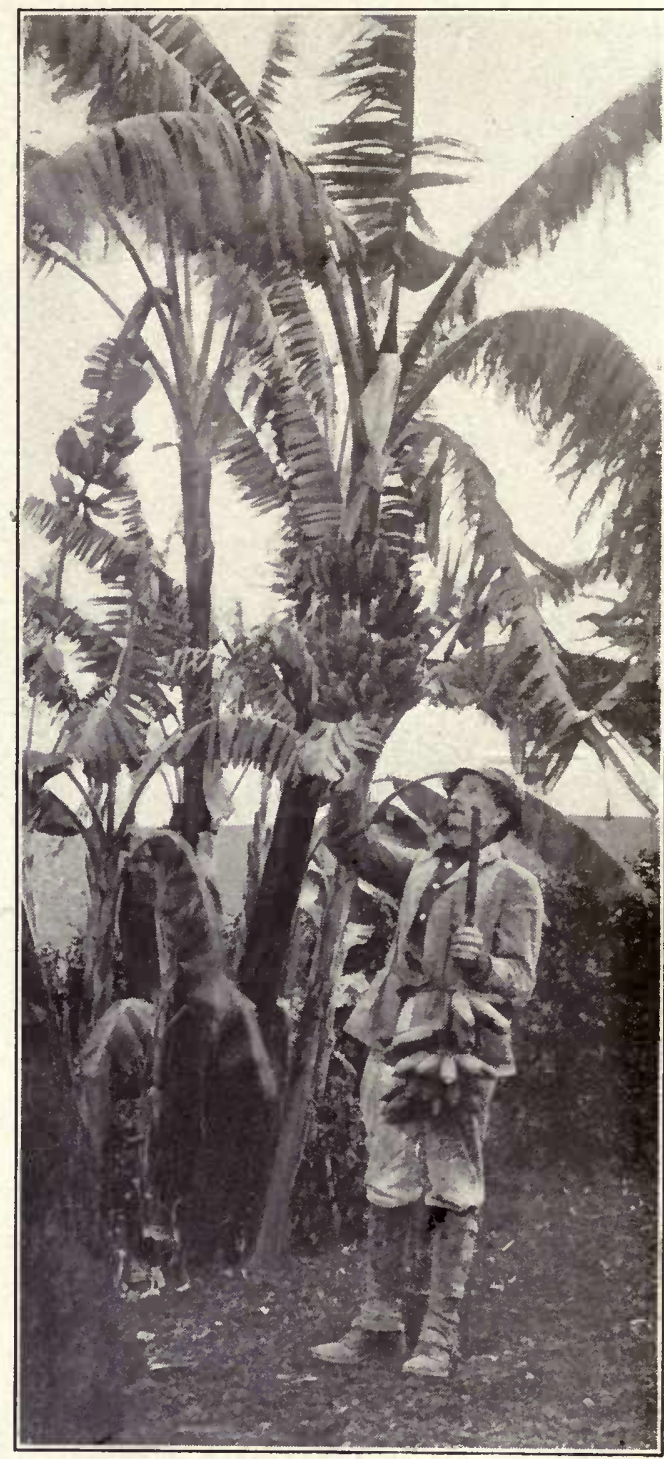

This picture was not taken in the tropics but on the property of Wm. Plotts, near Whittier, Los Angeles County, in the month of December. Bananas are part of the family diet the year round.

valuable varieties have been introduced by the Office of Foreign Seed and Plant Introduction of the United States Department of Agriculture, and if eventually this becomes an industry of any importance in California, we will owe a debt of gratitude to this great department of our National Government which has accomplished more in behalf of the agricultural and horticultural interests of the United States than any other institution of like character in the world. Many of these new varieties of jujube are now being experimented with at the Plant Introduction Garden near Chico, California. Some sorts are eaten fresh, while others are dried. The largest varieties are processed by boiling in sugar and honey. They make most desirable sweetmeats when so processed and are even more delicious than the Persian dates of commerce. The 


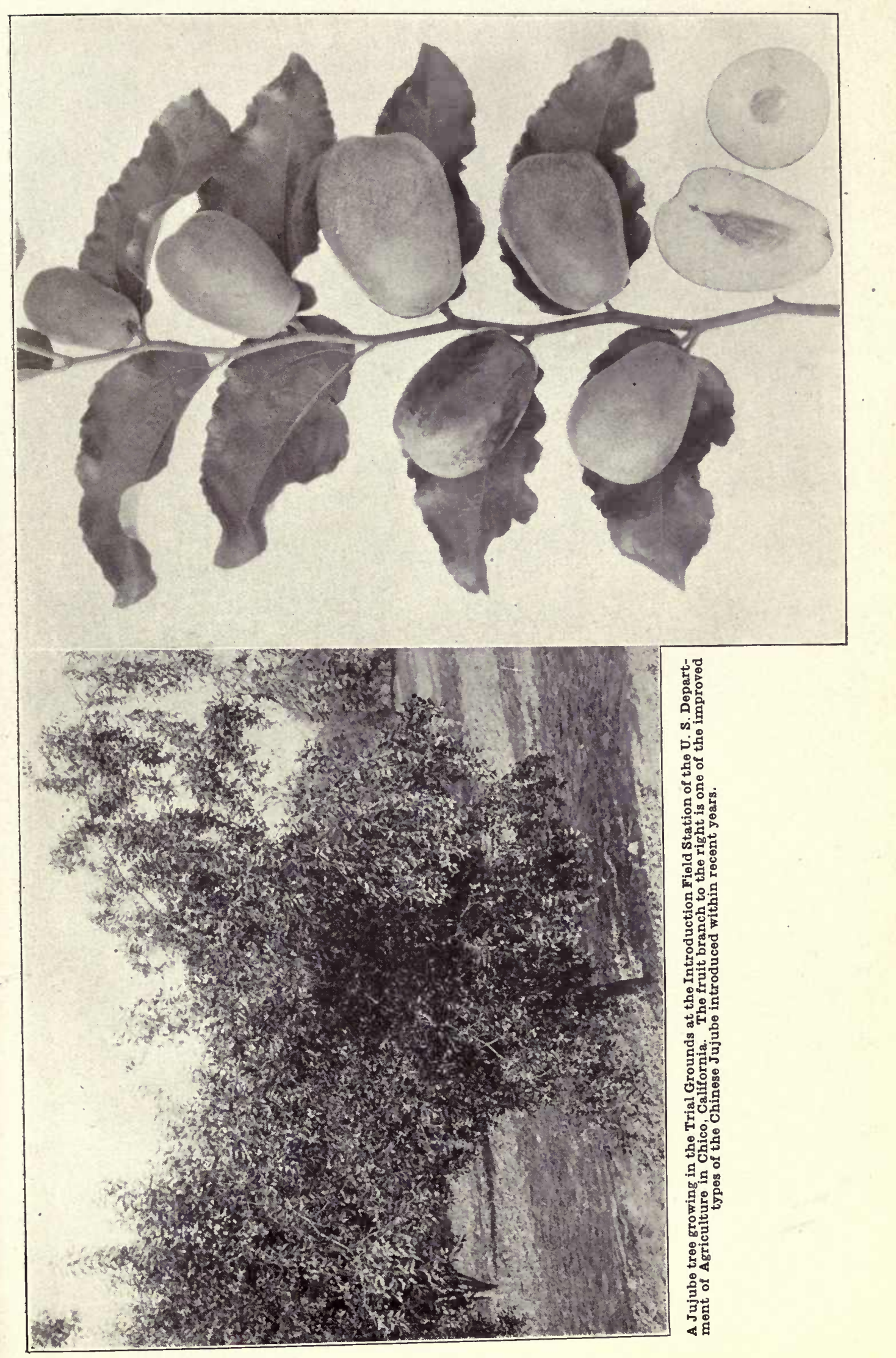




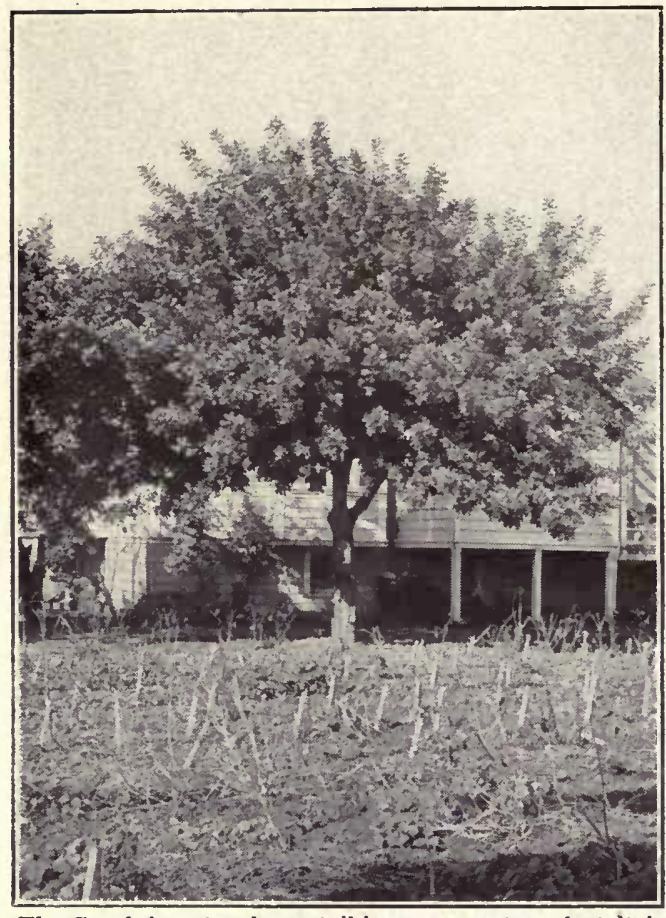

The Carob is not only a striking avenue tree, but it is adapted to the driest of locations. The beans make fine stock food.

trees bear enormously, and they are very ornamental. The fruits are very palatable whether processed or not, therefore we have in the jujube combinations which will cause it to become, once its value is better understood, a valuable aequisition to our list of fruits. The only varieties on the market now are those produced from seed.

\section{PROCESSING}

The eredit for successfully processing the first jujubes in the United States is due to Mrs. R. L. Beagles, wife of the Farm Superintendent of the Plant Introduction Field Station, of the U. S. Department of Agriculture, Chico, California. The process is as follows: First of all provide a tray with tacks driven through it a sixteenth of an inch to prick the fruits. Then cook in a syrup consisting of one cup of sugar to one of water, for a period of one hour. Drain the syrup off, roll the fruits in granulated sugar, and allow them to dry for a period of one week, when they are ready for consumption. The fruits should be gathered while firm.

\section{THE CAROB}

In the Cyclopedia of Horticulture, Bailey refers to the Ceretonia siliqua as a very handsome evergreen tree bearing large pods that are used somewhat for human food but chiefly for forage. The cultivation of this tree dates back to historic times. The impression prevails that this is a tree to which reference is made in the Bible as the honey locust or St. John's bread-fruit tree. It was introduced in California a number of years ago and the largest specimens are to be found growing in Santa Barbara. After it attains an age of six years it will withstand the cold weather of the interior valleys, but it must be protected while it is young, otherwise it will freeze to the ground, starting out again in the spring from the roots. There are thousands of acres of land in the southern part of the state on the hillsides and on soils of a rocky nature where this tree could be grown, and it would not only transform the landscape, being an evergreen, but would make entirely unproductive land valuable because of the great nutriment which the pods contain for the fattening of cattle, hogs, sheep, ete. Until a few years ago all the varieties grown in California were raised from seed. Frobably the largest collection of varieties were those which had been grafted on the seedling tree on one of my places near Fresno, the buds having been received from the Division of Seed and Plant Introduction of the United States Department of Agriculture. Fortunately this tree was well protected and has been the source of supply for budding over and replacing trees which have been killed by cold weather in other parts of the state. In the countries bordering on the Mediterranean sea the large pods, which are rich in protein and sugar, are a very important forage erop, being eaten with avidity by all kinds of steck, kesides furnishing considerable sustenance to the poor in times of scarcity of other foods. The pods are also used for the manufacture of

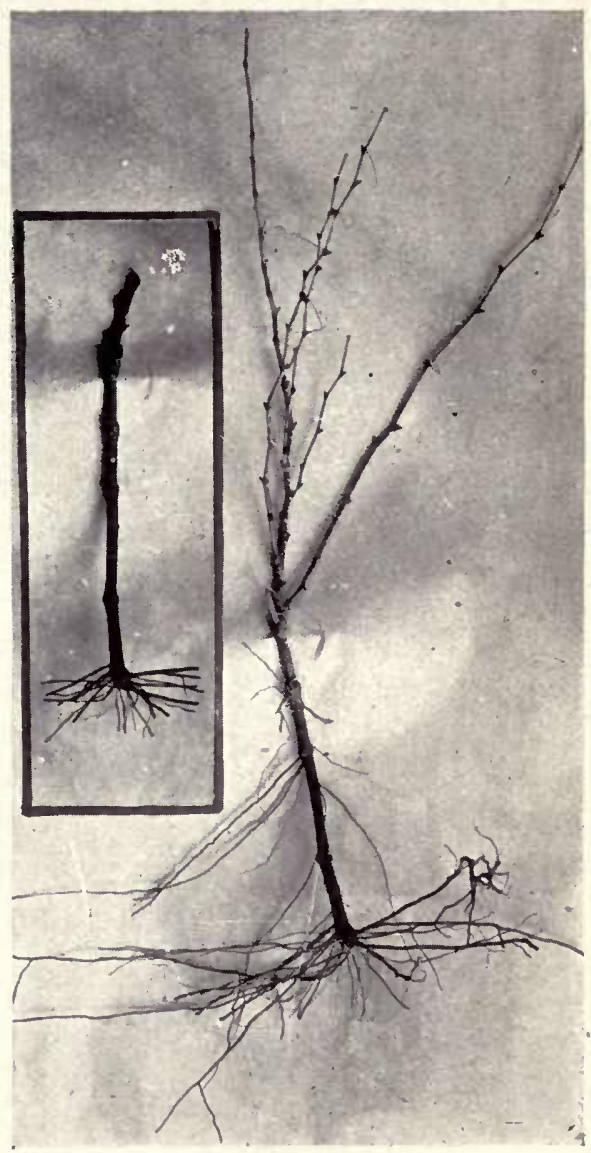

A pruned and unpruned grapevine. The figure to the left shows how to prepare vines for planting. 


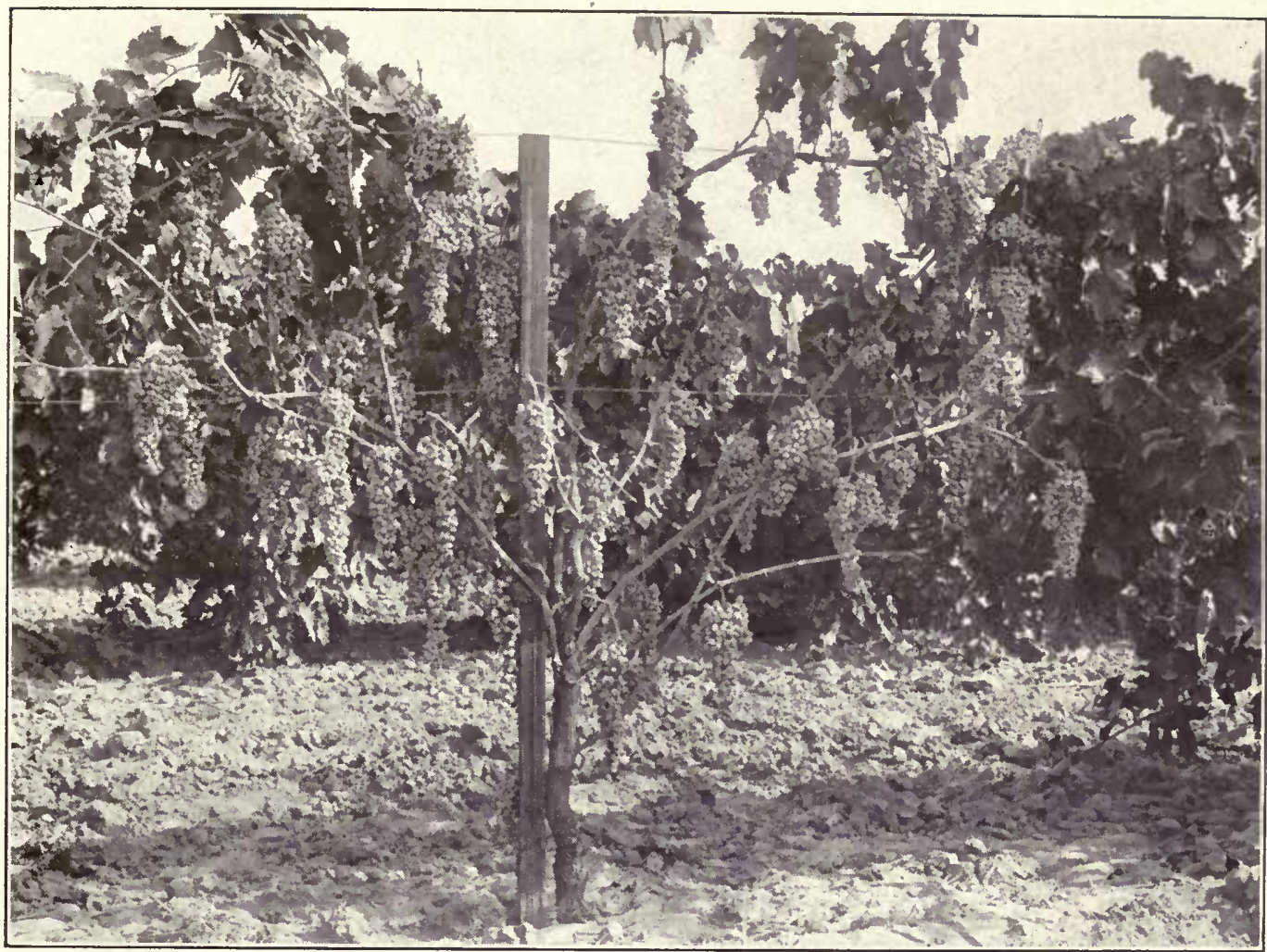

A three-year-old Thompson Seedless vine demonstrating the method of pruning and the distribution of the grapes.

syrups and a variety of fermented drinks. Thousands of tons are annually imported into England, where they are ground for stock food. Carob pods form the basis of the best condition powders for stock. The pods sell for sixty dollars per ton or even more than this in some instances. The tree is well adapted for avenue purposes, and although it will grow with little or no care it responds readily to goed care and cultivation. The tree blooms in the fall of the year and the crop of beans is ready for harvesting just a short time before the trees commence to bloom. The trees should be planted thirty feet apart. In order to grow a well shaped tree it is necessary to set a stake beside each tree. The head should be started four feet from the ground. For the first few years some pruning and thinning should be done, but after it has once taken on its form it requires very little attention. The varieties on the market now are seedlings. Within the next few years budded trees of recognized value will be offered for sale. The pods being hard and dry, drop to the ground when ripe of their own accord, or they are knocked off with light poles. The expense of harvesting is therefore very light.

It is a pleasure to note that the agricultural press is exploiting the possibilities of this tree becoming an important factor in the horticultural development of California. Many of the out-of-the-way places on the farm could be planted to good advantage with the carob.

\section{THE GRAPE}

Even in Europe there is a charm in the name "California." This should occasion no surprise, for within the confines of this state there is not a single variety of fruit which can not be grown to as great an advantage here as in its nativity, where the culture has extended into centuries. With the exception of the countries bordering on the Mediterranean, where there is no rain during the summer months, all the varieties of grapes for table purposes which flourish with us can only be grown in Europe under glass. The quality of grapes grown under glass is as a matter of fact better than those grown in the open. The culture of grapes in greenhouses is carried on more extensively in Belgium, Holland and England than in any of the other countries of Europe. The perfection which has been attained in growing such grapes, the ready demand for the fruit which retails in all the great markets of Europe at from fifty cents to one dollar per pound, according to the season, is another striking evidence of the prices which may be realized for carefully selected fruit. It is only in counties having a climate like that of San Franeisco that it will ever be practical to pursue this branch of the industry successfully. The advantage to be derived lies in the fact that in cool, foggy elimates it is possible to regulate the temperature and lave ripe grapes of the highest quality when all other grapes are off the market. The great strides that grape culture has made in California is apparent from the following statistics: raisin output not less than 150,000 tons annually; table grape 


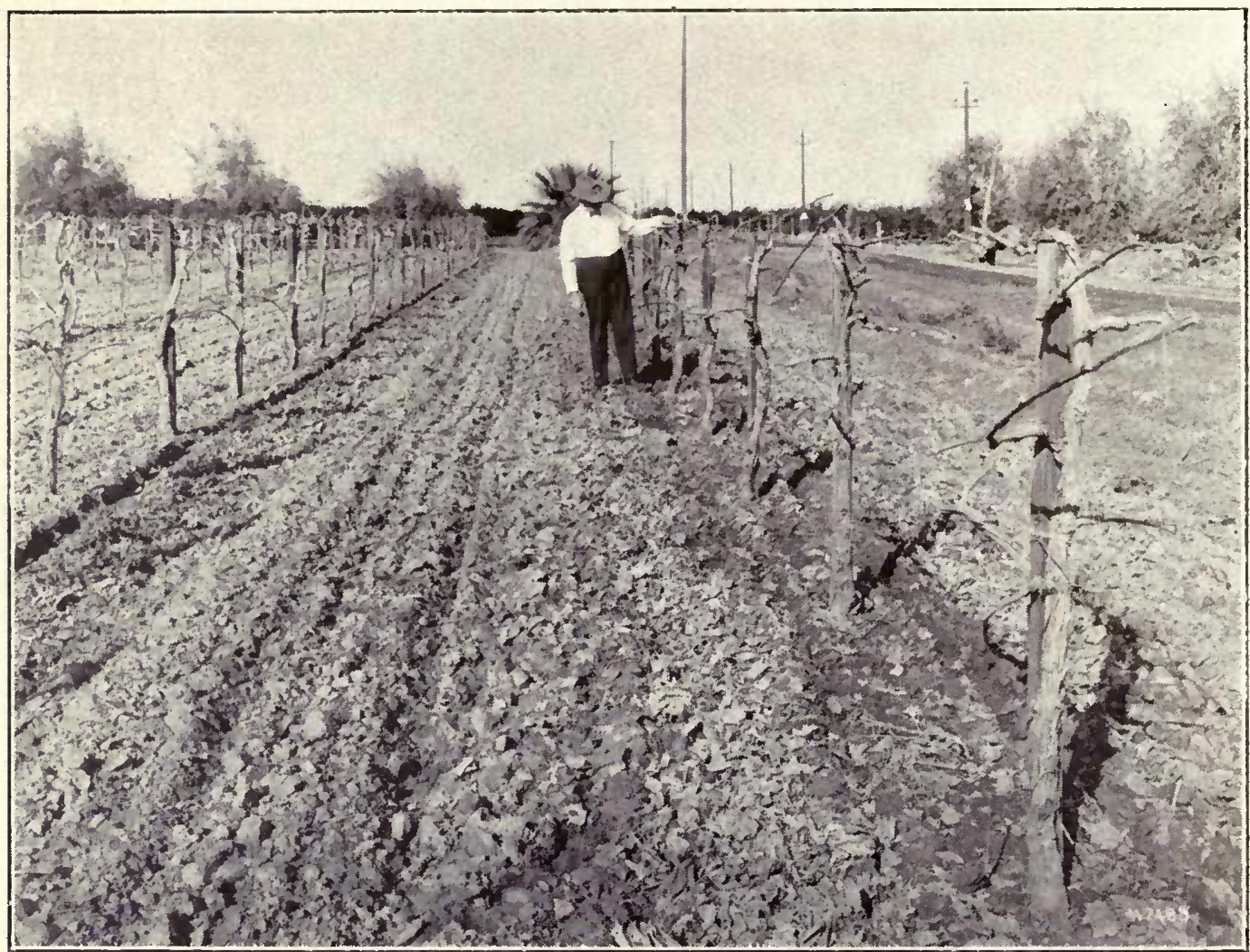

The correct method of pruning Emperor vines. These vines are four years old. Note the distribution of the spurs and the canes, which will very shortly be tied to the two trellis wires.

shipments 170,000 tons; wine and brandy produced $50,000,000$ gallons. Up to a few years ago there seemed to be very little chance for the development of the late table industry but now the method of shipping grapes packed in kegs in redwood sawdust has been discovered through the efforts of the Division of Pomology of the United States Department of Agriculture, and so another great field is open for exploitation. The first carload of grapes shipped out of California packed in this manner was forwarded by the writer in 1912. The work was carried on under the instructions of C. W. Mann, and under the direction of A. V. Stubenrauch, now deceased, of the United States Department of Agriculture. It was only after careful experimental work extending over a number of years that the value of sawdust as a preservative material was finally evolved. When grapes are packed in sawdust and placed under refrigeration the temperature being maintained at 32 degrees Fahrenheit, varieties like the Emperor, Cornichon, and Almeria will keep in perfect condition for several months. The shipments now average five hundred carloads annually. The kegs hold thirty-two pounds of grapes each. The great possibility for late table grape culture in California may be drawn from the fact that in normal times we import annually from Spain 1,000,000 kegs of Almeria grapes, each containing forty-five pounds of fruit. Cork dust which is used for packing demonstrates the complete use of a material in some form for a beneficial use.

\section{SITUATION AND SOILS}

The magnitude of the industry in California indicates that the growing of grapes is not confined to any one locality. It is very difficult for one to realize unless he has observed the climatic conditions of California carefully or fully appreciates the scope of this industry. Were it not for the variations in climate it never would have been possible to engage in so many branches of viticulture in this state. It is only in the great interior valleys, where there is very little or no rain during the summer and fall months, that it is practical to make raisins, and this is possible on account of the clear sunshiny days and the high temperatures which prevail. It is in these same valleys that the table grapes reach their greatest perfection. This does not mean that there are not certain sections in the Coast regions where table grapes can not be grown. However, the late ripening varieties are as a whole better adapted to the interior valleys than to the Coast regions. For light table wines, the Coast counties are found to be better adapted to the growing of the finer types of the wine varieties, while in the interior valleys in many cases the same varieties of grapes are grown, but on account of their high percentage of sugar it is very difficult to make light wir es from them, so instead they are used for making ports and sherries, and for the manufacture of brandy for fortifying purposes. The grape will thrive in a great variety of soils; in fact there are few soils in which it will not do well. The deeper and more alluvial 
the soil the better the production. Soils impregnated with alkali or where the water table is too elose to the surface should be avoided.

\section{LAYING OUT A VINEYARD}

First establish your base lines. It is best to have this done with a transit, particularly if there are no established regular subdivision lines to work from. If the base lines are not at right angles, the rows will not be straight, and nothing is more unsightly. Add to this the difficulty of plowing and cultivating and the advantages of straight rows will be readily understood. For planting use a steel woven No. 19 galvanized wire, dividing same up into sections as reeommended under the heading of "Methods of Planting," and at equidistant points on the ehain a piece of wire is wrapped to which markers
Having set the stakes along the outside line at the distanee apart the vines are to be planted, start at the same end of the field again and set another line of stakes parallel with the first line and the length of the chain distant from the outside line. Proceed in this manner until the entire field is laid out in cheeks. With this preliminary work done, and having exercised eare in the measurements to have the base lines parallel and the stakes in each block opposite each other, no diffieulty will be experieneed when planting commenees to have the vines line up.

\section{DISTANCE TO PLANT}

This always gives rise to much discussion, and opinions vary so that the planter is often in a quandry as to what course to pursue. The prevailing praetice is to

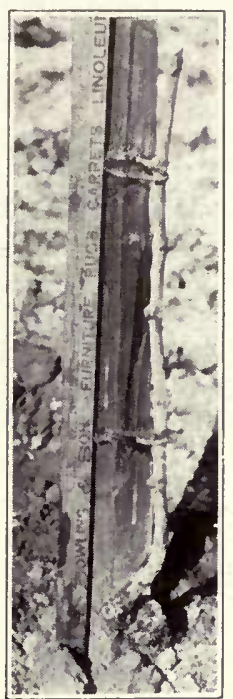

A one-year-old Muscat vine trained to single cane and cut back to twentyfour inches.
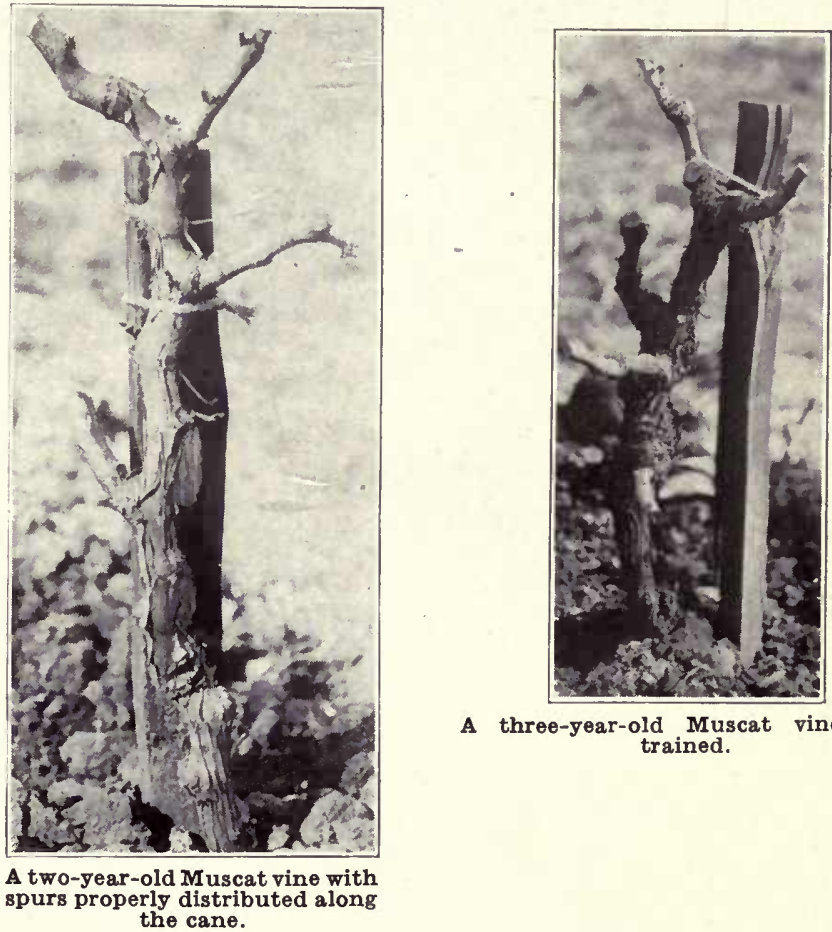

A three-year-old Muscat vine well trained. are attaehed and soldered into place. It is necessary, of course, to change the markers to other points for planting at greater or less distances. It is best to have the wire ehain the width of the eheek, the last link coming flush with the stake indieating the roadway. These roads between the checks should be at intervals of twenty-four rows for a wine and table vineyard and thirty rows for a raisin vineyard. Start at one corner of the field with the ehain, which should have three-inch rings at eaeh end for inserting the iron stakes. These should be made of one-half by two-ineh iron, two and one-half feet long and drawn down to a point at one end. The stakes which are to be used as markers may be split out of redwood, or any other material, for that matter, and at least six inches of one end dipped into a bucket of whitewash, so that the line of the base rows may be readily seen. plant wine grapes $8 \times 8$ feet, leaving out the twentyfifth row for an avenue. For wine and table grapes the avenues should not be farther apart than this. As it is necessary to carry out the grapes in lug boxes to the avenue, the pickers (if the work of harvesting is done by eontraet) demand more per ton for the pieking than where the eheeks are twenty-four vines wide. For types of raisin grapes which are to be short pruned and headed low where the drying is to be done on trays in the vineyard, any of the following distanees are satisfaetory: $8 \times 8,7 \times 10,6 \times 12$ feet, always leaving the wide rows east and west, so the trays shall get the full benefit of the sun's rays. In this case the eheeks may be thirty rows wide. For staked vines of raisin grapes, where the drying is to be earried on in the vineyard, $6 \times 12$ feet is undoubtedly the most economieal distance to plant, as picking is much faeilitated, the trays get 


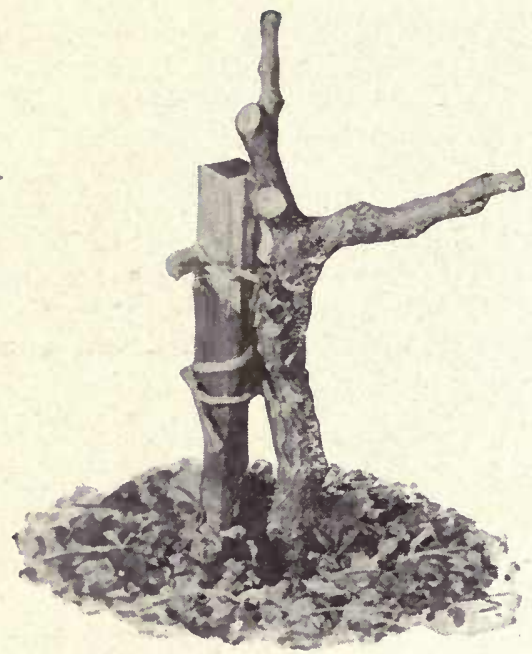

A two-year-old Muscat vine under the old method.

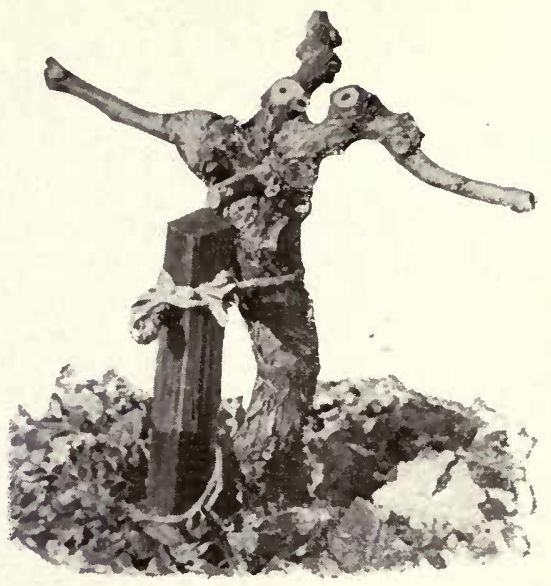

A three-year-old vine under the methods formerly recommended with the head started from a central point; no longer advocated. the full benefit of the sun, and the raisins cure quickly, which is not the case where vines are closer together. Table grapes should not be planted closer than $8 \times 10$ eet, with the wide rows north and south. The grapes then have more exposure to the sun and mature more uniformly. This rule applies more particularly to the varieties which ripen rather late, like Cornichon, Emperor, Gros Colman, Black Morocco, etc.

\section{PREPARING FOR PLANTING}

All rootlets, excepting those starting from the base of the vines, should be cut off. Next shorten in all the roots radiating from the base of the cutting from two to three inches.

Then prune the top of the vine, leaving only one spur with from one to three buds. The vines should be pruned a day or so in advance of the planting, and the work should be entrusted to careful men. As soon as pruned, the vines should be heeled in and the soil either wet or tamped down to prevent the roots from drying out. The heeling-in ground should be centrally located, so that it will not be necessary to carry the vines too long a distance to the planters.

\section{HOW TO PLANT}

Each man should be provided with a bucket or five gallon coal-oil can. A small quantity of water in the bottom will keep the roots moist. Each bucket should be filled with vines, and replenished from time to time wiih vines as they are needed by the planters.

The planting wire should be stretched across the first check to two stakes, which should be directly opposite each other. Each planter should have charge of two marks on the wire. As an illustration, figure on a basis of planting the vines eight feet apart each way and leaving out every thirty-first vine for an avenue. It would be necessary to have a wire chain 250 feet.long over all, including a two-foot link at each end for the ring to permit drawing the chain taut. To such a chain it would be necessary to have seventeen men, two to stretch the ehain across the field between the two stakes set opposite each other in the check and fifteen to doj the planting. The marks eight feet apart in the chain indicate where the vines are to be set. In planting, the vine should be set so that the collar will be level with the top of the ground when it is settled, except with grafted vines, which will be referred to later. The soil in the bottom of the hole should be loosened up, and that used to fill in should be top soil, the first few shovels of which should be well tramped in, the top being left loose. Having set this line of vines the chain is carried to the next two line stakes, and so on until the check is planted. Within one week after planting the earth should be settled around the vines either by hauling water to them or by irrigating, running the water in furrows along each row. This is important, for even with a good field boss over a crew of men, some of them will be careless, fail to tramp the soil around the roots, and unless a timely and heavy rain should cause the soil to settle, the vines will dry out and die.

\section{CARE AND PRUNING THE VINES}

The training of the vine should be given careful attention the first year of its growth. In order that the plant may not form a head close to the top of the ground a short stake allowing it to be a foot above the ground, should be driven beside each vine. These stakes should be one inch square and two feet long, as they should be taken out the first winter. Any cheap stake, provided it will support the growth of the vine, will answer. In July, before the growth of the canes has become lignified, they should be tied with three- or four-ply baling rope to the stake, and about one-third of the top growth cut off. This shortening in of the eanes causes them to become stocky, and as a result of the tying up there are a number of straight shoots, the strongest of which may be selected the following winter, the others being removed.

The most serviceable permanent stakes are the split stakes made out of Coast redwood. These stakes should at least be $2 \times 2$ inches. Their length will depend largely on the variety of grape to be trained to the stake. For 
Museat vines and other vines which do not make long canes a three-foot stake will answer. For. Malaga and stronger growing vines in its class use a four-foot stake, and for Emperor, Flame Tokay, Cornichon, Sultana, and Thompson Seedless the stake should at least be six feet long.

In making my recommendations in reference to pruning I am going to diseuss varieties on a basis of "Standards." In other words, a Museat and vines in its class, making short canes, will be referred to as low standards, meaning that the height of the cane would not exceed twenty-four inehes. The Malaga should be termed as a medium standard, eane not to exceed thirty-two inches, and the Thompson Seedless high standard, cane not to be longer than forty-two inches.

No diffieulty will be encountered under ordinary eonditions in seeuring a low standard eane the first year, provided the growth of the vine has been tied up as directed. If the eane shows by its size that it is not strong enough to be earried to its maximum height in the first winter pruning, it should be cut off to a point where it is sturdy, and during the growing season the strongest shoot from it should be selected and firmly tied to the stake. In tying to stake use nothing smaller than a three-ply baling rope. Anything smaller than this, should the eane grow vigorously, will eut it in two. On low and medium standards rub all the laterals off, starting not eloser than ten inches from the surface of the ground, and on the others anything below fourteen inches should be rubbed off. It is of the utmost importance to have the stem of the vine tied firmly to the stake to have it as straight as possible, for it will ultimately form the body of the vine. In the second winter when pruning the low standard, leave at least four spurs, getting them as evenly distributed as possible, and be sure to have one at the tip end of the vine. The medium standard should have at. least six and the high vine not less than eight. None of these spurs should exeeed five inches in length. A light erop of grapes may be expected from the vines in the second year by this method of handling. In the third winter each one of these spurs will have several eanes, and in the ease of the low and medium standard vines which ordinarily would not be trellised, two spurs with not more than three eyes in each should be allowed to remain. In succeeding years these eyes from the original stock may be inereased, depending on the growth of the vine. In the third year the trellising of high standard should commence; when this is done one cane and one short spur with three eyes or buds should be allowed to grow from the stock of the preeeding year. The objeet of this is to furnish wood for renewing the cane in the fourth year, for the first one will be eut off close to the original stoek. This method permits of the renewal of the bearing wood of the vine annually and promotes its vigor. There are several advantages in this method of pruning: One is that the vines eventually become selfsupporting, making an immense saving in stakes, when after a number of years they must be renewed. There is a tendeney on the part of all vines as they grow old to have large spurs die. When the vines are trimmed to a

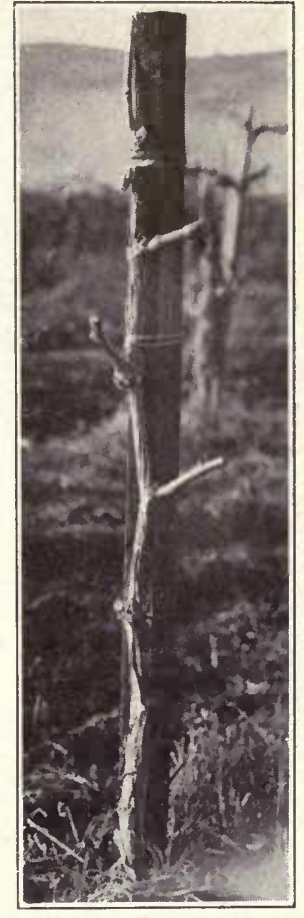

A two-year-old Emperor vine, properly trained.

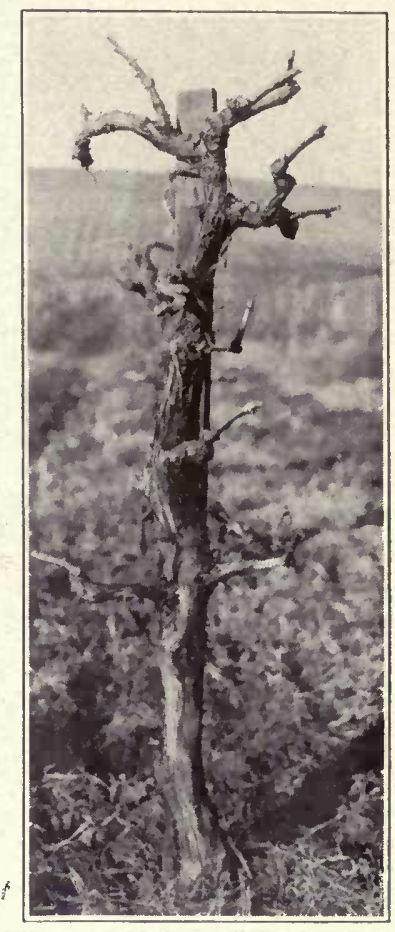

An eight-year-old Emperor vine with spurs well distributed along the body of the vine. head-say twelve inches from the ground-it very frequently happens that decay sets in where the heavy saw euts are made in removing the old spurs, and the vine either dies prematurely or there is such a slow renewal of new wood that it beeomes unprofitable.

For trellising, use a twelve-gauge wire and either staple it to the stakes, using a medium sized staple, or bore holes through the stakes and pass the wire through. To prevent the wires from becoming slack the end stakes in each row are braced, the braces being of sufficient length to reach from the top of the inside stake to the base of stake on the next row. At three years old a trellised vine should not have more than four eanes. This may in later years be inereased, but eight should be the outside limit.

A great saving can be made in tying up vines or canes, for that matter, to the stakes by stripping off the leaves from the California fan palm and using these strips in place of rope. These palm-leaf strips are not only very strong but are also very durable. The leaves should be cut two weeks in advance of using and exposed to the weather to cure before tearing them into strips.

In trellising, the cultivation of the vineyard is somewhat more expensive, as it only permits working the rows one way, so that the eenter between the rows must be worked out with a horse hoe. It has been found that by trellising, the harvesting of the erop is facilitated, the bunches are more evenly distributed, the vines produce larger erops and in addition to this there seems to be less danger from damage by early spring frosts. 


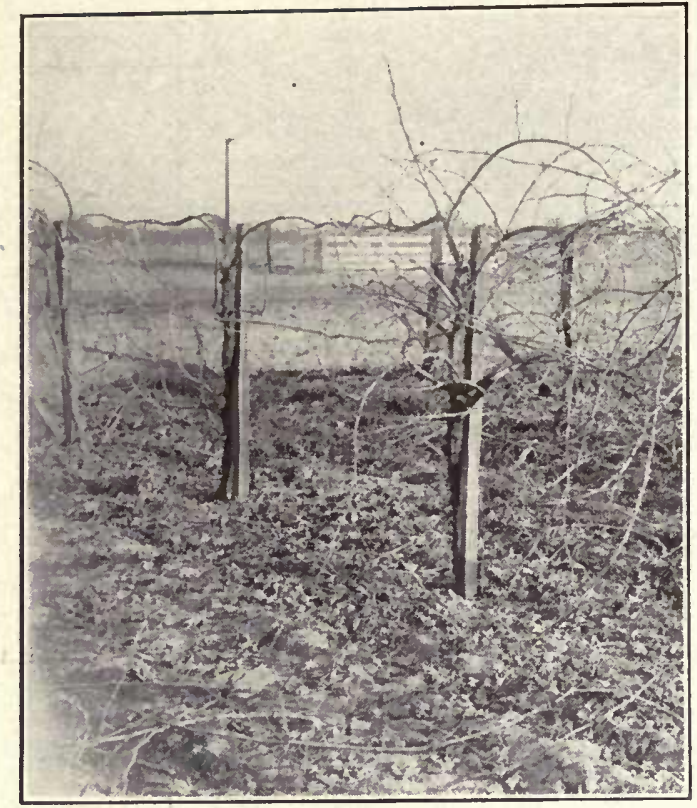

A three-year-old Thompson Seedless vineyard, trellised, showing pruned and unpruned vines.

\section{RESISTANT VINES}

The ravages of the phylloxera in the grape regions of France and the practical extermination of the French vineyards through this dreaded pest are too well known to require repetition here. Today France is producing more wine than she did in her palmiest days, prior to the time the pest was introduced. This wonderful change has been brought about by the grafting of the table, raisin and wine varieties, all of which are natives of Europe belonging to the Vitis Vinifera class, and none of which, no matter how strong they are, but will finally perish when attacked by the phylloxera.

The resistant sorts were originally wild American grapes, natives of the Mississippi valley. These were taken in hand by the French viticulturists, improved by hybridization and selection, until today a large number of sorts adapted to a variety of soils and locations have come into general use.

The destruction of Vinifera vines is due to the roots rotting whenever the insect makes a puncture, causing the vine to perish in time. In the roots of the resistants, although subject to these attacks, the punctures do not extend deeper than the bark of the rootlets, and as this is sloughed off each year, the roots are left as healthy as before. The grapes of the resistants are worthless; they simply serve as a stock for the more valuablc foreign varieties of wine, table and raisin grapes, all of which succumb to the attacks of the phylloxera on their own roots. The cultural directions already given for planting vines on their own roots may be applied to the resistants in so far as preparing the vines for planting. In planting the rootings the vines should be set so the union of the stock is at least an inch above ground. As soon as the vine is planted, cover it with soil, leaving only the top bud exposed. When the vines have a good strong growth, clear the soil away from them and cut off any roots which may be started from the scion. This is one of the important points in bringing a resistant vineyard into bearing, for if these roots are not cut off the resistant roots dwindle away and the vine reverts back to its own root. Suckers starting from the resistant cutting should also be removed.

It is necessary to follow up this root pruning for at least five years after the vineyard is planted, for the scion will invariably start out new roots if the soil from plowing gets banked up against it. In later years, after the wood of the vine becomes well hardened up, there is very little danger of the scion making roots. The same recommendations for training and pruning vines on their own roots may be followed with grafted vines.

\section{IRRIGATION AND CULTIVATION}

There are two essentials which go hand in hand not only in the great valleys of California but in many other parts of the state where the annual rainfall is not sufficient to maintain an active growth in the vine -cultivation and irrigation. Cultivation is very rarely carried on to an excess but irrigation is, and it frequently results in mueh harm to table grapes used for shipping purposes. The berries instead of being firm and plump become watery and as a result do not carry well. Even in the first year it is a mistake to irrigate vines too often. After the vines are set it is important to water them and subsequently during the growing season a furrow should be plowed out on each side of the row and about a foot from the vines, to carry the water used for irrigating. As soon as it has soaked away and before the ground gets too hard, cultivate thoroughly and loosen up the soil around each vine with a hoe. At the very least calculation the number of irrigations during the summer and early fall months should not exceed three. If the vines are making a strong growth and this condition can be maintained in them by cultivating, by all means depend on this to promote their vigor and a strong root system rather than to attempt to stimulate with too much water. "The less surface roots there are and the deeper the roots from the base of the vines go into the ground, the longer lived will be the vineyard, and the response in production will be all the greater, due to the care given the vine when it was first planted. After the vineyard comes into bearing a thorough irrigation, plowing out a ditch in the center of the row and filling it with water, is very beneficial, providing this application of water is given on or before the month of June. Instances may arise where it may be necessary to irrigate again at a later date. This is a matter which must be determined by the grower himself from his observations of the general growth and the healthfulness of the vines. Much interest has been taken within the last few years in winter irrigation. After the vines have become dormant there is no question but that the applying of water in the latter part of November, or any time in December, has a very stimulating effect on the vine when it starts to grow in the spring, and in addition to this it has the tendency to stimulate the growth of vegetation, all of which adds to the fertility of the soil when it is 
plowed during the spring. After the vineyard is pruned it should be plowed not less than six inehes deep. Immediately after plowing the soil should be hoed away from the vines, and all suckers should be eut off elose to them. The basin made in hoeing should not be filled, for among the many other benefits secured, the eggs and larvae of insect pests collecting around the vine are destroyed by exposure. The next step is eultivating, or if the ground is eloddy it is far better to use either a dise or harrow first to break up the clods, and then follow this up with eultivation. The eultivating should be continued as long as the shoots will not be broken off by the team and implement passing through the rows.

\section{FERTILIZING}

Very little attention has been given to the fertilizing of vineyards. Anyone having given this subjeet any thought must be convineed that wood and fruit can not be taken from the vines year after year without adding something to the soil to maintain its fertility. The problem of fertilizing or of growing cover erops in a vineyard should be given eareful attention. The expense of earrying on this work is so heavy and goes so deeply into the vineyardist's pocketbook that he fights shy of this problem quite frequently until it is too late. After many years of experimental work in my own vineyards, consisting of table, raisin and wine grapes, using commereial fertilizer, stable manure, and a variety of cover erops, I have come. to the eonelusion that in both the use of manure and the use of commereial fertilizer the best practice was to make the applications where the erop produced was not up to the standard it should be. A reeord was kept of the blocks in the vineyard where the vines were not growing well and where the crop was defieient, and liberal applications of barnyard manure and a complete fertilizer were made to better the condition of the vines. In applying manure it should be well deeomposed, if obtainable in this condition, and not less than ten tons to the acre should be put on. If possible this should be put on in December and the commereial fertilizer in the latter part of January, or in February, using not less than five hundred pounds to the aere, although double this quantity is better. Cover crops have as a rule been very unsatisfactory. The immense benefits to be derived from the use of eover crops have been exploited to the limit. I have been one of the many practical growers who have paid dearly for their experience, not only using them in vineyards but in orange orehards as well. I have tried all of them-fenugreek, vetch, Canadian field peas, rye and melilotus. The first three are failures in the interior valleys beeause it is impossible to plant them in the vineyards in October when the harvesting of the erop is going on, and seeondly beeause it is out of the question to apply any water at that time; thirdly, the eool, sharp air which is so apparent during the late fall and winter months, entirely at variance with the elimatie conditions in the eounties south of the Tehachapi, is not conducive to the growth of any of these erops unless it is Melilotus. In the eounties referred

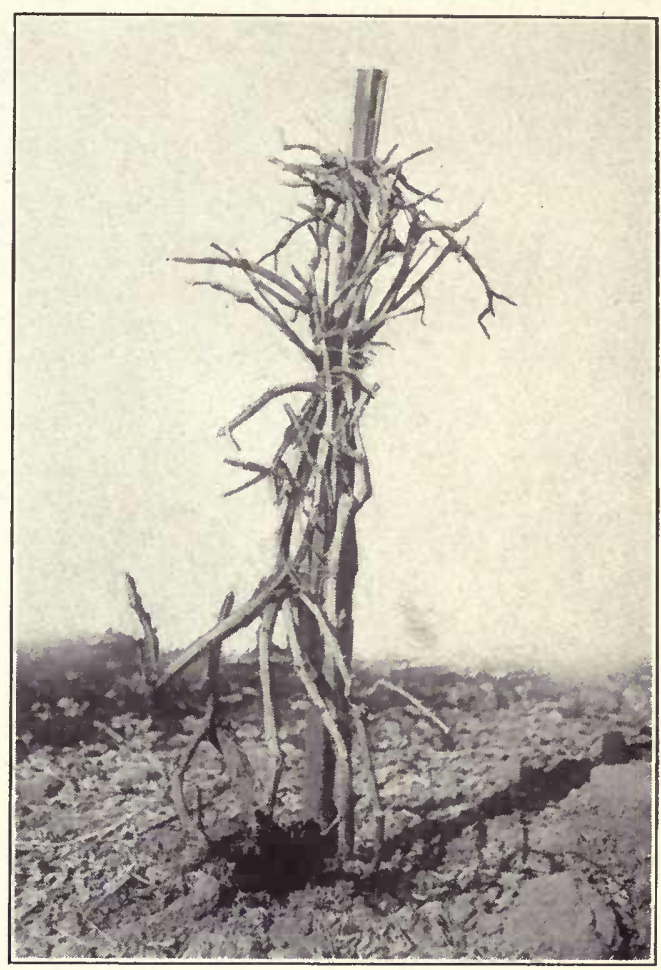

A Thompson Seedless vine with numerous stems. Abominable method of pruning.

to where the air is warm and where the water is carried in furrows made after the cover crop is planted these erops do well. However, there is one very important point which should not be lost sight of and that is to turn under a cover erop before it begins to draw on the soil and sap, the strength of the trees. Time and time again I have seen citrus orchards drained of their vitality to such an extent by allowing cover erops to remain in the ground too late in the season that it took several years for the orehard to get back to its normal condition and then only by very careful attention through fertilizing and irrigating. It is a safe rule to follow to plow all eover erops under on or before Mareh. The melilotus is the most satisfaetory erop in the interior valleys, but to even get results from it which are worth while the planting of the seed should be done in Oetober. It has one advantage over the other erops and that is that it grows even in cold weather providing there is moisture in the ground. The only advantage that rye has is that it may be sown after the first rains, and as it makes a very rapid growth it adds humus to the soil. Such lands as have not been planted to cover crops before should have the seed inoculated with nitrogen-bearing bacterial germs before planting.

\section{GATHERING FOR SHIPPING}

California is now and will continue to be the main source of supply for table grapes both for consumption in the United States and for export. The magnitude of the industry is a sufficient indication of its stability. The readiness on the part of the consumer to pay high 


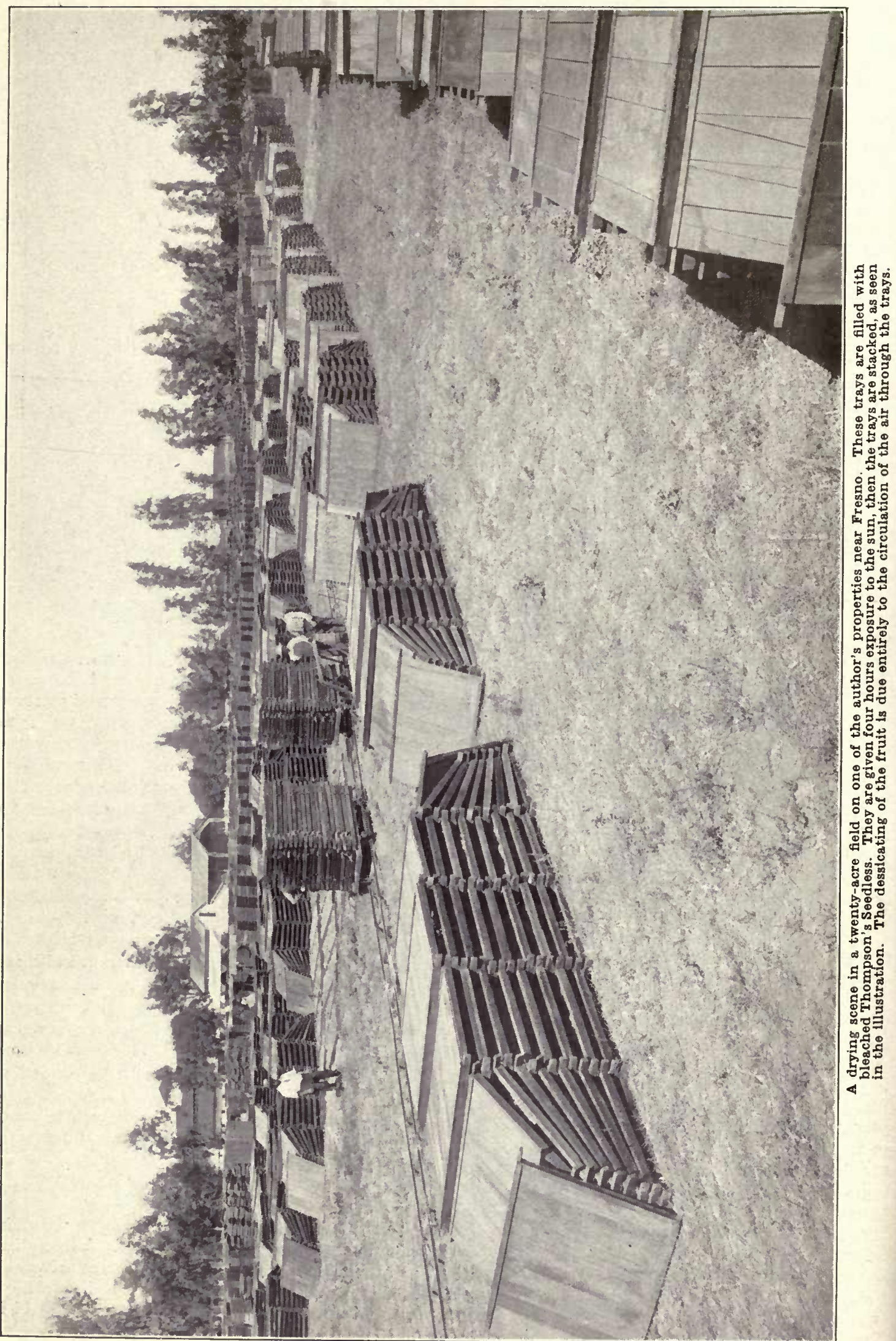


prices for good fruit verifies fully the profits to be realized by the grower who devotes proper attention to the care of his vineyard and in the gathering of the fruit. Recent laws which have been enacted not only regulate the sugar content which table grapes must have, which vary from seventeen per cent to nineteen per cent, depending on the variety, but is also going to do much toward standardizing the industry. Utter demoralization was facing table-grape industry, due to the avariciousness of unscrupulous shippers, who lost sight of the future of this business and only considered their immediate gains, entirely disregarding in many instances the amount of sugar the fruit contained as well as the quality of the grapes they were shipping. In picking table grapes the bunches should be cut off with a knife or shears and each bunch should be carefully laid in the picking box stem up. It is a good plan to cut off branches from the vines and place them in the boxes before laying in the grapes. Never have the bunches over one layer deep. Be sure to cover the top box when taking to the roadway in the vineyard with branches to prevent the bunches from being exposed to the sun. The wagon on which the lug boxes are hauled should be equipped with springs. The most satisfactory lug box for table grapes is $57 / 8$ inches deep, 17 inches wide inside measurement, and 24 inches long outside. Never pick grapes when they are wet or covered with dew except for nearby markets. The grapes are packed in veneer baskets four to the crate. All defective berries are cut out and bunches which are too compact have the berries removed to prevent bruising when packing in the baskets. A good part of the late table grapes, providing the berries are firm, are shipped in kegs in redwood sawdust. The first essential to success by this method of packing is to have the dust absolutely dry. Logs are especially eut for the purpose of manufacturing this dust, the grains of which must be coarse in order to secure the best results in keeping the grapes. The size of the kegs and drums (the latter being made out of veneer lumber) have been standardized - thirty-two pounds of grapes are packed to the keg. In packing the grapes an inch of dust is placed in the bottom of the package, then several layers of grapes followed by dust which is sifted through them by the shaking of the keg and striking its sides in order to make the sawdust fill up every interstice. In placing the kegs in the refrigerator cars they are loaded so as to permit of free circulation of air. After they are received at their destination, if placed in a temperature of thirty-two degrees Fahrenheit no difficulty is encountered in keeping them for several months in the very best of condition. Thus far the varieties which have been found the best adapted to this method of packing are the Emperor, Almeria, and Cornichon.

\section{MAKING RAISINS}

They are sun dried. Bearing in mind that there are one million tons of fresh grapes made into raisins annually in California some idea is derived of the benefit of the sun during the drying period in the great valleys of California. There are several methods employed in making raisins and the following terms are applied to them: Naturals, Oil Bleached, and Sulphur Bleached. As these methods have a rather important bearing on the industry $I$ deem it advisable to give information in detail on the several drying processes employed.

\section{NATURALS}

Wooden trays holding according to size from twentytwo to twenty-nine pounds of grapes are hauled to the roadways in the vineyard. The grapes are picked directly from the vines on to the trays, which are placed in every other row. In order to promote more rapid drying of the grapes it is customary to throw the soil up against the vines and run a smoother over this. The trays should slope to the south to receive the full benefit of the sun's rays. In picking, the grapes are placed on the side of the tray which is cleated. To make firstclass raisins the grape should have not less than twentyfour per cent sugar. Within a week or ten days' exposure the surface of the grapes exposed to the sun will be browned and wrinkled and when they reach this point they should be turned on to another tray. This is done by placing the uncleated side of a tray over the one on which the raisins have been drying. By a dexterous movement of the hands, which is readily acquired with a little experience, the raisins are turned on to the other tray. It takes from two to three weeks to complete the drying in the sun, depending on the weather conditions. While the raisins are still soft the trays are stacked and the drying from this point on proceeds in the stack. Careful attention should be given not to allow the grapes to remain exposed to the sun too long, for this not only toughens them but causes quite a loss in weight, thus cutting heavily into the grower's pocketbook. They remain on the trays until they reach a point where, when taking them between the hands and pressing them, no juice is expressed from the individual berries and when they are dropped they fall apart readily.

\section{OIL BLEACHED}

The raisins instead of being dark when handled in this manner present a dark coppery hue. It is used more for the purpose of hastening drying than for any other reason. There is, however, a marked change in the flavor of the raisins, which is very much appreciated by a great many consumers. In order to carry out this work it is necessary to have quite an equipment. The grapes are all hauled to the drying ground, which should be an open space centrally located in the vineyard - a piece of ground planted to alfalfa serving the purpose better than anything else. The solution in which the grapes are dipped has quite an important bearing on the resultant product. This is prepared as follows: take eight pounds of caustic soda, one gallon of olive oil, three gallons of water. Place in a heavy iron kettle and boil slowly for three hours, adding water occasionally during the course of cooking. Then take the emulsion and place in another kettle adding enough water to make five gallons in all. Boil this slowly for about an hour, or until it becomes a thick jelly. The solubility of the emulsion is determined by taking a spoonful of the jelly and placing it in cold 


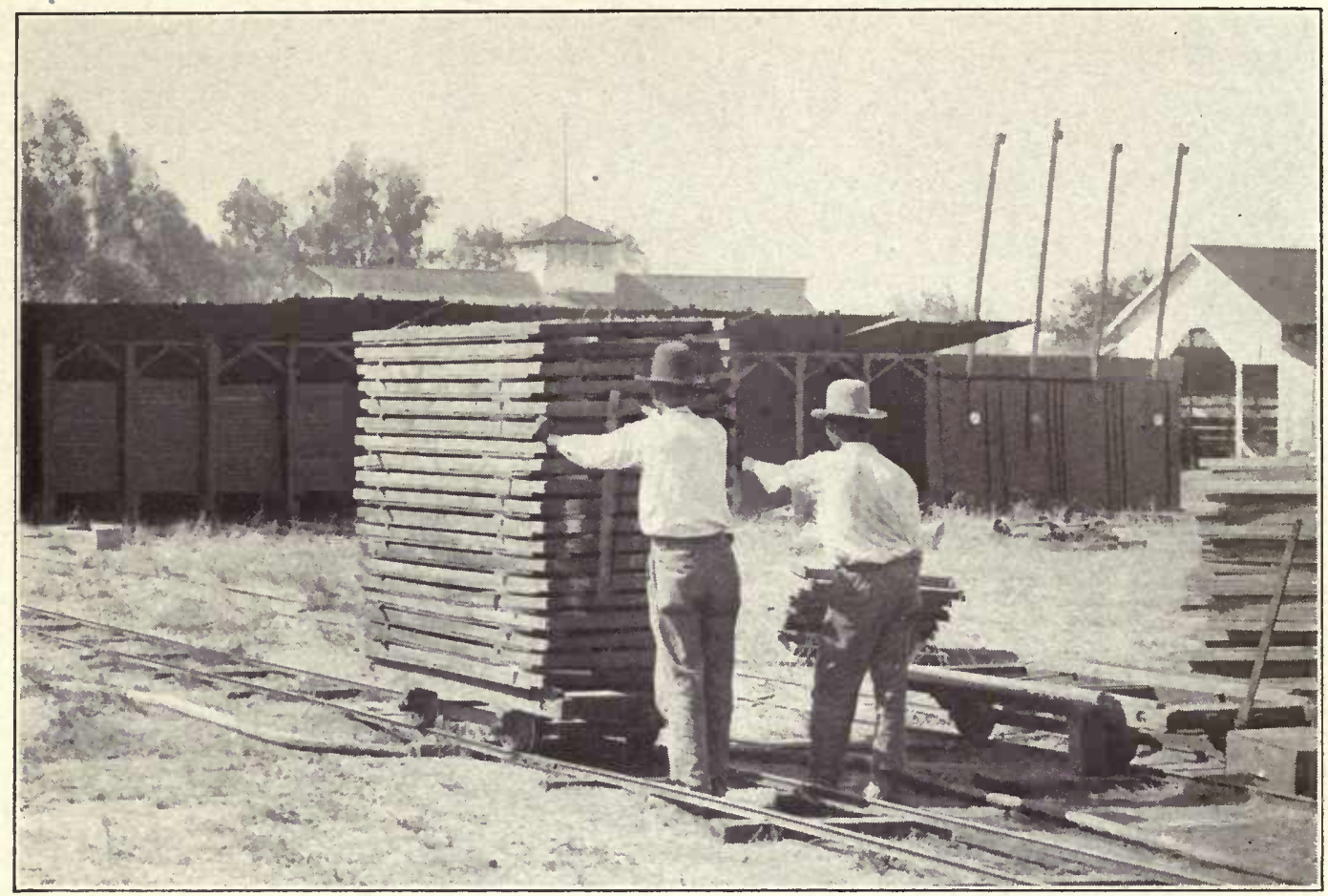

Sulphur houses. The car in the foreground is the tray transfer car for hauling the trays from the fruit shed to the sulphur houses.

water. If it dissolves readily and without making suds it is ready for use. For each one hundred gallons of water use four pounds of caustic soda and a quart of the emulsion. The dipping tank, which should be constructed out of galvanized iron, should hold not less than two hundred gallons of the solution and this should be maintained at a temperature of 200 to 208 degrees Fahrenheit by either placing steam pipes in the bottom of the tank or by having a fire under the tank to heat the water. The grapes when processed in this manner should not have less than twenty-two degrees sugar content by a saccharometer. They are immersed for a period of fifteen seconds. This may be varied according to the way the skins eut. The creases in the skin of the berries when the bunches are exposed to the air is an indication that the dip is sufficient. After the grapes are dipped in the solution they are immersed in a tank holding cold water (which is changed frequently) to free them from the lye solution.

To handle this quantity of grapes expeditiously it is necessary to have the following equipment: first of all there should be a shed or building to house the equipment as well as for the men engaged in the dipping. A revolving crane having a shallow tray made of heavy galvanized wire mesh is attached to the arm of the crane. A lever bolted to the upright post raises and lowers the tray as it is moved from the receiving station, then to the tank holding the solution. From there it goes to the rinsing tank, and finally to the station where the trays are lined up to receive the processed grapes. The trays are then taken to the drying yard on trucks running on tracks. All discolored grapes and grapes which are badly mildewed, or which are partially dried, having a dark appearance, should not be dipped. This is particularly important when making the sulphur-bleached raisins. The time of exposure of grapes treated in this manner is less by half than those which are not processed.

\section{SULPHUR BLEACHED}

This method has been used more for processing the Thompson Seedless grapes than for any other variety. The demand for it arose from the endeavor of the California growers to produce a raisin which would compete with the processed Sultanina Blanche from Asia Minor. This is the correct name for the Thompson Seedless. The processing is the same as for the preceding, except in this case they are exposed to the fumes of sulphur for four hours. The trays are then spread out and exposed to the sun on the drying yard for about the same period, when they are stacked, and they remain in this stack, the air circulating through them causing the desiccating of the fruit. Bcfore transferring. the raisins to the sweat boxes they are separated into three grades. The first has a uniform light straw color; the second is not quite so even in color; and the third grade consists of imperfect berries and those which are more or less discolored. With a temperature ranging around one hundred degrees. in the shade during the drying period this type of raisin is ready for the sweat box within fourteen days. The raisins are beautiful to look at but when eaten they have a decided taste of sulphur which militates against them as an article of food. In spite of all this there is a heavy demand for this class of goods and they sell for a higher price in the market than any other raisins. 


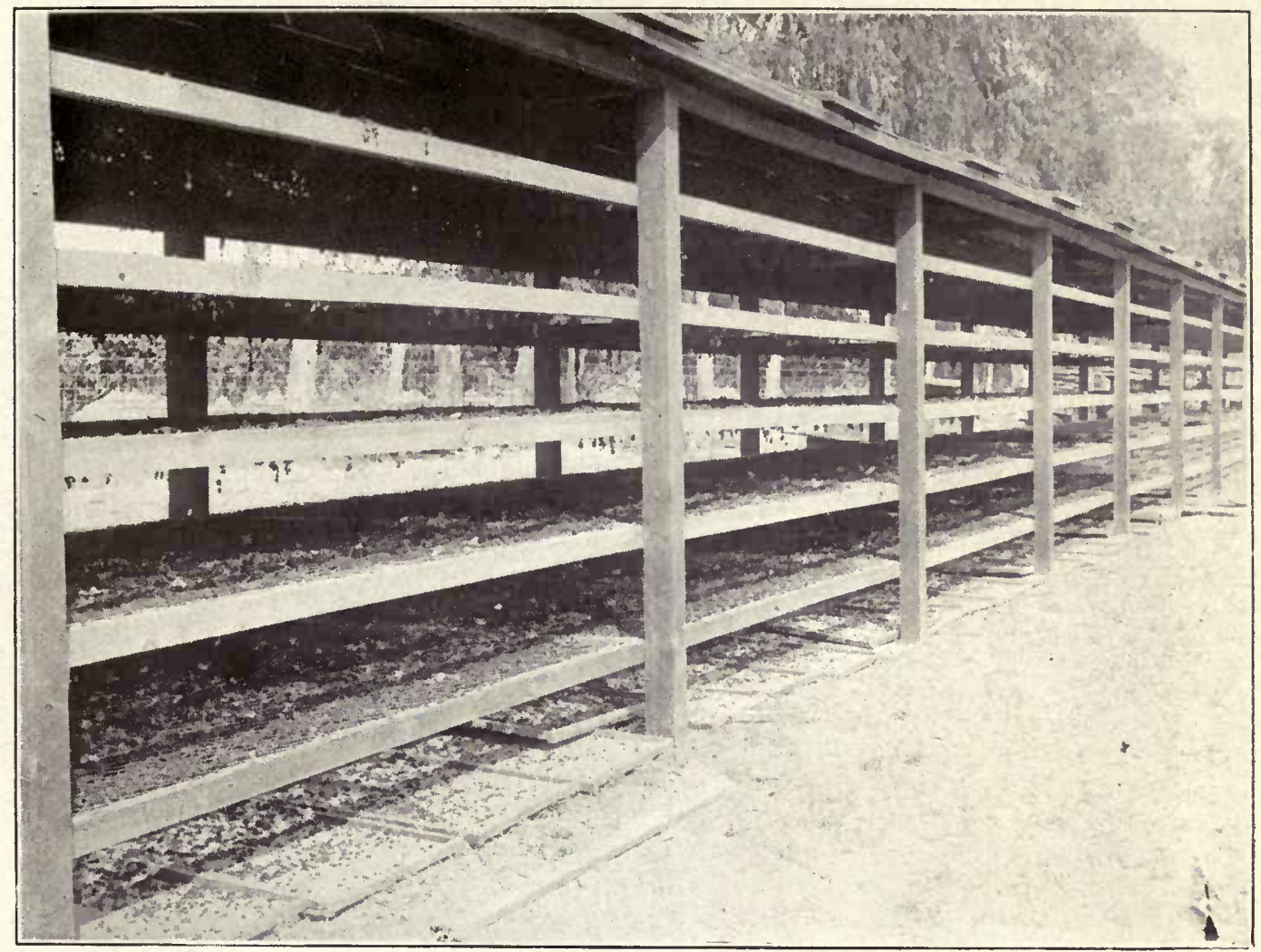

The frame structure used for drying raisins under the new process, by means of which a great saving is made in the weight of grapes, used to produce a pound of raisins. This process has been patented but will not be enforced.

\section{NEW METHOD OF HANDLING RAISIN GRAPES}

For a number of years I have been carrying on a series of experiments for the purpose of producing not only a high quality raisin with a thinner skin but in addition to this to evolve a process by means of which it would take a lesser quantity of grapes to produce a pound of raisins. After carrying on the experiments in a small way I finally concluded to process several tons, with the most satisfactory results, both in the quality of the raisin and in the reduction of the quantity of grapes necessary to produce a high-class raisin. The method of processing is the same as for making an OilBleached with the exception that it is necessary when dipping the grapes to cut the skins in such a manner that they will show decided creases, otherwise they do not dry as readily nor do the raisins have a uniform color. The trays on which the grapes are placed after they come from the dipper are made of three-inch mesh poultry netting. In order to prevent the berries from falling through this tray while they are being transferred to the drying yard it is necessary to have underneath each wire tray the standard wooden tray to catch all the berries which may shell off of the bunches. The trays used for this purpose should be three feet wide and six feet long. Instead of having the raisins spread out on the ground, with this method the wire trays are placed on racks about twelve inches apart in a structure built of rough lumber and having a covering made out of trays to prevent the sun from coming in contact with the raisins while they are being dried. The shed should run east and west and should be shaded on the south side with burlap, otherwise the raisins exposed to the afternoon sun take on a decided red tinge. The raisins processed and dried in this manner have a greenishyellowish tinge, and a decidedly attractive flavor. The skin is very tender and one point above everything else which will appeal to the grower is the fact that it does not take more than three and a half pounds of grapes to produce one pound of raisins. With a temperature of one hundred degrees in the shade the time of drying does not exceed fourteen days. The drying is accomplished entirely by the circulation of air through the shed. The bunches hang through the wire mesh, eliminating all danger of fermentation or discoloration because of their exposure to the air. To carry this process out on the ordinary trays is simply out of the question because the grapes instead of drying would ferment. Expert raisin men who have sampled the raisins produced by this method have been enthusiastic in their praises of them. The process has been used more with Thompson Seedless than with any other variety, although experiments have been made with Muscats, and there is no reason why it can not be employed with this variety of grape as well, because as far as flavor is concerned the raisin has everything in its favor. It has a translucent color, and, like the Thompson Seedless, the loss of weight in drying is very materially reduced. 


\section{COMMERCIAL VARIETIES OF TABLE GRAPES}

Almeria, Cornichon, Black Morocco, Black Ferrera, Black Hamburg, Dattier de Beyrouth, Emperor, Flame Tokay, Gros Colman, Malaga, Maraville de Malaga.

\section{COLLECTION OF TABLE GRAPES NAMED IN THEIR ORDER OF RIPENING}

\section{July}

Joannene or Lignan, Chasselas de Fontainebleau (White Sweetwater).

\section{August}

Chasselas Ciotat, Black Monukka, Thompson Seedless, Fink Thompson Seedless (Sultania Rosea), Roeding's Improved Thompson Seedless, Buckland Sweetwater, Assouad Zeine, Malaga.

\section{September}

Angulato, Dattier de Beyrouth, Black Hamburg, Gros Guilliaume, Flame Tokay, Golden Champion, Black Malvoise, Rose of Peru, Sabal Kanski, Gradiska, Damas Rose, Black Ferrera.

\section{October}

Maraville de Malaga, Black Cornichon, Emperor, Gros Colman, Olivette Blanche, Black Morocco, Olivette de Vendemain, Ohanes d'Almeria.

\section{November}

Dronkane.

\section{AMERICAN VARIETIES OF TABLE GRAPES WHICH THRIVE IN CALIFORNIA}

Agawam, Catawba, Concord, Isabella, Moore's Early, Niagara, Pierce or Isabella Regia, Worden, Campbell's Early.

\section{RAISIN GRAPES NAMED IN ORDER OF THEIR RIPENING}

Zante Currant or Black Corinth, White Corinth, Thompson Seedless, Sultania Rosea, Sultana, Muscat.

\section{COMMERCIAL VARIETIES OF WINE GRAPES}

Alicante Bouschet, Aramon, Black Malvoise, Burger, Carignan, Feher Zagos, Grenache, Mission, Petit Syrah, Zinfandel.

\section{VARIETIES OF RESISTANT GRAPES ADAPTABLE TO CALIFORNIA SOILS}

Aramon X Rupestris Ganzin No. 1, Berlandieri X Riparia, Mourvedre X Rupestris 1202, Riparia X Rupestris 3306, Riparia X Rupestris 3309, Riparia X Rupestris $101^{14}$, Riparia X Cordifolia Rupestris $106^{8}$, Rupestris St. George, Solonis X Raparia 1616.

The United States Department of Agriculture and the University of California are making careful observa. tions as to the adaptability of the many varieties of resistants to California soils and the affinity of the vinifera varieties to them when grafted. Determination as to their bearing qualities and many other details which will be of great benefit to the practical grower are being worked out in the experimental stations.

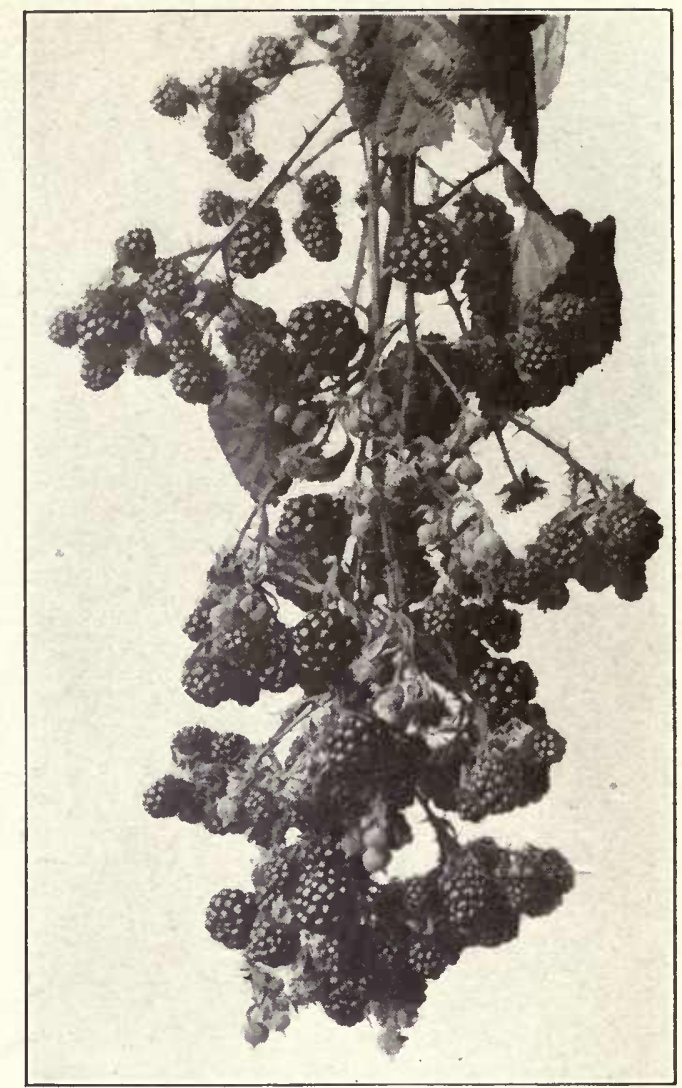

The Himalaya Blackberry produces a succession of crops all summer.

\section{THE SMALL FRUITS}

This term usually applies to the berry family: blackberries, currants, gooseberries, raspberiies, strawberries. The whole Pacific slope, wherever fruit soils and sufficient moisture prevail, is adapted to their successful culture. It is practical in Oregon and Washington to grow the small fruits with little or no irrigation. This is largely due to the rains which occur so frequently there during the entire summer. In California even in the coast counties, where they have fog and where during the height of the summer season it very rarely becomes warm, irrigation nevertheless is an essential requisite toward successful berry culture. All varieties of berries luxuriate under the favorable climatic conditions which exist in the coastal counties from San Luis Obispo northward. The quality and size of the berries which are practically out of season in the midsummer months in the interior valleys are at the height of perfection in these counties during that season of the year. No man with a farm should be without a berry patch. Berries are of such easy culture, add so much to the delicacies of the table, and are so easily harvested, it is difficult to understand how even a farmer not engaged in the fruit business could fail to have a berry patch close to his home not only to supply the table with fresh fruits during the early summer months, but also to have the berries in surplus made into jellies and jams for use during the winter season. Where conditions are 


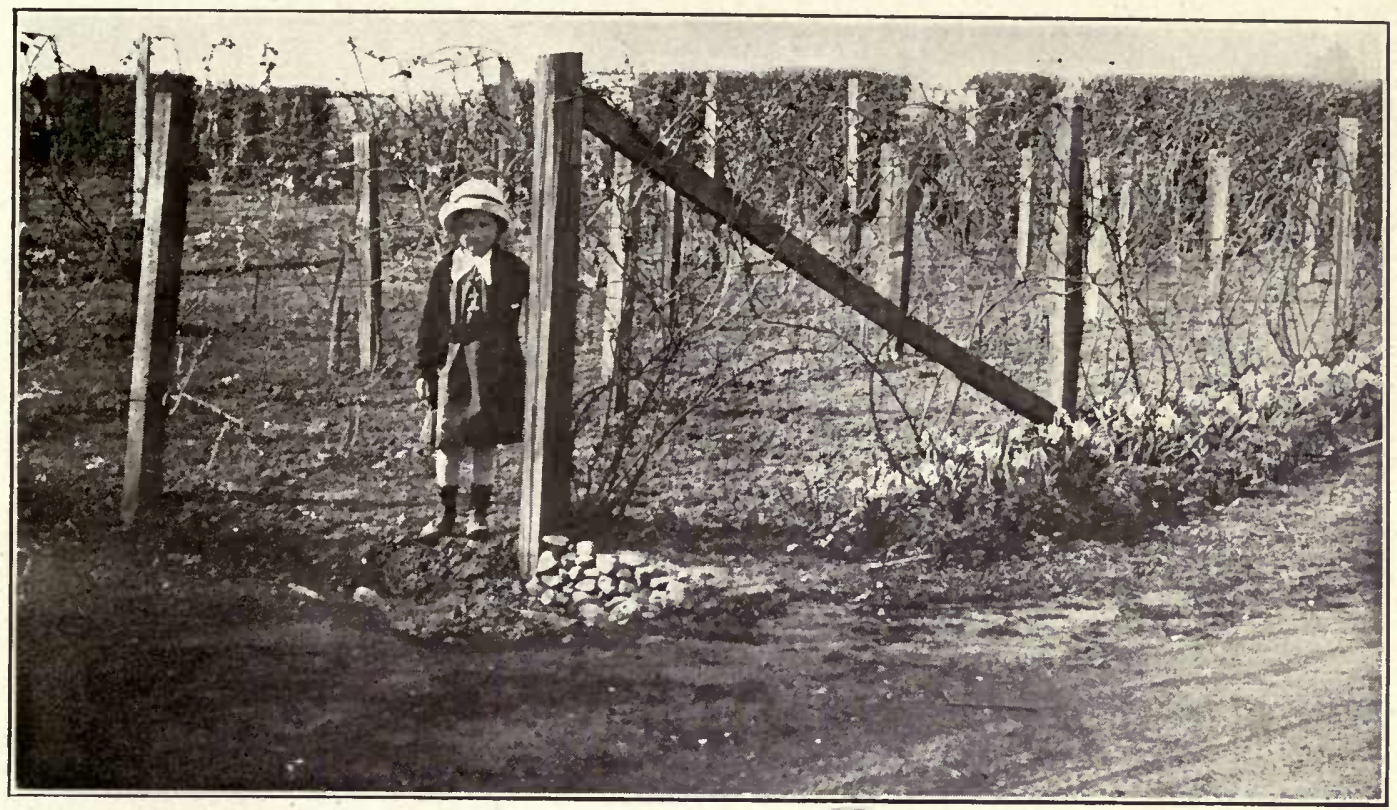

A berry patch for the home. By planting an assortment, it is possible to have berries from April to December in California. Row 1. Loganberries; Row 2. Cuthbert Raspberries; Row 3. Himalaya Blackberries.

favorable for berry culture and close to the markets of any consequence they could be made immensely profitable when grown along commercial lines.

\section{PREPARING THE GROUND}

The preparation of the ground should be thorough. The roots being close to the top of the ground and of a small rather fibrous nature, the importance of having the soil in the very best possible condition to insure a good stand of plants and a satisfactory growth must be apparent to anyone engaged in berry culture. Thorough dressing with well rotted stable manure will do much to promote a vigorous growth the first season, and having secured this, profitable crops may be expected the second year after planting. Mulching with stable manure and discretion in the use of commercial fertilizer will do much to maintain thriftiness in the plants and with it a heavy production of fine, large, luscious berries. As has already been stated berries can not be grown in California without irrigation. So before planting, the land should be graded, having the grade as uniform as possible to prevent flooding. A berry grower should be absolutely certain of water when it is required, and should there be any question about the supply from ditches, a pumping plant should be installed to have water available whenever it is needed, for a delay of even a few days may mean the loss of the entire crop.

\section{STRAWBERRIES}

In laying off the ground for strawberries it should be graded so the plot has a gradual fall. Extreme care is necessary in this, otherwise sections of the beds may become submerged in irrigating, thus causing the berries to rot. There are several methods of laying out strawberry beds. In the counties of Alameda, Santa Clara and Santa Cruz, where the business is carried on on a commercial scale, the berry plants are set in a bed two feet wide with a ditch between. The plants are set eighteen inches apart and about four inches from the edge of the bed. In the southern part of the state it is customary to hill up a single row about six inches high with a ditch between. Should there be much fall to the piece of the ground in which the planting is made wooden or metal weirs should be placed in the fields so that when irrigating the patch the water in any one section will be on a level. It is very important during the fruit season to keep the plants in an active state of growth by irrigating, weeding and hoeing. In order to obtain large, highly flavored berries pinch off the runners as fast as they appear; this will cause the plants to stock out, as it were, and the very finest strawberries may be expected the following season.

\section{STANDARD VARIETIES}

Banner, Brandywine, Jessie, Marshall.

\section{THE BLACKBERRY AND RASPBERRY}

The most satisfactory way of handling blackberries is to plant in rows six feet apart, with eight feet between the rows. The first season all the shoots which have attained a height of two feet should be shortened into twenty inches. This will cause them to send out many lateral shoots, so that instead of having the fruiting shoots confined to a few canes, there will be a number of lateral shoots from each of the main canes for producing fruit clusters. These laterals should have one-half of their growth cut off in the winter months. In the second year, as soon as the season's crop has been harvested, cut away the fruiting wood, so that all the energy of the plant will be forced into the new growth. The young shoots should again be cut back at the proper 


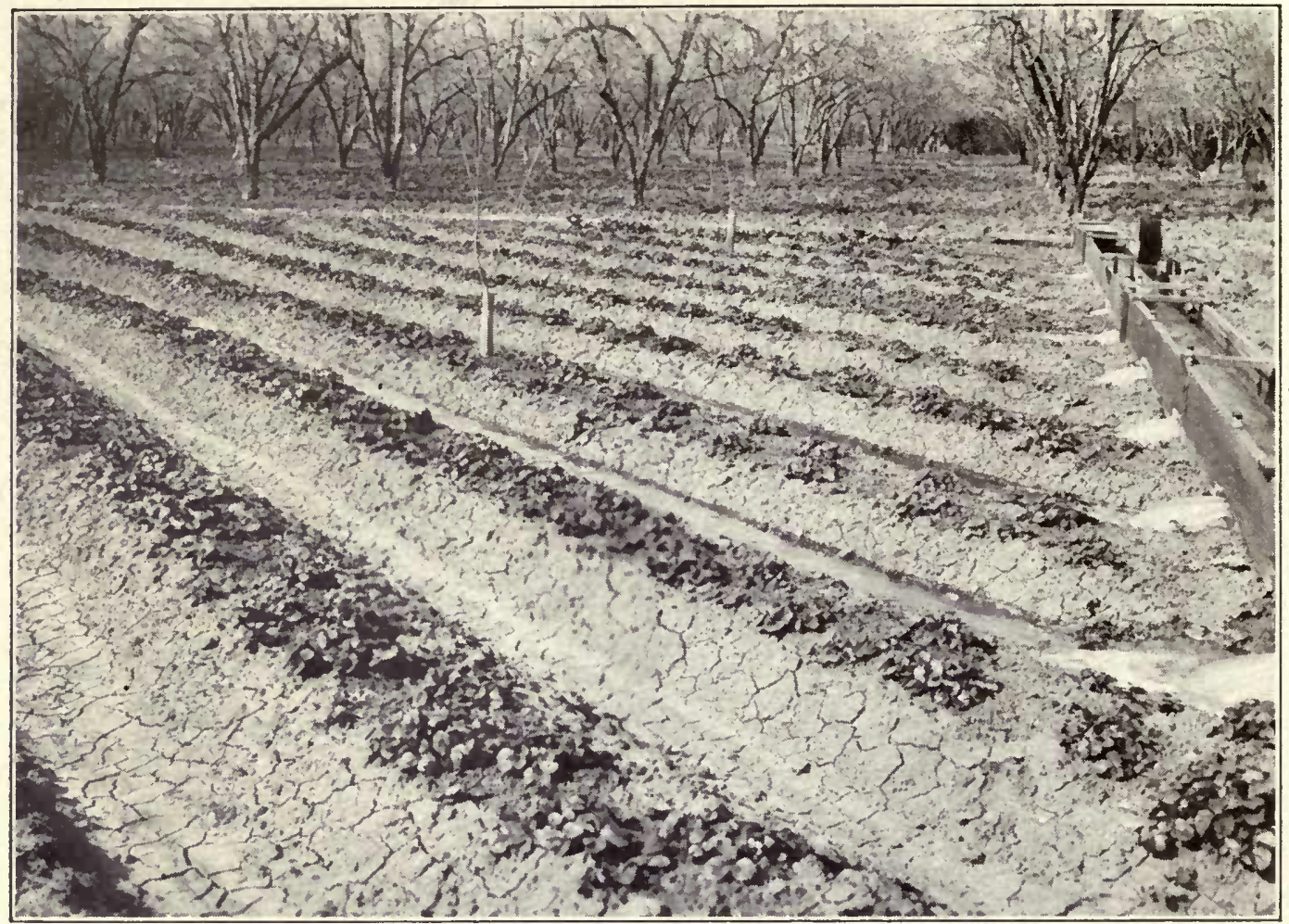

Strawberry beds and the method of irrigating them.

height to develop laterals, and these, as has already been directed, should be cut back in the winter months. This method of pruning has other advantages by making the canes sturdy and self-supporting, and causes the fruit to be distributed over the entire plant instead of being confined to the terminal growth.

By having the rows eight feet apart, cultivation can be carried on with a horse, a very important point. A good supply of water, thorough cultivation and liberal application of rotted barnyard manure are important factors in the cultivation of the blackberry.

\section{POPULAR VARIETIES OF BLACKBERRIES}

Crandall's Early, Erie, Evergreen, Lawton.

\section{POPULAR VARIETIES OF RASPBERRIES}

Cuthbert, Golden Queen, Gregg, Superlative.

\section{LOGAN, MAMMOTH AND HIMALAYA BLACKBERRIES}

These berries are practically in a class by themselves, and the cultural directions for one apply to the other, so we will consider them under the same head. They should be planted in rows six feet apart and eight to ten feet between the rows. The best results are obtained by trellising the runners to wires on heavy posts which will hold the wire taut. As soon as the fruiting season is past the fruiting canes should be cut away and the new canes be bunched together and wound around the wire. At least two wires should be strung on the posts, so that as soon as one wire is covered the remaining canes may be wound around the other. By following this method from year to year a heavy crop of large, fine berries may be looked for annually.

A novel method of handling them is to plant in squares $8 \times 8$ feet. Drive three stakes one and one-half feet into the ground, using 2 inch $\times 2$ inch $\times 6$ feet posts. Nail an old barrel hoop on the top of the posts, and another two feet from the top. The shoots are trained over these hoops. It is simply astonishing the amount of fruit which will be obtained by this method of handling. Another satisfactory plan is to set 4 inch $\mathrm{x} 6$ inch $x 7$ foot pests twenty feet apart and nail 1 inch $x 3$ inch $x 18$ inch cross ties to each post. Set the pcsts three feet in the ground and string No. 12 galvanized wire on the cross ties, holding it in place with staples. The new shoots should be trained across, winding them around the wires from one wire to the other.

\section{VARIETIES RIPENING IN THE ORDER LISTED}

Loganberry, Mammoth Blackberry, Himalaya Blackberry.

\section{THE DEWBERRY}

The improved varieties of dewberry or trailing blackberry are very popular. They are enormous croppers, produce fruit of the very best quality, which ripens fully two weeks earlier than any of the blackberries. Plants should be set four feet apart, with rows six feet apart. When there is not sufficient rainfall to kecp the vines in active growing condition, irrigation should be 


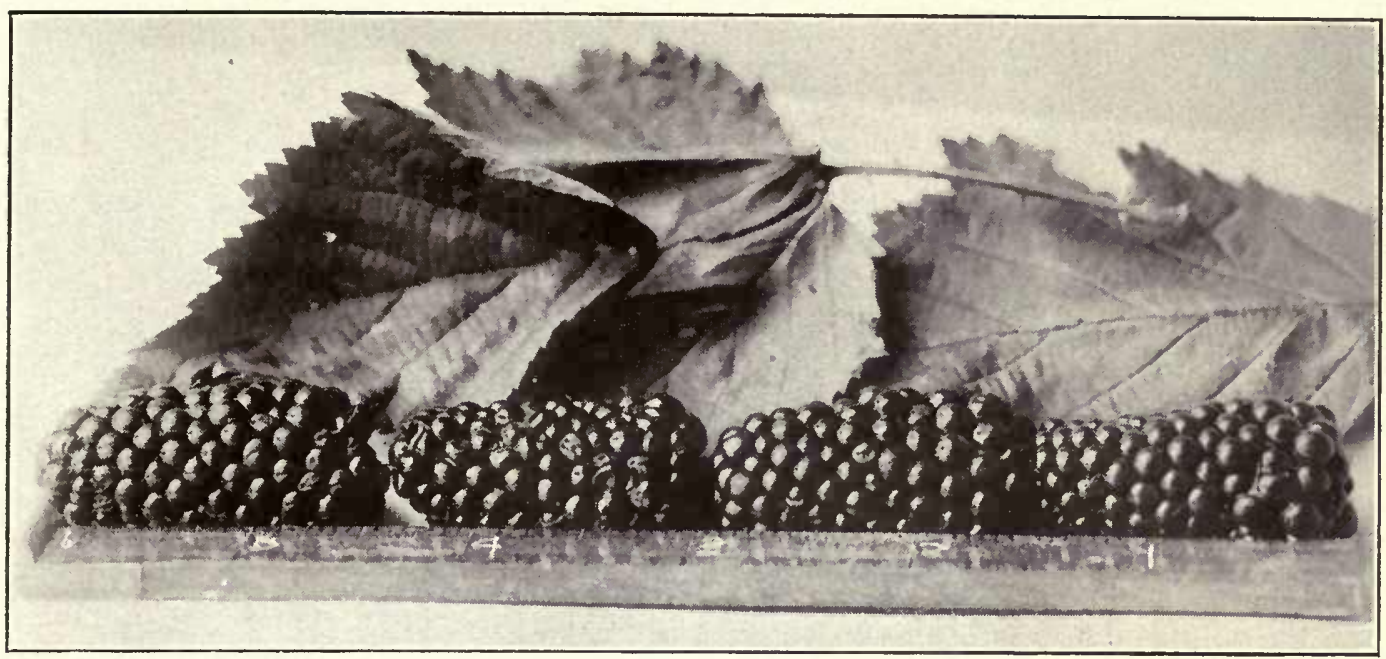

The Mammoth Blackberry originated in California, an all-around berry which has held its own as a standard with the growers.

practised. Immediately following the harvesting, all the old canes should be cut off, and the following spring the new ones should be trained to a wire two feet from the ground. The method of trellising is the same as for the other varieties of trailing vines, except that the canes are trained closer to the ground.

\section{POPULAR VARIETIES}

Garclena, Lucretia.

\section{CURRANTS AND GOOSEBERRIES}

The district in which either one will grow to advantage seems to be confined to the counties surrounding San Francisco bay. It is useless to attempt to grow them in the interior valleys, for the dry, hot air and the bright sunshine causes thom to succumb very quickly. They do very well, however, in the mountainous regions in any part of the state at an elevation of from three to five thousand feet. In the districts in which they thrive they are as a rule planted between orchard rows, and if well manured, cultivated and pruned they produce abundantly without irrigation. The only variety which will grow in the interior is the Crandall's black currant. In setting either currants or gooseberries the rows should be six feet apart and the plants set three feet apart in rows. It is not necessary to dwell on the value of the currant nor its uses, for every housewife knows that there is no jelly so highly colored and flavored as that made from the currant. Plants are trained as bushes. They should be pruned every winter. This should consist of thinning and the removal of dead wood. If there is an inclination for the plants to grow out of shape, the current season's growth should be shortened in.

\section{COMMERCIAL VARIETIES OF CURRANTS}

Cherry, Crandall's Black, Fay's Prolific, Perfection, White Grape.

\section{COMMERCIAL VARIETY OF GOOSEBERRY}

Oregon Champion.

\section{VEGETABLE AND ESCULENT ROOTS}

The shipping and canning of asparagus has developed into a very important industry in this state. There are few vegetables which are more popular than asparagus. The very fact that it will grow and produce with very little or no care should cause every family to have at least a few plants in their vegetable garden. It becomes tough and quite bitter after it is out of the ground for a few days. To fully appreciate its delicious flavor, asparagus must be eaten the very day that it is cut. There is a difference of opinion as to when it should be cut. That it is more tender just as the tips begin to poke their heads above ground is a fact which must be admitted without much argument. The first and second years after planting it is far better not to cut the stalks but to allow them to grow. The plants should be set three feet apart and the rows should be at least six feet apart. In planting, spread out the roots and plant six inches below the surface of the ground. Asparagus is a gross feeder, and unlike most other plants liberal applications of stable manure and rock salt, well worked into the soil, are very valuable adjunets to its successful culture.

\section{THE STANDARD VARIETIES}

Canover's Colossal, Palmetto.

\section{THE GLOBE ARTICHOKE}

There are two distinet types of artichoke. The one so much prized by epicures and which is so extensively grown in California, particularly in the suburbs of San Francisco, where it produces from early winter and practically through the entire summer, is the Globe artichoke (Cynara Scolymus). It is a gross feeder and must be well manured. In the interior sections of the state its flower buds do not appear until late spring. The plant presents a very tropical appearance and is therefore a valuable addition to any garden. The flower buds should be cut off as soon as they are well formed and before the scales open, otherwise they are tough and tasteless. Never allow the flowers to mature, 


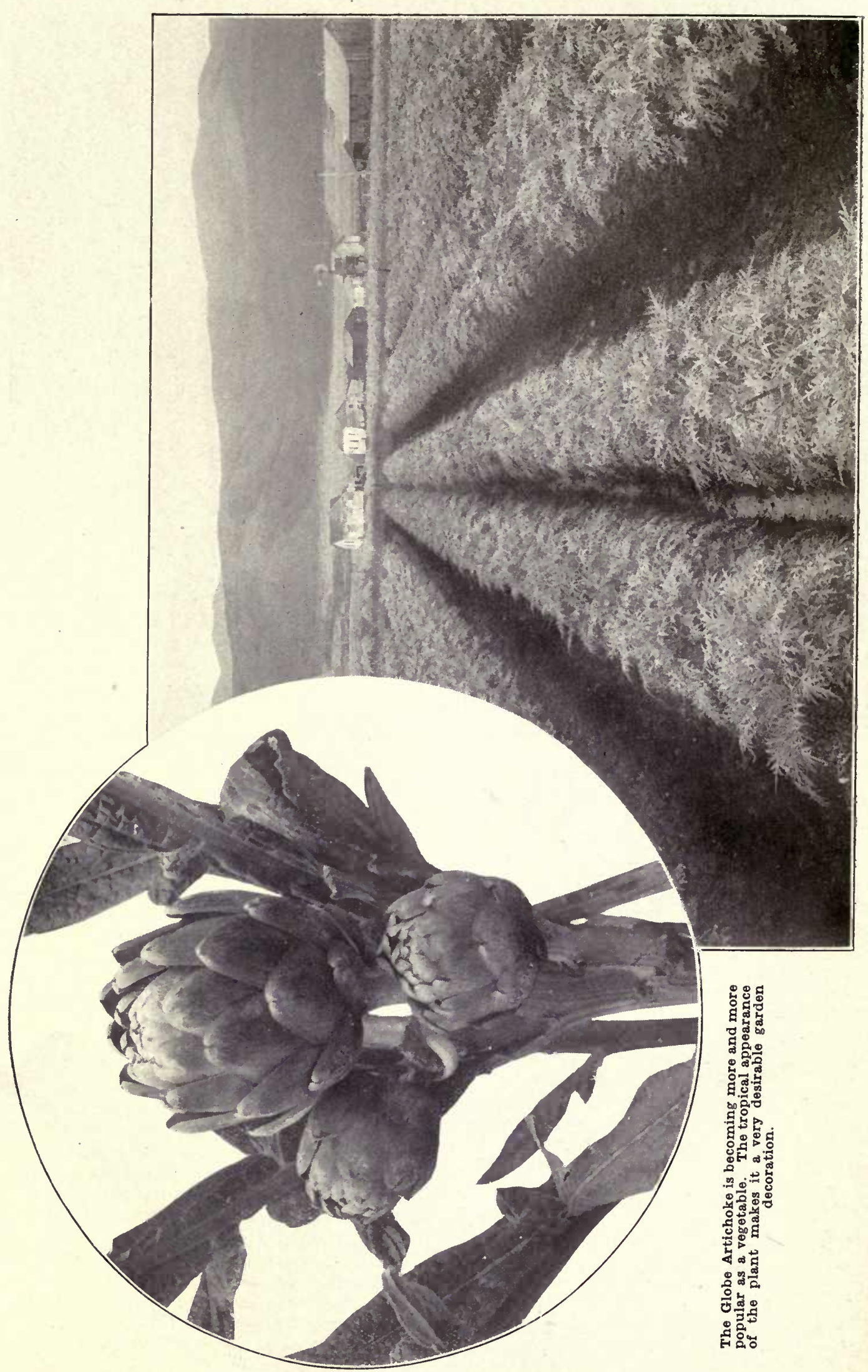




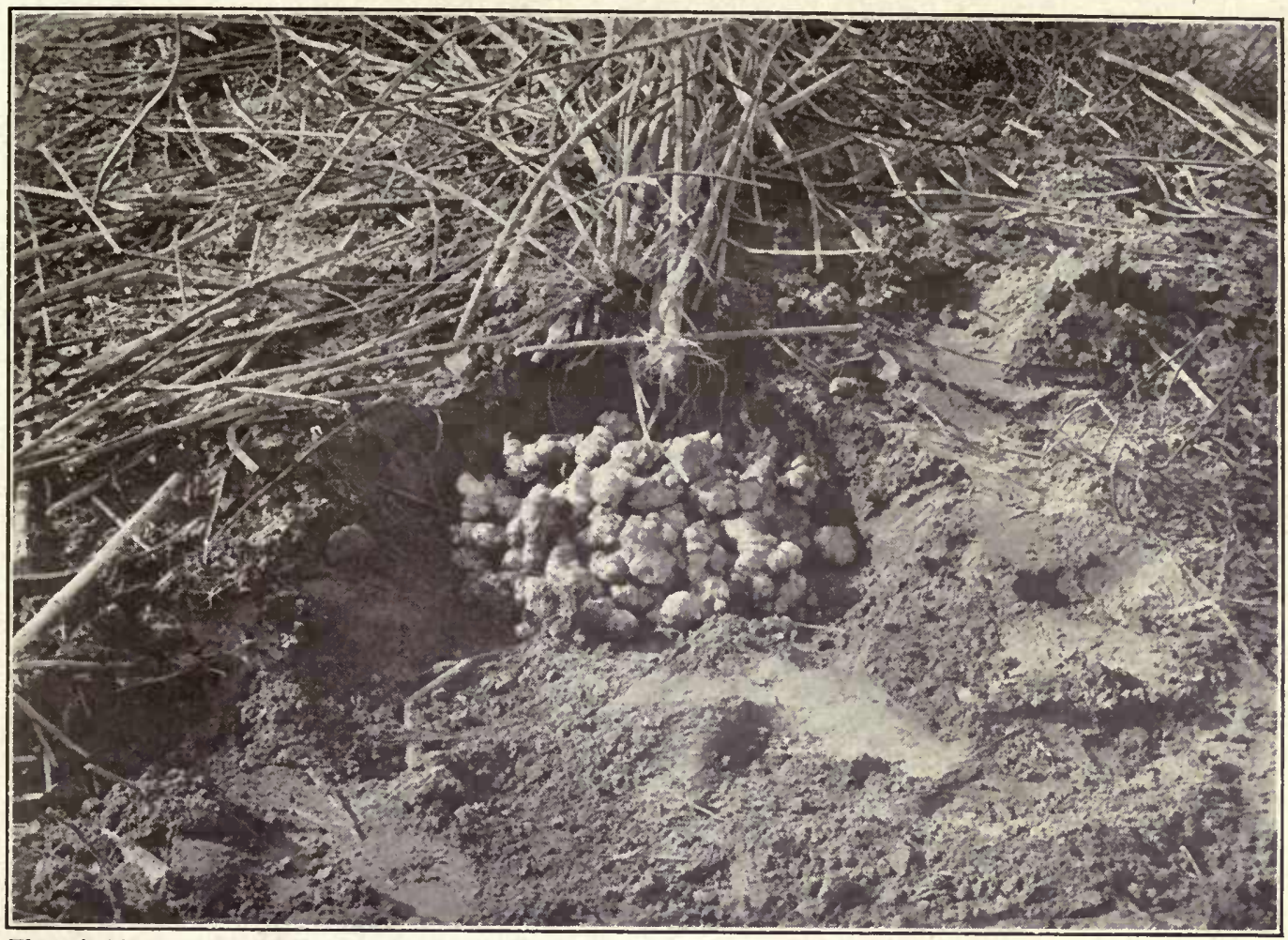

There is big money in hogs. Then why not plant the Jerusalem Artichoke? The great fattener during the winter months. The hogs do their own harvesting.

as the plants will dwindle down and die. Suckers should be taken during the winter months and planted three feet apart, with the rows six feet.

Experience has demonstrated that the best quality of artichokes is produced by cutting the plants down during the month of July, thus stimulating the growth, causing them to produce an abundance of flower buds during the winter and spring months. San Francisco county is the great artichoke center of California, shipments annually aggregating five hundred carloads from this point.

\section{THE JERUSALEM ARTICHOKE}

The Jerusalem artichoke (Helianthus Tuberosus) is radically different in its character of growth from the preceding, and will thrive on any well drained soil. The tubers should be cut to single eyes and planted eighteen inches apart with rows four feet apart. The method of cultivation and hilling is practically the same as for potatoes. The tubers are not mature until the tops are frozen, when they may be dug up and used for hog feed, or the animals may be turned loose to feed and root them out themselves. They produce enormously on good soil-with liberal cultivation and moderate irrigation, fifteen to twenty tons to the acre. This vegetable is highly prized by the French people, and in New Orleans, where it is extensively grown, it is prepared for use by stewing, for making soups and as a salad. For the farmers of California it possesses so much merit that no farm having a few hogs should be without a patch of these tubers, which will supply feed during the winter months when all other foods are scarce and high.

\section{THE RHUBARB}

With the introduction of the Crimson Winter rhubarb from Australia and the improved varieties which have been developed from it, it is possible to have rhubarb on our markets during the entire year. The Crimson Winter is at the height of its production in the midwinter months, and the climatic conditions of the southern part of the state seem to be much better adapted to its culture than the coast counties around San Francisco bay, where the Myatt's Linnaeus, Victoria and Niles Giant do so remarkably well. It supplies the market with the most delicious and healthful vegetable when all deciduous fruits, except the apple, are out of the way. For stewing and for pies it makes a dessert dish which is very much relished. The plants are gross feeders. They adapt themselves almost in any soil, although they simply luxuriate in the deep, loamy black soil. To secure the best results in the production of stalks, a liberal application of stable manure is very beneficial, and this, after the plants are four years old, should be supplemented with the application of nitrate of soda not to exceed two hundred pounds to the acre, or blood and bone at the rate of four hundred pounds per acre. These fertilizers should be applied by plowing out furrows on each side of the rows of the plants, throwing it back, and then irrigating. If after the fertilizer is applied it is followed by a good soaking rain, the irrigating will not be necessary. 


\section{INDEX TO CONTENTS}

A

Page

Almond

Stocks. .

Classification ......................... 30

Pruning................................ 30

Gathering ..................... 30

Irrigation.......................... 30

Commercial Varieties. ................. 32

Period of Ripening................... 32

Apple

Soil and Situation.

Points to be Observed.

Shaping the Tree.

Roots.

Thinning. .

Gathering and Storing

Commercial Varieties

Crab Apples.

Apricot...

Stocks.

Pruning.

Thinning .

Gathering.

Irrigation

Commercial Varieties

Ripening Period.

Artichoke, Globe

Jerusalem . .

Avocado

Stocks......

Distances Apart and Pruning.

Gathering

Eating the Avocado.

Irrigation .

Meritorious Varieties.

\section{B}

Banana........................... 78

Varieties........................... 78

Berries:

Blackberry and Raspberry................... 93

Currants.......................... 95

Dewberry............................. 94

Gooseberry . . . . . . . . . . . . . . . . . . 95

Himalaya Blackberry..................... 94

Loganberry......................... 94

Mammoth Blackberry. . . . . . . . . . . . . . . . . 94

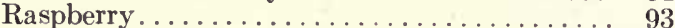

Strawberry........................ 93

Blackberry............................... 93

Himalaya......................... 94

Mammoth............................ 94

Popular Varieties of Blackberries............ 94

Blackberry and Raspberry.................. 93

Popular Varieties of Blackberries. . . . . . . . . . . 94

Popular Varieties of Raspberries............. 94

Caprification....................... 42

Planting Caprifig Trees.................... 46

Varieties of Caprifigs...................... 48

Carob............................... 80

Cherimoyer..................... 76
Page

Cherry .............................. 15

Stocks............................ 15

Pruning....................... 16

Gathering ...................... 16

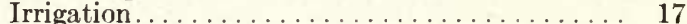

Commercial Varieties................ 17

Time of Ripening in a Cherry Section....... 17

Chestnut......................... 32

Pruning. . . . . . .

Stocks ...................... 33

Gathering and Storing................ 33

Varieties of Commercial Value........... 33

Citrus Fruits.......................... 57

Soil and Situation................... 59

Selecting the Trees.................... 60

Method of Planting.................. 61

Stocks for Citrus Trees................... 61

Distances Apart.................... 62

Pruning......................... 63

Pruning the Lemon ................. 63

Pruning the Pomelo................... 64

Pruning the Lime.................... 64

Pruning the Citron.......................... 64

Care of the Orchard.................. 64

Fertilizers and Fertilization. . . . . . . . . . . . . . 65

The Time to Plant..................... 66

Packing the Orange.................... 67

Growing, Curing, Packing the Lemon. . ...... 68

Sorting as to Quality.................. 70

Commercial Varieties of Oranges........... 70

Period of Ripening................... 70

Commercial Varieties of Lemons............. 70

Varieties of Lemon Worthy of Trial......... 70

Commercial Varieties of Pomelos............. 70

Varieties of Pomelos Worthy of Trial........ 70

Commercial Varieties of Limes............... 70

Variety of Limes Worthy of Trial.......... 70

Commercial Variety of Citron............... 70

Currants............................ 95

Commercial Varieties of . ............... 95

Currants and Gooseberries................. 95

Commercial Varieties of Currants............. 95

Commercial Variety of Gooseberry............ 95

D

Dewberry

Popular Varieties of

\section{F}

Feijoa .

Fig.

Localities Favorable for $\ldots \ldots \ldots \ldots \ldots \ldots . \quad 39$

Brief History....................... 39.39

Caprification........................... 42

Planting and Pruning. ..................... 45

Freezing to the Ground $. . \ldots \ldots \ldots \ldots \ldots \ldots \ldots, 45$

Planting Caprifig Trees................... 46

Gathering............................... 46

Gathering and Drying.................. 47

Irrigation.......................... 48

Crop Sure-No Failures..................... 48

Varieties of Commercial Value............... 48

Varieties Worthy of Trial.................. 48

Varieties of Caprifigs....................... 48 


\section{ROEDING'S FRUIT GROWERS' GUIDE}

Fruit Growing as a Business:

Beginning Right.

Preparation of the Soil

Selecting Nursery Stock.

Time to Plant. .

Treatment when Received.

Preparing Trees for Planting.

How to Plant.

Square System .

Quincunx System.

Hexagonal System.

Alternate System.

Planting Distances

Number of Trees to the Acre

Blasting the Holes.

Important Details .

Bringing an Orchard or Vineyard into Bearing.

Must be Cut Back.

Irrigation.

Fruits, Small

Preparing the Ground

\section{G}

Globe Artichoke.

Gooseberries

Commercial Variety of

Grape.

Situation and Soils.

Laying Out a Vineyard.

Distances to Plant. .

Preparing for Planting.

How to Plant......................

Resistant Vines.........................

Irrigation and Cultivation .

Fertilizing

Gathering for Shipping.

Making Raisins.

Naturals

Oil Bleached.

Sulphur Bleached........ . . . . . . . . . . . . .

Commercial Varieties of Table Grapes. . .

Collection of Table Grapes Named in Their Order of Ripening.

American Varieties of Table Grapes Which Thrive in California.... . . . . . . . . .

Raisin Grapes Named in Order of Their Ripening

Commercial Varieties of Wine Grapes

Varieties of Resistant Grapes Adaptable to California Soils

Guava.

81

82

83

83

84

84

84

86

86

87

87

89

89

89

90

91

92

92

\section{$\mathbf{H}$}

Himalaya Blackberry

\section{$\mathrm{J}$}

Jerusalem Artichoke

Jujube

Processing.

\section{L}

Logan, Mammoth and Himalaya Blackberries... Varieties Ripening in the Order Listed

I.oganberries

I.oquat.

Varieties to Grow
$\mathbf{M}$

Page

Mammoth Blackberries.

\section{N}

Nuts.

Almond

Chestnut.

Pecan.:.

Pistachio . . .

Walnut........................ 35

Nectarine....................... 29

Season of Ripening. . . . . . . . . . . . . . 29

O

Olive .

Pickling the Olive

Planting. .

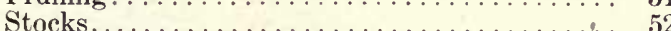

Gathering. . . . . . . . . . . . . . . . . 53

Methods of Pickling. ................... 53

How to Make Olive Oil . . . . . . . . . . . . . . . 53

Ripe Olives for Home Consumption......... . 55

Commercial Pack.................... 55

Canning Ripe Olives. . . . . . . . . . . . . 55

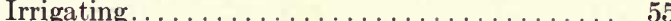

Varieties Commercially Important . . . . . . . . 57

Period of Ripening................... 57

\section{$\mathrm{P}$}

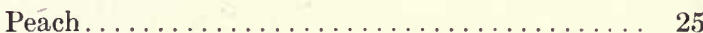

Stocks....................... 26

Distances Apart. . . . . . . . . . . . . . . 26

Pruning. ..................... 26

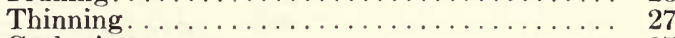

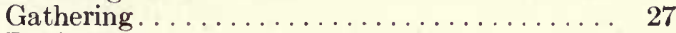

Drying. ...................... 27

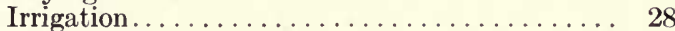

Commercial Varieties................. 28

Varieties Named in the Order in Which They

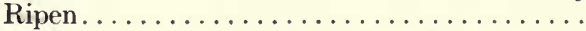

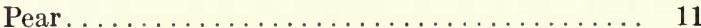

Soil and Situation .................. 11

Distances Apart and Stocks............... 12

Pruning and Shaping............... 12

Thinning. ........................ 13

Gathering and Ripening. ............. 14

Irrigation ......................... 14

Commercial Varieties................. 15

Time of Ripening. . . . . . . . . . . . . . 15

Pecan.......................... 33

Conditions Favoring its Growth . . . . . . . . 33

The Harvesting. . . . . . . . . . . . . . . 35

Varieties Which Have Proved Meritorious in California.

Persimmon

Planting and Pruning. ............. 71

Commercial Varieties................ 72

Varieties Worthy of Trial.............. 72

Time of Ripening of Commercial Varieties.... . 72

Pistachio......................... 35

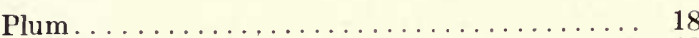

Stocks....................... 18

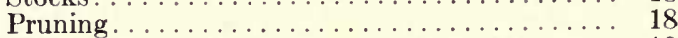

Thinning. . . . . . . . . . . . . . . . . 19

Gathering. . . . . . . . . . . . . . . 19

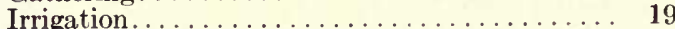

Commercial Varieties for Shipping. . . . . . . 19

Commercial Varieties for Canning . . . . . . . . 19

Time of Ripening................. 19 
Page

Pomegranate.

72

Distances Apart and Pruning ....... 72

Gathering

Meritorious Varieties.................... 73

Prune $\ldots \ldots \ldots \ldots \ldots \ldots \ldots . \ldots \ldots \ldots$

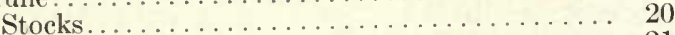

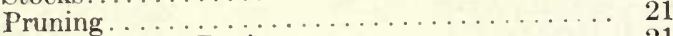

Gathering and Drying.............. 21

Commercial Varieties for Drying. . . . . . . . 22

Commercial Varieties for Shipping. . . . . . . . 22

Period of Ripening. ................. 22

\section{Q}

Quince.

Time of Ripening

\section{$\mathbf{R}$}

Raisins, Making

Naturals

Oil Bleached

89

Sulphur Bleached

New Method of Handling Raisin Grapes
Raspberry

Popular Varieties of Raspberries.

Rhubarb.

\section{S}

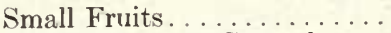

Preparing the Ground.

Strawberries

Standard Varieties.

\section{V}

Vegetable and Esculent Roots The Standard Varieties.

Walnut

\section{W}

How to Plant........

Pruning 36

Special Features.................. 36

Gathering and Curing................. 37

Commercial Varieties.................. 39

Varieties Worthy of Trial. . . . . . . . . . . . . 39

Timber Trees . . . . . . . . . . . . . . . . . . 39

\section{LIST OF ILLUSTRATIONS}

\section{A}

Almond Tree, Three-year-old .

Apple Tree, with Well-balanced Head

With Leaders and Laterals Shortened In.......

Apricot Tree, Showing Successful Pruning . . . . . . 22

One-year-old....................... 23

Two-year-old . . . . . . . . . . . . . . . . . 23

Six-year-old. ...

Artichoke, Globe . . . . . . . . . . . . . . 96

Jerusalem....................... 97

Avocado Tree, Fine Type of . . . . . . . . 74

Hard-shelled Avocado.

\section{B}

Bananas, on Property of Wm. Plotts, near Whittier, Los Angeles County................. 78

Blackberry, Himalaya... . . . . . . . . . . . . . . 92

Mammoth.

Berry Patch for the Home: Loganberries, Cuthbert Raspberries and Himalaya Berries.

9

(1)

7

74

Same Tree Cut Back and Thinned ..........

Calimyrna Fig Orchard, near Fresno......... 38

Washing and Cleaning Dried Calimyrna Figs.. 47

Caprifig:

Stringing Capris on Raffia Fibre............ 42

Branch of Roeding's No. $3 \ldots \ldots \ldots \ldots \ldots \ldots \ldots .440$

Roeding's Caprifig No. 3, Showing Magnificent Crop of Mamme or Winter Figs . . . . . . . . 44

Carob Tree...................... 80

Cherimoyer Tree................. 76

Cherry Tree, Two-year-old ............... 15

Four-year-old . . . . . . . . . . . . . . . . 16

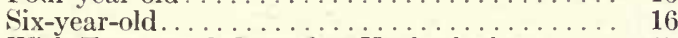

With Framework Branches Unchecked ....... 17

Magnificent Cherry Orchard ............. 17
Branch of Roeding's No. 3 Caprifig

Calimyrna Fig.

Stringing the Capris on Raffia Fibre

Fig Wasp (Blastophasga grossorum)

Wire Basket which is Suspended in the Calimyrna Fig Trees....................

Roeding's Capri No. 3, Showing Maguificent Crop of Mamme or Winter Figs. . . . . . . . .

One-year-old Orchard-grown Fig Tree ..........

Three-year-old Fig Tree, Showing Current Year's Growth.

Washing and Cleaning Dried Calimyrna Figs...

Fig Trees Just After Pruning..............

Old Fig Tree Cut Back to Develop a New Head.

Fig Wasp (Blastophaga grossorum) ..........

\section{G}

Globe Artichoke...................... 96

Grapevine, Pruned and Unpruned. . . . . . . . . . . s so

Three-year-old Thompson Seedless.............. 81

Four-year-old Emperors, Properly Pruned ....... 82

One-year-old Muscat.................. 83

Two-year-old Muscat. . . . . . . . . . . . . . . . . . 83

Three-year-old Muscat, well Trained.......... 83

Two-year-old Muscat Under Old Method ....... 84

Three-year-old Muscat with Head Started from Central Point. .......................... 
Page

Two-year-old Emperor Properly Trained....... 85

Eight-year-old Emperor with Spurs Well Distributed.

Three-year-old Thompson Seedless showing Pruned and Unpruned Vines............. Thompson Seedless with Numerous Stems..... Drying Thompson Seedless................. Sulphur Houses Used for Bleaching the Thompson Seedless...

Frame Structure for Drying Raisins............

\section{$\mathbf{H}$}

Himalaya Blackberries

92,93

\section{$\mathrm{J}$}

Jerusalem Artichoke.

Jujube Tree Grown by U. S. Department of Agriculture, Chico, California................

Fruit Branch of Chinese Jujube.............

\section{L}

Lemon Tree, Four-year-old Eureka.

Transplanted from Nursery to Orchard with Branches Shortened In................

One-year-old Properly Pruned................

Loquat Orchard of C. P. Taft, Section of . ...... 77

Loquats from Same, One of His Improved

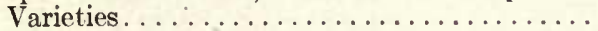

\section{M}

Mammoth Blackberry.

Muscat Grapevine, One-year-old . . . . . . . . . . . .

Two-year-old....................... Three-year-old, well Trained . . ...................

Two-year-old Under Old Method. ...............

Point. .

0

Olive Tree, One-year-old ...................... Same, with Branches Shortened In............. Three-year-old Ascolano .........................
Same, with Branches Thinned Out and Properly Pruned.

Sixty-acre Mission Olive Orchard of Seven-yearold Trees: ...

Model Olive Plant of Los Angeles Fruit Growers' Association.

Same, Showing Grinding Up of Olives Before

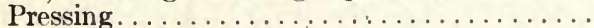

Bottling Room........................

Orange, Washington Navel. ............... 70

Orange Orchard, Six-year-old Valencia Late.... . 59

Orange Tree, One-year-old, Unpruned.......... 63

Same, Pruned........................... 64

Three-year-old, Unpruned. . . . . . . . . . . . . 65

Same, Pruned .......................... 65

Orchard near Exeter, Bird's-Eye View of . . . . . . 2
$\mathbf{P}$

Page

Peach Tree, Four-year-old .................. 24

One-year-old, Nursery-grown.............. 25

Onc-year-old, Orchard-grown ............... 25

Two-year-old Unpruned. . . . . . . . . . . . . . . 25

Same, Pruned....................... 25

Four-year-old, Unpruned................ 26

Same, Pruned...................... 26

Selma Cling Peach.................... 28

Pear Tree, One-year-old Orchard. ............. 11

Three-year-old Bartlett.................. 11

Five-year-old Bartlett.................... 12

Eight-year-old Bartlett Pear Orchard........ 12

Monarch Pear Trees near Santa Clara ....... 14

Pear Orchard, Irrigating, by Furrow System... 13

Pecan, Stuart, a Paper-shell Variety. . . . . . . . . . 32

Grafted Paper-shell Variety............... 34

Persimmon, Hachiya...................... 72

Four-year-old Hyakume Persimmon Tree...... 71

A Well-balanced Persimmon Tree.......... 71

Pistachio Tree, Twenty-year-old............. 35

Planting:

Square System....................... 5

Quincunx System.................... 6

Hexagonal System......................... 6

Alternate System.................. 7

Planting Board...................... 7

Plum Tree, Two-year-old . . . . . . . . . . . . . . . . . 18

Three-year-old ....................... 18

Six-year-old ............................... 19

Santa Rosa Plum..................... 19

Pomegranate Tree................... 73

Pomelo, Marsh's Seedless................ 58

Budded on Citrus Trifoliata Root, Resulting in

Unevenness in Size of Trees............ 69

Prune Tree, Improved French .............. 20

Three-year-old French Prune Orchard,

Unpruned . . . . . . . . ............. 21

Three-year-old French Prune Orchard, Pruned..

\section{$\mathrm{S}$}

Strawberry Beds and Methods of Irrigating Them

\section{T}

Thompson Seedless Grapevine, Three-year-old. ... 81 Three-year-old, Showing Pruned and Unpruned Vines....

With Numerous Stems

n..........

Sulphur Houses Used for Bleaching. . . . . . . . .

\section{W}

Walnut Tree, Grafted, Just from Nursery....... 36 Same, Topped and Root Pruned for Planting... 36

With Fine Symmetrical Head. ............ 37

Top-worked .

Franquette Walnut.................. 37 



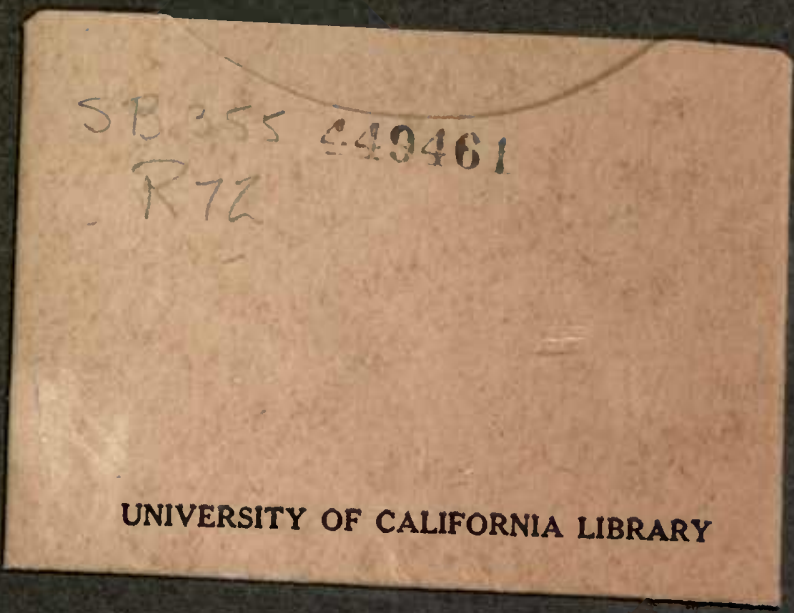

\author{
UNIVERSITY OF CALIFORNIA LIBRARY
}


